Innovations for Navigation Projects Research Program

\title{
Underwater Geotechnical Foundations
}

Landris T. Lee, Jr., and Richard W. Peterson

December 2001

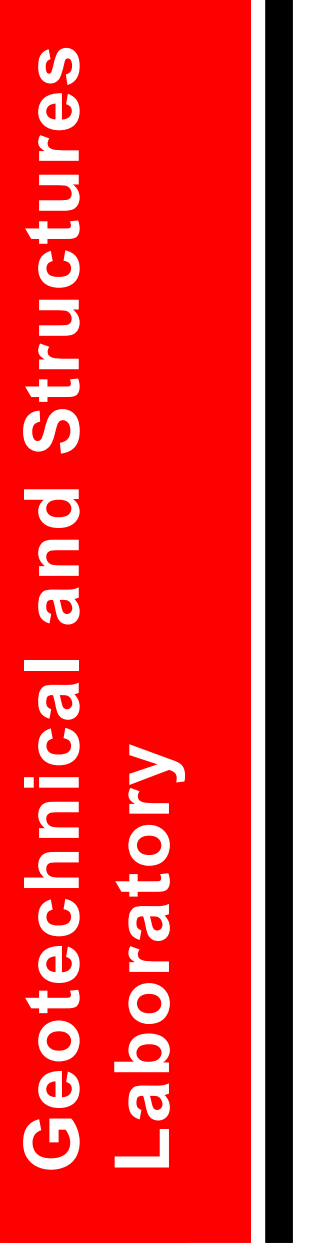


The contents of this report are not to be used for advertising, publication, or promotional purposes. Citation of trade names does not constitute an official endorsement or approval of the use of such commercial products.

The findings of this report are not to be construed as an official Department of the Army position, unless so designated by other authorized documents. 


\section{Underwater Geotechnical Foundations}

by Landris T. Lee, Jr., Richard W. Peterson

Geotechnical and Structures Laboratory

U.S. Army Engineer Research and Development Center 3909 Halls Ferry Road

Vicksburg, MS 39180-6199

Final report

Approved for public release; distribution is unlimited 


\section{Contents}

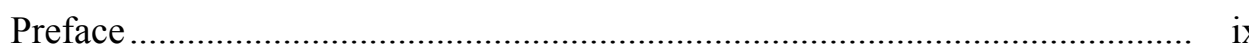

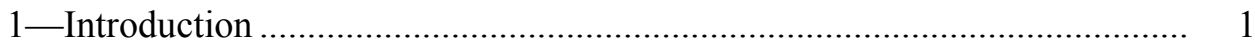

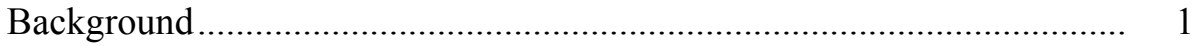

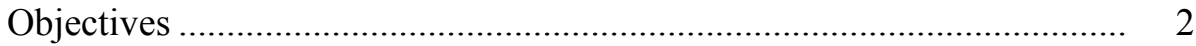

Scope

2-Selected Case Histories .............................................................................. 4

Navigation, Flood Control, and Dam Structures........................................ 4

Thames River flood barrier .................................................................... 4

Eastern Scheldt storm surge barrier................................................... 6

Mississippi River Lock and Dam 26 guidewall.................................. 8

Monongahela River gated dam....................................................... 8

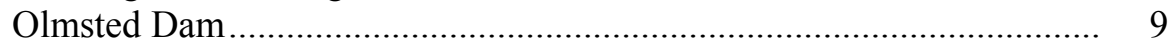

Lake Mead intake structure ............................................................. 9

Adriatic Sea piled breakwater structure .................................................. 9

Argentina piled jetty ......................................................................... 9

Offshore lighthouses .................................................................... 10

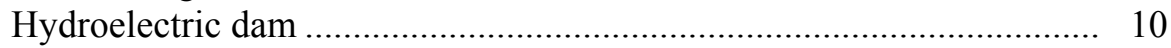

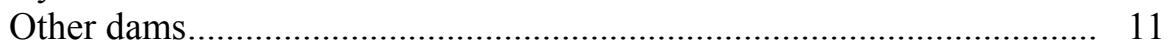

Bridges ...................................................................... 12

Brooklyn Bridge ………………......................................... 12

Tappan Zee Bridge .............................................................. 13

Newport, RI, Bridge .............................................................. 13

Confederation Bridge .................................................................... 14

Great Belt eastern bridge ....................................................... 14

Akashi Kaikyo Bridge ................................................................ 15

New Benicia-Martinez Bridge ...................................................... 15

Pocomoke River Bridge rehabilitation ............................................... 16

Immersed Tube Tunnels and Pipelines ............................................... 16

Bay Area Rapid Transit (BART) Tunnel............................................ 17

Boston Tunnel......................................................................... 17

Chek Lap Kok Airport transportation links ....................................... 17

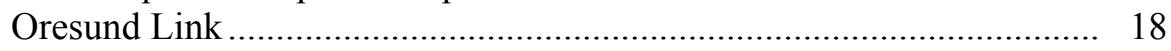

Puget Sound gas pipeline ................................................................ 18

North Sea gas pipeline ................................................................... 19

Los Angeles sewage sludge outfall................................................. 19

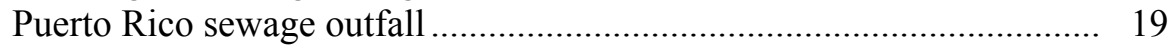

Offshore Oil Platform Structures ….................................................... 20 
Jacket and jack-up structures ........................................................ 21

Compliant tower structures................................................................ 24

Tension-leg platform structures ......................................................... 25

Gravity-based structures ……....................................................... 26

Other Underwater-Founded Structures ............................................... 28

Wharf off-loading system.............................................................. 28

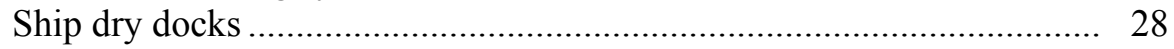

Berlin's Potsdamer Platz ................................................................ 29

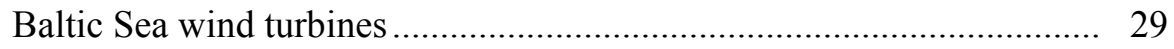

Offshore military tracking platforms ................................................ 30

Bantry Bay tanker terminal............................................................ $\quad 30$

Submerged oil storage tank ......................................................... 31

3-Foundation Site Assessment .............................................................. 32

Site and Foundation Selection Process ….............................................. 32

Site Assessment and Characterization ................................................ 34

Preliminary assessment.................................................................... 34

Hydrographic surveying and environmental data collection .................. 34

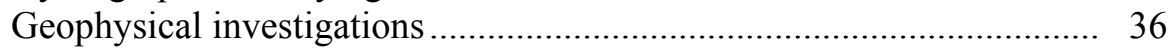

Soil and Rock Engineering Properties .................................................. 38

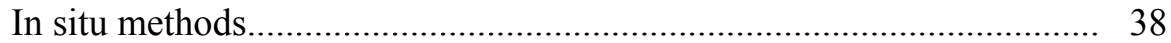

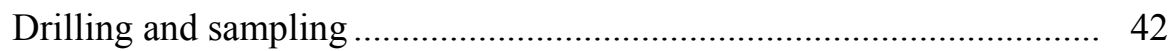

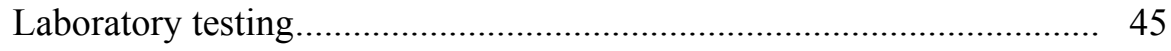

4-Design Considerations ....................................................................... 49

Foundation Types ….................................................................. 49

Improved-site foundations .......................................................... 51

Gravity-based foundations........................................................ 52

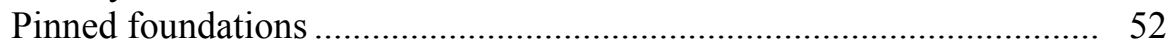

Foundation Selection Criteria and Design Issues ................................ 57

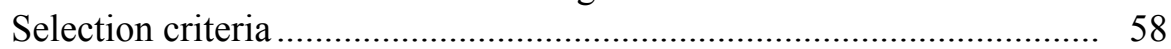

Design considerations......................................................... 58

Analysis and verification testing ……............................................ 70

Quality Control and Assurance Issues ............................................... 71

Engineering design phase ............................................................... 72

Specifications and contract document phase ...................................... 73

Recent Corps of Engineers underwater foundation contracts................. 76

5-Foundation Preparation and Construction ............................................. 80

Quality Control and Quality Assurance Issues .................................... 80

Preconstruction phase ..................................................................... 80

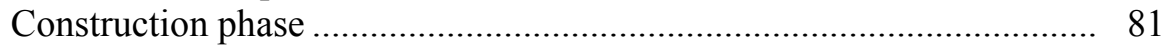

Acceptance phase …..................................................................... 83

Postconstruction monitoring phase..................................................... 83

Foundation Installation and Testing................................................... 84

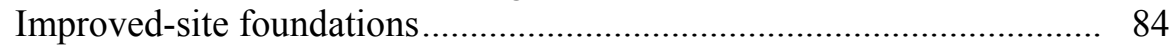

Gravity-based foundations........................................................... 94

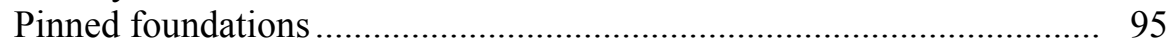

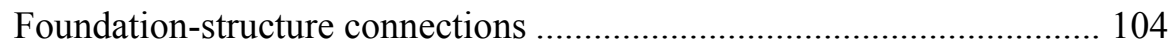

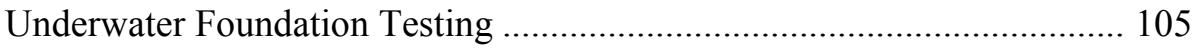




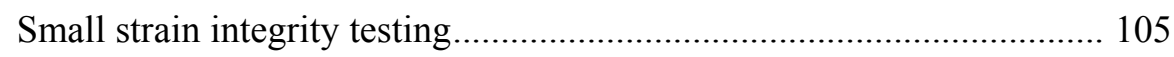

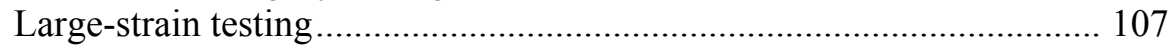

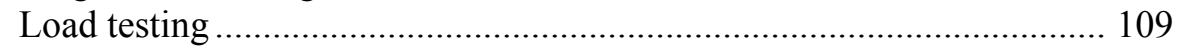

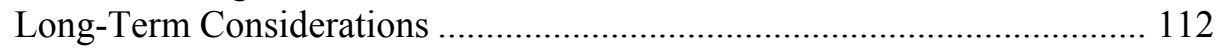

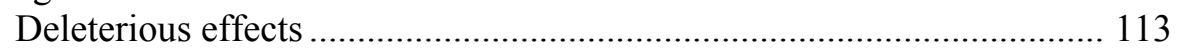

Foundation behavior monitoring ..................................................... 116

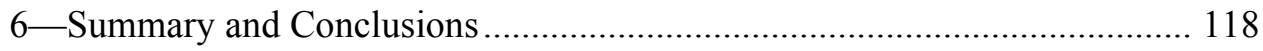

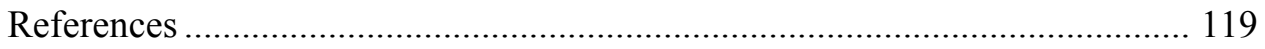

Appendix A: Underwater Foundation References_-by Topic ........................ A1

Case Histories - Bridges ............................................................................ A1

Case Histories - Immersed Tube Tunnels and Pipelines .......................... A2

Case Histories - Navigation, Flood Control, and Dam Structures.............. A2

Case Histories - Offshore Oil Platform Structures .................................... A3

Case Histories - Other Underwater-Founded Structures .......................... A9

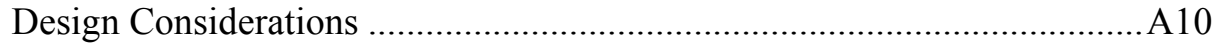

Foundation Monitoring and Long-Term Considerations ...........................A28

Inspection, Testing, and Quality Assurance Considerations ........................A31

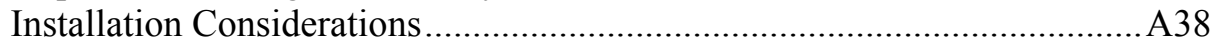

Site Assessment Considerations................................................................551

SF 298

\section{List of Figures}

Figure 1. In-the-wet foundation concept for the Corps of Engineers' lift-in Olmsted Dam structure ...................................................... 3

Figure 2. Thames River flood barrier gates................................................ 5

Figure 3. Underwater foundation construction sequence............................ 5

Figure 4. Eastern Scheldt storm surge barrier .............................................. 7

Figure 5. Monongahela River gated dam and foundation ........................... 8

Figure 6. Kish Bank lighthouse — gravity-based structure ......................... 10

Figure 7. Sketch of Brooklyn Bridge underwater caisson........................... 12

Figure 8. Tappan Zee Bridge foundation ................................................. 13

Figure 9. Confederation Bridge foundation ............................................. 14

Figure 10. Akashi Bridge ................................................................... 15

Figure 11. Pocomoke River Bridge in-the-wet foundation rehabilitation with pinpiles...................................................................... 16

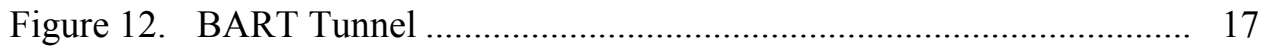


Figure 13. Boston Tunnel foundation .................................................. 18

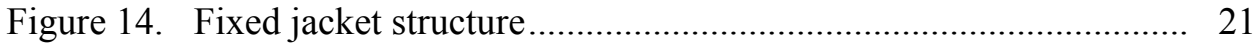

Figure 15. Jack-up structure installation ................................................ 22

Figure 16. Jack-up platform on soft soil ................................................. 23

Figure 17. North Sea fixed jacket with bucket foundation........................... 24

Figure 18. Compliant tower platform......................................................... 24

Figure 19. Compliant tower foundation footprint ....................................... 25

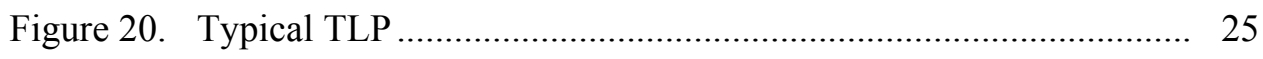

Figure 21. Mini-TLP structure .............................................................. 26

Figure 22. TLP suction pile foundation ................................................... 26

Figure 23. Statoil's Gullfaks C platform .................................................. 27

Figure 24. Hibernia's gravity-based foundation......................................... 27

Figure 25. Widescan ${ }^{\mathrm{TM}}$ digital side-scan sonar image ................................ 36

Figure 26. Bonneville Dam stilling basin mapping using SeaBat ${ }^{\mathrm{TM}}$ technology ....................................................................... 37

Figure 27. Remote vane shear device....................................................... 40

Figure 28. Remote CPT operation from a surface vessel........................... 41

Figure 29. Offshore wireline sampling technique ...................................... 44

Figure 30. Sketch of idealized model of in situ stresses ............................ 47

Figure 31. Example of an improved-site foundation................................... 51

Figure 32. Underwater impact-driven pipe pile installation without a template.......................................................................... 53

Figure 33. Cast in situ onshore pinned foundation...................................... 54

Figure 34. Suction pile foundation .......................................................... 55

Figure 35. Excavating a cased borehole.................................................... 56

Figure 36. Casing and pile assembly for an offshore drilled shaft foundation .......................................................................... 57

Figure 37. Improved-site foundation under Bethlehem Steel's graving dock near Baltimore................................................................ 61

Figure 38. Eastern Scheldt improved-site foundation sequence for gravity-base piers ................................................................ 61

Figure 39. Suction dewatering in an underwater silt layer........................... 62

Figure 40. Possible failure modes of a gravity-based foundation ................. 64

Figure 41. Scaling relationships for 1 -g and centrifuge models .................. 71

Figure 42. Reinforcing cage for the drilled shaft load test prior to project construction at Braddock Locks and Dam 2 ..... 
Figure 43. Pinned foundation details, Braddock Locks and Dam 2.

Figure 44. Pile driving with submersible vibratory hammer, New Orleans IHNC pile test project.

Figure 45. Clamshell excavation and soil sampling in the Columbia River 85

Figure 46. Deep-sea dredging operation 86

Figure 47. Two types of underwater ejectors

Figure 48. Gradation curve for underwater pipeline stable backfill material

Figure 49. Vibratory compactor

Figure 50. Vibratory compaction pontoon Mytilus used in the Eastern Scheldt project

Figure 51. Vibratory stone column installation.......................................... 91

Figure 52. Eastern Scheldt mat-sinking pontoon ....................................... 92

Figure 53. Deep cement mixing system .................................................. 93

Figure 54. Eastern Scheldt CPT results—-before and after vibrocompaction

Figure 55. Vulcan steam hammer advertisement from 1957 Civil Engineering magazine .......................................................... 96

Figure 56. Menck 500T underwater hammer.............................................. 96

Figure 57. Underwater hydraulic slender hammer.................................... 97

Figure 58. IHC underwater hammers ...................................................... 97

Figure 59. ICE 1412 hydraulic vibratory pile hammer ............................... 99

Figure 60. Vibratory-driven pipe pile without an underwater template ......... 100

Figure 61. Offshore rotary drilling operation for grouted pipe piles in

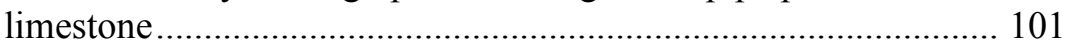

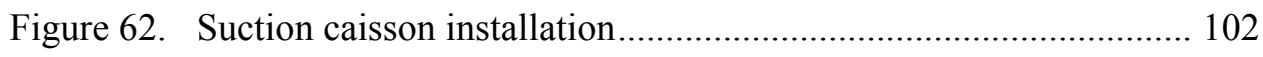

Figure 63. Pile-mounted suction pump skid............................................... 102

Figure 64. Pile template positioning for Shell's Auger TLP......................... 103

Figure 65. Crosshole sonic logging integrity test......................................... 106

Figure 66. Parallel seismic integrity test .................................................... 106

Figure 67. Pulse echo method integrity test ............................................... 107

Figure 68. Pile dynamic analysis test ........................................................ 108

Figure 69. Comparison of actual pile load test results with WiscPDA

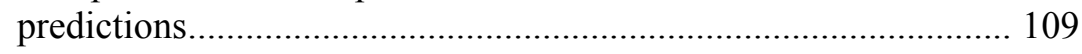

Figure 70. Osterberg cell at the rebar cage bottom ................................... 110 
Figure 71. Braddock Locks and Dam 2 drilled shaft load test configuration

Figure 72. Load test on underwater drilled shaft showing test configuration for scour design with load/deflection curve results. 112

Figure 73. Scour development around a pinned foundation 113

Figure 74. Offshore fall-pipe rock dumping 114

Figure 75. Precision rock placement 115

Figure 76. Exposure zones for piling 115

Figure 77. Foundation monitoring sensors on the Gullfaks C platform 116

\section{List of Tables}

Table 1. Underwater Foundations ......................................................... 50

Table 2. Underwater Foundation—General Selection Considerations ....... 59 


\section{Preface}

This report was prepared for Headquarters, U.S. Army Corps of Engineers (HQUSACE), as part of the Innovations for Navigation Projects (INP) Research Program. The study was conducted under INP Work Unit 33144, "State of the Art for Preparing Foundations Underwater," managed at the U.S. Army Engineer Research and Development Center (ERDC), Vicksburg, MS.

Dr. Tony C. Liu was the INP Coordinator at the Directorate of Research and Development, HQUSACE; Research Area Manager was Mr. Barry Holliday, HQUSACE; and Program Monitors were Messrs. Bruce Riley and Mike Kidby, HQUSACE. Mr. William H. McAnally of the ERDC Coastal and Hydraulics Laboratory was the Lead Technical Director for Navigation Systems;

Dr. Stanley C. Woodson, ERDC Geotechnical and Structures Laboratory (GSL), was the INP Program Manager.

The research and preparation of the report were accomplished by Dr. Richard W. Peterson, Principal Investigator for Work Unit 33144, and Mr. Landris T. Lee, Jr., Co-Investigator, both of the ERDC GSL. Work was conducted under the general supervision of Dr. Joseph P. Koester, Chief Geotechnical and Earthquake Engineering Branch; Dr. Robert L. Hall, Chief, Geosciences and Structures Division; and Dr. Michael J. O'Connor, Director, ERDC GSL.

At the time of publication of this report, Dr. James R. Houston was the Director of ERDC, and COL John W. Morris III, EN, was Commander and Executive Director.

The contents of this report are not to be used for advertising, publication, or promotional purposes. Citation of trade names does not constitute an official endorsement or approval of the use of such commercial products. 


\section{Introduction}

The U.S. Army Corps of Engineers has been tasked with designing, building, and maintaining numerous structures located on or within bodies of water including rivers, lakes, waterways, and coastal areas. Each of these structures has a geotechnical foundation system that enables the structure to perform a useful service or function throughout its design life. Each foundation is uniquely designed to match the structure's function and engineering requirements constrained by the underwater geological site conditions.

\section{Background}

Underwater foundations have been constructed throughout history. The earliest type of underwater foundation appears to have been driven stakes or piles around the edges of water bodies. Ancient settlements built on piles around lakes in present-day Scotland, Switzerland, Italy, and Ireland have been dated to about 4,000 years ago. The ancient Phoenicians built docks and ports (such as Tyre) using underwater construction methods. The Greeks and Romans used piles for shore works along the Mediterranean and many other locations (Fleming et al. 1992, D'Appolonia 1972). Herodotus, a Greek writer who lived in the 4th century B.C., wrote about African dwellings erected on piles driven into a lake. In Britain, evidence of bridge timber piles about $9 \mathrm{ft}(3 \mathrm{~m})$ long was found in the Tyne River. Vitruvius, a Roman architect, wrote the treatise De Architectura, which describes using sheet piles for dams and other water structures. The Roman engineers also developed concrete and used it for placement of bridge piers. During the Middle Ages, cities such as Venice and Amsterdam were built upon timber piles (Fleming et al. 1992).

Not until the 19th century did soil engineering principles become incorporated into the foundation construction process. Changes in materials and installation technology began to take place. Pile-driving by man or horse power was replaced by a steam engine that raised a cast-iron ram and released it to impact the timber pile. Metal piles became available in the mid-1830s. In 1824 Joseph Aspdin patented his hydraulic cement, which became known as portland cement, and the French introduced reinforced concrete. Driven piles could be replaced by bored shafts since the hydraulic cement could be placed underwater (Fleming et al. 1992). 
Modern soil mechanics, which offered an explanation for the behavior of soil foundations, was not advanced until the early 20th century. Since that time, numerous foundation types, materials, and installation technologies have been developed for onshore applications (Parkhill 1998). Underwater foundation technology initially lagged behind onshore technology, especially in soil sampling and testing (Focht and Kraft 1977). In other areas such as site assessment, foundation material selection, installation methods, and equipment, the offshore technology has been uniquely developed. For example, the offshore industry almost exclusively used pile foundations without benefit of preliminary site investigations until the 1940s (Focht and Kraft 1977). Design guidelines for some types of underwater foundations have evolved separately from onshore guidelines (American Petroleum Institute 1993), while site assessment methods and installation equipment have been specifically developed for underwater foundations.

Deepwater site exploration and foundation construction techniques have been used for scientific research and military purposes, but the offshore industry has a profit motive to build functional foundations (Brown 1972). Although the underwater foundation projects designed and constructed by the U.S. Army Corps of Engineers may not be located beyond the Continental Shelf, the use of state-of-the-art offshore foundation applications will likely be influential.

\section{Objectives}

Underwater foundation selection and design choices have generally been based on foundation construction in the dry, that is, within a pre-installed cofferdam that isolates the construction from the surrounding body of water, or on dry land with water diversion. Construction on dry land is normally the fastest and least expensive method (American Society of Civil Engineers (ASCE) 1998). However, the dry land method may not be an option unless the body of water can be feasibly diverted. Cofferdam design and construction efforts require additional time and expense to be budgeted for project completion. The benefits of faster paced and more economical construction within the water (in the wet) without cofferdams have been demonstrated in many case histories, and the Corps has begun exploring the feasibility of in-the-wet technology, as illustrated in Figure 1. The Corps' first major in-the-wet project (Monongahela River Braddock Dam) is currently under construction and is expected to save $\$ 5$ to $\$ 15$ million while reducing contract duration by 1 year (ASCE 1999a).

To obtain a technical project database of in-the-wet foundation design and construction requires time and experience, and some Corps Districts are compiling individual project information at specific sites. No written Corps-wide guidance for underwater foundation design and construction is currently available. Most of the technical expertise is held by specialist design firms and contractors. The information contained in this report cannot be found in a concise form or single document elsewhere in the literature. 


\section{Scope}

The purpose of this report is to provide an overview of underwater geotechnical foundation design and construction and preliminary guidance based on past and current technology applications. Most of the state-of-the-art technology comes from the marine offshore industry, because of its complex foundation engineering challenges in the deep-ocean frontier.

Direct applications may or may not be made to underwater foundations based in shallower rivers and inland waterways, but most of the principles, techniques, and equipment are related.

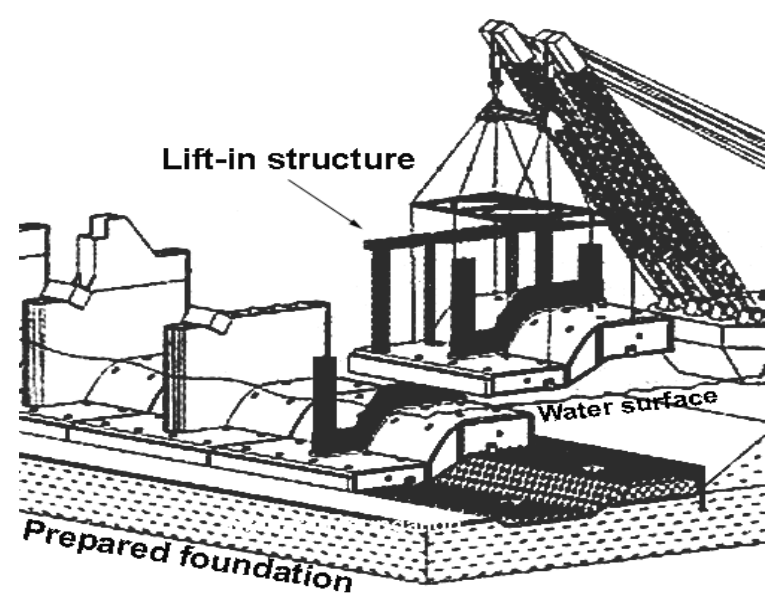

Figure 1. In-the-wet foundation concept for the Corps of Engineers' lift-in Olmsted Dam structure (after Gerwick News 1999) 


\section{Selected Case Histories}

In-the-dry foundation construction requires diversion of the existing water body or isolation of the construction from the water body. In-the-wet foundation construction may not adversely impact the navigation system and is relatively unaffected by flood stages or tidal fluctuations when compared with in-the-dry construction. Also called "float-in" or "lift-in" construction, in-the-wet construction requires underwater preparation of the foundation prior to placement of the superstructure (ASCE 1998). Several types of structures have been constructed using in-the-wet techniques, and selected case histories illustrate aspects of those techniques.

\section{Navigation, Flood Control, and Dam Structures}

In-the-wet construction methods are rare for these types of structures in inland (shallow) waterways. This construction method is recognized (ASCE 1998) but definitely plays a lesser role than the cofferdam (in-the-dry) construction method.

\section{Thames River flood barrier}

This project combined in-the-wet foundation preparation and initial construction followed by in-the-dry construction of the superstructure within a cofferdam. The purpose of the project was to prevent tidal floods in the London area. Over the past several centuries, the Thames River has slowly been rising due to land settlement in southeast England and London and the increase in the river estuary tidal range. In addition to these changes, the North Sea surge tides always present a flood threat to the London area.

After the disastrous 1953 tidal surge floods, the Government appointed a committee to make recommendations, and a flood barrier was proposed. By 1970, after approximately 14 design ideas were analyzed, the structure's location and design concepts were agreed upon. Construction commenced in 1973 (Gilbert and Horner 1984) and was completed in 1982. The completed project is shown in Figure 2. 


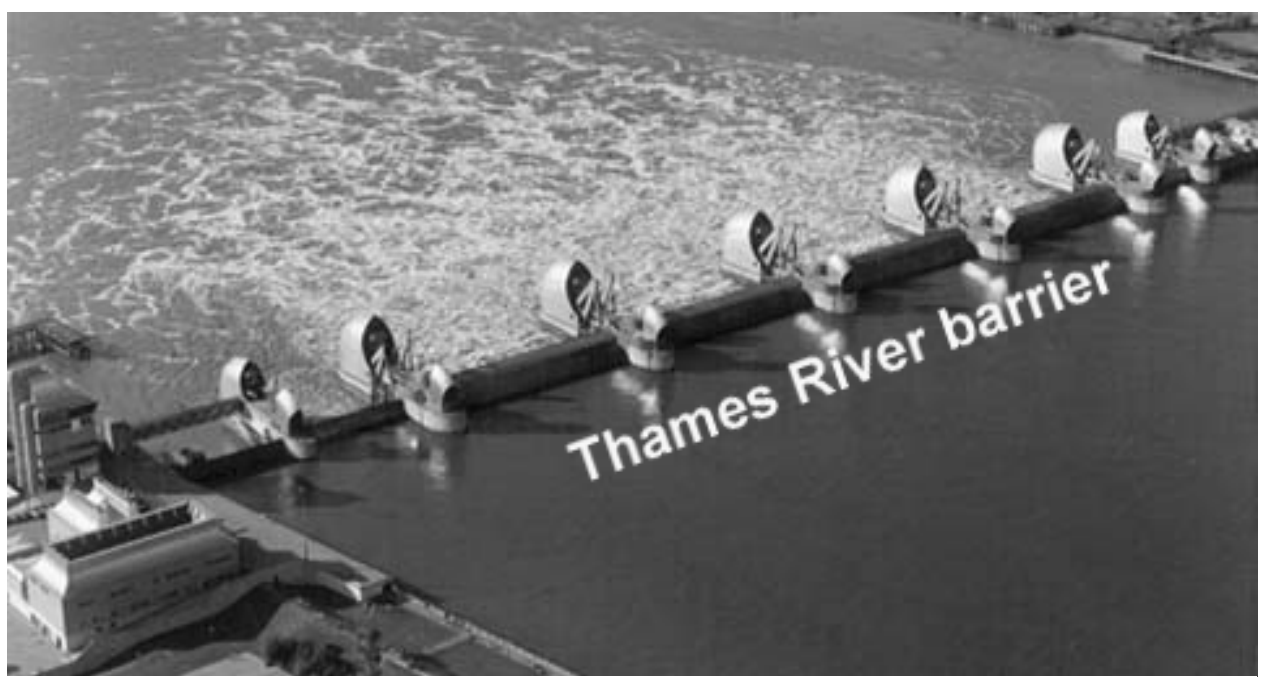

Figure 2. Thames River flood barrier gates (after Gilbert and Horner 1984)

The foundation project consisted of constructing four piers in sequence from the south side of the river, followed by construction of five piers in sequence from the north side. Access to the piers was provided by a jetty constructed from the south side. Bottom sills connected each pier. The riverbed consisted of chalk overlain with alluvial deposits of gravel, sand, and clay up to $50 \mathrm{ft}$ (16 m) thick. Six pier foundations were sited on the chalk, and three pier foundations were sited on sand deposits. Underwater excavations and concrete placements were required (Figure 3). Prior to excavation, sheet piles forming a future cofferdam were driven into the chalk at each pier location. The distance from the tops of the sheet piles to the base of the excavation was about $90 \mathrm{ft}(27 \mathrm{~m})$.

Special problems were encountered during the underwater foundation preparation. Leveling and cleaning up the bottom of the excavation in the chalk posed a challenge due to redeposition of river silt during each tide. Explosives were used to remove chalk wedged in the sheet-pile troughs. Special air-lift pumps were developed to scour the excavation bottom.

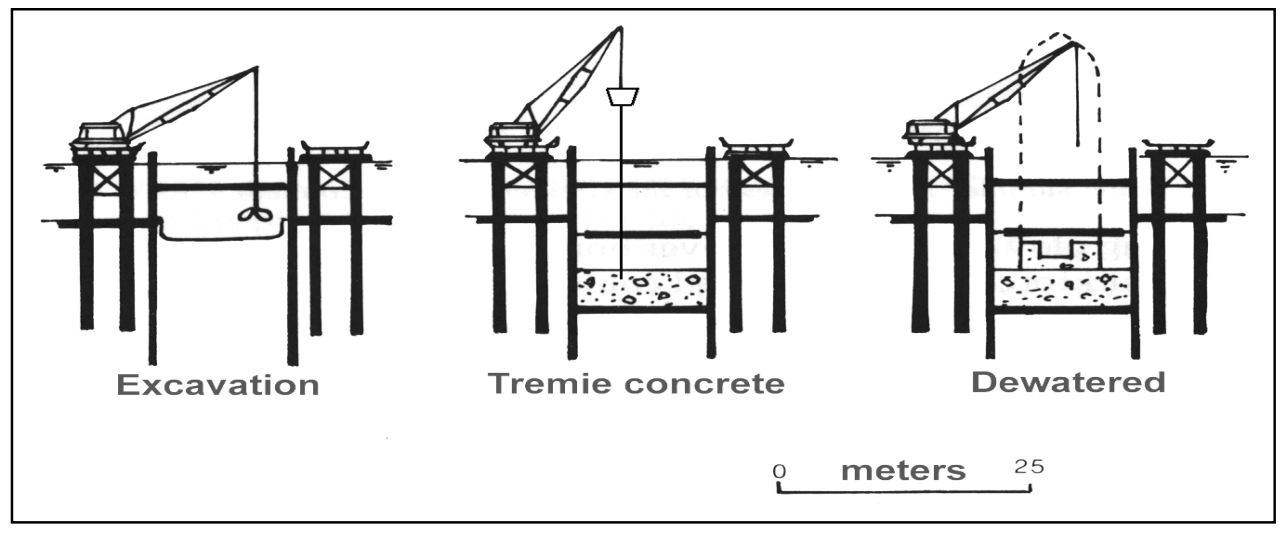

Figure 3. Underwater foundation construction sequence (after Gilbert and Horner 1984) 
Underwater concrete placement for each pier base was accomplished using 12-in. (30-cm)-diam tremie pipes transporting approximately 7,000 tons of concrete around the clock for 5 days. Each concrete base thickness was $15 \mathrm{ft}$ $(5 \mathrm{~m})$. Coring confirmed optimal jointing with the undisturbed chalk surface. The cofferdams were dewatered, and pier construction proceeded. By 1982 the project was essentially completed.

\section{Eastern Scheldt storm surge barrier}

On the eastern side of the English Channel, the Netherlands are also subjected to the whims of the North Sea. The 1953 floods provided an impetus for the Government to launch the Delta Project, which was designed to protect the Netherlands at the confluence of the Rhine, Maas, and Scheldt Rivers. After construction of seven dams and flood barriers, the Eastern Scheldt storm surge barrier and two auxiliary lock and dam structures (which comprised the final part of the project) were completed in 1986 (DOSBOUW 1987).

The storm surge barrier spans the mouth of the Eastern Scheldt, and was the most complex portion of the entire Delta Project. The typical current is about 5 fps $(1.5 \mathrm{~m} / \mathrm{sec})$ and bottom slope is 1 in 7 (Heijnen and Vermeiden 1979). Three tidal channels with depths up to $99 \mathrm{ft}(30 \mathrm{~m})$ were crossed with a structure whose foundations consisted of piers and connecting sills. Each pier was prefabricated using prestressed concrete and weighed up to 18,000 tons. Figure 4 shows the barrier layout with a typical pier detail. The piers were built inside a dry ring dike with a bottom approximately $49 \mathrm{ft}(15 \mathrm{~m})$ below sea level. To move the piers, the dike was flooded, and each pier developed a buoyant weight of about 9,000 tons. A lifting vessel capable of hoisting 10,000 tons lifted and transported each pier to its final site. Once at the site, each pier was lowered to the prepared seabed, internally ballasted, and grouted at the prepared foundation contact.

The seabed floor consisted of young Holocene fine to medium sands and silt. It was modified to accept the piers. No piling or concrete foundations were used. Site investigation using a specially designed geotechnical platform yielded cone resistances ranging from 14.5 to $145 \mathrm{psf}$ (0.7 to $70 \mathrm{kPa}$ ) (Heijnen and Vermeiden 1979). Since these resistances were below those required for adequate bearing capacity, special preparations were required to enable adequate bearing capacities.

First, the seabed was excavated (a "cunette" excavation), and unsuitable material (silt) was replaced with sand where necessary. The sand was compacted over a distance of $263 \mathrm{ft}(80 \mathrm{~m})$ around each pier by a specially built floating compacting rig. The rig drove four large vibrating rods into the subsurface and compacted layers up to $59 \mathrm{ft}(18 \mathrm{~m})$ thick. The compaction process took 3 years to complete. The quality control system included another specially built craft equipped with a conventional drill rig and a diving bell that conducted soil sampling and density measurements during the compaction process. 


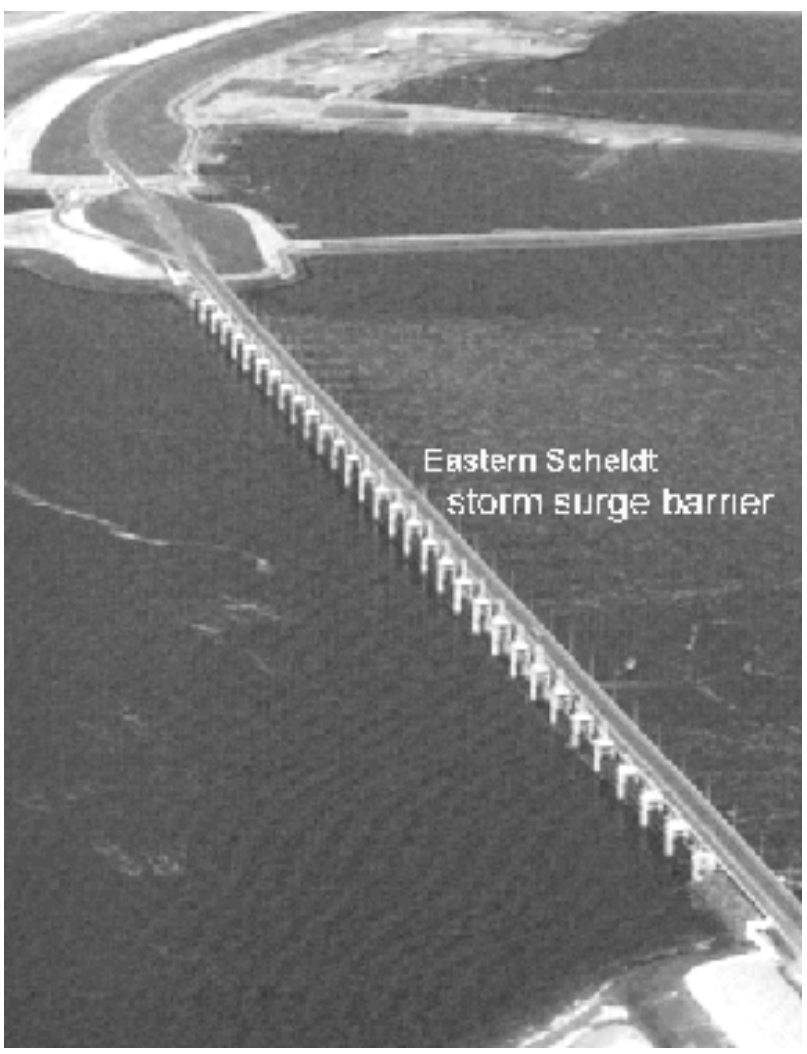

a. Storm surge barrier

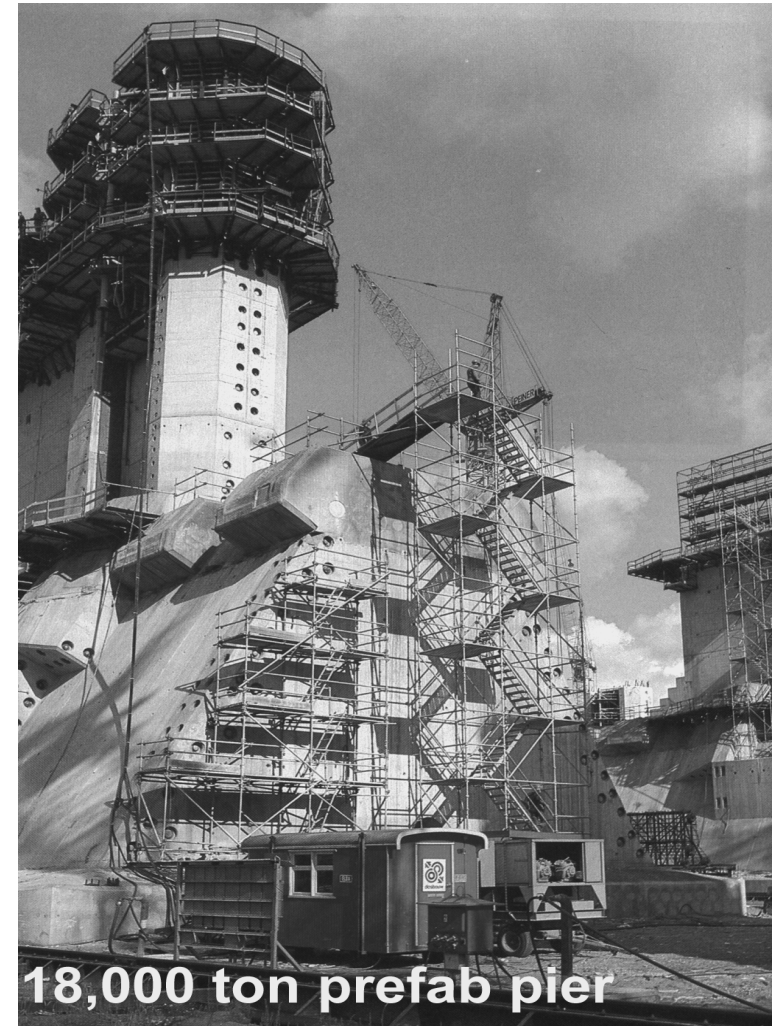

b. Storm surge barrier float-in pier detail

Figure 4. Eastern Scheldt storm surge barrier (after DOSBOUW 1987)

The compacted seabed was then dredged, leveled to the designed depth, and covered with $658 \times 138 \times 1.2 \mathrm{ft}(200 \times 42 \mathrm{~m} \times 36 \mathrm{~cm})$ prefabricated foundation mattresses. The mattresses were fabricated offsite and transported to each location, where they were unrolled onto the seabed by specialized floating equipment. Each mattress consisted of graded aggregates sandwiched between reinforced support fabric. After the upper mattress was placed, a block mattress (containing concrete blocks of varying thicknesses) for leveling purposes was positioned. Each pier was then placed directly on its respective block mattress.

A graded stone aggregate sill was placed between each pier to stabilize the piers and prevent bottom scouring in the event a gate failed to close. A stonedepositing barge crane placed the rocks weighing up to 11 tons (10 metric tons) with densities up to 2.5 tons $/ \mathrm{cu}$ yd ( 3 metric tons $/ \mathrm{m}^{3}$ ) into their underwater locations. About 5.5 million tons of stone were placed into position over a period of about 2 years. After completion of the underwater sill, precast concrete sill beams were lowered into place to rest on the underwater sill. The remaining superstructure elements were then positioned and placed between the piers. 


\section{Mississippi River Lock and Dam 26 guidewall}

The upstream guidewall at the Corps' Lock and Dam 26 replacement on the Mississippi River is founded on 118 caissons. Each caisson consists of a 6-ft (1.8-m)-diam open-ended pipe pile driven $51 \mathrm{ft}(15.5 \mathrm{~m})$ into sands and gravels in the river bottom, which is about $40 \mathrm{ft}(12.2 \mathrm{~m})$ below the river surface. After vibratory driving was completed, the piles were internally excavated under a positive pressure head to prevent blowout and then filled with concrete. A load test using eight $3-\mathrm{ft}(0.9-\mathrm{m})$-diam reaction piles driven to bedrock validated design assumptions (Demsky and Moore 1989).

\section{Monongahela River gated dam}

A recently contracted $\$ 107$ million "in-the-wet" project is the Pittsburgh District's new gated dam next to the existing Braddock Locks and Dam 2 on the Monongahela River in Pennsylvania (U.S. Army Corps of Engineers 1998). The underwater foundation system will consist of a dredged area with sheet-pile cutoff walls in the riverbed alluvium and concrete drilled shafts socketed into bedrock, upon which will rest two float-in precast concrete dam elements (Figure 5).

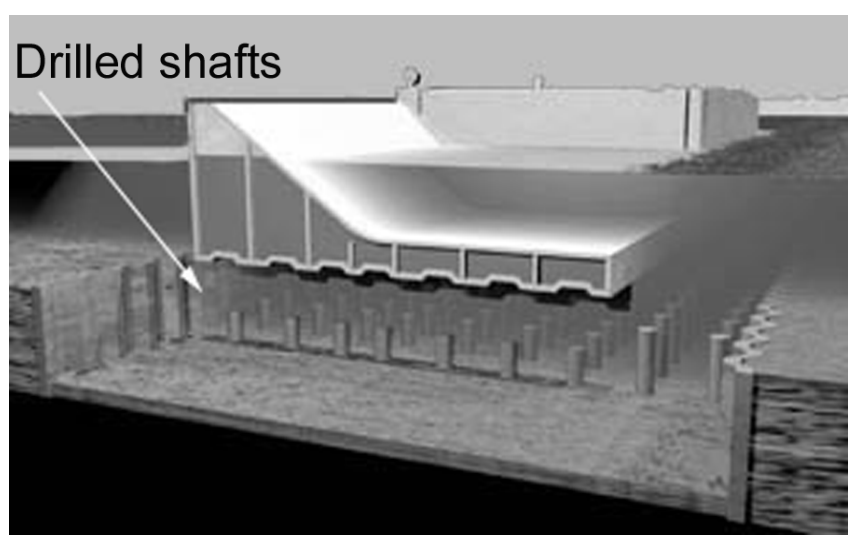

Besides the novel features of the concrete float-in elements, the predominant work feature for the underwater foundation will be drilled shafts. These provide the deep foundation support for the precast concrete elements, and also function as anchor piles for positioning the precast concrete elements. The drilled shaft (similar to a caisson or pier) is basically a pinned foundation system consisting of a 78-in. (1.9-m)-diam by $30-\mathrm{ft}(9-\mathrm{m})$-long open steel pipe

Figure 5. Monongahela River gated dam and foundation (after Gerwick News 1998) pile (casing) driven with a vibratory hammer to bedrock, then rotarydrilled through the bottom end and further drilled without casing about $17 \mathrm{ft}(5 \mathrm{~m})$ into the bedrock. Steel reinforcement and instrumentation tubes for later sonic testing will be inserted to bedrock and tremie-concreted. Steel shear pin connectors provide the attachments for the subsequently positioned precast concrete dam elements.

The two 300-ft (91-m)-long, 103-ft (31-m)-wide, and 21-ft (6-m)-deep precast segments will be internally tremie-grouted. Once finished, the dam height will be about $81 \mathrm{ft}(25 \mathrm{~m})$ and about halfway submerged. Construction is expected to be completed in 2002 (ASCE 1999a). 


\section{Olmsted Dam}

Another innovative Corps of Engineers project is being designed to replace and update navigation and flood control capabilities on the lower Ohio River, 15 miles from its confluence with the Mississippi River. The Olmsted Dam project has been designed as float-in (in-the-wet) construction and will be the only wicket dam in the United States when completed. Currently under contract are \$224-million twin locks being constructed within \$55-million in-the-dry cofferdams (ENR 1996).

\section{Lake Mead intake structure}

Lake Mead serves as the main source of drinking water for southern Nevada, including Las Vegas. The lake is impounded by the Hoover Dam. As part of a water supply improvement program, a water-intake shaft and tunnel system is being constructed. The intake shaft was installed in the wet and will eventually be connected to an underground tunnel and distribution system.

The intake structure was floated in and placed in 240-ft (73-m)-deep water onto a specially prepared underwater foundation on a steep underwater slope. A bench was excavated, and a pile-drilling template was positioned on the level excavation. Downhole hammer-drill equipment was used to drill anchor piles that were subsequently grouted. A second template was keyed into the first template, and a $20-\mathrm{ft}(6.5-\mathrm{m})$-diam shaft was drilled an average length of $100 \mathrm{ft}(30 \mathrm{~m})$ into stable rock. The first $30 \mathrm{ft}(9 \mathrm{~m})$ was steel-cased. The shaft was then grouted after the float-in steel riser intake structure was placed into position. Personnel dives were minimized during construction by using remotely operated vehicles (ROVs), a high-resolution positioning system, and sonar equipment (Norwesco Marine 1999).

\section{Adriatic Sea piled breakwater structure}

Approximately 1.25 miles $(2 \mathrm{~km})$ off the Italian coast near Manfredonia on the Adriatic Sea, a breakwater structure was constructed to protect new offshore docking facilities (Toppler, Harris, and Maaten 1971). The breakwater design was basically a heavy concrete slab resting on battered piles in $36 \mathrm{ft}(11 \mathrm{~m})$ of water. The 4-ft (1.2-m)-diam steel pipe piles are battered at a 3:1 incline to resist the design load of 3.3 tons $/ \mathrm{sq} \mathrm{ft}\left(30 \mathrm{tons} / \mathrm{m}^{2}\right.$ ). A two-dimensional pile-driving template made of precast concrete was designed as a permanent addition to the breakwater structure, and extended above the waterline to serve as a driving guide. Model testing was conducted during the design phase.

\section{Argentina piled jetty}

The foundation of an offshore jetty installed at Puerto Deseado, Argentina, was constructed in the rhyolite bedrock (Nakayama 1992). Each of the 147 piers (diameter $4 \mathrm{ft}(1.2 \mathrm{~m})$ ) was socketed $13 \mathrm{ft}(4 \mathrm{~m})$ into the rock using a 
MACH-120R rock drill. The bedrock inclined approximately $30 \mathrm{deg}$, and drilling was conducted on a self-elevating (jack-up) platform in a water depth of $60 \mathrm{ft}$ $(18 \mathrm{~m})$. The chosen rock drill operated by down-the-hole suspension hammering with 720 blows per minute, which helped eliminate slippage down the steep incline.

\section{Offshore lighthouses}

One of the first permanent offshore gravity-based structures is the Kish Bank Lighthouse located off the coast of Ireland (Young, Kraft, and Focht 1975). This structure was built in 1965 in the protected Dun Laoghaire harbor, floated 8 miles $(13 \mathrm{~km})$ off the entrance to Dublin Bay, and lowered $67 \mathrm{ft}(20 \mathrm{~m})$ to the seabed (Figure 6). Another gravity-based lighthouse is the Royal Sovereign Lighthouse, floated off the coast of Eastbourne, England, in 1968 and sunk in 47-ft (14-m) water depth (Antonakis 1972).

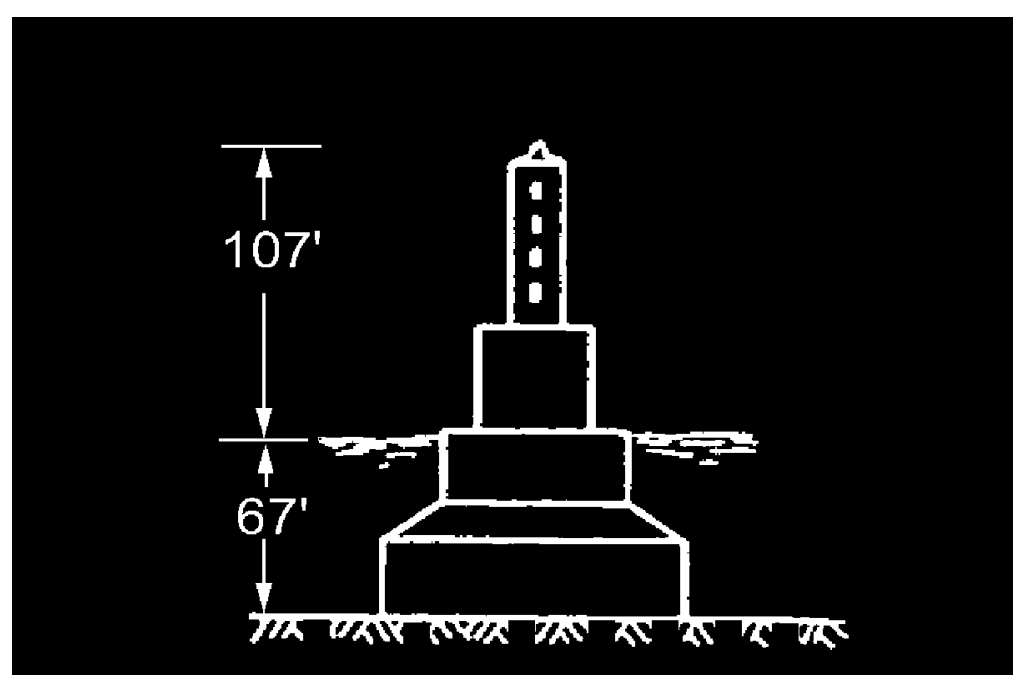

Figure 6. Kish Bank lighthouse gravity-based structure (after Young, Kraft, and Focht 1975)

\section{Hydroelectric dam}

British Columbia's Hugh Keenleyside earth dam foundation was constructed in the wet on the Columbia River between 1965 and 1969 (Bazett and Foxall 1972). No seepage cutoff wall was designed since the bedrock is located about $450 \mathrm{ft}(137 \mathrm{~m})$ below the sand-gravel riverbed in $90 \mathrm{ft}(27 \mathrm{~m})$ of water. To control seepage, an impervious glacial till blanket was constructed beneath the future dam extending upstream $2,200 \mathrm{ft}(669 \mathrm{~m})$ from the future dam upstream toe. The as-designed maximum final slope of the blanket was 1:10.

The foundation was installed by free-fall dumping till, sand, and gravel materials into the river using bottom-opening barges and above-water bulldozers. The till blanket overlies sand and gravel backfilled in water depths to $55 \mathrm{ft}$ (17 m). 
Extensive survey control was established to define the boundaries and depth of the underwater foundation. An echo-sounding vessel defined the water depth and bottom topography. Shoreline-surveyed grid lines established the vessel's survey patterns using shore-based transits and hand-held radio communication. Current and turbidity meters were used to monitor the river's velocity and water quality. Turbidity exceeding $5 \mathrm{ppm}$ was not allowed during construction because of adjacent industrial water-supply intakes.

Underwater inspection and sampling tasks were accomplished primarily by scuba divers wearing wetsuits. The divers monitored preliminary hydraulic dredging and subsequent construction operations for silt sediment control, which had a prominent influence on the project's schedule. Another major problem was segregation and loss of fines during dumping. Quality control measures included density determinations using standard penetration tests, gradation analysis sampling, large-scale testing experiments, and piezometer instrumentation.

\section{Other dams}

The High Aswan Dam in Egypt was partially constructed underwater in a maximum water depth of $131 \mathrm{ft}(40 \mathrm{~m})$. The underwater portion of the core consists of coarse sand that was grouted after placement. Vibrator-compacted dune sands form adjacent underwater zones. The dam height is $364 \mathrm{ft}(111 \mathrm{~m})$. Hong Kong's Plover Cove Main Dam was partially constructed underwater after soft foundation materials were removed. Other projects listed by Johnson, Compton, and Ling (1972) include the Mississippi River's Chain of Rocks rockfill dam, Columbia River's Dalles Closure and Wanapum Dam, and Ghana's Akosombo Dam.

The first dam project built across a major U.S. river without channel diversion was the Chain of Rocks rock-fill dam across the Mississippi River near St. Louis, MO. This $\$ 4.5$-million Corps of Engineers (St. Louis District) project avoided the time and expense of diverting the river, building cofferdams, or dewatering the site in order to build this navigation improvement. Although the rock-filled section was about 56 percent of the total dam's length, the rock-filled length of $1,800 \mathrm{ft}(547 \mathrm{~m})$ was constructed to be $210 \mathrm{ft}(64 \mathrm{~m})$ wide at the bottom and $30 \mathrm{ft}(9 \mathrm{~m})$ wide at the top. Four rock sizes ( 6 tons to 8 in.) were placed in water depths to $30 \mathrm{ft}(9 \mathrm{~m})$ using barge-mounted rock grapple cranes and a specially designed tremie pipe (fall-pipe). Rock was placed in 5-ft (1.5-m) lifts in a sequential fashion described by Smith (1962).

Another hydroelectric dam (Wanapum Dam) built on the Columbia River was completed in 1963. Instead of constructing an impervious bottom blanket as done at Hugh Keenleyside, the river was diverted, a cutoff was constructed, and an embankment dam was completed with an impervious core over a grouted slurry trench. Underwater backfilling of pervious sand and gravel was accomplished between upstream and downstream rock-fill dikes. Underwater consolidation of the pervious fill (maximum depth of $50 \mathrm{ft}$ or $15 \mathrm{~m}$ ) was performed using vibroflotation equipment. After consolidation was completed, 
the slurry trench was constructed, and the remaining dam was constructed as detailed by Engstrom (1963).

\section{Bridges}

Underwater foundations have been constructed in the wet for numerous bridge structures crossing rivers, bays, and nearshore locations.

\section{Brooklyn Bridge}

It took 13 years to construct this bridge over New York's East River. Work began in 1870 on a unique and labor-intensive method of constructing underwater foundations. Two wooden caissons were sunk on either side of the river upon which the bridge superstructure rests. The unique features included the size of the caissons and the use of compressed air beneath the caissons, which allowed the workers (sandhogs) to muck out the soil. As the soil was removed, the weighted caissons eventually settled to the bedrock layer and were filled with concrete. Compressed air had been used before during construction of the Mississippi River bridge at St. Louis, but not to the extent used at the Brooklyn Bridge.

The caisson on the Brooklyn side of the East River was a 168-ft-long by 102-ft-wide by 15 -ft-deep $(51 \times 31 \times 5 \mathrm{~m})$ inverted box. It was constructed upriver in the dry using wood timbers, and weighed 16 million pounds $(7.2 \mathrm{Gg})$. It was floated downriver, set within a frame, and weighted down with stones until it penetrated the river bottom. Compressed air was pumped in, which expelled the water and allowed entrance by the sandhogs (Figure 7). Many lives were lost before the caisson foundation was excavated down to the bedrock layer, and compression sickness (caisson disease or the "bends") injured many of the sandhogs (Delaney 1983).

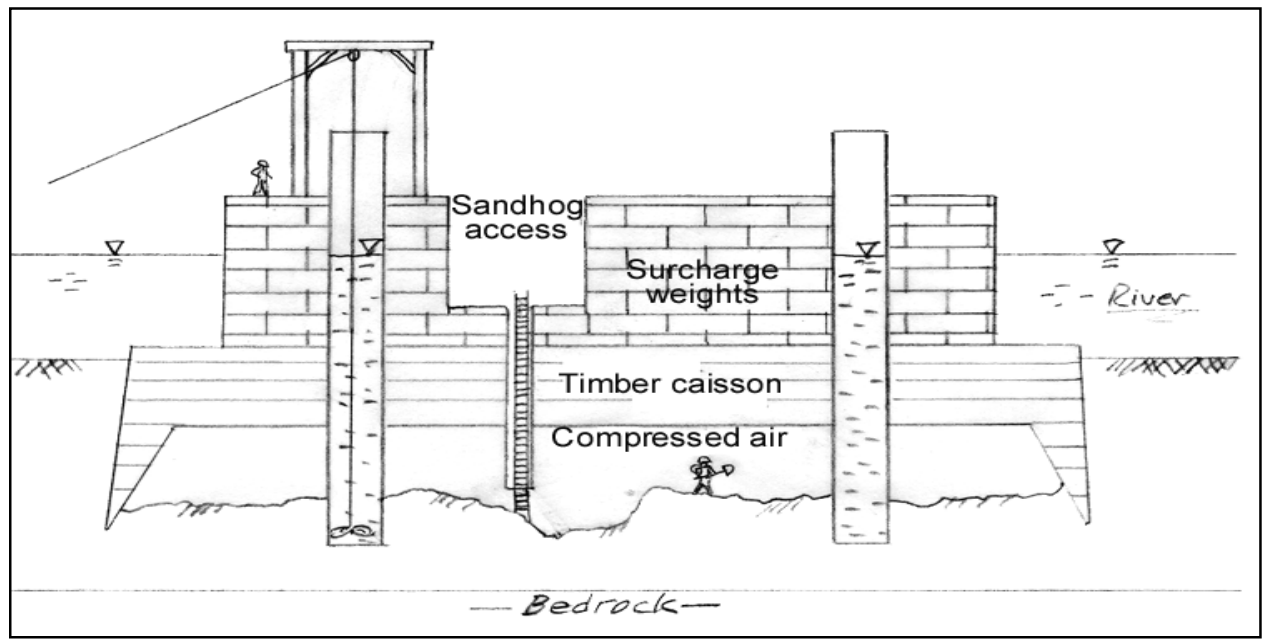

Figure 7. Sketch of Brooklyn Bridge underwater caisson (after Delaney 1983) 


\section{Tappan Zee Bridge}

The 6-mile-long $(9.6 \mathrm{~km})$ Governor Malcolm Wilson Tappan Zee Bridge, which crosses the Hudson River about 13 miles north of New York City, is one of the largest bridges in the United States. The bridge is named from the local Tappan Indian tribe and the word "zee" is Dutch for "sea." The bridge is the key structure on the 641-mile New York Thruway System and was rededicated in 1994 in honor of the former Governor Malcolm Wilson. Construction began in 1952, and the bridge became operational in 1955. More than 40 million vehicles presently use the bridge each year (New York State Thruway 1999).

The central span over the main channel is supported by eight concrete caissons on steel H-piles driven to bedrock (Figure 8). The concrete caissons are basically hollow concrete boxes that were built on shore, then towed into the channel and sunk onto prepared 5-ft-thick $(1.5-\mathrm{m})$ sand and gravel blankets on the river bottom. Steel sheet piles surround each concrete caisson. The steel Hpiles were then driven through the box to depths of $270 \mathrm{ft}(82 \mathrm{~m})$ to the bedrock layer. As the upper bridge supports were constructed, the water inside the boxes was pumped out to provide a buoyant platform. Approximately 70 percent of the structure's dead weight is supported by these eight buoyant caissons, and this design saved millions of dollars during the construction phase.

\section{Newport, RI, bridge}

New England's largest suspension bridge (the Claiborne Pell bridge) crosses Narragansett Bay with a water depth of $160 \mathrm{ft}(49 \mathrm{~m})$ and bottom current velocity to $4.5 \mathrm{fps}(1.4 \mathrm{~m} / \mathrm{sec})$. The $\$ 17$ million foundation system was constructed beginning in 1965 and is composed of steel H-piles and drilled shafts supporting tremie-concreted footings resting on backfilled sand (Hedefine and Silano 1968).

Dredging to remove $20 \mathrm{ft}(6 \mathrm{~m})$ of silt and unsuitable material was accomplished at each bridge pier. Next, 512 steel piles (14BP102) $70 \mathrm{ft}$ (21 m) long were driven to refusal in shale and dense sand formations at spacings of $4 \mathrm{ft}(1.2 \mathrm{~m})$ on center. A special pile-driving lead with retractable spuds at the lower end was built to accommodate piles driven by a McKiernan-Terry S14 hammer. Lateral deviation of 6 in. $(15.2 \mathrm{~cm})$ was permitted. Divers in a diving bell made the underwater cutoffs using an

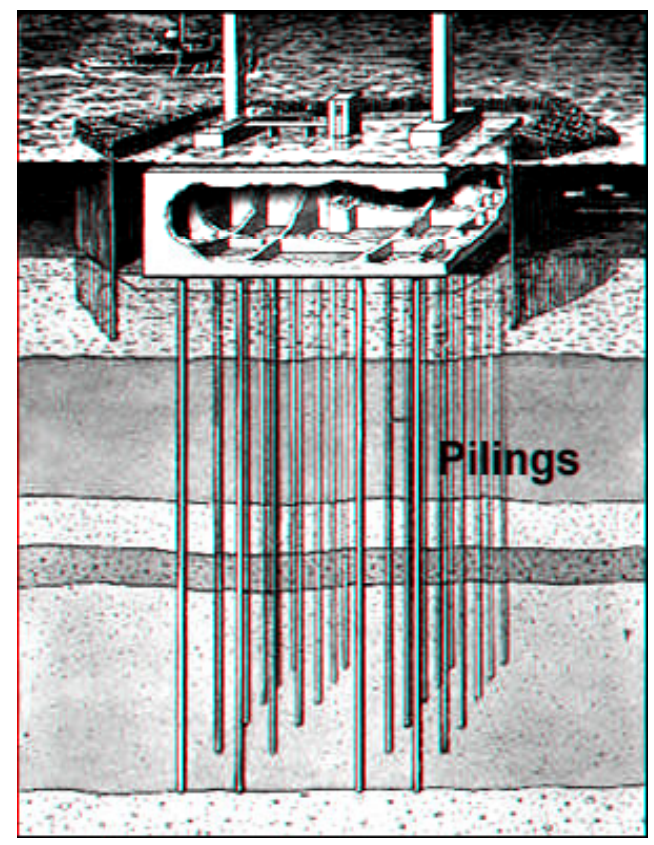

Figure 8. Tappan Zee Bridge foundation (after New York State Thruway 1999) electric oxygen arc. After the piles were cut, a sand/gravel fill (40 to 80 percent passing the 3/8-in. sieve with less than 5 percent passing the No. 200 sieve) was placed on the bottom. Template guide pipe piles (casings) were then driven to assist with placement of the bottom footing form. 
Each steel footing form, including the attached steel reinforcement bars, weighed over 400 tons and required a heavy-lift crane vessel to sink it onto the pile template. After the footing form was rested on the bottom, a steel hollowshaft caisson form was lowered onto it. Both forms were tremie-concreted in a continuous operation. Graded riprap (50 to 100 percent passing the 12 -in. mesh, 20 to 50 percent passing the 5 -in. mesh, and 0 to 20 percent passing the 1.5 -in. mesh) was placed around the completed foundation to prevent 4-ft $(1.2-\mathrm{m})$ depth maximum design scouring.

\section{Confederation Bridge}

The world's longest continuous crossing over water subject to ice floes was constructed during a 4-year period and spans the Northumberland Strait between Canada's Prince Edward Island and New Brunswick.

The bridge was built on precast concrete piers and base foundations (Figure 9). Each base weighed almost 6,000 tons and was lowered into place on the seabed. Each base underside had three pedestals that were set at different elevations to keep the base elevated at the correct grade on the sloping seabed. To ensure uniform stress transfer between the concrete structure and seabed, concrete was tremied between the base underside and the foundation rock. Tremied concrete was selected instead of compacted gravel because it was believed that better placement accuracy and better settlement resistance would be achieved with concrete (Carter 1998).

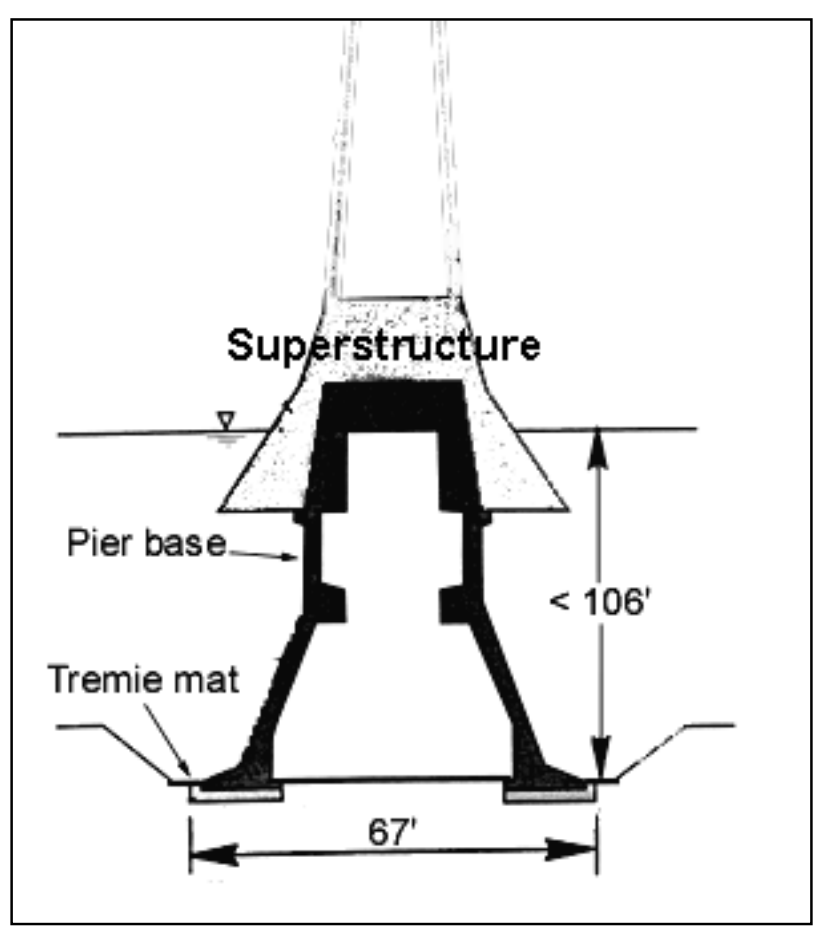

Figure 9. Confederation Bridge foundation (after Carter 1998)

\section{Great Belt eastern bridge}

This bridge spanning the shipping channel between the Baltic Sea and the North Sea is the last part of Denmark's Great Belt transportation link, which opened in 1998. Unsuitable material with low bearing capacity was discovered after construction began, requiring additional excavation dredging. Although caisson construction took place offsite, the foundation preparation was done prior to towing and positioning the caissons. Some of the methods used to construct the improved-site foundation included dredging with a bucket dredge to minimize disturbance of boulder clay, clearing sediment siltation with suction equipment, placing crushed stone material in layers with a sidedumping vessel, performing vibration 
compaction with powerful plate vibration units, and screeding the foundation top layer level to a 2-in. (50-mm) tolerance (Gerwick News 1992).

\section{Akashi Kaikyo Bridge}

The world's longest suspension bridge (1.9-km center span) crosses the Akashi Strait in Japan (Figure 10). Completed in 1998, the bridge construction took 10 years. Foundation preparation required dredging to a consolidated gravel layer $46 \mathrm{ft}(14 \mathrm{~m})$ below the seabed. Steel caisson foundations were floated in and sunk into position in water currents up to $13 \mathrm{fps}(4 \mathrm{~m} / \mathrm{sec})$. During placement of the foundations, a wave-breaking apparatus was used to allow accurate positioning and placement of the caissons. High-performance concrete was then placed by tremie pipe (Yao, Berner, and Gerwick 1999). After the caissons were in place, graded aggregate was placed based on hydraulic laboratory scour protection testing results conducted by the Honshu-Shikoku Bridge Authority (1996). In 1995, during construction, the Kobe earthquake epicentered 2.5 miles $(4 \mathrm{~km})$ from the bridge and shook the foundations. Although the span distance was increased (less than $3.2 \mathrm{ft}(1 \mathrm{~m})$ ), it was concluded that the foundations and anchorages had not been damaged (Kajima Corporation 1998).

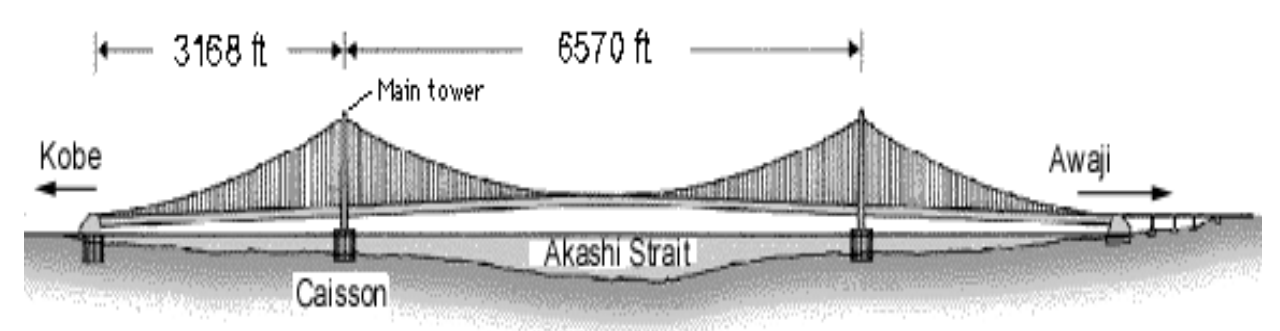

Figure 10. Akashi Bridge (after Kajima Corporation 1998)

\section{New Benicia-Martinez Bridge}

A parallel crossing of the Carquinez Strait near San Francisco is currently under construction and will be completed by 2003 (ASCE 1999b). The new bridge (I-680) is designed to withstand a 1,000-year-return earthquake (the maximum credible earthquake) and will be constructed in water currents of $7 \mathrm{fps}$ $(2 \mathrm{~m} / \mathrm{sec})$. The bridge ductility requirements called for unusually deep drilled shafts into the underlying weathered sandstone bedrock. The bedrock layers are uneven, and dip at angles up to $70 \mathrm{deg}$. The water depth ranges to $60 \mathrm{ft}(18 \mathrm{~m})$, underlain by mud deposits to $85 \mathrm{ft}(26 \mathrm{~m})$ deep. Severely weathered bedrock underlies the mud.

During feasibility and design studies, the scouring effects of additional piers next to existing bridge piers were considered. Six types of candidate foundations 
were analyzed (Gerwick News 1990), and final design selection was 7.2-ft (2.2-m)-diam steel casings drilled 60 to $100 \mathrm{ft}$ (18 to $30 \mathrm{~m}$ ) into the bedrock.

Steel reinforcing will be placed in the shafts and filled with tremied concrete. The rock socket depths were chosen based on the seismic design bending moments and overturning forces.

\section{Pocomoke River Bridge rehabilitation}

A bascule pier drawbridge originally built in 1921 over the Pocomoke River in Maryland rests on wood piles that became severely exposed due to riverbed scour. To stabilize and support the bridge, grouted pinpiles were installed (Bruce 1992). Each of the 24 piles was drilled from the bridge deck approximately $60 \mathrm{ft}$ $(18 \mathrm{~m})$ through the soft mud bottom into a dense sand layer. Each pile consists of a 7-in. (18-cm)-diam steel casing into which epoxy-coated rebar and wire tendons were placed and grouted (Figure 11). The wire tendons were prestressed

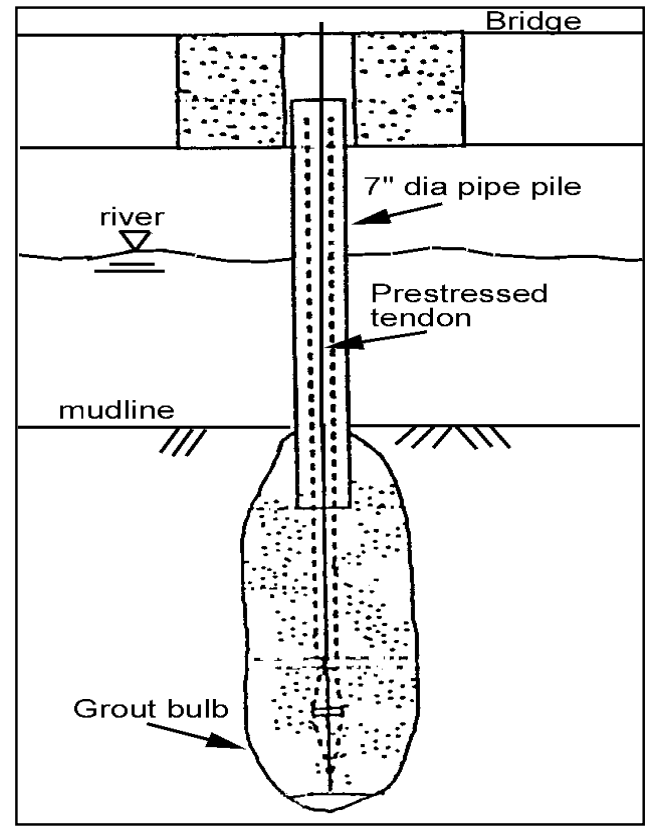

Figure 11. Pocomoke River Bridge inthe-wet foundation rehabilitation with pinpiles (after Bruce 1992) to 82 kips $(365 \mathrm{kN})$ and released about a week later to allow the design pinpile load of 82 kips to be mobilized without allowing bridge deck settlement. An on-land validation of the design was conducted using test piles driven through an 8 -in. $(20-\mathrm{cm})$-diam outer casing to simulate underwater conditions. After driving, the test piles were loaded to $200 \mathrm{kips}(889 \mathrm{kN})$ after having been prestressed to 82 kips to obtain load/deflection data. Permanent displacement was less than 0.1 in. $(0.25 \mathrm{~cm})$.

\section{Immersed Tube Tunnels and Pipelines}

The basic concept of the immersed tunnel sunk in an underwater trench dates back to the ancient Babylonians (Palmer and Roberts 1975). Numerous tunnels, sewer lines, pipes, and other subaqueous structures have been constructed using the immersed tunnel concept, where the structure is ballasted and sunk onto a prepared bottom or trench and then may be deballasted after coupling. Various types of foundations support these structures, including tremied/backfilled sand bases, compacted sand and gravel bases, grout/concrete pads, adjustable jacks, and caissons.

Immersed tube tunnels include the Detroit River tunnel, the Detroit-Windsor tunnel, Mobile's Bankhead and I-10 tunnels, the Texas Baytown tunnel, Virginia's Hampton Roads and Chesapeake Bay tunnels, Baltimore's Fort McHenry tunnel, and the Netherlands' Maas River tunnel (Palmer and Roberts 1975). Others include Tokyo's Dainikoro tunnel (Paulson 1980) and Greece's Aktion-Preveza tunnel (Geotronics 1997). 


\section{Bay Area Rapid Transit (BART) Tunnel}

Completion of the Trans-Bay Tube segment of the San Francisco BART in 1969 was considered a major civil engineering feat. Constructed in 58 sections and reposing on the bay floor at depths to 135 feet $(41 \mathrm{~m})$, the $\$ 180$-million project took 6 years to design and 3 years to contract and build (Brugge 1974). Watertight composite steel and concrete sections were fabricated in a dry dock, launched, and towed to the site. Each section was ballasted and sunk into a preexcavated trench (Figure 12).

The sections were then connected and welded into one continuous structure. Instead of excavating to bedrock, the structure lies on a layer of softer deposits for the purpose of damping possible seismic shocks (Kassel 1986).

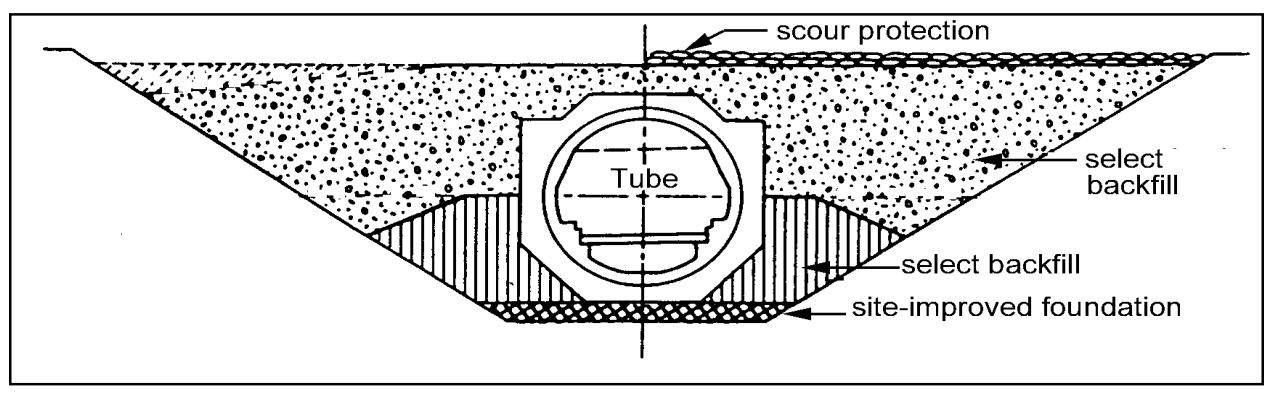

Figure 12. BART Tunnel (after Kassel 1986)

\section{Boston Tunnel}

The Boston Central Artery/Tunnel project is expected to cost $\$ 10.8$ billion. It will replace elevated highway structures with underground tunnels linking interstate highways and the airport upon final completion in the year 2004. Six concrete immersed tube sections provide the crossing under the Fort Point Channel. Each 48,000-ton tube section was precast on shore, winched and positioned using global positioning system surveying technology, and sunk into a 20-ft (6-m)-deep dredged excavation (Green 1996, Angelo 2000). Unlike other immersed tunnels, each tube section rests on caissons drilled into the subsurface below the dredged excavation (Figure 13). The additional foundation supports were needed to prevent damage to an underlying subway tunnel. Should the immersed tube sections accidentally fill with water, they could cause the underlying tunnel to fail (Brudno and Lancelloti 1992).

\section{Chek Lap Kok Airport transportation links}

Hong Kong's new airport construction involved multiple contracts providing transportation linkages, including highways, railroads, and ocean terminals. The final link to Hong Kong's central district and the third underwater crossing of Victoria Harbor is a 1.25-mile (2-km)-long submersed highway tube connecting Hong Kong and West Kowloon. The tube segments were precast on land and 


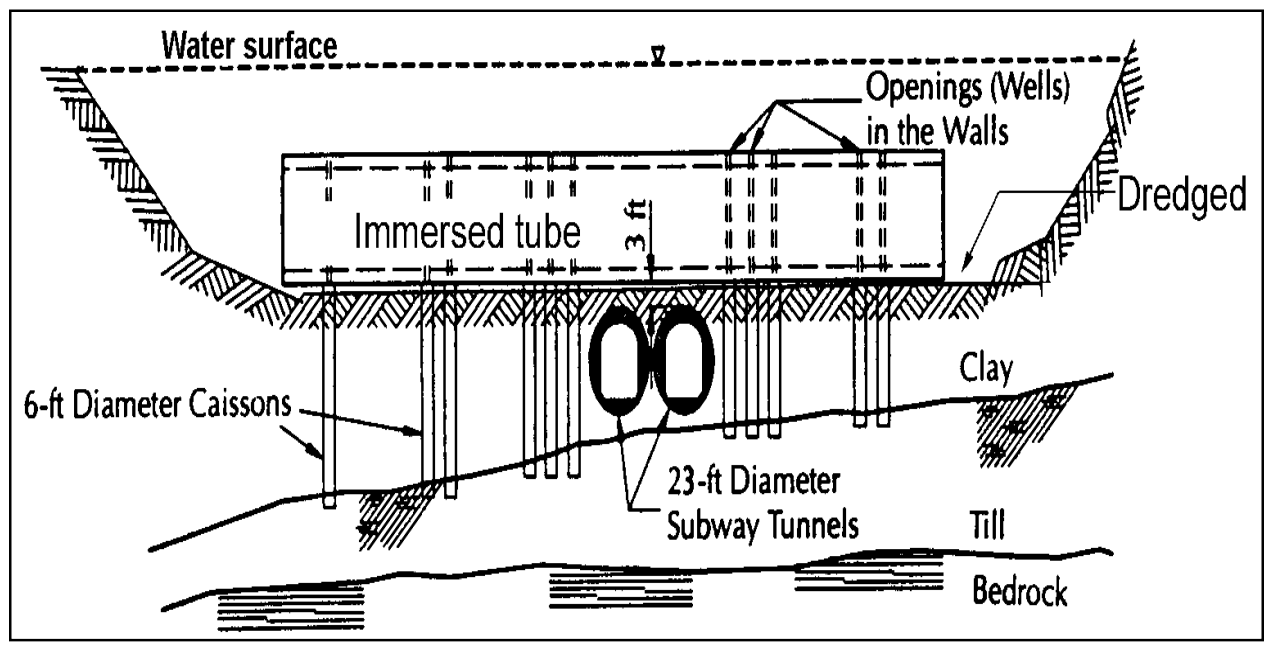

Figure 13. Boston Tunnel foundation (after Brudno and Lancelloti 1992)

towed into the harbor, where they were sunk across its main channel. A trench was dredged across the harbor bottom to receive the tube segments. Horizontal jacks were used to draw the segments together to create a seal. Sand was pumped below the sections to create permanent foundations, and backfilled rock provided protection from scouring erosion and anchor drags. The submerged highway is performing successfully as the final stage of the Airport Core Program (Kosowatz 1995).

\section{Oresund Link}

The rail and tunnel connection between Copenhagen, Denmark, and Malmo, Sweden, allows an unprecedented direct link between those two countries. The western end of the link is the world's longest immersed tube tunnel (2.5 miles, or $4 \mathrm{~km}$ ) carrying both a railroad and highway. It is composed of 20 precast concrete segments (55 kt each) floated into place and positioned onto a prepared gravel base within a dredged trench (Oresundskonsortiet 1999).

\section{Puget Sound gas pipeline}

Dual 8-in. (20-cm)-diam pipelines were placed in 600-ft (182-m)-deep water in Washington's Puget Sound in 1969 (Bomba and Seeds 1970). At the time, this was the world's deepest pipeline project. Geotechnical information was gathered using geophysical subbottom profiling. Sediments obtained by core barrel sampling ranged from boulders to silty clays. Although no deep trenching was performed, 4-ft (1.2-m) layered rock placement around and over the pipe was accomplished using a barge-mounted clamshell bucket and a tremie (fall-pipe) hopper. Inspection by divers (to $150-\mathrm{ft}$ depth) and video cameras verified the effectiveness of the placement techniques. 


\section{North Sea gas pipeline}

The Ekofisk oil and gas production complex in the middle of the North Sea began development in the 1970s. Many "firsts" were accomplished at this site, including the first major offshore gravity-based foundation for a concrete underwater oil storage tank (Focht and Kraft 1977).

Major underwater pipelines were constructed to transport the oil and gas to the shores of Norway, Denmark, England, and Germany. The longest pipeline carries gas to Emden, Germany, for a distance of 275 miles $(440 \mathrm{~km})$. This $3-\mathrm{ft}$ (1-m)-diam pipeline is laid to a maximum seabed depth of $230 \mathrm{ft}(70 \mathrm{~m})$ in a backfilled trench. Trenching operations to approximately $10 \mathrm{ft}(3 \mathrm{~m})$ below the seabed were conducted using a "jet sled" method and were backfilled with natural (sand) material. Minimum cover requirements of 20 in. $(50 \mathrm{~cm})$ were regulated to minimize accidental ship anchor and trawler damage to the pipeline. Postconstruction surveys indicated that approximately 10 percent of the pipeline had backfill less than 20 in. $(0.5 \mathrm{~m})$, so engineered backfill operations were conducted after the pipeline was operational.

Two backfill systems were designed and implemented. The first was trailing suction hopper dredges that dredged and transported fine sand and gravel, respectively, to a drill ship. The drill ship conveyed the respective materials to the pipeline via a fall-pipe system. The second system was a bulk-carrier ship converted to haul the respective materials to the pipeline site, then convey them to the pipeline using a fall-pipe system with attached electrohydraulic thruster units for precise backfill acoustic positioning over the pipeline. To backfill the approximate length of 23 miles $(37 \mathrm{~km})$ with these two systems took about 2 years and cost twice as much as the original pipeline laying and trenching operation (Loeken 1980).

\section{Los Angeles sewage sludge outfall}

In 1957, a steel 22-in. (56-cm)-diam pipeline was pulled 7 miles $(11.2 \mathrm{~km})$ offshore and sunk in 300-ft (91-m)-deep water within a 7-day period. Specially designed equipment made this feat possible. After the pulling operation was completed, a unique submarine pipeline trencher with jet nozzles straddled the pipe as it laid on the seabed and trenched about $6,000 \mathrm{ft}(1,824 \mathrm{~m})$ from the shoreline into the ocean. As high-pressure water and air jetted through the nozzles, the bottom material was cut away, allowing the pipe to settle into the trench. The deepest trenching (about $15 \mathrm{ft}$ or $5 \mathrm{~m}$ deep) was performed in the surf zone, where sheet piles were used to protect the trench excavation. Other unique equipment and installation techniques are discussed in Construction Methods and Equipment (1957) and Narver and Graham (1958).

\section{Puerto Rico sewage outfall}

The world's deepest ocean sewage outfall was recently constructed off the coast of Ponce. The 3.5-mile (5.6 km)-long, 4-ft (1.2-m) pipeline lies at a 
maximum depth of $450 \mathrm{ft}(137 \mathrm{~m})$ on the seafloor. The pipe sections were towed into position and lowered from barges to the seabed. Deep anchors consist of grout-filled bags lowered from the surface. Shallow mud deposits required an excavated trench into which the pipe was placed to achieve neutral buoyancy (Powers 1997).

\section{Offshore Oil Platform Structures}

Perhaps the best examples of underwater foundation in-the-wet construction are found in the offshore industry's structures, due to their unparalleled sizes, costs, complexity, and remote locations around the world. Offshore (outside sheltered waters) oil exploration and production began after World War II off the Louisiana coast. The first offshore steel-piled platform was fabricated in Morgan City, LA. Seven years later, the first jack-up drilling rig was placed offshore. Since that time, more than 5,500 platforms have been installed in the Gulf of Mexico (Hunt and Gary 2000).

Water depths of 20 to $50 \mathrm{ft}$ ( 6 to $15 \mathrm{~m}$ ) were typical for the first fixed platforms erected on steel pipe pile foundations. The 1- to 2-ft (0.3- to 0.6-m)diam piles were typically driven to refusal to support loads of 200 to $400 \mathrm{kips}$ ( 890 to $1,780 \mathrm{kN})$. Gradually, the fixed platforms were built in water depths to $200 \mathrm{ft}(61 \mathrm{~m})$, and significant advances were being made in marine geotechnical engineering.

Proprietary research programs were being conducted by the oil companies for the purpose of reducing design uncertainties since the test and performance databases were incomplete. For instance, land-based pile load tests ranged to only 300 tons $(1,320,000 \mathrm{~kg})$, whereas the typical offshore pile load was about 2,000 tons $(8,800,000 \mathrm{~kg})$ (Focht and Kraft 1977).

Progress was also made in other aspects of marine geotechnical engineering, including tension-loaded piles, laterally loaded piles, earthquake and hurricane hazards, and new types of foundations (e.g., suction caissons). Mobile drilling platforms consisting of pile-and-mat supported jack-up platforms and tension-leg platforms (TLP) supported by tension pile foundations were being built in the Gulf of Mexico. In the North Sea, the typically encountered clay seabed dictated that other foundation systems be designed, including drilled pile foundations and gravity-based foundations. Technology for gravity-based structures (GBS) has since been applied in the Gulf of Mexico (Hunteman, Anastasio, and Deshazer 1979). Suction caissons were first installed in the North Sea (Senpere and Auvergne 1982), and they have since been used in the Gulf of Mexico. Adaptations of the suction caisson technology have been applied to jacket platforms, jack-up platforms, TLPs, and "skirted" GBS foundations.

In general, offshore structures are attached to the seabed either rigidly (fixed structures) or flexibly (floating structures). Those rigidly attached to the seabed may be either fixed or mobile. Structures that are not attached to the seabed are mobile and may be production platforms, storage facilities, off-loading facilities, or exploratory drill platforms. The mobile nonattached structures are not 
discussed here since they are dynamically positioned and do not require foundation preparations. Most oil production platforms are attached to the seabed either rigidly (jackets, jack-ups, gravity-based, and compliant structures) or flexibly (floating TLP, mini-TLP, and spar structures). The foundation systems for the platforms are either pinned (driven, drilled, or suction-induced) or gravity-based, or combinations of the two.

\section{Jacket and jack-up structures}

Offshore oil production platforms are commonly built on a fixed "jacket" structure that is a tubular steel frame that is either floated or lifted in, positioned on the seabed, and pinned with pilings (Figure 14).

A "jack-up" structure is intended to be mobile and has a modified foundation including a spud can arrangement that is stabbed into the seabed floor (Figure 15).

The first mobile offshore platform designed for use in 100-ft (30-m) depths with a soft soil foundation was a pile-andmat supported jack-up platform (Focht and Kraft 1977). It consisted of six 4-ft (1.3-m)-diam pipe piles supporting an 80by $100-\mathrm{ft}(24-$ by $30-\mathrm{m})$ steel mat (Figure 16). The bearing pressure on the mat base ranged between 200 and $400 \mathrm{psf}$ ( 9.6 to $19.2 \mathrm{kPa}$ ) depending on the deck load. This foundation system is a combination gravity base underpinned by driven piles and was installed in the Gulf of Mexico.

Most jacket platforms have pinned foundations with driven piles, and are the most common type of offshore oil

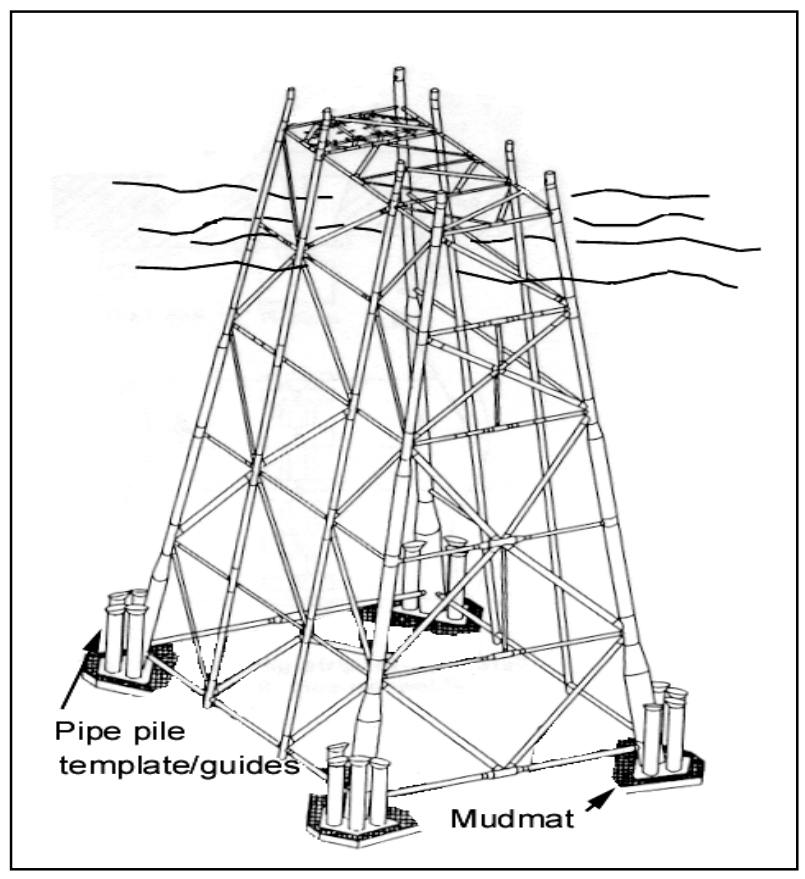

Figure 14. Fixed jacket structure (after White and Drake 1994) platform (Lacasse 1999). They are located worldwide, including the Gulf of Mexico, North Sea, Atlantic, and Pacific Oceans. For example, Exxon decided to use a jacket platform for its Hondo structure in California's Santa Barbara Channel. The Hondo platform's steel pipe piles (54-in. diam $\mathrm{H} 375$-ft length) were driven using nonsubmersible Vulcan and Menck hammers above the 850-ft (258-m)-deep ocean floor (Bardgette and Irick 1977).

The Alba Northern jacket structure installed in the North Sea has four steel mudmats to which pipe pile templates are attached. The single-launched jacket was floated in and installed in 414-ft (138-m) water. Each footing was pinned by 


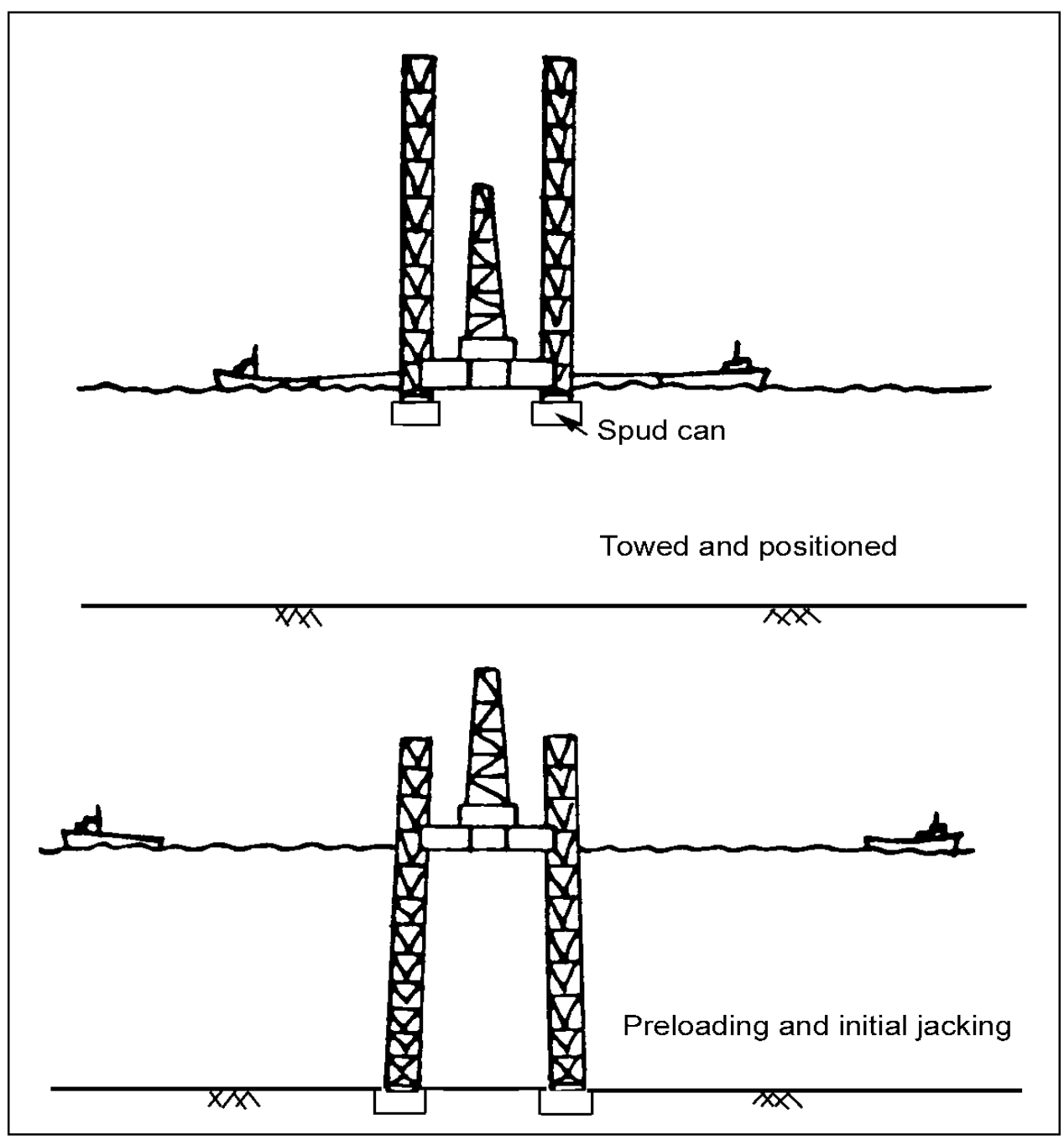

Figure 15. Jack-up structure installation (after Kobus and Whittington 1978)

four 96-in. (2.4-m)-diam piles that were driven $264 \mathrm{ft}(88 \mathrm{~m})$ with hydraulicpowered underwater hammers (White and Drake 1994). An innovative antifouling coating of cupro-nickel sheeting bonded to neoprene was applied to the steel structure to prevent marine growth.

An alternative to single-launched jacket designs for water depths in the 500- to 700-ft (167- to 233-m) range is Shell's two-piece grouted Enchilada platform in the Gulf of Mexico (Dorgant et al. 1998). After setting the base section, eight 84 -in. (2.33-m)-diam steel pipe piles were driven to $385 \mathrm{ft}(128 \mathrm{~m})$ using the free-riding IHC S-400 underwater hydraulic hammer without any supporting guides. The jacket top section was lifted into position and groutsealed.

Shell's Cognac jacket platform was installed 1,025 ft (342 m) below the Gulf of Mexico surface and was the world's first three-segment jacket (Sterling et al. 1979). The pinned foundation consists of 24 pipe piles, $7 \mathrm{ft}(2.3 \mathrm{~m})$ in diameter and $625 \mathrm{ft}(208 \mathrm{~m})$ long, driven through outrigger-type skirt pile sleeves. Each pile penetrated $450 \mathrm{ft}(150 \mathrm{~m})$ into the seabed. 


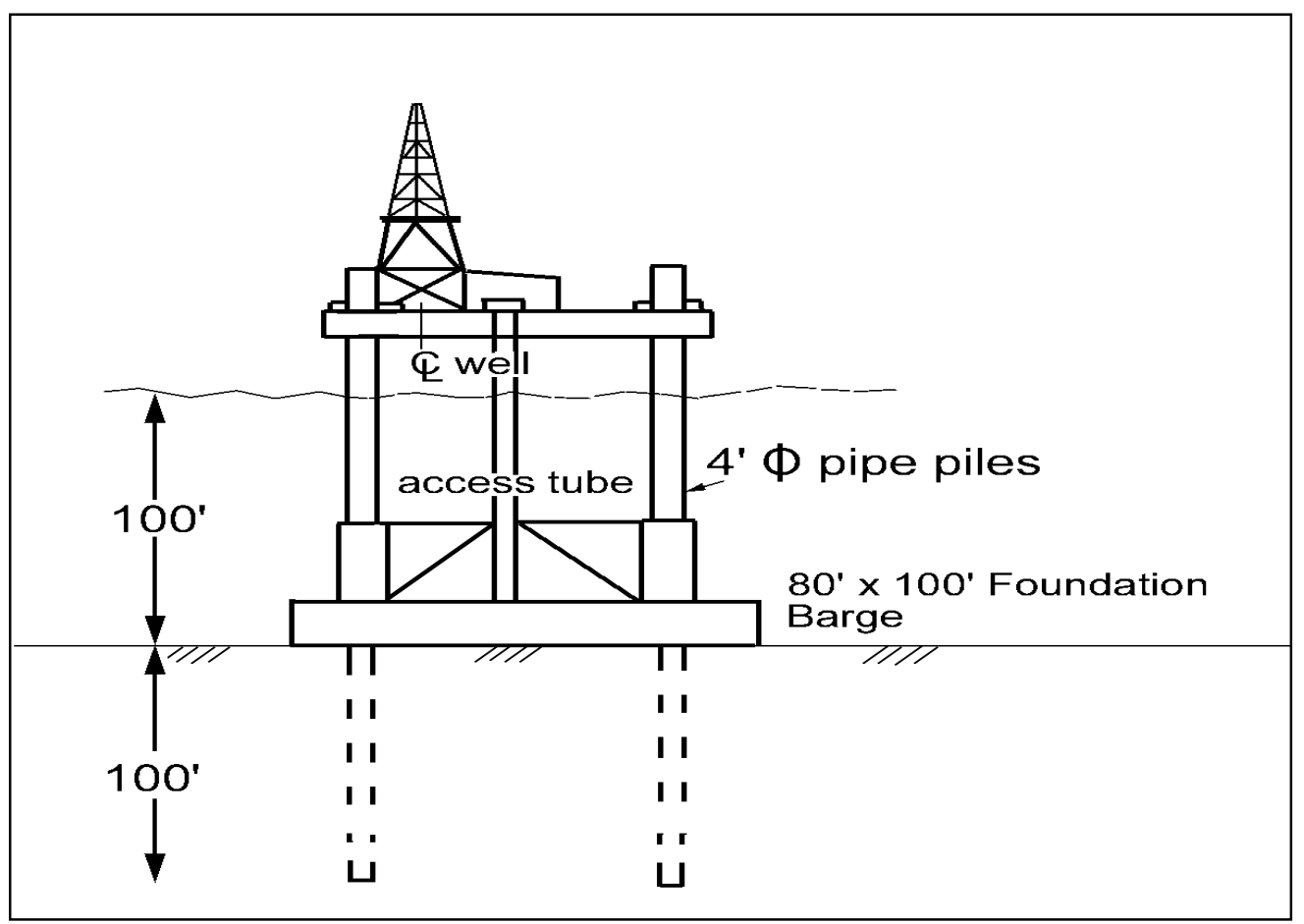

Figure 16. Jack-up platform on soft soil (after Focht and Kraft 1977)

The world's largest installed jacket structure is the Bullwinkle, at a Gulf of Mexico water depth of 1,350 ft (400 m) (Offshore Technology 1999).

Combining driven piles with drilled insert piles was required for the construction of the Goodwyn "A" steel jacket platform off Australia. Calcareous soil caused difficulty driving $8.7-\mathrm{ft}(2.65-\mathrm{m})$-diam piles past $382 \mathrm{ft}(116 \mathrm{~m})$ below the mudline. Therefore, $6.5-\mathrm{ft}(2-\mathrm{m})$-diam insert piles were drilled to a depth of $595 \mathrm{ft}(181 \mathrm{~m})$ below the mudline. The annulus between the piles was grouted with a specially designed grout mix (Gerwick News 1993).

Suction-pinned foundations replaced traditional piled foundations on Statoil's innovative Europipe jacket platform in the North Sea. The circular ("bucket") foundations with skirts increase the vertical compression and shear load capacity and provide substantial tensile load capacity (Baerheim, Hoberg, and Tjelta 1995).

The Europipe four-leg jacket (Figure 17) stands in $210 \mathrm{ft}(70 \mathrm{~m})$ water. Each bucket has a diameter of $36 \mathrm{ft}(12 \mathrm{~m})$, weighs 192 tons (215 tonnes), and penetrates about $18 \mathrm{ft}(6 \mathrm{~m})$ below the seabed. The jacket was lifted in, positioned on the seabed, and the buckets were suction-pumped to achieve penetration. The void between the seabed and the bucket top was then grouted to ensure an even support. 


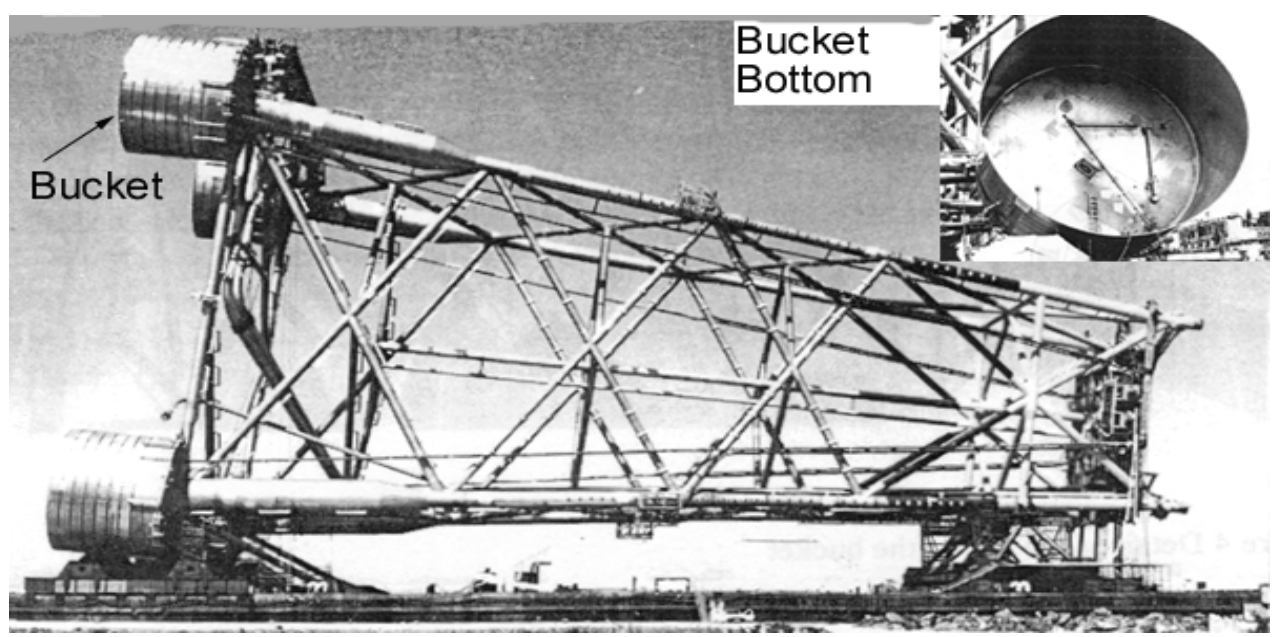

Figure 17. North Sea fixed jacket with bucket foundation (after Baerheim, Hoberg, and Tjelta 1995)

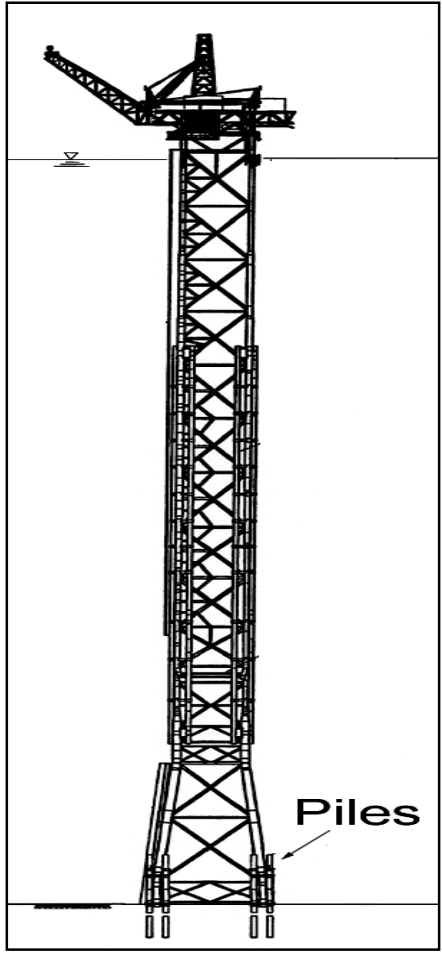

Figure 18. Complaint tower platform (after Will 1999)

\section{Compliant tower structures}

The compliant tower (CT) is a modified steel jacket structure (Figure 18) that occupies a much smaller footprint on the seabed (Figure 19). It is designed for sway periods of about $30 \mathrm{sec}$ instead of typical platform sway periods of about $3 \mathrm{sec}$. As a result, resonance is reduced and wave forces do not amplify the natural vibration frequency of the structure. Maximum design displacement (100-year hurricane event) is 1.5 to 2 percent of the water depth. In contrast, floating systems (TLP and Spars) may have lateral movements of up to 10 percent of the water depth.

The idea of the CT concept was initially used in the Bay of Biscay in 300-ft (91-m) water depth (Appert and Burger 1997). The most recent deepest CT installations are Amerada Hess' Baldplate installed off Texas in 1,650-ft (550-m) water depth and Texaco's Petronius installed in 1,754-ft (583-m) depth in the Gulf of Mexico, although Petronius production wells are not scheduled to be on-line until 2001 (Will 1999).

The Baldplate is the first freestanding, nonguyed $\mathrm{CT}$ and was the tallest free-standing structure in the world when constructed. Its 12 pipe piles (diameter $7 \mathrm{ft}(2.1 \mathrm{~m})$; length $428 \mathrm{ft}(130 \mathrm{~m})$ ) each have an ultimate capacity of 8,400 tons (74.7 MN) (Will et al. 1999).

The TLP foundation resists tensile and lateral forces imposed by semisubmersible structures (Figure 20). Many design variations have been used for offshore platforms, but the principle is the same (providing an anchoring system for floating platforms). 


\section{Tension-leg platform structures}

Conoco's North Sea Hutton TLP was installed in 1984 and is the world's first TLP oil production platform (Stock, Jardine, and McIntosh 1993). The site, $475 \mathrm{ft}$ $(145 \mathrm{~m})$ below water surface, is underlain by stiff glaciomarine tills and dense sands. Each of the four pinned foundations has eight $6-\mathrm{ft}(1.8-\mathrm{m})$-diam pipe piles driven $200 \mathrm{ft}(60 \mathrm{~m})$ below the mudline, and each pile group normally resists a tensile load of 1,100 tons $(1,000$ metric tons) and a surface platform lateral offset of $66 \mathrm{ft}(20 \mathrm{~m})$.

The largest TLP in the Gulf of Mexico (and the deepest TLP in the world) is Conoco's Ursa located in 3,800-ft (1,267-m)-deep water (Digre, Kipp, and Hunt 1999). Sixteen 96-in. (2.4-m)-diam pipe piles, $417 \mathrm{ft}$ $(139 \mathrm{~m})$ long, provide the pinned foundation. Each pile

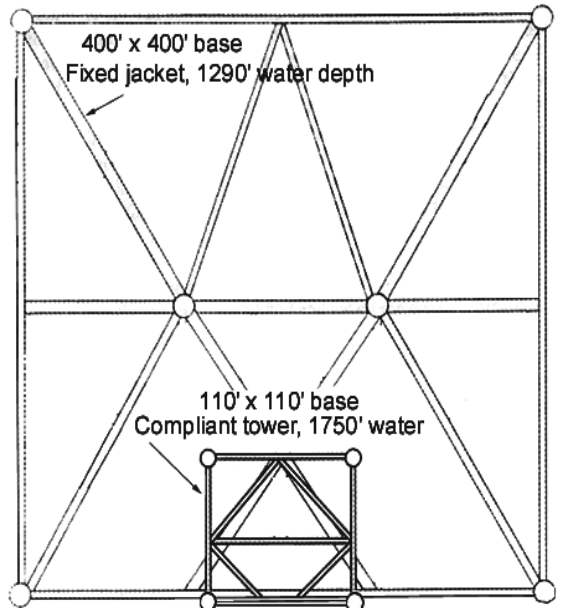

Figure 19. Compliant tower foundation footprint (after Will 1999) self-penetrated $125 \mathrm{ft}(42 \mathrm{~m})$ into the seabed prior to underwater driving.

The majority of TLP foundations are pinned with driven piles, but gravity-based foundations are also used. For example, Conoco's North Sea Heidrun TLP is tethered to four concrete gravitybased foundations (Mitcha, Morrison, and Oliveira 1997).

For "marginal" oil production sites, more economical "mini-TLP" platforms are constructed, which are typically smaller and faster to install. British Borneo's Morpeth platform (Figure 21) is a mini-TLP installed to a depth of 1,670 $\mathrm{ft}(557 \mathrm{~m})$ in the Gulf of Mexico. Six pipe piles, each 84 in. $(2.3 \mathrm{~m})$ in diameter by $340 \mathrm{ft}(113 \mathrm{~m})$ long were driven into the seabed. Each 214-ton $(195,000-\mathrm{kg})$ pile self-penetrated to $130 \mathrm{ft}(43 \mathrm{~m})$ prior to driving (Redfern, Calkins, and Matten 1999).

Other variations of the TLP concept include

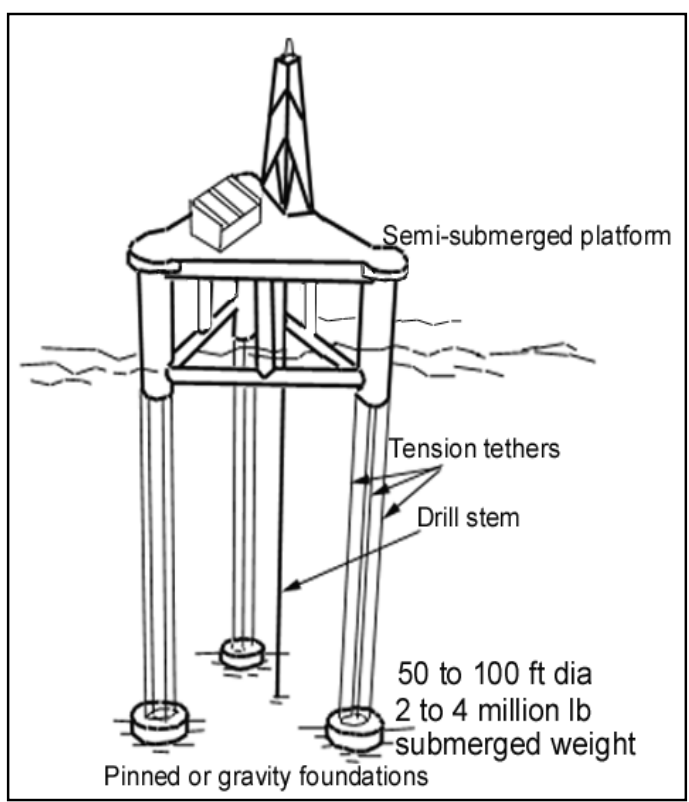

Figure 20. Typical TLP the Spar and Deep Draft Caisson Vessel (DDCV). Examples of each are the Gulf of Mexico's Neptune production Spar platform and the Hoover Diana DDCV (Offshore Technology 1999).

The Snorre platform in the North Sea became the first TLP to use suction caissons instead of driven piles (Figure 22). Concrete gravity cells with perimeter skirts (suction caissons) of $66-\mathrm{ft}(20-\mathrm{m})$-diam were installed in very soft clays at a water depth of $1,050 \mathrm{ft}(320 \mathrm{~m})$. Piles were determined to be unacceptable because of extremely low clay soil friction (bearing) capacity. 


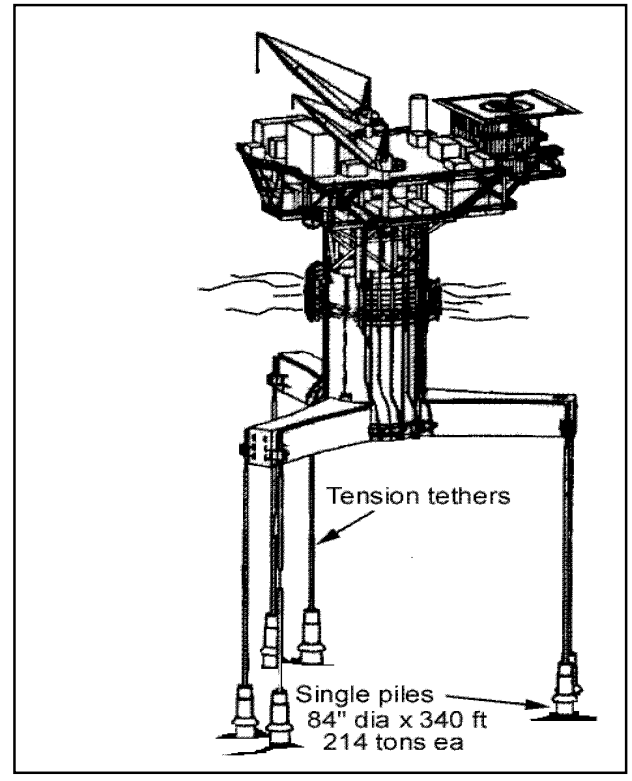

Figure 21. Mini-TLP structure (after Redfern, Calkins, and Matten 1999)
Each cell group (out of four total groups) has a total submerged weight of 6,250 tons $(7,000$ metric tons) after being ballasted with 3,125 tons (3,500 metric tons) of iron ore and olivine. The 100-year design storm maximum tension load for each cell group is 12,678 tons (14,200 metric tons), and the average tension load is balanced with the cell group weight. Accounting for the cell group weight, the average long-term load experienced by the soft clay soil is zero (Christophersen 1993).

\section{Gravity-based structures}

The advantage of gravity-based over pinned structures is their shorter installation duration, which is a big factor in reducing exposure to hostile storms in the North Sea and North Atlantic. The structures are constructed onshore or in protected waters, towed into position, and sunk to the sea floor. Installation can be accomplished during good weather windows (Young, Kraft, and Focht 1975).

The first major offshore gravity foundation was placed in the North Sea in 1973 (Focht and Kraft 1977). It was a 305-ft (93-m)-diam concrete oil storage tank in the Ekofisk Complex weighing 490,000 tons (444 million kg) that was a

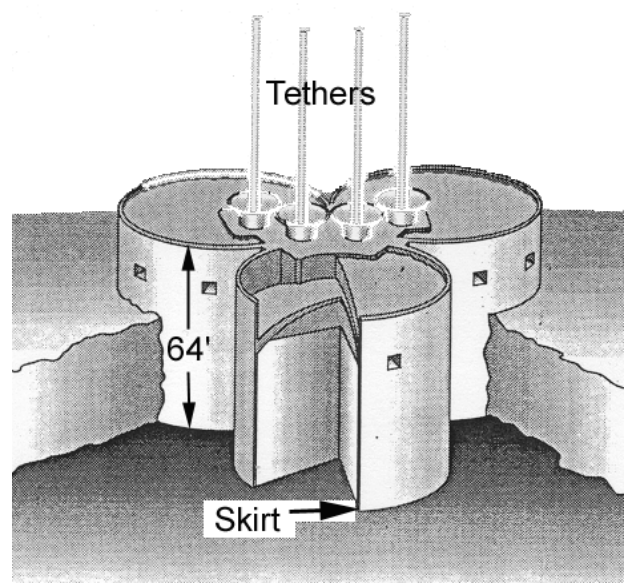

Figure 22. TLP suction pile foundation (after Christophersen 1993) float-in structure installed in $230-\mathrm{ft}(70-\mathrm{m})$ water depth. No piles were used to support the structure.

Another offshore foundation "first" occurred on another Ekofisk Complex structure. Drilled and underreamed shafts were constructed in the hard clay seabed instead of driven piles. The land-based practice of installing drilled shafts instead of driven piles at stiff or hard clay sites was common, but had not been used offshore, especially in water depths to $350 \mathrm{ft}$ (107 m) (Focht and Kraft 1977).

In 1978 the first concrete gravity production platform was installed in the Gulf of Mexico (Hunteman, Anastasio, and Deshazer 1979). Although it was actually a combination gravity and pinned foundation structure, it holds a place in offshore foundation history. The offshore site was located in only 12-ft (4-m) water depth. Foundation preparation of the seabed was required to prevent scouring. The seabed was dredged $7 \mathrm{ft}(2.3 \mathrm{~m})$ deep, and a 2-ft (0.7-m)-thick oyster shell mat was placed in the excavation. The platform was towed to the site, ballasted, sunk onto the prepared foundation, and pinned with perimeter piles. Limestone rock riprap was then installed around the perimeter to prevent scour. 
At the time of its installation, the North Sea's Draugen GBS was the tallest concrete structure ever constructed (Alm, Bye, and Egeland 1995). It is located in approximately $750 \mathrm{ft}(250 \mathrm{~m})$ of water on a very hard clay seabed with embedded boulders. Although the upper material had a fairly low undrained shear strength of $312 \mathrm{psf}(15 \mathrm{kPa})$, it increased to $20,800 \mathrm{psf}(1,000 \mathrm{kPa})$ at $18 \mathrm{ft}$ $(6 \mathrm{~m})$ of depth. Concrete skirts at the base of the structure penetrated an average of $24 \mathrm{ft}$ $(8 \mathrm{~m})$ into the seabed as a maximum suction pressure of approximately $51 \mathrm{psi}(350 \mathrm{kPa})$ was applied.

The North Sea Troll I GBS has skirts that penetrate $108 \mathrm{ft}(36 \mathrm{~m})$ into the stiff clay with undrained shear strength of approximately 5.2 tsf $(500 \mathrm{kPa})$. The platform rests in 1,000-ft (303-m) water depth (Andenaes, Skomedal, and Lindseth 1996).

The first offshore gravity-based platform to use suction caissons was Statoil's Gullfaks C (Figure 23) in the North Sea, installed in 1989 (Tjelta 1992). This \$2-billion GBS platform was placed on normally consolidated soft clay at a water depth of $720 \mathrm{ft}(220 \mathrm{~m})$. A soil drain system was designed and preinstalled into the caissons. This drainage system allowed faster consolidation of the foundation soil, which resulted in increased strength of the material. Another GBS example is the Hibernia structure installed in the Grand Banks off Newfoundland in 1990 (Offshore Technology 1999).

It is a 495,000-ton (450,000-metric ton) concrete caisson $321 \mathrm{ft}(106 \mathrm{~m})$ tall with a $27-\mathrm{ft}$ (108-m)-diam base (Figure 24) ballasted with 452,000 tons $(411,000$ metric tons) of iron ore (magnetite) and placed in 242-ft (80-m) water depth. The seabed was prepared by "sweeping" with a deep-sea hopper dredger. The caisson has 16 "fingers" to resist icebergs, and was designed to withstand a 500-year event collision with a 1 million metric ton iceberg and a 10,000-year event collision with a 6.6 million ton ( 6 million metric ton) iceberg.

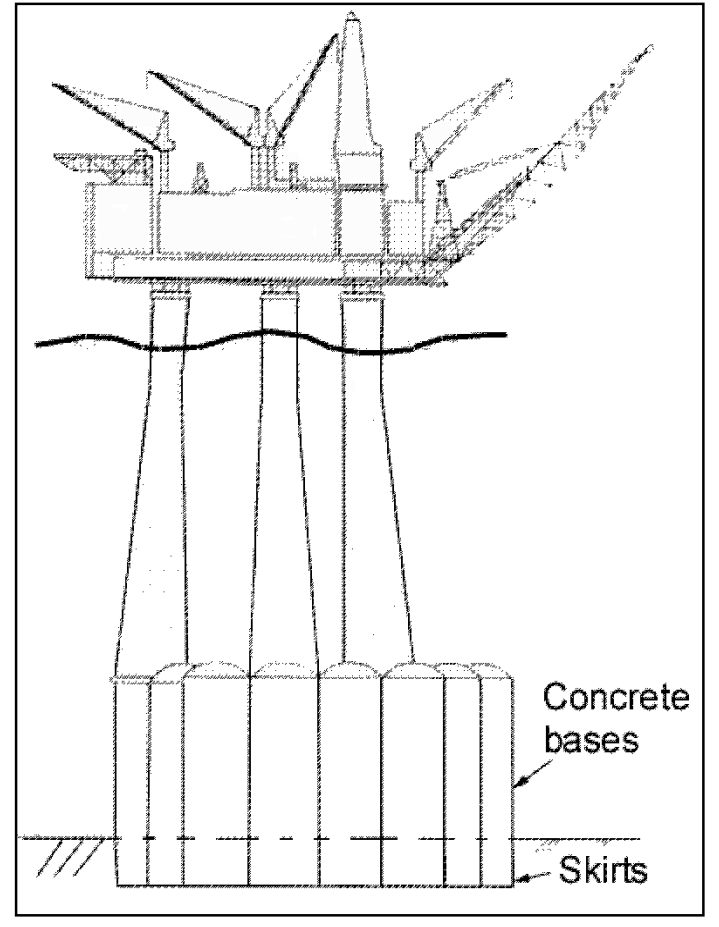

Figure 23. Statoil's Gullfaks C platform (after Tielta 1992)

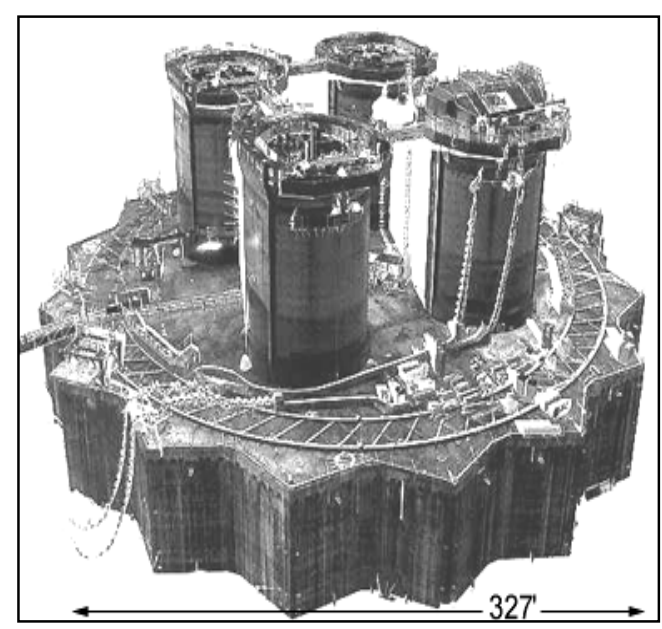

Figure 24. Hibernia gravity-based foundation (after Offshore Technology 1999) 


\section{Other Underwater-Founded Structures}

\section{Wharf off-loading system}

A large-capacity (2,000-ton) transport barge was designed for use at a marine fabrication industrial yard to off-load and deliver equipment at two existing wharfs in Connecticut (Abbott and George 1989). The barge was designed to jack up to the wharf elevation, thus eliminating the need for heavy lifting cranes on the wharf. For each separate wharf, a special underwater foundation was constructed to prevent the spuds from punching through the soft clay $(1,000-\mathrm{psf}$ or $49-\mathrm{kPa}$ shear strength), $35 \mathrm{ft}(10.7 \mathrm{~m})$ below the water surface. Since the 1,200 -ton $(10,676-\mathrm{kN})$ leg design could not be supported by the soft clay, and due to the site conditions at each wharf, two separate foundations were designed and constructed.

At one wharf, bedrock was located $35 \mathrm{ft}(10.7 \mathrm{~m})$ below the mudline. Prefabricated steel cofferdam cylinders (diameter $28 \mathrm{ft}$ or $8.5 \mathrm{~m}$ ) were driven $75 \mathrm{ft}(23 \mathrm{~m})$ into the bedrock, excavated, and filled with crushed stone. Precast concrete pads, $20 \mathrm{ft}(6.1 \mathrm{~m})$ in diameter and $5 \mathrm{ft}(1.5 \mathrm{~m})$ thick, were placed on top of the crushed stone cofferdams to support the barge's spud legs. Placement tolerance of 9 in. $(230 \mathrm{~mm})$ for caisson installation was met.

At the other wharf, bedrock was located $50 \mathrm{ft}(15.2 \mathrm{~m})$ below the mudline, so other foundation alternatives were considered. The design load for each leg foundation was 2,000 tons $(17,794 \mathrm{kN})$. A reinforced earth pad overlain by a precast concrete base was installed with minimal dredging. Three $10-\mathrm{ft}(3-\mathrm{m})$ thick compacted pads of crushed stone, sandwiched between mats of steel strips, were placed in a $15-\mathrm{ft}$ (4.6-m)-deep excavated hole. Special procedures were devised to construct the underwater reinforced earth pad. Precast concrete pads, $25 \mathrm{ft}(7.6 \mathrm{~m})$ in diameter and $5 \mathrm{ft}(1.5 \mathrm{~m})$ thick, were placed on top to support the barge s spud legs (Abbott and George 1989).

\section{Ship dry docks}

During the World War II era, the U.S. Navy undertook a massive construction effort to build dry docks for shipbuilding and repair at its numerous naval facilities. Construction took place at Pearl Harbor, Norfolk, Philadelphia, Mare Island, Brooklyn, San Diego, and other locations. Dry docks are classified as graving (basin excluding water) or floating (buoyancy principle). In general, one of two construction methods was used, with the basic difference being the concrete placement method (above-water or tremied). These methods were

a. Underwater excavation and tremied concrete construction, followed by dewatering.

$b$. Underwater excavation concurrently with deep well-point dewatering prior to concrete placement. 
Sheet pile installation and dredging operations typically began the construction effort, followed by underwater H-pile installation. The piles were designed to resist uplift during reduction of hydrostatic pressure as the dock was dewatered, and also to carry dock operation compressive loads through any underlying soft layers into a firm stratum below. Construction methods, especially for tremie concrete, were discussed by Harris (1942) and Johnson, Compton, and Ling (1972).

Tate (1961) detailed construction of a Puget Sound floating dry dock with dimensions of 1,180 by $180 \mathrm{ft}$ ( 359 by $55 \mathrm{~m}$ ) built to overhaul Pacific Fleet aircraft carriers. Design, construction, and subsequent operation depended on an elaborate network of continuously operating dewatering pumps. After dredging to $40 \mathrm{ft}(12 \mathrm{~m})$, the underwater site was backfilled (hydraulic jetting from deck scows) with a sand/gravel mix consisting of 3-in. maximum size with less than 10 percent passing the 100-mesh screen. Sheet-pile bulkheads were installed, the site was dewatered, and in-the-dry construction proceeded. Prior to concrete placement, vibroflotation equipment was used to increase the foundation's bearing capacity (by increasing its relative density).

Millard and Hassani (1971) detailed the construction of Bethlehem Steel's graving dry dock for shipbuilding near Baltimore. The dimensions of the dock were 1,200 by $200 \mathrm{ft}$ ( 365 by $61 \mathrm{~m}$ ). This dry dock depended on continuously operated dewatering pumps during shipbuilding operations to reduce hydrostatic pressure against the relatively thin walls and floors. During construction, up to $70 \mathrm{ft}(21 \mathrm{~m})$ of soft materials was dredged to expose underlying sand with adequate bearing capacity. Sand was also used as backfill and was placed by bottom-dumping scows (barges). An underwater embankment was also needed as a construction dike. After the site was enclosed by dikes and sheet-pile cells and dewatered, the sand fill was compacted using vibratory pile-driving equipment.

\section{Berlin's Potsdamer Platz}

Beginning in 1995, construction began in Germany's new capital to support the government's office move from Bohn to Berlin. The high-rise buildings have basements to depths of $56 \mathrm{ft}(17 \mathrm{~m})$ below ground. Artificial lakes and city regulations curtailed dewatering schemes during construction, which required foundations to be built underwater. Pontoon-mounted excavators dug the foundation pits, and divers manually cleaned the bases and positioned sheet piles. Steel pilings were vibrated into the subsurface to resist buoyancy of the concrete base slabs. The base slabs (up to $5 \mathrm{ft}(1.5 \mathrm{~m}$ ) thick) were placed underwater. After dewatering the sheet-pile enclosure, the structural slab was cast in place, and the structure was constructed in the dry (Reina 1996).

\section{Baltic Sea wind turbines}

The first offshore pilot projects demonstrating the electrical-generating potential of wind turbines were constructed at locations off the Denmark and Sweden coasts in the Baltic Sea (Danish Wind Turbine Manufacturers 
Association 1998). Studies have been conducted not only for the electrical aspects of wind power, but also for the types and costs of underwater foundations.

Four types of wind turbine foundations have been constructed in the wet: concrete (float-in), combination concrete gravity footing with a steel pedestal, steel pile, and steel tripod (jacket) with $3-\mathrm{ft}(1-\mathrm{m})$-diam steel pile anchors. Installation costs as a function of water depths for each type of foundation were analyzed. In water depths to about $30 \mathrm{ft}(9 \mathrm{~m})$, the concrete gravity platforms were the most expensive. The simplest foundation is the single steel pile with diameter between 11 and $14 \mathrm{ft}(3.5$ and $4.5 \mathrm{~m})$, driven 30 to $60 \mathrm{ft}(20$ to $30 \mathrm{~m})$ into the seabed. The jacket was the least expensive, but was found to be unsuitable for depths less than $18 \mathrm{ft}(6 \mathrm{~m})$ due to tripod interference with approaching service vessels.

\section{Offshore military tracking platforms}

In 1978, the U.S. Navy contracted design and construction of four aircrafttracking tower structures to be built in the Atlantic Ocean 30 miles $(48 \mathrm{~km})$ off North Carolina in water depths to $105 \mathrm{ft}(32 \mathrm{~m})$. Each tripod tower is supported by underwater 42 -in. (107-cm)-diam steel pipe piles driven through a template with penetrations to $270 \mathrm{ft}(82 \mathrm{~m})$ below the mudline into dense sands and stiff clays. Rigid design requirements (20-year operational life, excursion limitations of $1 \mathrm{ft}$ lateral and $1 \mathrm{deg}$ rotational in 60-mph winds and sea state 7) dictated applied pile loads up to 1,005 tons in tension and 1,479 tons in compression. The design penetration depths were based on a safety factor of 1.5 . Several abovewater Vulcan diesel hammers were used to achieve the design penetrations without jetting or predrilling. As an interesting note, predriving analysis using the wave equation predicted that design penetrations could not be achieved (Ling 1978).

\section{Bantry Bay tanker terminal}

This deepwater crude oil terminal is located 1,100 ft (334 m) off Ireland's southwestern coast and is founded on battered 40-in. (102-cm)-diam steel pipe piles in 100-ft (30-m) water depth. The piles are $220 \mathrm{ft}(67 \mathrm{~m})$ long and were driven through boulder clays and silts to bedrock. A $20-\mathrm{ft}(6-\mathrm{m})$ portion of the tips was rock-socketed by drilling. Initial driving efforts were difficult due to the waves and lack of any driving template. Driven piles left unbraced due to the short winter work schedule envelope failed at weld connections due to the wave action. Larger work platforms, bigger pile hammers, and spud-mounted pile templates corrected this situation. Boulder inclusions in the drilled sockets were reduced by increasing the bit diameter and using powerful airlift ejectors. Reinforcing bars and concrete were then placed in each pile (Fox 1970). 


\section{Submerged oil storage tank}

The Khazzan Dubai I is a 500,000-barrel oil steel storage tank located 60 miles (96 km) off Dubai in 154-ft (47-m) water depth (Chamberlin 1970). This unique structure has no enclosed bottom (it holds oil by water displacement), and its circular sides are connected to the seafloor by $3-\mathrm{ft}(1-\mathrm{m})$ diam pipe piles. The structure was towed to its site, ballasted by air displacement, and sunk onto a level (1:100) unimproved seafloor. For each pile, a 42-in. $(107-\mathrm{cm})$-diam hole was rotary-drilled $100 \mathrm{ft}(30 \mathrm{~m})$ into the layered clay, silt, sand, and weathered limestone subsurface, using a tricone bit and underreamer. The pile was lowered into the hole and cemented to both the formation and the structure with expansion grout having 28-day compressive strength of 3,000 psi $(21 \mathrm{MPa})$. Full-scale tests of grouted structure connections were conducted. 


\section{Foundation Site Assessment}

\section{Site and Foundation Selection Process}

Site investigations are an essential part of the underwater site selection, foundation design, and foundation installation elements. Adequately planning and executing a site investigation is especially critical for determining the geotechnical influences prior to foundation selection and design (American Petroleum Institute 1989; James 1987; Hitchings, Bradshaw, and Labiosa 1976). Preliminary design efforts require that site surveying and assessment efforts be under way, and the completed site characterization should be finalized prior to final design. Special consideration must be given to the possibility of construction contract problems if a complete site characterization is not conducted prior to final design.

The site conditions (including topography, bottom current, sediment loading and scour, and other environmental conditions) and engineering properties (including soil/rock lithology and stratigraphy, strength, durability, compressibility, and seismic concerns) must be explored and characterized prior to foundation final selection and design (Herrmann, Raecke, and Albertsen 1972).

Topics that need to addressed during the general site and foundation selection process are outlined below.

Site assessment. Geologic, topographic, and geographic influences are important within the given project's political boundary and should be studied extensively during the site selection process. Nearby industrial or urban situations may impose unique restrictions. In addition to the surrounding land assessment, the seabed/riverbed physical qualities (such as depth, slope, and underwater obstructions) are important. Underwater obstructions include deadfalls, snags, cable crossings, and other sunken objects. The water body's physical, chemical, and environmental characteristics are also vitally important and include the following:

Tidal variation

Current profile and hydraulic characteristics

Hydrographic data 
Icing traits

Seasonal underwater visibility

Sedimentation and scouring potential

Salinity and/or temperature variations, and water chemistry

Environmental quality considerations and regulations

Aquatic characteristics (expected problematic species)

Soil and rock engineering properties. A subsurface investigation is vitally important in the foundation selection and design process since it helps the designer understand the soil/rock response to the imposed structural loads. An adequate evaluation of the engineering properties of the seabed or river bottom requires a time-consuming and often costly site investigation, including in situ testing and sampling, laboratory testing, and data analysis. The adequacy of this program may be difficult to assess, given the uncertainties involved for an investigation to be conducted for a remote underwater site. The presence of the water barrier above the site demands innovative or modified utilization of landbased techniques and equipment to achieve reliable and accurate results.

Structure function. The structure's intended function must be properly identified. Two aspects of the structure's foundation function that must be addressed are its intended design life and its degree of confidence requirements (factors of safety, risk analysis, and design uncertainty).

Structure characteristics. Physical size, configuration, submerged weight, load distribution, installation sequence, and dynamic load resistance are important variables to be considered in the foundation selection process. For instance, both land- and water-based structures may be designed to resist wind loads, but the water-based structure must also resist hydrodynamic current drag and wave and ice loads that ultimately are fed into the foundation design requirements.

Installation requirements. Inherent in the foundation selection and design process are the questions of installation equipment and labor, procedures, and quality control. Composition, size, and weight of the foundation components dictate the equipment and methods for transporting, positioning, and installing on the seabed or river bottom. Coordination with above-foundation structural elements' installation requirements will guide foundation selection. Maintaining quality control and verifying quality assurance are important considerations that have to be addressed during the foundation selection process since they will be matched to the specified foundation system.

Contract cost. Balancing the requirement for a reasonable degree of confidence in the foundation's utility with the goal of achieving the lowest project cost is another important variable in the foundation selection process. Reduced competition due to a smaller number of foundation contractors with experience in a given foundation system is not a cost deterrent. As foundation contractors gain more experience and the number of competitors increase, lower bids will result. Consideration must be given to the potential contractors' and subcontractors' capabilities and experience records when selecting a foundation 
type, not only to obtain a higher probability for successful installation, but to potentially lower the contract bid amounts.

\section{Site Assessment and Characterization}

Noninvasive assessment/characterization techniques, including bathymetric and hydrographic surveys, are conducted to determine the depth and bottom topography. Visual site assessments may be accomplished using remotely operated vehicles outfitted with video cameras. Geophysical surveys such as side-scan sonar are conducted to determine subbottom profiles of debris, sediments, soil, and rock.

\section{Preliminary assessment}

Preliminary information-gathering consists of building a site-specific database detailing site location and configuration, water conditions (water depth, density and salinity profiles, temperature variations, current profile from the water surface to the foundation bed, tidal variations), and sediment conditions.

Marine charts typically show navigation aids, water depths, and navigation obstructions including underwater cables and pipelines. Marine charts in digital format are available from the U.S. Department of Commerce's National Oceanic and Atmospheric Administration (NOAA) for coastal areas and the Great Lakes; the Department of Defense's National Imagery and Mapping Agency (NIMA) for open ocean and foreign waters; the U.S. Army Corps of Engineers for inland rivers, lakes, and canal systems; and the U.S. Geological Survey for land-based topography. Georeferenced digital maps with aerial and satellite photography are available from various commercial vendors. The NIMA has recently established a vector-based digital maritime chart database named the Digital Nautical Chart, available freely to U.S. Government agencies with data-sharing agreements and by commercial agreement to public commercial vendors. Comprehensive inland waterways information is available on Internet sites maintained by the National Weather Service and NOAA (http://www.riverwatch.noaa.gov) and the Corps of Engineers (http://water.mvr.usace.army.mil).

\section{Hydrographic surveying and environmental data collection}

Underwater site surveys are required to map bottom topography and cartographic features. Site surveying is conducted from either a surface-based platform or a submersible platform. Surface-based platforms are operated from ships, pontoons, or barges and generally operate on principles of reflected acoustic signal-processing using compression wave energy to determine water depths referenced to mean sea level. Surface position is determined using global positioning system (GPS) receivers that are operated either in a stand-alone mode or referenced to known latitude-longitude-elevation stations for increased accuracy (differential positioning). GPS navigation and surveying principles and 
equipment were state of the art in the early 1990s, and are supplanting long-range radio navigation and radio beacon survey-positioning systems. GPS equipment development has focused on miniaturizing the receivers and providing a "total station" package to enable faster and more accurate survey results.

Having a highly accurate above-water reference datum provided by GPS technology allows for better positional accuracy beneath the surface. Echosounding (sonic) technology provides positioning data between the water surface and the bottom. Single-beam technology is being replaced by newer single-head multibeam (SHMB) technology and equipment. Several equipment manufacturers provide state-of-the-art equipment, and the Corps of Engineers is using those capabilities. For example, the Los Angeles District has acquired and used SHMB technology since the early 1990s for navigation works such as the Pier 400 harbor project (USACE 1999b).

The new International Hydrographic Office "Standards for Hydrographic Surveys" describe four orders of surveys, with Order 1 being the most stringent. Horizontal and vertical accuracy and maximum sounding line spacing for hydrographic surveys are established using formulas depending on average depth of investigation. For example, at a $99-\mathrm{ft}(30-\mathrm{m})$-depth coastal site, survey results should be accurate to at least $21 \mathrm{ft}(6.5 \mathrm{~m})$ horizontally with depth accuracy of $2 \mathrm{ft}(0.63 \mathrm{~m})$ (Harris 1999).

Submersible platforms consisting of remotely operated vehicles (ROV) or autonomous underwater vehicles (AUV) enable site surveying and topographic mapping in deeper water. The AUV systems do not have tethers, which eliminates tether hydrodynamic drag and results in faster survey operations. A downside of AUV technology is the lack of consistent and reliable energy sources for propulsion and onboard instrumentation. Development of acceptable sources (including batteries, fuel cells, and engines) is being undertaken by commercial and academic endeavors. An ideal AUV would have little or no input from an operator (i.e., would be preprogrammable) and would be capable of running its survey grid pattern at speeds of 1 to $2 \mathrm{~m} / \mathrm{sec}$ while avoiding underwater obstacles. AUVs specifically designed for surveying operations have been developed which are capable of acoustically transmitting relatively accurate survey data but are not yet completely autonomous. Operator input is still required to adjust the survey instruments to match shifting seabed conditions and perform diagnostic functions for quality control (Bjerrum and Krogh 1998).

Environmental data collection is conducted to measure water quality data such as current velocity, density, temperature, and water chemistry profiles. Numerous equipment is available to obtain such data. To reduce the effect that the instrument itself has on the measured variable, new devices have been developed and are being used. For example, instead of using a standard current meter to obtain a velocity profile, electromagnetic current meters (EMCM) were developed based on the principle that a conductor (water) flowing through a magnetic field (current meter probe) produces a voltage proportional to its velocity. To further reduce the instrumentation effects, EMCM technology is being supplemented by newer noninvasive sensors based on acoustic emission principles. Acoustic current meters, side-scan sonar, and secscan sonar devices 
allow current measurements to be taken at a single point or over a broad area. ROV and AUV platforms are also being packaged to provide multiple sensor instrumentation for bathymetric and environmental data collection (Sonsub 1999, Reson 1999, ORE 1999, Ultra Electronics 1999).

\section{Geophysical investigations}

Geophysical methods have evolved as major investigative tools for underwater site assessment and geotechnical exploration purposes. They are useful for detecting and delineating geological deformational features, including bottom and subbottom faults, scarps, rock and mud slides; for obstacle detection (Figure 25); landscape mapping (Figure 26); and for mapping other features critical to underwater foundation location and design.

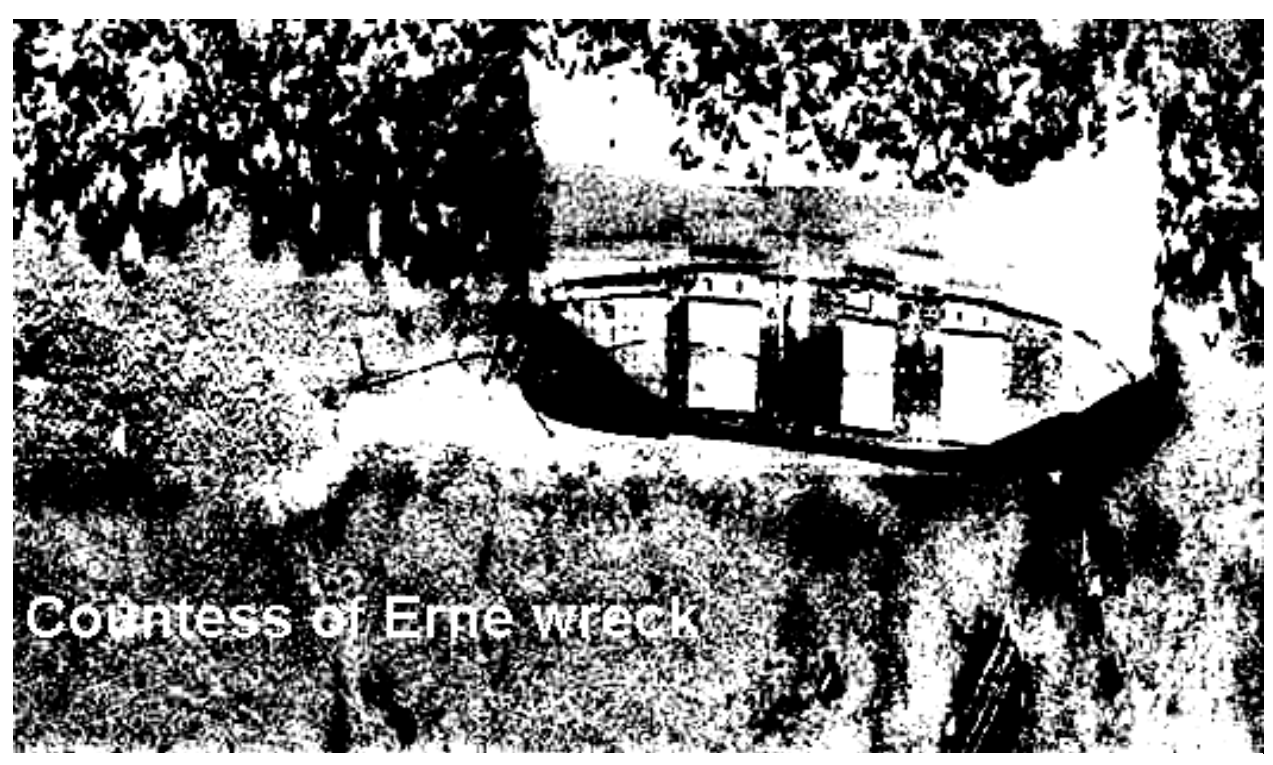

Figure 25. Widescan ${ }^{\mathrm{TM}}$ digital side-scan sonar image (after Ultra Electronics 1999) enables underwater obstacle detection

Offshore exploration technology relies on geophysical investigations to determine potential reservoir locations and to estimate potential yields. Nearsurface geophysics accomplishes different functions at much shallower depths, but the principles are the same. Sound waves (acoustic and seismic), electrical resistance, electromagnetic signals, gravimetry, and radar principles and procedures are used in near-surface geophysical investigations, and each method is chosen for suitability depending on the intended function of the investigation (Beasley et al. 1997a, b).

Underwater acoustic and seismic methods are typically used for underwater site investigations; the required depth of investigation usually dictates which method is employed. Acoustic methods (subbottom profiling, side-scan sonar, and echo-sounding) exploit compression wave propagation techniques and 
provide excellent results for determining stratigraphy just below the mudline. Seismic methods exploiting reflected or refracted shear wave propagation are useful for deeper investigations.

In general, the denser the subbottom material, the deeper the penetrability for these two methods. The implementation of geophysical acoustic methods and hydrographic surveying methods often overlaps due to the available equipment and technology. Multibeam echosounding and side-scan sonar equipment is capable of providing detailed landscape mapping of the

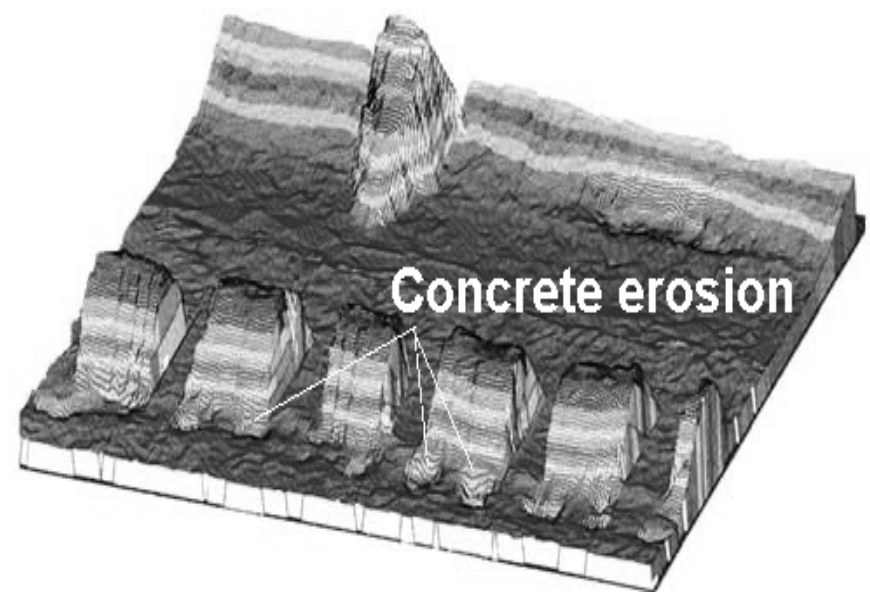

Figure 26. Bonneville Dam stilling basin mapping using SeaBat ${ }^{\mathrm{TM}}$ technology (after Reson, Inc. 1999) seabed (or river bottom), which allows interpretation of geologic deformational features as well as providing physical positioning data for engineering surveys (Reson 1999, ORE 1999, Ultra Electronics 1999). Side-scan sonar methods are also used for quality control and monitoring of dredging and ocean disposal of dredged material. Mosher, Currie, and Sullivan (1997) investigated using sidescan sonar mosaics to monitor ocean disposal at depths to $822 \mathrm{ft}(250 \mathrm{~m})$.

Geophysical seismic investigations for offshore exploration use 3-D and 4-D (three- and four-dimensional time-lapsed) interpretation methods to map stratigraphy and reservoir deposits thousands of feet below the seabed. Advancing technology, such as ocean bottom cable systems, allows higher resolution and more accurate repeatability due to the fixed receiver (geophone and hydrophone) locations on and inside the seabed (Beasley et al. 1997a, b).

Other geophysical technologies commercialized in the offshore industry that may have application in foundation site characterization are the seismic-whiledrilling (SWD) method, in which the advancing drill bit serves as the seismic source, and the wireline vertical seismic profiling (VSP) method (McMillin 1999). The major advantage of the SWD method is reduced costs during oil exploration drilling since the VSP method is not conducted in real time during the drilling operation.

High-resolution seismic data are also collected in shallow-water environments such as rivers and tidal areas. Typically, only 2-D interpretation methods are used, due to increased costs in conducting and interpreting 3-D highresolution surveys. River bottom soil and rock stratification may be detected to depths greater than $100 \mathrm{ft}(30 \mathrm{~m})$ with $1-\mathrm{ft}(0.3-\mathrm{m})$ vertical resolution when interpreting 2-D data. Advanced processing and interpretation techniques allow deeper depths with higher resolutions. Instead of ocean bottom cables, the receivers are located on surface-towed platforms. Typically, a single channel system with a boomer source and a receiver is used, but multichannel systems are also used at more geologically complex sites. 
Rivers and canals provide special challenges to geophysical investigations due to navigation restrictions and changing currents during the course of an investigation, as well as data interpretation of multiple mode reflection geometry caused by changes in river bottom and bank slopes (Toth, Vida, and Horwath 1997). As the available computer equipment and processing software becomes more adapted to shallow-water surveys, transition to high-resolution 3-D methods will likely become more commonplace in shallow-waterway project investigations.

\section{Soil and Rock Engineering Properties}

To obtain detailed subbottom information, geotechnical investigations are needed. Subsurface in situ testing and drilling and sampling techniques are required to determine or verify site geology, depth to bedrock, soil stratigraphy, etc. Preliminary assessment of the engineering properties of the soil or rock can be developed from the analyzed exploration data.

The soil/rock strength profile with depth is predicted from the interpreted soil/rock parameters (friction angle, apparent cohesion, etc.) resulting from the in situ and lab testing programs.

Recent trends suggest that in situ testing is strongly recommended to complement sampling (Reese and Isenhower 2000). Samples are retrieved and tested to establish correlations to the in situ tests. The resulting soil/rock parameter selections and prediction of the strength and deformation profile with depth are input into the final engineering criteria for foundation design. Some discussions of the underwater geotechnical site investigation process are found in Heijnen and Vermeiden (1980) for an improved site foundation; Hitchings, Bradshaw, and Labiosa (1976) for a gravity-based foundation; and Angemeer (1972) and Audibert and Hamilton (1998) for a pinned foundation. Lunne and Powell (1993) provide details for offshore in situ testing applicability when evaluating engineering soil parameters for various soil and foundation types.

\section{In situ methods}

In situ testing allows evaluation of engineering properties without physically retrieving samples, often without requiring a predrilled borehole. Geophysical techniques and equipment may be used to acquire geotechnical engineering properties. Geotechnical devices frequently used for underwater in situ testing are the remote vane shear device, the cone penetrometer, and the pressuremeter. These methods were initially developed for land-based applications but have been adapted for underwater site characterizations. The remote vane was the first in situ tool to be routinely used in the early 1970 s, followed by the cone penetrometer and the pressuremeter (Briaud, Riner, and Ohya 1984).

Geophysical methods. Geophysical investigations can provide overall 
information regarding engineering properties at the foundation site such as anticipated sediment type, stratigraphy, depth to bedrock, and dynamic properties. Preliminary soil index properties may also be inferred, and studies have shown correlation between geophysical measurements and engineering properties of the subbottom (Mahmood and Hough 1978; Kutter, Arulanandan, and Dafalias 1979; Fountain 1979; Haynes et al. 1993; Nauroy and Meunier 1993; Stokoe and Rosenblad 1999).

Acoustic methods (sonar and subbottom profilers) provide no direct engineering properties information. Shear wave methods furnish the shear modulus, G, of the subsurface material whether it be soft mud or solid rock. The shear wave geophysical method is matched to the site and its required investigation depths. For example, intrusive methods include seismic cone penetration (SCPT) and borehole (crosshole, downhole, and suspension) logging techniques. Nonintrusive methods include refraction surveys and surface wave profiling (Stokoe and Rosenblad 1999). Other marine geophysical methods to obtain engineering properties include gamma logging for bulk density measurements (Perlow and Richards 1972) and electrical resistivity to measure index properties of soils (Kutter, Arulanandan, and Dafalias 1979).

Vane shear device. Shear strength less than about 2 tsf $(200 \mathrm{kPa})$ in cohesive sediments is measured using a vane shear testing system in which the unit is either deployed over the side of a surface vessel or lowered through a drill string (wireline technique) (Lunne and Powell 1993). As the unit settles onto the bottom on its attached template or reaches the borehole bottom, a vane penetrates undisturbed soil. The vane is then rotated, and the soil's shearing resistance (measured by a rotational strain gauge transducer) is correlated to its undrained shear strength.

Deep-sea vane shear strength measurements were made in the early $1960 \mathrm{~s}$ from manned research submersibles such as the U.S. Navy's Trieste and Deepstar 4000, Woods Hole's Alvin, and Lockheed's Deep Quest (Perlow and Richards 1972; Inderbitzen and Simpson 1972; Hirst, Richards, and Inderbitzen 1972). Their operational depths ranged to about $20,000 \mathrm{ft}(6,080 \mathrm{~m})$, but sampling depths were limited to about $5 \mathrm{ft}(1.5 \mathrm{~m})$ below the sea bottom (Noorany 1972). Tethered testing platforms placed directly on the ocean floor were developed by the late 1960s and early 1970s (Richards et al. 1972). The $R U M$ was an unmanned tethered tracked bottom crawler that was instrumented with a vane shear device and other sampling tools and had an operational depth of $6,000 \mathrm{ft}(1,824 \mathrm{~m})$ (Anderson et al. 1972). The Navy's DOTIPOS tethered platform vane could penetrate $10 \mathrm{ft}(3 \mathrm{~m})$ below the mudline (Noorany 1972).

The offshore industry began using vanes located on tethered submersibles that were operated remotely from surface drilling ships using the wireline technique (Perlow and Richards 1972; Doyle, McClelland, and Ferguson 1971). Deploying the vane device from a platform resting on the ocean bottom later became more common (Dutt et al. 1997).

New-generation remote vane shear devices such as the Halibut II (Figure 27) have been developed to reduce testing setup time, to increase the incremental 
penetration depth, and to perform cyclic testing (Dutt et al. 1997). Cyclic in situ vane tests are conducted to observe the effects of fully reversed, two-way loading. The vanes are torqued for 5 to 11 cycles, and the plotted results are useful for design calculations required for structures undergoing dynamic loading such as wave impact. Remote memory units attached to the vane allow for betterquality data collection.

Cone penetrometer. Cone penetrometer technology, which has seen many successful land-based applications during the past decades, has also been adapted to underwater site characterization. This technology is applicable to both cohesive and cohesionless soils. The penetrometer delineates stratigraphy, provides penetration resistance data that can be empirically correlated to soil strength and deformation parameters, measures pore-water pressure, and is

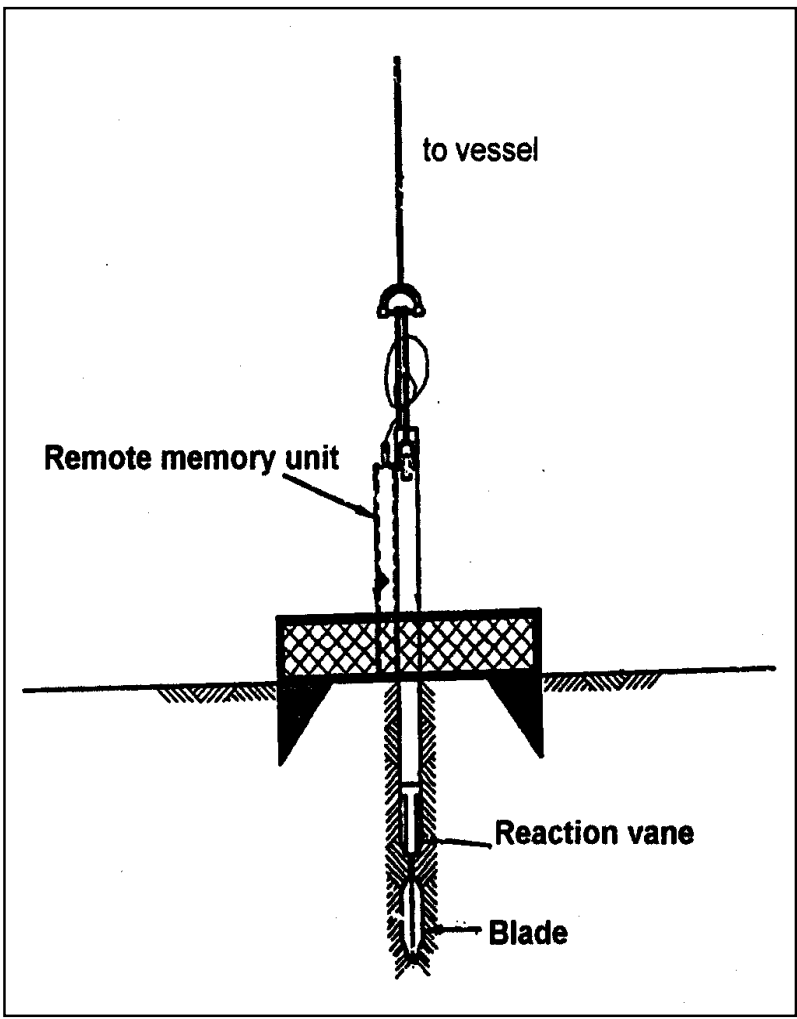

Figure 27. Remote vane shear device (after Dutt et al. 1997) adaptable for applications requiring specialized sensors, such as resistivity and seismic geophysical investigations. Soil sample retrieval may also be achieved using modified cone penetrometer equipment. Particularly useful is the pore-water pressure measurement capability (piezocone or PCPT). Determining subsurface porewater pressures and indirectly assessing in situ permeability is important in understanding the presence or absence of pore-water gradients in the subsurface soil layers, which may cause problems with the future foundation's static and dynamic stability. Lunne and Powell (1993) state that the piezocone is the most important in situ tool for offshore use.

The cone penetrometer test (CPT) has been used worldwide during the 20th century as an onshore site investigation method that is relatively fast and economical and produces consistent data (FHWA 1978, ASTM 1991). Various changes and technical improvements have been made, but the CPT remains particularly useful in assessing soil classification and strength while probing on-the-fly. Offshore CPT provides more accurate soils data than just sampling alone (Marr and Endley 1982). 
Underwater CPT for deep-ocean exploration was conducted in the early 1970s on tethered submersibles such as the Deep Quest (Hirst, Richards, and Inderbitzen 1972), the Alvin (Perlow and Richards 1972), and the DOTIPOS (Noorany 1972). Penetration depths were limited to about $10 \mathrm{ft}$ (3 m). A specially designed manned submersible (Mission) for geotechnical site investigation was used for the Eastern Scheldt project in the late 1970s. The Mission held two men breathing supplied surface air in a submerged steel capsule that was lowered to the seafloor. A hydraulic ram inside the capsule pushed the CPT and soil sampling rods $100 \mathrm{ft}(30 \mathrm{~m})$ below the mudline (Heijnen and Vermeiden 1980).

From the 1970s, the CPT has been conducted either from seafloor-based systems (similar to the one shown in Figure 28) or down-the-hole (wireline) systems. Some of the seafloor systems included McClelland's Seacalf and Stingray (Ferguson, McClelland, and Bell 1977); Fugro-McClelland's Seasprite (Lunne and Powell 1993); the U.S. Navy's XSP-40 (Beard and Lee 1982); European systems by A.P. van den Berg $(R O S O N)$ and the Danish Geotechnical Institute's SCORE (Lunne and Powell 1993); and TSP (Humphrey and Adams 1995). The TSP system was designed to operate in water depths to $9,900 \mathrm{ft}$ $(3,000 \mathrm{~m})$ while probing to soil depths of $230 \mathrm{ft}(70 \mathrm{~m})$.

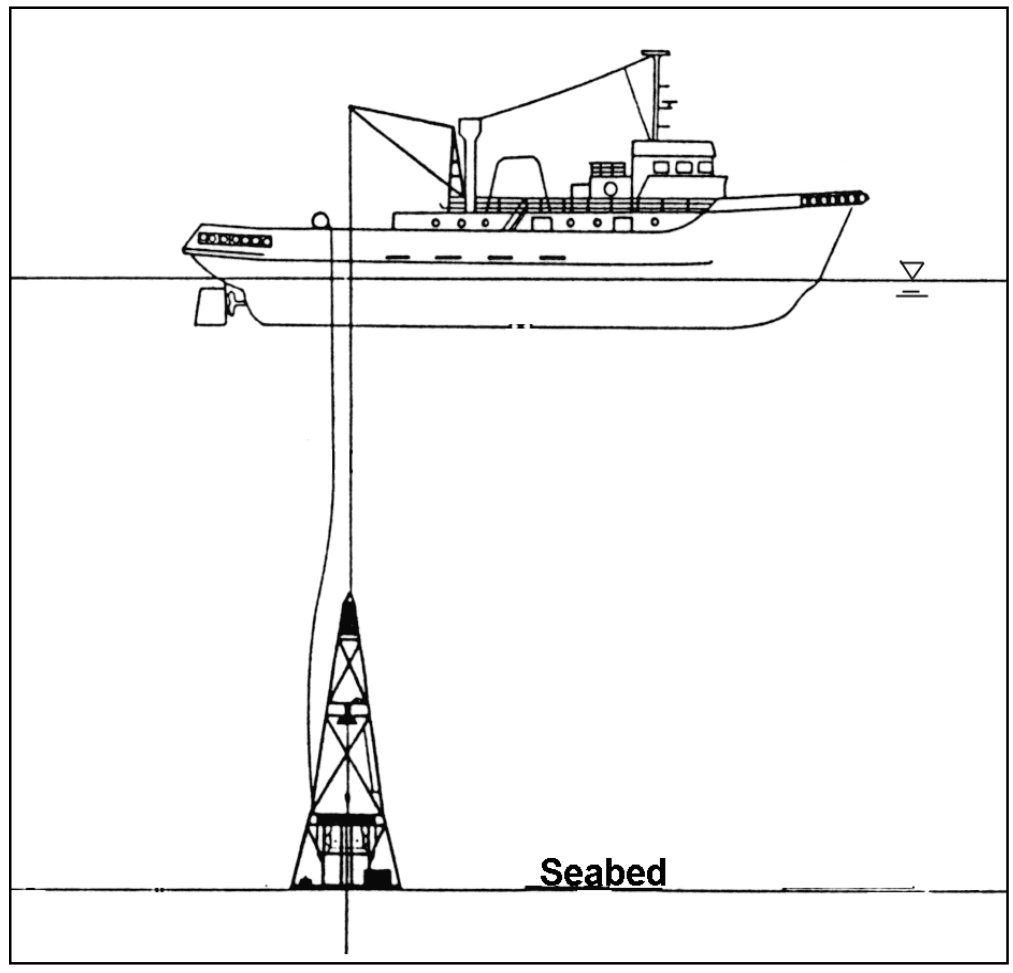

Figure 28. Remote CPT operation from a surface vessel (after James 1987)

The wireline technique allows multiple downhole tools and samplers to be used in the same borehole. One example of a wireline system using multiple downhole tools is McClelland's Swordfish, in which the CPT probe is advanced 
$10 \mathrm{ft}$ (3 m) below the borehole base (Meyer, Harman, and King 1982).

McClelland's Dolphin system stores all data in its memory module and does not have an umbilical cable (Focht, Johnson, and Rivette 1986; Lunne and Powell 1993). The Dolphin system also includes a piezometer probe to measure porepressure dissipation. The remote memory module stores up to 135 min of porewater pressure dissipation data. After the tool is retrieved, the data are downloaded and analyzed (Preslan and Babb 1979, Dutt et al. 1997). FugroMcClelland's WISON and Geocean's MASCOT systems operate in the shallower North Sea environment (Lunne and Powell 1993).

The U.S. Navy recently developed a dynamic penetrometer system that is dropped over the side of a surface vessel, falls through the water column, and surficially penetrates the seafloor while simultaneously measuring probe deceleration using Doppler sound imaging. Correlations between deceleration time and relative density of cohesionless soils have been made (Orenberg et al. 1996).

The seismic cone penetration test has been performed from seafloor-based and surface platforms since the late 1980s (Lunne and Powell 1993). Penetration depths on the order of $200 \mathrm{ft}(60 \mathrm{~m})$ have been achieved (Stokoe and Rosenblad 1999).

Pressuremeter. Another in situ testing tool is the pressuremeter, which was introduced (onshore) by Kogler and Scheidig in the 1920s (Parkhill 1998) and was further developed by Menard in the 1950s. The pressuremeter operates on the principle of expanding a vertical cylinder horizontally into the surrounding soil while measuring the volumetric strain and applied pressure. Correlations are made to determine the soil's in situ horizontal stress and shear strength. The pressuremeter test (PMT) is particularly suited for determining resistance to induced static and cyclic lateral loads on piles and drilled shafts (Bowles 1988; Briaud, Smith, and Meyer 1983; Briaud, Riner, and Ohya 1984). The major limitation of obtaining quality data from the PMT is the requirement for a carefully prepared borehole (Bowles 1988). To overcome borehole preparation problems, the self-boring pressuremeter test was developed.

Offshore pressuremeters have been developed by various companies (Reid et al. 1982; Suyama, Ohya, and Imai 1982; Lunne and Powell 1993) and are generally wireline self-boring.

\section{Drilling and sampling}

Geotechnical drilling and sampling operations are typically required to supplement the in situ test data and to extract samples. Often a boring is advanced for purposes of obtaining information, such as soil and rock classification from visual inspection or blow counts from the standard penetration test. However, the primary advantage of the drilling and sampling operations is to retrieve undisturbed or disturbed samples from the subbottom for subsequent laboratory testing. Before, during, or after the samples are retrieved, various types of devices may be advanced in a cased or an uncased borehole for purposes 
of obtaining in situ geotechnical information about the subbottom. For example, smaller diameter wireline piezocone penetrometers have been developed specifically for use inside boreholes. The PCPT is mechanically extended past the borehole opening to probe virgin soil for the purposes of obtaining porewater pressure, which has been correlated empirically to in situ permeability as well as the standard data obtained by the CPT ahead of the advancing drilled borehole (Dutt et al. 1997).

Underwater soil sampling techniques and equipment development have generally followed those of land-based methods. Prior to the 1940s, the offshore industry did not conduct preliminary site investigations. The first marine foundation site investigation for an offshore structure was drilled from a fixed platform in 30-ft (9-m) water depth in the Gulf of Mexico in 1947. As the oil platform water depths increased, so did the capacities of the exploratory drill platforms, and they evolved from fixed platforms to mobile drill rigs on barges. Perhaps the most challenging location was the Bay of Fundy, where fixed-piston samples of soft marine clays were recovered from depths of $326 \mathrm{ft}(99 \mathrm{~m})$ while coping with $25-\mathrm{ft}(8-\mathrm{m})$ tides and currents up to $8 \mathrm{fps}(2.4 \mathrm{~m} / \mathrm{sec})$. This type of exploration method using conventional land-based sampling techniques was used for most subsea locations at water depths to about $200 \mathrm{ft}(60 \mathrm{~m})$ until the year 1962 (Focht and Kraft 1977).

In 1962, an oil company conducted a program to gather geotechnical data along the outer Continental Shelf to depths of $600 \mathrm{ft}(180 \mathrm{~m})$. Instead of a floating barge, a purpose-built boat was outfitted with a large drilling rig. Special lightweight 3-in.-diam drill pipe and wireline sampling tools were developed to penetrate $300 \mathrm{ft}(90 \mathrm{~m})$ below the seabed. The wireline samplers enabled sample retrieval without bringing the drill pipe sections back to the drill rig (Focht and Kraft 1977).

In the 1970s and 1980s the offshore industry moved into deeper waters in the Gulf of Mexico, and geotechnical site investigation techniques and equipment were developed to meet those challenges. Investigations at seafloor depths of $2,900 \mathrm{ft}(880 \mathrm{~m})$ were conducted. The Shell "Mensa" project required investigations at a seafloor depth of 5,315 ft $(1,616 \mathrm{~m})$. Up to the mid-1990s, total penetration (water and soil column) of geotechnical drilling and sampling for the majority of the Gulf of Mexico projects had been limited to about 6,600 $\mathrm{ft}$ $(2,010 \mathrm{~m})$ based on available surface vessels. In 1997, a converted dynamically positioned diving support semisubmersible was mobilized to provide site investigation capabilities for deeper sites. It allowed drilling to water depths of $9,900 \mathrm{ft}(3,000 \mathrm{~m})$ and had a total drillstring capability of $11,840 \mathrm{ft}(3,600 \mathrm{~m})$ (Dutt et al. 1997).

A recent Gulf of Mexico program sponsored by several oil companies and the National Science Foundation collected geotechnical data in water depths to $7,700 \mathrm{ft}(2,340 \mathrm{~m})$. A series of in situ vane shear tests, pore-pressure measurements, deepwater coring, sample retrieval, and laboratory tests were conducted (Sea Technology 1999).

The methods of underwater sampling and selection of equipment are 
arbitrarily divided into two general categories depending on the water depth and sampling depth: shallow sampling depths to $100 \mathrm{ft}(30 \mathrm{~m})$ below the mudline, and deeper sampling depths. Most geotechnical sampling has been done from the water surface using a fixed or mobile platform (Noorany 1972). Numerous systems employed for soil sampling from submersible seabed platforms in deeper water were described by Tirey (1972) and Hironaka and Green (1971). Most of the platforms had submersible hydraulic rotary drills, but some had submersible hydraulic vibratory hammer-type drills predating submersible vibratory pile hammers by almost 2 decades.

Sampling tools specifically used for underwater sampling include diver-held samplers, the Boomerang corer, box corer, gravity corers, vibratory corer, wireline samplers, and dredging grab samplers (U.S. Army Corps of Engineers 1996). In general, the diver-held samplers, corers, and grab samplers are used for shallow sampling penetrations. For deeper penetrations, wireline samplers are

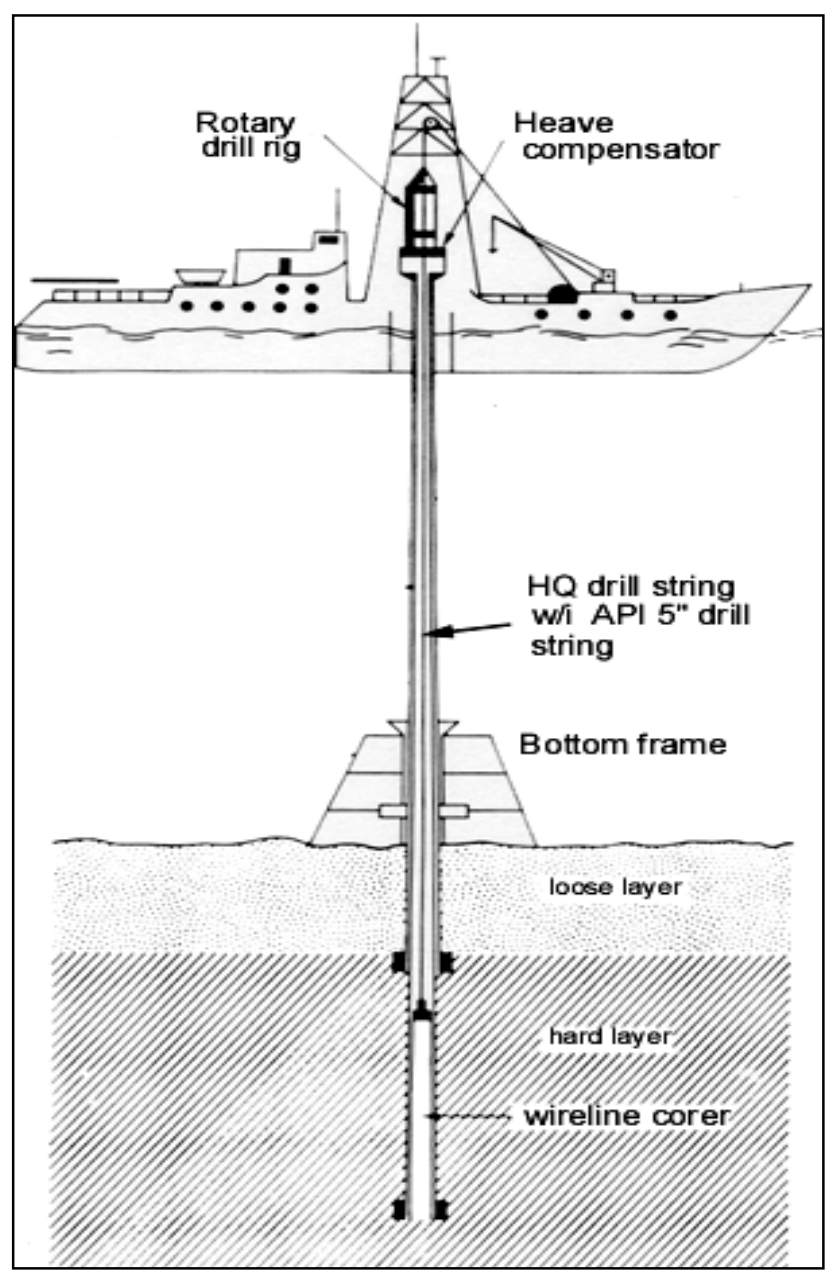

Figure 29. Offshore wireline sampling technique (after CLAROM 1994) used (Noorany 1972). An illustration of one type of wireline sampling configuration is shown in Figure 29. Tirey (1972) discussed a range of types of submersible, remote, and diver-operated sampling equipment, including rotary and vibratory drilling tools. A noteworthy comment was that regardless of the sampling tool, no feasible sampling method completely eliminates sample disturbance. Furthermore, the disturbance of samples obtained at nearshore and offshore sites was generally greater that the disturbance of samples obtained on land because of the greater difficulty of obtaining quality samples. Reese and Isenhower (2000) reported that wireline sampling techniques caused more disturbance than the worst onshore sampling methods when applied to the offshore environment.

The popular onshore ASTM D 1586 standard penetration test (SPT) consists of dropping a 140-1b (308-kg) weight $30 \mathrm{in} .(0.76 \mathrm{~m})$ onto a drill string with a 2 -in. (51-mm)diam sampling tube attached at the bottom. 
The number of blows required to penetrate the sampler 12 in. $(300 \mathrm{~mm})$ into the borehole bottom is correlated to the soil's classification and strength. The recovered sample may be used for laboratory testing purposes (Acker 1974).

The SPT may be used for nearshore and river locations where the wave heights are minimal, but the offshore industry does not traditionally use the test because the fall height of the hammer cannot be accurately controlled unless the ship heave is compensated (Hitchings, Bradshaw, and Labiosa 1976). Bazett and Foxall (1972) compared and discussed SPT blow counts from a natural riverbed and subsequent underwater-placed fill from a spud-barge platform. Babcock and Miller (1972) compared vibracore sampling to SPT data and found good correlations in low blow count soil deposits.

Offshore rotary core sampling is generally used only for identification purposes, but wireline tube sampling is generally used for the full range of soil types and strengths (Hight 1993). The two most common types of tube sampling methods are push sampling and piston sampling. Most push sampling uses 3-in. (76-mm)-diam thin-walled Shelby tubes for undrained soil strengths up to about 6 tsf $(600 \mathrm{kPa})$. Thicker walled tubes are used to recover dense sands and hard clays. Tube liners are used for upper sediments with little or no shear resistance. Piston samplers are used in soft and firm clays when sample retention would be a problem (Hight 1993), but piston sampling is not commonly used offshore in the Gulf of Mexico (Jeanjean, Andersen, and Kalsnes 1998). McCoy (1972) discussed piston sampling characteristics in the North Atlantic.

Another offshore sampling method uses large-diameter borehole technology to obtain bulk samples with techniques and equipment similar to those used onshore. Larger boreholes (diameter between 1 and $10 \mathrm{ft}, 0.3$ and $3 \mathrm{~m}$ ) enable larger sample sizes for better quality classification and testing. Unlike dredging samples that are obtained from shallow depths, large-diameter boreholes allow sampling at depths approaching $400 \mathrm{ft}$ (120 m) (Schwank 1997).

\section{Laboratory testing}

To the extent that site assessment is not complete until all engineering design parameters are obtained, many of the retrieved soil/rock samples undergo laboratory testing. The laboratory testing program should be tailored to obtain engineering parameters for preliminary design of the intended foundation system. For example, both monotonic and cyclic shear strength profiles are needed for determining the holding capacity of suction caissons (Jeanjean, Andersen, and Kalsnes 1998). Sangrey, Clukey, and Molnia (1972) discussed methods to obtain strength profiles from disturbed or remolded samples.

The types of soil (and/or rock) laboratory tests conducted for underwater foundations should accomplish the following objectives (Sullivan, Wright, and Senner 1980): (a) material identification and classification, (b) behavior under anticipated field levels of stress and strain, (c) compressibility characteristics under sustained loading, and (d) stress-strain characteristics and pore-pressure response under cyclic loading. 
The tests on soil materials should include index properties (submerged unit weight, Atterberg limits, mineralogy, grain-size analysis, moisture content, chemical composition, and specific gravity). Strength tests should be conducted using either "undisturbed" or remolded sample specimens. Unconsolidatedundrained (UU) tests can be conducted to assess short-term behavior, whereas consolidated-drained (CD) or consolidated-undrained (CU-bar) tests with porepressure measurements are needed to assess the long-term behavior.

Conventional soil strength tests imply static (monotonic) loading conditions and include direct simple shear tests, unconfined compression triaxial tests, UU triaxial tests, miniature shear vane, Torvane, fall cone, and hand penetrometer, among others. Computed strength and stiffness parameters $\left(c_{u}, \phi_{u}\right.$, $E_{u}$ ) from these test data establish the undrained shear strengths of the soil specimens.

To determine normalized and effective stress strength parameters, CD (direct shear) tests or isotropically consolidated (CIU-bar) and anisotropically consolidated $\left(\mathrm{Ck}_{\mathrm{o}} \mathrm{U}-\mathrm{bar}\right)$ consolidated-undrained monotonic triaxial compression tests are conducted (Sullivan, Wright, and Senner 1980). For the triaxial tests, pore-pressure measurements are required to determine the effective stress states (Audibert and Hamilton 1998). The CD test, by definition, yields effective stress strength and stiffness parameters $\left(\mathrm{c}_{\mathrm{u}}, \phi_{\mathrm{u}}{ }^{\prime}, \mathrm{E}_{\mathrm{u}}{ }^{\prime}\right)$.

Less conventional tests are often required as an attempt to replicate anticipated dynamic and cyclic loading conditions, such as the loading conditions caused by wind, wave, and seismic loads. Cyclic anisotropically consolidatedundrained $\left(\mathrm{C}_{\mathrm{y}} \mathrm{CK}_{\mathrm{o}} \mathrm{U}\right)$ triaxial compression and cyclic direct simple shear tests are typically performed to define the cyclic stress-strain behavior of soils. A laboratory test to determine the shear wave velocity and maximum shear modulus is conducted using a resonant column device (Jeanjean, Andersen, and Kalsnes 1998).

To determine stress history of cohesive soils, consolidation tests are routinely conducted. The overconsolidation ratio can be determined using the constant strain and incremental loading oedometer tests. Consolidation test data are used to determine the time-settlement curve and void ratio-effective stress relationships (Sullivan, Wright, and Senner 1980).

Uncertainty in laboratory test data interpretation arises from the effects of soil heterogeneity, sample disturbance, in situ stress history and loading conditions, and testing accuracy. For example, in a layered soil subjected to loading condition imposed by a structure (see Figure 30), a triaxial compression test would best simulate the failure conditions immediately under the structural footing, whereas the direct shear test would better simulate the loading conditions at the deeper portion of the failure plane as it is passing through the layered soil. Likewise, as the slip surface daylights at some distance from the footing, the triaxial extension 


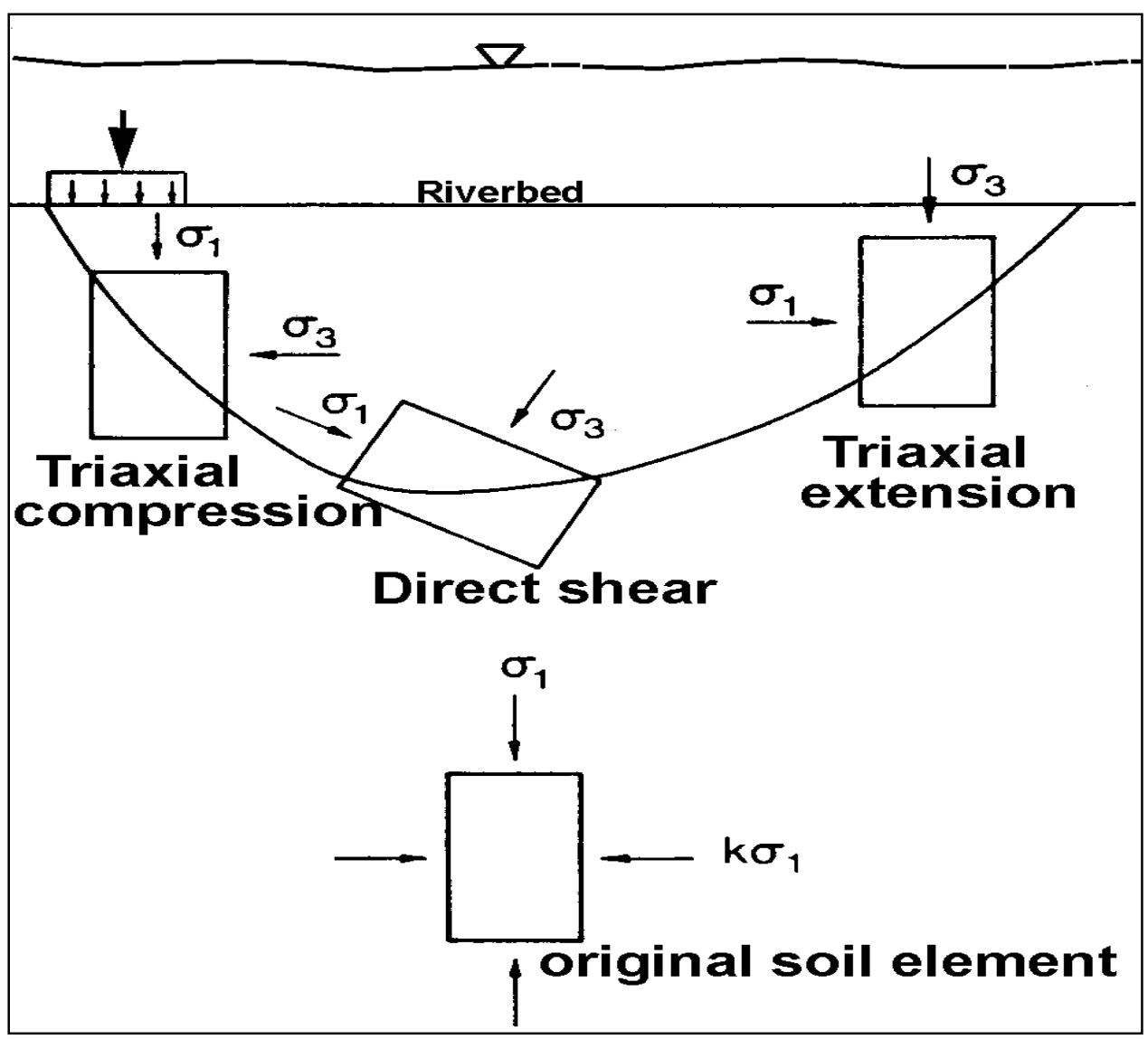

Figure 30. Sketch of idealized model of in situ stresses (after Sullivan, Wright, and Senner 1980)

test would better replicate the loading conditions due to the reversal of principal stresses.

One method for assessing the reliability of laboratory data uses soil parameter empirical correlations. Sullivan, Wright, and Senner (1980) discussed these uncertainties and suggested correlations for comparison. For example, an estimate of the remolded shear strength for an overconsolidated clay can be made from its liquidity index. The ratio of normally consolidated clay shear strength to effective overburden stress is related to its plasticity index. Fine sand's friction angle is related to its relative density and voids ratio. However, it should be emphasized that these empirical correlations should not be substituted for a detailed laboratory investigation.

In addition to the strength and deformation characteristic for rock, the rock material properties should include porosity, density, sonic velocity, permeability, ductility, strength, slake durability, hardness, and thermal properties. Rock mass strengths are rated by either the RMR or Q systems (Goodman 1989).

Offshore foundation material (soil and rock) databases are available that can be used for planning the laboratory investigation and interpreting the test results. 
These databases are especially useful for planning cyclic loading test programs, such as suggesting methods to reduce the number of site-specific cyclic tests.

Andersen and Jostad (1999) list references for available databases of North Sea and Gulf of Mexico clay soils. Numerous other references to site-specific soil/rock characteristics related to geotechnical foundations are available in the literature and include the following:

Sabine River delta (Grosch and Reese 1980)

Offshore Florida calcareous sands (Dutt et al. 1986)

Offshore Southern California (Mahmood and Reifel 1978)

Mississippi Delta (Gulf of Mexico) weak sediments (Shephard, Bryant, and Dunlap 1978; Booth and Garrison 1978)

Gulf of Mexico underconsolidated clays to dense sands (Stockard 1979)

Alaska coastal waters (Sangrey, Clukey, and Molnia 1979)

Hawaii calcareous sands ( $\mathrm{Lu} \mathrm{1986)}$

Offshore Cuba coral sands (Puech, Bustamante, and Auperin 1990)

Offshore Brazil calcareous soils (Ping et al. 1984)

Offshore Australia calcareous sands and sandy silts (Parkin et al. 1990; Tan, Parkin, and Yee 1990; Randolph et al. 1996)

Borneo marine clays (Gemeinhardt and Yan 1978)

Offshore India (Stockard 1986)

Offshore China dense sands (Tsien 1986)

Arabian Gulf hard clays, dense sands, rocks, and coral (Tagaya et al. 1979; Settgast 1980; Stevens, Wiltsie, and Turton 1982; Vines and Hong 1984)

Gulf of Suez calcareous sands and silts (Dutt and Cheng 1984, Dutt and Teferra 1986)

North Sea stiff clays (Heerema 1979)

North Sea soft clays (Karlsrud and Nadim 1990)

North Sea dense sands (Jardine and Overy 1996, Zuidberg and Vergobbi 1996)

North Sea boulder clays (Fox, Parker, and Sutton 1970)

North Sea chalk (Vijayvergiya, Cheng, and Kolk 1977; Davie, Ehlers, and Antes 1978) 


\section{Design Considerations}

\section{Foundation Types}

Numerous foundation types are constructed onshore (as land-based construction), and they broadly fall into either the "shallow" or "deep" foundation category. By definition, the shallow foundation embedment depth is less than its minimum lateral dimension and includes spread footings and mats. The deep foundation embedment depth is much greater than its minimum lateral dimension. Examples include piles and shafts (Herrmann, Raecke, and Albertsen 1972). Since the terms shallow and deep may be confusing when applied to underwater foundations, those terms will not be used for the remainder of this document.

Underwater foundations may be classified into one or more of the following general categories: improved-site, gravity-based, and pinned. Improved-site foundations include those that are dredged, excavated, backfilled, leveled, and/or site-modified. Gravity (or gravity-based) foundations include those that distribute the structure's loads over a soil/rock area wide enough to adequately resist the imposed loads. Pinned foundations distribute the structure's loads deeper into the soil/rock materials. Table 1 provides a generalized description of foundation types for selected case histories and includes prominent foundation preparation/construction features.

Certain structures are generally associated with a given foundation type. For example, most immersed tube tunnels depend on site-improved foundations. Likewise, the vast majority of offshore oil production platforms in the Gulf of Mexico depend on pinned (driven-pile) foundations. However, foundation types may also be combined for certain structures. For example, some gravity-based foundations such as concrete bridge piers require site improvements prior to float-in or lift-in placement of the piers. Likewise, some gravity-based foundations include piles. Some suction-pile foundations imitate both gravitybased and pinned foundations in that they may be designed to distribute their ballasted weight over a large lateral area during vertical penetration.

For gravity and pinned foundations, an improved-site foundation may or may not be needed. Based on published case histories, typical deep offshore practice does not include improving the site prior to installing either gravity or pinned foundations. However, for shallow-water gravity foundations, some type of site improvement is usually provided. Two examples of Corps projects that will use 


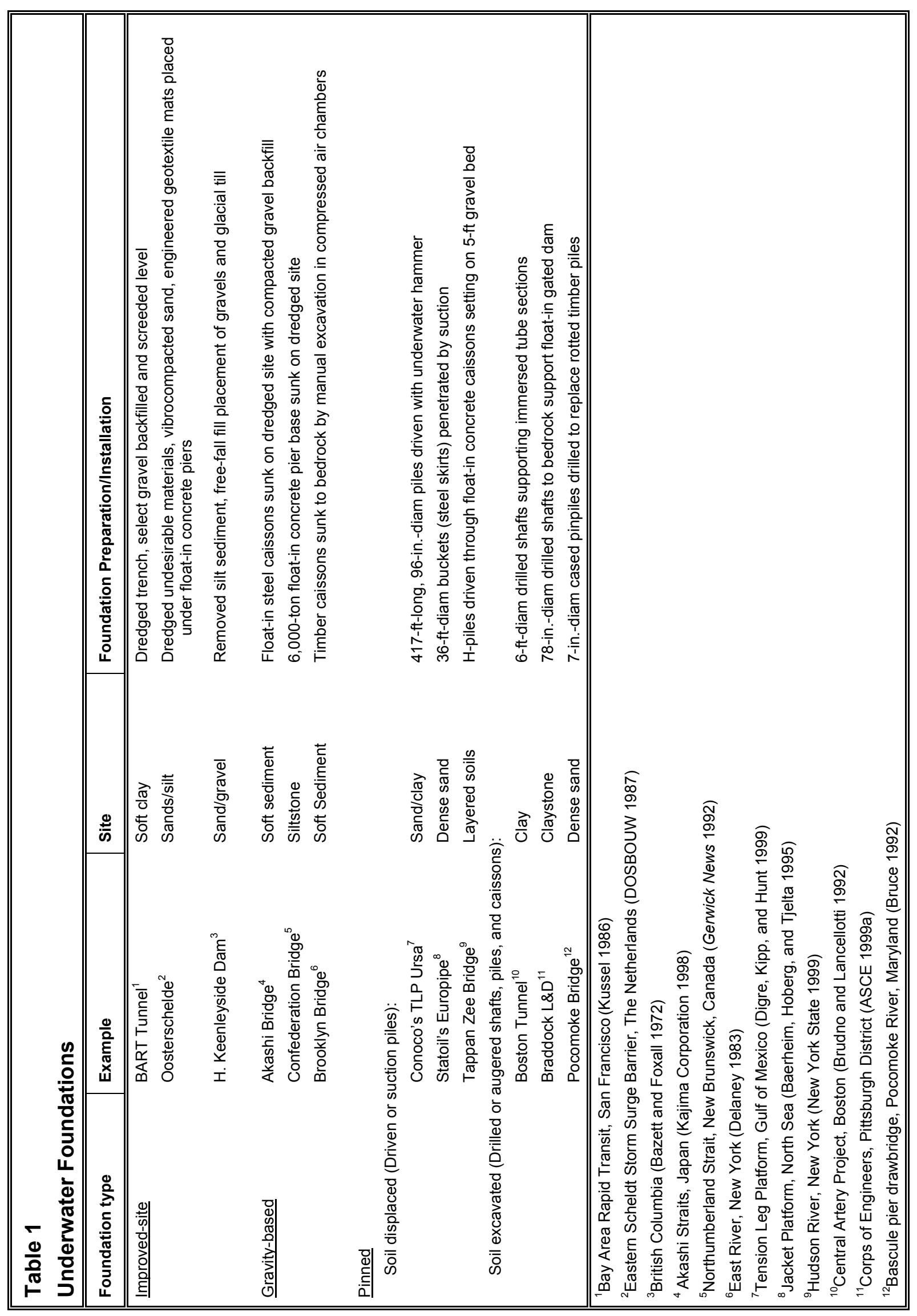


site improvement in conjunction with pinned foundations are the Corps'

Braddock and Olmsted Dams. At Braddock Dam, the float-in precast elements will be ballasted and attached to pinned foundation (drilled shafts). Softer sediments will be dredged prior to and during construction (as needed). At Olmsted Dam, the lift-in precast elements will be placed on pinned foundation (driven-pipe piles). Site improvement will include dredging, sand vibrocompaction, and articulated mat placement (Personal Communication, 2 March 2001, Dale E. Berner, consulting engineer, Ben C. Gerwick, Inc., San Francisco, CA).

\section{Improved-site foundations}

An improved-site foundation modifies the existing soil (or rock) in the seabed or riverbed. Methods include preloading, dredging, backfill, leveling, consolidation, or other engineered modifications. Figure 31 illustrates one example of an improved-site foundation. In the case of immersed tunnels, pipelines, breakwalls, dry docks, and some float-in/lift-in structures, an improved site may be the only foundation system needed.

Dowse (1979) described an innovative improved-site methodology employing self-supporting (hydrostatic pressure) sand islands for foundations for oil platforms in water up to $200 \mathrm{ft}(61 \mathrm{~m})$ deep. Basically, an impervious membrane is filled with dredged sand, and the water is then pumped out. Such hydrostatically supported confined-pressure sand islands are capable of supporting surface loads that are proportional to the drained shear strength of the sand. Each island can be built within a 2-week period depending on the specific design. Disadvantages are the amount of dredging required to supply the sand fill, the limitations of a soft soil underbase, and the construction handling and placement of the impervious membrane.

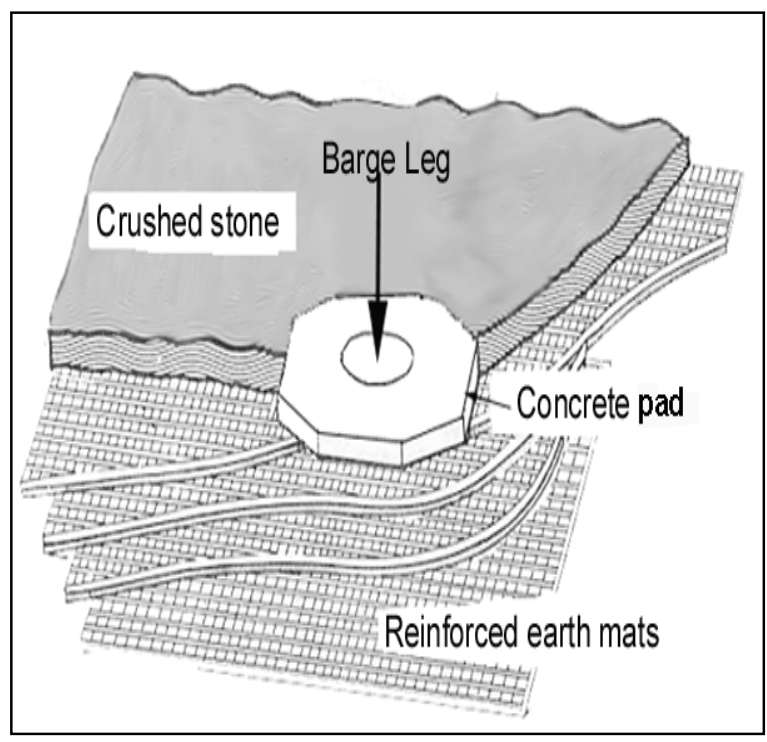

Figure 31. Example of an improved-site foundation (after Abbott and George 1989)

Numerous other examples of improved-site foundations are noted in this report. Dredging, fill placement, consolidation, soil improvement, and mat reinforcing are some of the methods used during construction of an improved-site foundation. 


\section{Gravity-based foundations}

Gravity-based foundations are broadly classified because the load-carrying capacity is primarily determined by the size and weight. These foundations are similar in function and design to the land-based foundations that are classified as "shallow," since their embedment depths are generally less than their lateral dimensions. Typical gravity foundations are constructed of precast concrete elements that are either floated or lifted in and allowed to sink into the mudline or onto an improved-site foundation. Once installed, the underbases may be filled with cast-in-place concrete or grout via underwater tremie tubes or other type of ballasting materials. For example, the main pier bases supporting the Confederation Bridge in Canada are lift-in precast concrete elements resting on a tremied concrete bed over mudstone and siltstone layers. Each of the forty-four 6,000 -ton pier bases rests on a ring footing of tremied concrete having an approximate diameter of $67 \mathrm{ft}(20 \mathrm{~m})$ and an approximate thickness of $6 \mathrm{ft}$ $(1.8 \mathrm{~m})$.

Smaller gravity-based foundations have been constructed of steel instead of concrete. For example, offshore foundations for wind turbines have been constructed of steel gravity foundations that are basically steel boxes sunk to the seabed and filled with olivine (DWTMA 1998). The steel box size was designed to be 42 by $42 \mathrm{ft}$ (14 by $14 \mathrm{~m}$ ) with a weight of about 90 tons (100 metric tonnes) for a water depth to $30 \mathrm{ft}(9 \mathrm{~m})$.

Wooden timbers form the gravity base of the Brooklyn Bridge, which was completed in 1883. Two wooden box structures, one on each side of the river, were weighted with stones to enable contact with the underlying bedrock (Delaney 1983). Each box weighed about 16 million pounds $(7.3 \mathrm{Mg})$ with a footprint of about $17,000 \mathrm{sq} \mathrm{ft}(1,579 \mathrm{sq} \mathrm{m})$. Examples of present-day wooden gravity-based foundations are rare, since the preferred materials are either concrete or steel.

For offshore structures, submerged gravity-based foundation weights may approach 1 million tons. A modification of the gravity base concept is the addition of suction skirts around the foundation perimeter to help resist lateral, tensile, and cyclic loads imposed on the gravity foundation.

\section{Pinned foundations}

Pinned foundation embedment depths are greater than the minimum lateral dimension, and include piles and drilled shafts. They are installed to achieve greater lateral stability, to provide greater uplift resistance, to provide greater resistance to scouring compared with gravity-based foundations, and to minimize the potential for differential settlement of certain critical structures. The two general types of pinned foundations are those that displaced soil (that is, piles) and those in which soil was removed (drilled shafts). Pinned foundations are constructed of wood, steel, concrete, grout, stones, or polymer materials that are pinned into the seabed or river bottom by application of driven or drilled-energy sources. Techniques and equipment for deep-water (typically more than 300-ft) 
shaft, pile, and caisson construction are generally found within the offshore oildrilling industry.

Displaced soil. These methods include driving piles into the soil or weak rock by impact, vibratory oscillation, hydraulic pushing or jacking methods, rotating, jetting, or suction techniques and equipment. Hydraulic pile-driving is virtually noiseless and vibration-free, while pile jetting is a time-saving piledriving method (Tsinker 1988). A brief discussion of several types of displacedsoil piles follows.

- Driven preformed piles. Examples of driven preformed piles include tubular steel (open or closed end pipe) piles, solid steel (H-, X-, A-, or sheet) piles, timber piles, precast (prestressed and/or reinforced) concrete piles, and polymer piles. Figure 32 illustrates an underwater impact-driven pile installation procedure. The advantages of driven preformed piles include the following:

a. The pile materials are preformed and subject to fabrication and site (quality control/quality assurance) inspection.

$b$. The pile materials can withstand high bending and tensile stresses.

c. Numerous choices for pile materials, equipment, and installation procedures are available.

d. Onsite fabrication permits very long lengths of piles for site-specific conditions.

The disadvantages of driven preformed piles include:

a. Above-water noise and vibration may be excessive.

$b$. Soil disturbance may affect surrounding structures.

- Cast in situ piles. Examples of cast in situ piles include stone columns (Cemcol), compacted concrete pile (Vibro-Franki, not commonly placed underwater), Atlas screw pile (not yet commonly

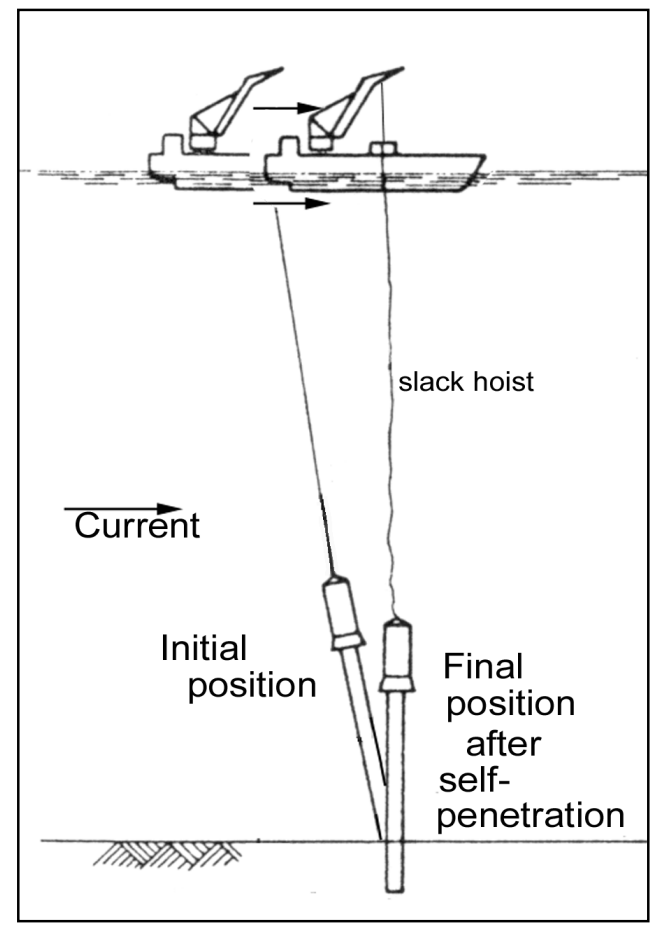

Figure 32. Underwater impact-driven pipe pile installation without a template (after Jansz and Brockhoff 1979) used underwater according to Reese and Isenhower 2000), and micropiles (which are grouted minipiles or pinpiles installed without drilling).

Figure 33 illustrates an onshore Atlas screw pile installation procedure. The advantages of cast in situ piles are:

a. No need for permanent casing. 
b. May be more economical for specific sites.

c. No cuttings and, hence, no disposal of cuttings required.

The disadvantages of cast in situ piles include:

a. Limited experience in underwater environments and (for certain proprietary systems, such as Cemcol, Atlas, Vibro, Franki, Vibrex, and Fundex) extremely limited specialized contractor experience.

b. Cannot be extended above riverbed without casing and special procedures.

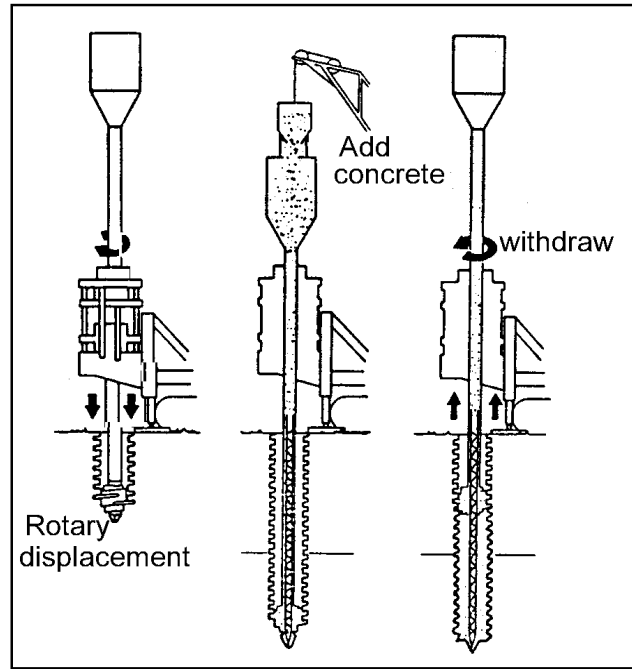

Figure 33. Cast in situ onshore pinned foundation (Atlas screw pile method) (after Hollingsworth and Imbo-Burg 1992)
A special case of the cast in situ pile is represented by the soil and grout cast in situ foundation, which is generally designed as an improved-site foundation instead of pinned. This type of foundation improvement is used primarily for onshore applications, although deep cement mixing has been used offshore (although primarily outside the United States).

Two examples of the soil and grout cast in situ foundation improvement include jet-grouted columns (grout injected into soil from highpressure jets) and mixed soil columns (grout mixed with soil, also called deep cement mixing). The advantages and disadvantages mirror those for cast in situ, as previously noted.

- Driven cast in situ piles. An example of the driven cast in situ pile includes an open- or closed-ended steel casing or pipe pile that is driven and then backfilled with concrete. The advantages of this type of pile are as follows:

a. The length can be easily adjusted to match the bearing stratum.

$b$. Site-specific modifications, such as an enlarged base or bells, are possible.

c. Noise and vibration during driving may be reduced.

d. The internal pile material, such as concrete or grout, will not be affected by handling or driving stresses.

The disadvantages of driven cast in situ piles include these:

a. Mixing and placement of the concrete or grout may require special equipment and inspection considerations.

$b$. The inspection and placement of the reinforcing bar cage may require special considerations or techniques. 
- Self-penetrating (suction) piles. The placement of suction piles (also called buckets, skirts, suction caissons, anchor piles, or suction anchors) operates on the principle of foundation underpressure (see Figure 34). The suction pile is placed on the sea bottom, and the entrapped water is pumped out to create an underpressure relative to the surrounding water pressure, which causes the pile or caisson foundation to penetrate into the seabed (Senpere and Auvergne 1982). These are commonly called "skirts" in the offshore industry literature if they are attached to gravity-based foundations, especially tension leg platforms. (It should be noted, however, that the offshore literature also refers to "skirt" piles on jacket platforms, which are driven piles instead of suction piles.)

The advantages of self-penetrating (with suction) pile may include one or more of the following:

a. Less equipment required for installation.

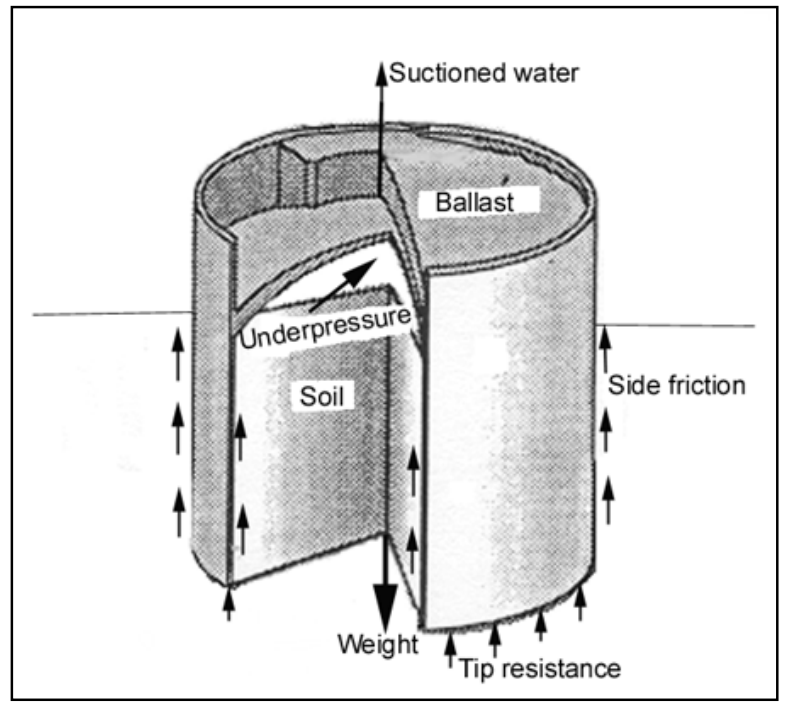

Figure 34. Suction pile foundation (after Andersen and Jostad 1999)

b. Shorter installation time.

c. May be fairly easily removed or relocated.

The disadvantages of self-penetrating (with suction) pile include:

a. Highly dependent on soil conditions (technology somewhat limited on predicting penetration depth).

b. Excessive differential pressure (underpressure) may cause internal soil heave.

c. Relatively limited/unproven technology outside the offshore industry.

- Other types of piles. Piles may also be modified to increase their performance, design life, and function. One such variation is the spin-fin pile, which screws itself into the subsurface as it is driven. It has been reported that it could provide twice the tensile load resistance as that of similar size conventional piles (ASCE 1992). It should be noted, however, that some of these pile foundation types were designed for onshore applications and are not normally installed in the underwater environment.

Excavated soil (caissons, drilled shafts, and pin piles). These methods include installing the pile, caisson, or drilled shaft during or after excavation of 
the soil and/or rock, as illustrated in Figure 35. The advantages of the excavated pile include the following:

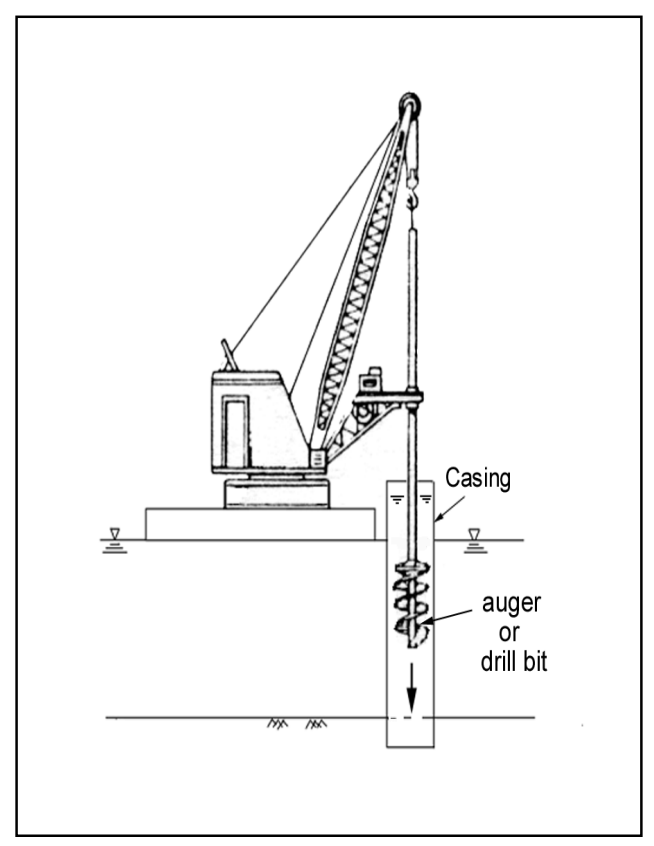

Figure 35. Excavating a cased borehole a. Lengths are easily adjusted to match the bearing stratum.

b. Cuttings supplement or verify site investigation borings.

c. Very large diameters are possible for extraordinary loads, compared with pile groups.

d. Suitable for sites that preclude driven foundations, such as cases in which large rocks and boulders are encountered.

e. The material used to construct the pile is not subject to handling or driving stress.

$f$. Very long piles are possible.

g. Construction noise and vibration are reduced.

$h$. Less influence on adjacent structures due to ground heave or disturbance.

Typical disadvantages of excavated piles include:

a. Concrete and grout require special equipment and inspection considerations.

b. Placement and inspection of the reinforcing bar cage may require special techniques/considerations.

c. Cannot be extended above riverbed without casing and special procedures.

d. Possible end-bearing reduction in sandy stratum.

A brief discussion of several types of (excavated soil) piles follows:

- Augered cast-in-place. The augered cast-in-place pile system has been used onshore since the 1940s. Two methods are available. One method consists of drilling a hollow-stem auger to depth and then pumping grout or concrete into the hollow stem as the auger is withdrawn. Reinforcing rods may be inserted into the concrete through the hollow-stem auger (Neate 1989). The excavated soil is brought to the surface as cuttings. For use of this system under water, external casing would be required if the concrete extends above the mudline. The second method uses continuous-flight auger equipment to excavate soil inside a driven 
casing. Numerous equipment manufacturers and techniques are available for this popular (onshore) method.

- Rotary drilled. Rotary drilling methods are used to create a borehole in soil or rock. Basically, the drill string (drill pipe or casing) is rotated into the subsurface while a vertical load or pressure is applied (Figure 36). The cutting tool rips into the soil or rock, and the cuttings are flushed to the surface by drilling fluid. Several techniques are available to remove the cuttings from the borehole, including positive circulation, reverse circulation, duplex drilling (inner and outer drill strings), percussive rotary, and compressed air. Case histories of in-the-wet foundation installation using rotary drilling methods are more common for rock foundations (Norwesco 1999, Nakayama 1992, Santiago et al. 1986, Burt and Harris 1980, Steinke and Strasser 1978, Chamberlin 1970). However, rotary drilling methods are also used in stiff clays such as those found in the North Sea (Focht and Kraft 1977).

- Pin piles. The use of pin piles has increased in recent years, especially in situations with difficult access or restricted vertical clearance. For example, bridge

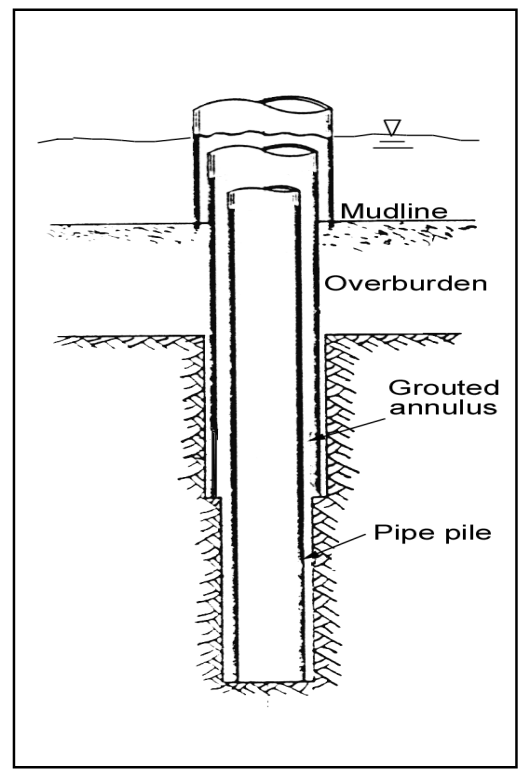

Figure 36. Casing and pile assembly for an offshore drilled shaft foundation (after Steinke and Strasser 1978) foundation rehabilitation has become a major market for these piles (Pearlman et al. 1997). Pin piles are small-diameter drilled and grouted piles. Their diameters range from 5 to 12 in. (127 to $305 \mathrm{~mm})$, and their axial compression and tension capacities range from 50 to 200 tons (445 to $1780 \mathrm{kN}$ ). The most common installation technique is to rotary-drill an openended steel pipe into the subsurface. A reinforcing bar cage is then installed inside the casing, and pressurized grout (or tremied grout in rock formations) is pumped into the casing to extend the "bond zone" below the open end of the pile.

\section{Foundation Selection Criteria and Design Issues}

The foundation must be selected, designed, and constructed to achieve acceptable performance during its anticipated lifetime. Selection and design criteria for onshore (land-based) foundations are listed in numerous publications, but published criteria for selection and design of underwater foundations are, in general, somewhat limited. Although the offshore industry has published guidelines for foundation design, installation, behavior, and testing (American Petroleum Institute 1993), the selection guidelines covering all possible types of underwater foundations are not commonly found in the literature. As foundation costs increase and different foundation types become more available to designers and constructors, Reese and Isenhower (2000) suggested that greater emphasis will be placed on selecting the best foundation for a particular application.

The selection procedures for underwater foundations do not differ significantly from those for onshore procedures, as the design requirements for 
both types of foundations are similar. The design criteria are dependent upon the appropriate soil/rock properties (that is, shear strength or bearing capacity, settlement, differential settlement, etc.). The major difference in the selection process for underwater foundations stems from unique installation problems and environmental conditions, such as wind, wave, and ice loadings to which many onshore foundations are not subjected. Table 2 addresses some of the general selection considerations.

Underwater foundation selection and design may be somewhat more complicated than for onshore foundations because of the unique loading configurations, installation requirements, and greater uncertainties in site investigation and selection of appropriate soil parameters. However, the offshore industry has greatly advanced geotechnical practices in the last 25 years, and application of those practices will eventually merge into the general foundation selection process. For example, suction piles have become competitive alternatives to driven piles and gravity-based foundations. Risk analysis and partial safety factor design are becoming more commonplace in offshore foundation design and analysis, as is model testing using the centrifuge (Lacasse 1999).

\section{Selection criteria}

Engineering and economic analyses are necessary to select the proper foundation system. The traditional choices for selection of onshore foundations are deep foundations or spread footings. Each foundation type is generally associated with given structures. For example, traditional U.S. engineering practice is to specify piles for bridge foundations. It has been reported that 66 percent of U.S. bridge foundations are founded on piles, 25 percent are placed on spread footings, and the remainder are drilled shafts (DiMillio 1999). In contrast, England's highway bridges rely almost extensively on spread footings, even in coal mine subsidence areas where piles could reduce settlement. Likewise, the U.S. building industry almost exclusively uses spread footings, even though some building items, such as doors, windows, and utilities, are much more sensitive to settlement than are piled highway bridges. Thus, foundation selection may be based on industry and local practice, which may not necessarily be the best choice. General selection criteria for underwater foundation systems, which have been compiled from case histories and published information for both onshore and offshore foundations, are discussed below.

\section{Design considerations}

Improved-site foundations. An improved-site foundation may be the least complex of all foundations because the foundation itself is not "connected" to the superstructure. An improved-site foundation is usually composed of a leveled surface (excavated or backfilled) overlying either modified or natural soil and/or rock material. Modification of the soil or rock implies that those materials have been physically or chemically altered to be able to transmit the loading imposed 
by the superstructure into deeper material without failure due to bearing capacity, settlement, or differential settlement.

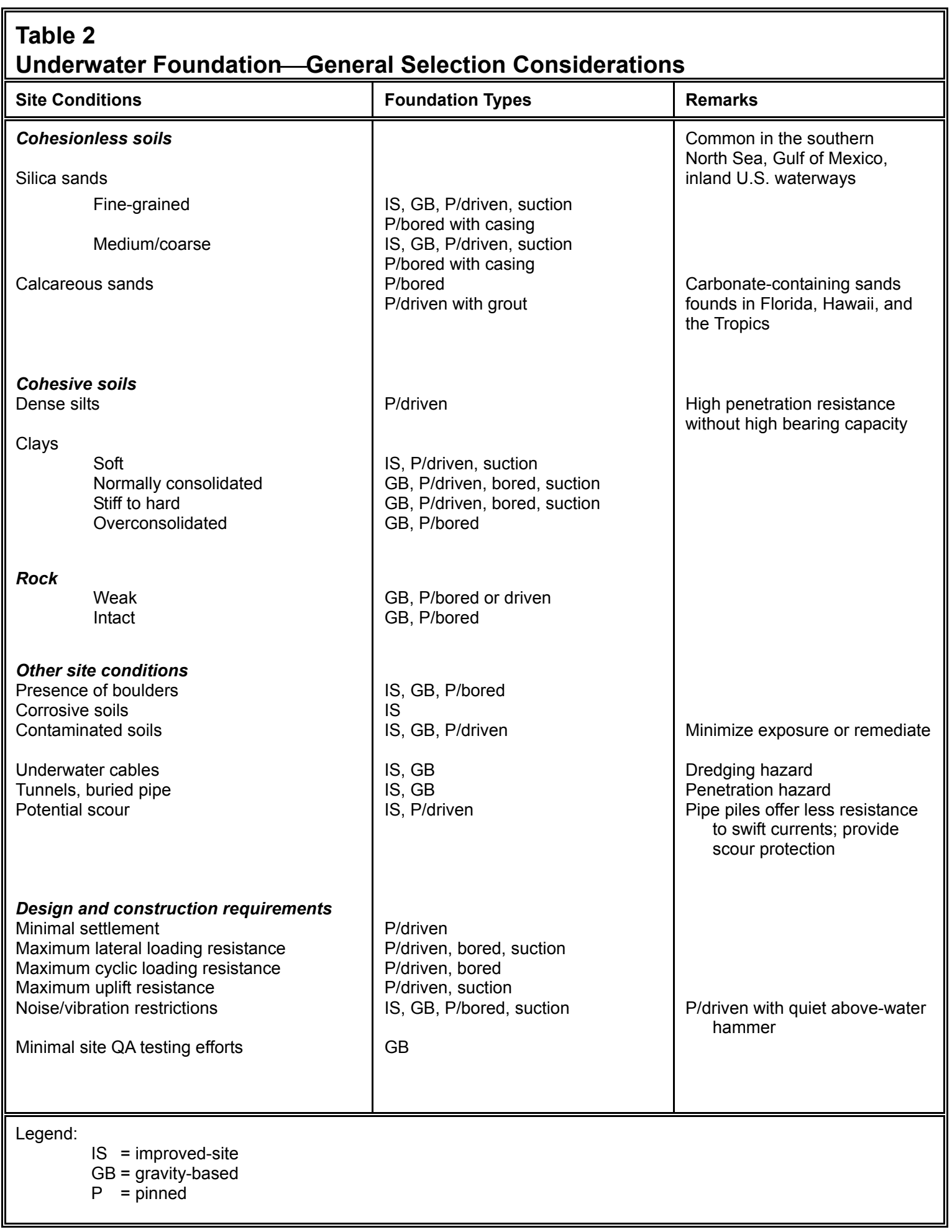


Alternatively, the prepared surface may underlie man-made materials such as geotextiles or bridging mats. The superstructure itself is designed to transmit the imposed loading to the underlying foundation material through its footprint (foundation), which has been designed (sized) to minimize the settlement and movement of the structure. Figure 37 illustrates an improved-site foundation with numerous features, including excavation dredging, backfilling, and mechanical modification by vibratory compaction. Figure 38 illustrates usage of man-made bridging mats and geotextiles combined with dredging excavation and vibratory compaction.

An underwater embankment foundation must be designed for stability and minimal settlement similar to an onshore design. The onshore methods for computing slope stability may be applied with the caveat that spatial variation will be analyzed. Since the underwater variability will likely be greater than for onshore slopes, solutions yielding the single critical shear surface and minimum factor of safety should be expanded to include spatially variable factors of safety. Liedtke and Wright (1999) analyzed this approach using the UTEXAS3 software package.

Dredging, excavation, and (back)fill placement design principles are similar to those used onshore. Namely, unsuitable materials are removed and replaced with more suitable material. Disadvantages of dredging and backfilling include environmental concerns in sensitive marine or riverine environments, contaminated dredged material issues, and possible scarcity of nearby suitable fill materials.

In addition to excavation and replacement, in situ modifications may also be required to increase the soil/rock strength, reduce settlement, or to improve stability. In sands, the primary goal is to increase the relative density. In clays and weak rocks, the primary goal is to increase the undrained shear strength. Three techniques available to achieve those goals are mechanical, hydraulic, and chemical modifications. Mechanical modifications include physical rearrangements of the soil matrix and include modifications by inclusions and/or confinement. Hydraulic modifications include dewatering schemes. Chemical modifications include grouting and soil mixing schemes (Hausmann 1990).

Mechanical modifications using reinforcing mats, steel mats, prefab rock blankets, or geotextile fabrics have the effect of creating dense layers with improved strength characteristics, as well as serving as filters to minimize erosion or scour. The foundation bearing capacity and settlement design then becomes a multiple-layer subgrade analysis with stiffer and more competent layers overlying softer strata. For example, Abbot and George (1989) determined that steel reinforcement meshes overlaid with granular layers would reduce potential settlement by 66 percent and increase shear strength by a factor of 800 as compared to the unimproved site.

Mechanical modification using vibrocompaction is sometimes referred to as vibroflotation if water jetting accompanies the vibration. Vibrocompaction mechanically rearranges soil particles into a denser configuration by the use of vibrating shafts and is used exclusively for cohesionless soils. Vibrating shaft 


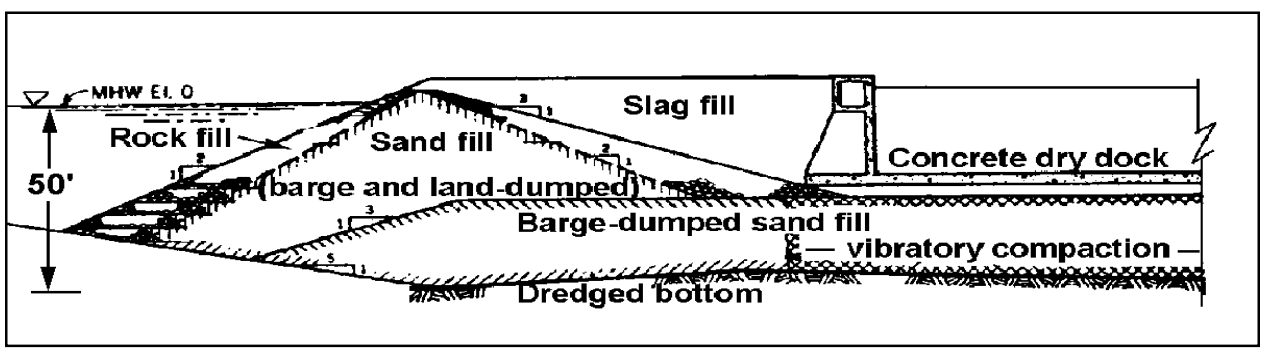

Figure 37. Improved-site foundation under Bethlehem Steel's graving dock near Baltimore (after Millard and Hassani 1971)

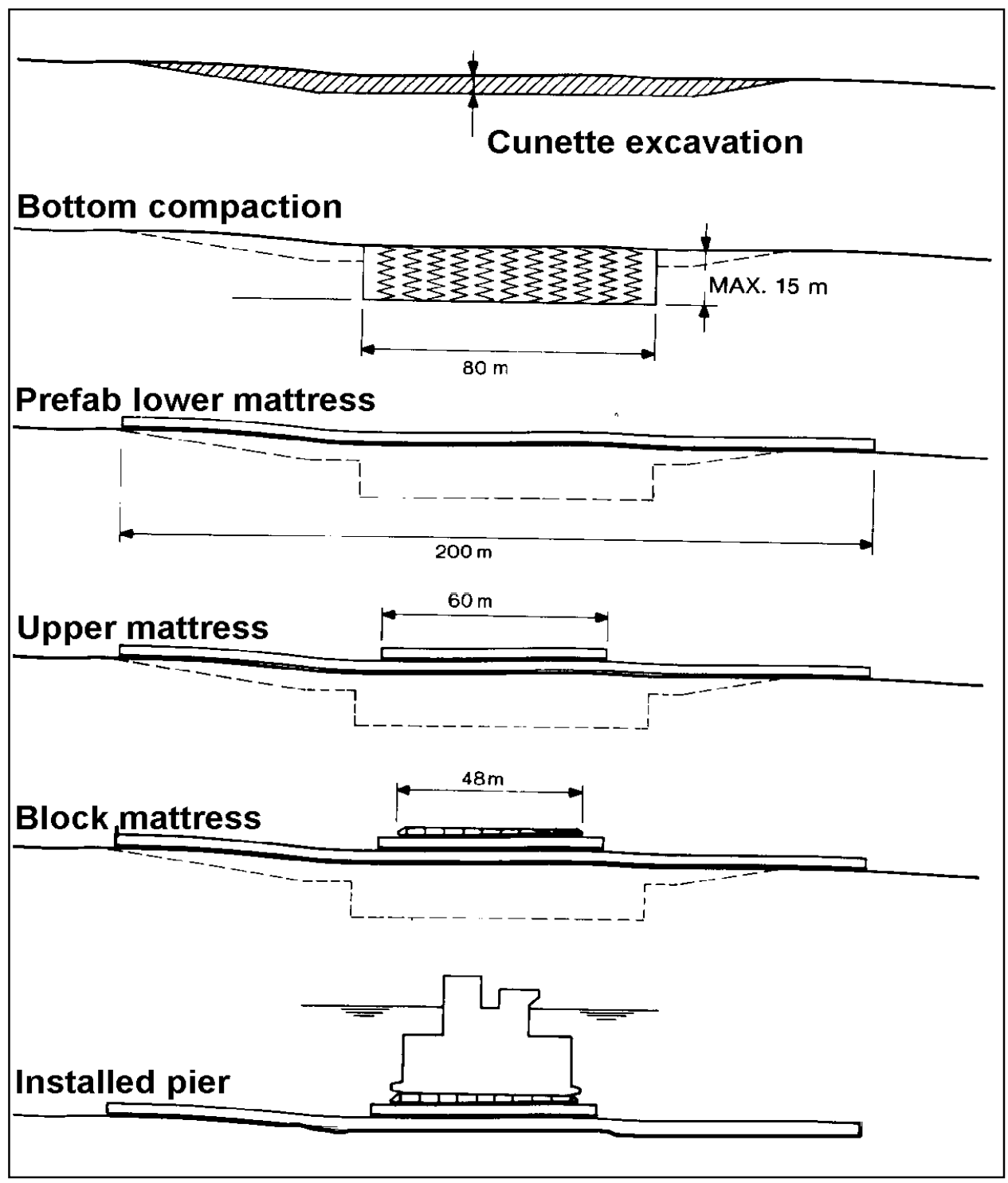

Figure 38. Eastern Scheldt improved site foundation sequence for gravity-based piers (after DOSBOUW 1987) 
equipment may be specially designed or may simply be a vibratory hammer attached to a pipe pile. The effectiveness of vibrocompaction in silty sands is marginal to good but in silts and clays is poor (Hayward Baker 1999a). The design process for vibrocompaction consists of first calculating the predicted settlement (knowing soil gradation and relative density) and then designing sufficient densification using vibrocompaction to reduce the expected settlement to a desired value. The final density is determined by acceptance testing using standard penetration, cone penetrometer, pressuremeter, or actual load tests. Several case histories document the use of vibrocompaction techniques to densify cohesionless soils. Tate (1961) reported that vibroflotation performed on drained sands achieved a relative density increase up to 90 percent from the original 50 percent; Millard and Hassani (1971) disclosed that use of a vibratory hammer/pipe pile to densify a cohesionless soil increased the bearing capacity by 100 percent and reduced design settlement by 50 percent; and Jonker (1987) cited similar results using underwater vibrocompaction of the cohesionless materials in the Eastern Scheldt project.

Hydraulic modification to consolidate cohesive soils involves drainage techniques. Both vertical and horizontal drains have been successfully used underwater. The first documented underwater installation of vertical drainage wicks in North America was performed during site improvement prior to construction of the Pascagoula (Mississippi) Naval Base. More than 4,000 wicks were placed underwater to consolidate the underlying soft bottom silts at the site of a new berthing pier. A 20 -ft $(6-\mathrm{m})$ sand surcharge was used to cause the consolidation (Munn 1989). Disadvantages of wick drains include the need for specialized equipment, the requirement to provide consolidation surcharge, and the time required for consolidation to achieve significant gains in soil strength.

Horizontal drainage to dewater silt layers at underwater depths of $64 \mathrm{ft}$ $(20 \mathrm{~m})$ has been accomplished using a vacuum pumping system, as illustrated in Figure 39. The purpose of dewatering was to allow larger volumes of dredged

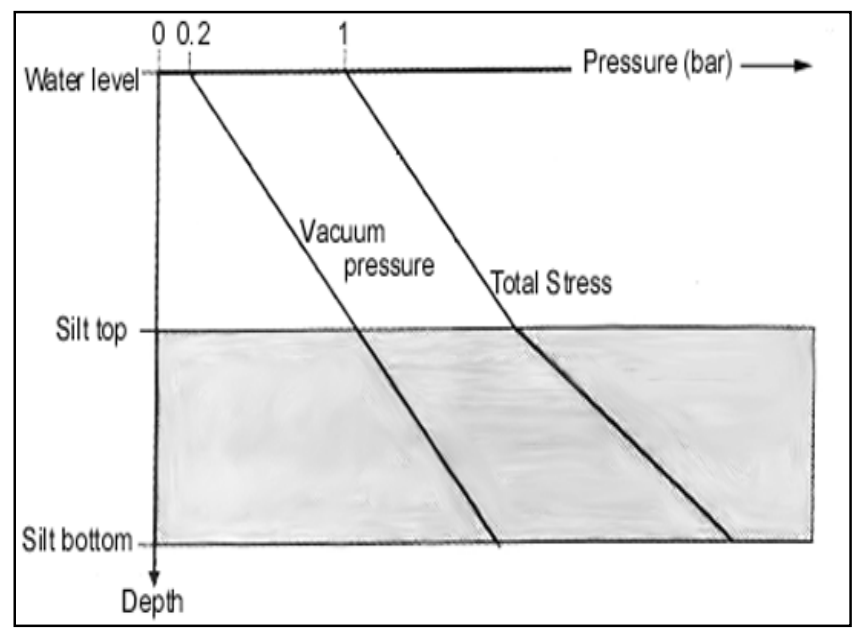

Figure 39. Suction dewatering in an underwater silt layer (after Aerts, Devlieger, and Vandycke 1999) material to be placed in an underwater disposal area. Collector pipes were installed as successive silt layers were added to the disposal area.

Storage capacity of the 986 - by 1,300 - by 16 -ft (300- by 400 - by $5-\mathrm{m})$ underwater disposal area was increased about 20 percent by dewatering the silt. Density after dewatering was increased by about 5 percent (Aerts, Devlieger, and Vandycke 1999).

Chemical modification techniques have been used for relatively shallow soft soil seabeds for bottom-founded offshore oil 
structures in the Arctic and for harbor areas of Japan. In the Alaskan Beaufort Sea, man-made islands have been constructed in the relatively shallow water depths of $10 \mathrm{ft}(3 \mathrm{~m})$ to support drilling platforms. Halebsky and Wetmore (1986) discussed several methods of soil modification and concluded that, of the methods proposed (dredging/backfilling, soil wick drains, soil freezing, and deep cement mixing), deep cement mixing offered an economical advantage. The dredging/backfilling and soil wick drains methods were assumed to increase the original soil strength by a factor of 2 whereas the deep cement mixing method (in situ soil strengthening using cement, or DCM) was found to increase the original soil strength by a factor of 70. In many locations, especially in Arctic regions, soils with shear strengths as low as $500 \mathrm{psf}(24 \mathrm{kPa})$ are found. Since exploratory oil-drilling structures require soil shear strengths of 1,000 to 2,500 psf (50 to $20 \mathrm{kPa}$ ) and permanent structures require greater shear strengths, increasing the soil shear strengths by a factor of 10 to 20 would make most weak soils acceptable.

The major disadvantages of the DCM technology include the specialized equipment that is required and the required time for curing. This technology for underwater applications is more commonly used in Japan than in the United States. Japanese DCM barges operate in water depths to $230 \mathrm{ft}(70 \mathrm{~m})$ and modify the soil to depths of $165 \mathrm{ft}(51 \mathrm{~m})$ beneath the seafloor. Typical curing times to achieve maximum design strengths are 2 to 3 months.

Gravity-based foundations. For gravity-based foundations, the superstructure is "connected" to the foundation (footprint), and the foundation is designed to resist the imposed compression, tension, overturning, lateral, and dynamic forces. Design should include the following considerations (as illustrated in Figure 40):

a. Stability against overturning, bearing capacity failure, sliding, or combinations thereof.

b. Static deformation (settlement and differential settlement).

c. Dynamic loading and response.

d. Hydraulic instability from scour or wave pressure piping.

e. Construction/installation effects, such as excessive pore-pressure buildup during base installation.

In general, onshore shallow foundation design procedures are used (American Petroleum Institute 1993). The bearing capacity of the soil is calculated using the undrained strength parameters $(\phi=0)$ for clays or the drained strength parameters for sands. The shear strength of the soil/rock is converted into resisting values for the imposed loading conditions by the selection of appropriate bearing capacity factor(s). Applicable soil parameters are inserted into standardized equations, and the failure load is calculated. 


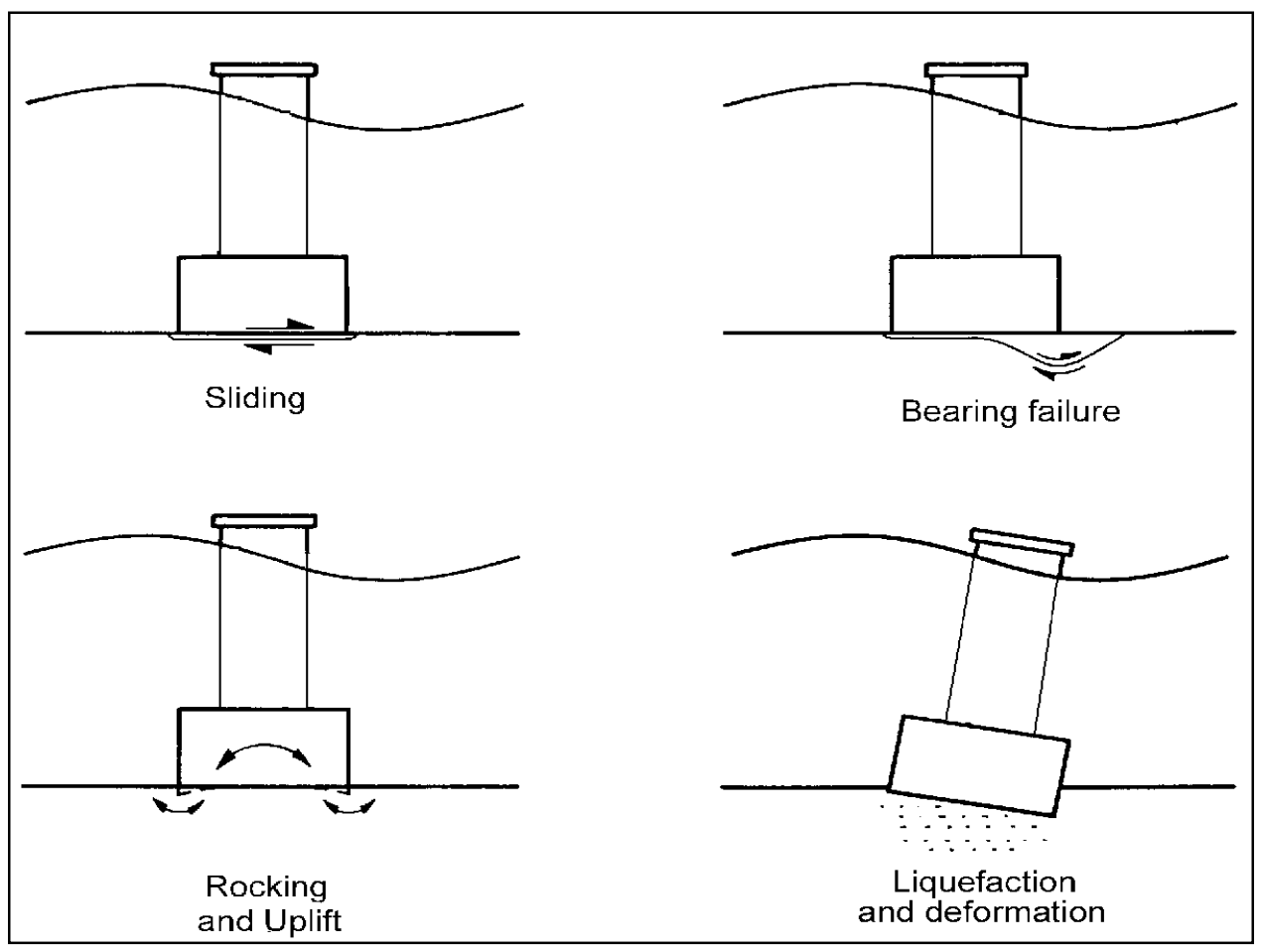

Figure 40. Possible failure modes of a gravity-based foundation

Dividing the failure load by the effective foundation area yields the ultimate bearing capacity $\left(q_{u}\right)$. The ultimate bearing capacity is then divided by the required (or chosen) safety factor.

The American Petroleum Institute (API 1989) recommends (with caveats) a safety factor of 2 for underwater foundations, while the Department of the Army (1983) recommends a safety factor from 1.5 to 3 for nonhydraulic structures, depending upon the values of the dead and live loads. Sliding stability calculations take horizontal and inclined loads into account. The maximum horizontal load at soil failure is calculated for either a drained or an undrained condition. API's recommended safety factor is 1.5 .

A more comprehensive approach to design is to couple the limit states design (LSD) concept with probabilistic assessment. This concept considers two limit states: ultimate limit states (ULS) and serviceability limit states (SLS). ULS involves soil strength, ultimate bearing capacity, overturning, sliding, and other structural safety conditions. The ULS methodology incorporates the load and resistance factor design (LRFD) concept, which uses partial factors accounting for uncertainties and variability. The SLS methodology involves conditions such as differential settlements from construction and service loads. Becker (1996) provides an overview of the LSD process for gravity-based foundation design.

Layered soils require additional considerations to prevent "punch through" (bearing capacity failure). The majority of jack-up drilling rig accidents are caused by foundation problems, and the majority of foundation problems are 
caused by punch-through on layered soils (Sharples, Bennett, and Trickey 1989). Senner and Cathie (1993) discuss methods to design and assess likelihood of bearing capacity failures on layered soils, including (a) strong clay overlying weak clay, (b) sand overlying clay, (c) strong soil overlying weak soil, and (d) thin weak layers.

Calcareous (carbonate) sands require special attention. They may exhibit high friction angles in laboratory testing, which leads to overestimating actual bearing capacity. However, the load-carrying capacity of carbonate sands may be somewhat lower because of their highly compressible behavior (Dutt and Ingram 1988, LeTirant and Nauroy 1994).

Static deformation considerations include both short- and long-term effects. The compression index and the coefficient of consolidation are obtained from laboratory (or other suitable type test) consolidation test data. The vertical stress distribution for the before- and after-loading conditions can be calculated using elastic theory. Using these criteria, the total and differential settlements can be calculated and compared with the allowable displacements.

Considerations of dynamic behavior include cyclic loading from wind, current, waves, ice, and earthquakes. Soil-structure interactions must be examined for each anticipated loading situation. Failure during cyclic loading may be associated with large horizontal or rotational cyclic displacements, large settlements, or combinations thereof. The undrained bearing capacity of certain clayey soils may be significantly lower during cyclic loading than monotonic loading. To analyze the static bearing capacity after cyclic loading, the postcyclic static shear strength must be known (Andersen, Kleven, and Heien 1988). Andersen and Lauritzsen (1988) describe procedures for determining the cyclic and postcyclic bearing capacity of gravity-based foundations on undrained clay. Typical characteristic cyclic loads imposed on a North Sea gravity-based foundation are these: (a) a horizontal wave load of 67,443 tons $(600 \mathrm{MN})$, (b) a wave moment of 3,417,096 ton-ft (100,000 MNm), and (c) a vertical wave load of 44,962 tons ( $400 \mathrm{MN})$. These cyclic loads are based on the typical design storm with a 100-year return period (Andersen, Kleven, and Heien 1988).

Scour skirts, riprap, or other scour protection methods are designed to prevent soil erosion and undercutting. Excessive hydraulic gradients during and after foundation installation may cause piping and excessive disturbance to the supporting soil.

Designs of gravity-based foundations sited on rock generally follow the same approach as for soils, but use slightly different methods. The failure methods are the same as for soils, but the mechanisms are different. The geotechnical parameters are also different. Rock strength classification is typically based on either the RMR system (Bieniawski 1974) or the Q system, also called the NGI system (Barton, Lien, and Lunde 1974). Appropriate rock strength parameters are input, and allowable resistance values for bearing and sliding are calculated using safety factors or probabilistic methods. Becker et al. (1998) discussed design methods for underwater bridge piers founded on weak rock. 
Pinned foundations. Pinned foundations are typically employed to provide end-bearing and/or frictional resistance to imposed compression, tension, lateral, and dynamic loads. Pinned or pile foundations are installed into the subsurface soil and/or rock either by displacement or excavation. Impact-driven piles displace (dislocate) the soil. Drilled caissons or shafts require borehole excavation. Most of the offshore structures use pinned foundations consisting of driven piles. Lacasse (1999) reported that there are an estimated 6,000 offshore piled structures around the world.

As a very general rule, bored piles are selected where there is a relatively shallow bedrock stratum to develop end-bearing resistance, whereas driven piles are selected for soils in which a high friction resistance can be used. However, this dividing line is not distinct, and the pile type selection is usually governed by installation economics and environmental conditions such as noise and vibration (Thornton 1992). The most common offshore foundation type is a driven tubular open-ended (pipe) pile designed for axial loading with minimum lateral loading in granular and cohesive soils (ARGEMA 1992). An offshore pipe pile typically has a diameter of about $7 \mathrm{ft}(2.1 \mathrm{~m})$, a wall thickness of about 2 in. $(5 \mathrm{~cm})$, and penetration length of 300 to $400 \mathrm{ft}$ ( 90 to $120 \mathrm{~m}$ ). The pile's size and length are commonly determined by the required bending moment and by the penetration depth to develop the necessary resistance to compressive and tensile loads. As a rule of thumb for design purposes, Gerwick (1971) suggested that the maximum compressive load was approximately twice that of the maximum tensile load. In the event that excessive soil resistance to driving (refusal) is reached prior to the designed tip penetration, several techniques are available to achieve design penetration and include combinations of driving and drilling methods.

After the type of pinned foundation has been selected, the designer must then determine the number, length, and size of the piles or drilled shafts. Several design guides for piles and shafts are available, including API RP2A (1993); Federal Highway Administration guides for bridge foundations, piles, and drilled shafts (Hannigan et al. 1997; Armour and Groneck 1998; Raushe, Goble, and Moses 1997; Bruce and Juran 1997; Baker et al. 1993; Barksdale and Bachus 1983; Lam and Martin 1986; O'Neill 1988; and Reese 1984); U.S. Army Corps of Engineers 1991 and 1994 (Engineer Manuals 1110-2-2906 and 1110-1-2908); American Society of Civil Engineers (1981, 1984, and 1993); Construction Industry Research and Information Association (1993); and other publications (Whitaker 1976, ARGEMA 1992).

The offshore industry has used the recommended empirical design methods of the American Petroleum Institute, since its API RP2A was first published in 1969 , primarily for Gulf of Mexico fixed platforms founded on open-ended steel pipe piles. Several iterations over the years have produced the latest design recommendations (API 1993). The design guidelines are based on extensive research and load tests, extrapolated to the actual loads imposed on offshore structures. It is interesting to note that although the largest pile capacity in the API database is about 4,000 kips (18 MN), typical axial capacities (loads) for offshore piles range from 10,000 to 15,000 kips (44 to $67 \mathrm{MN}$ ) per pile. For compliant towers, the pile capacities are about 30,000 kips (133 MN) per pile. 
Although the design guidelines have been vigorously extrapolated, the field results have remained acceptable (Pelletier, Murff, and Young 1993).

API's design format uses both the Working Stress Design and the Load and Resistance Factor Design methods. In deference to the European Community process of developing international offshore platform design standards through the International Standards Organization (which has a reliability-based format), the LRFD method will likely predominate (Pelletier, Murff, and Young 1993; Toolan and Horsnell 1993). The LRFD method includes partial safety factors (reduction factors for soil parameters and multiplication factors for loads) instead of lumped safety factors.

Other international offshore pile design codes are regulated by Det Norske Veritas (DNV 1989) and the Department of Energy, U.K. (1986). Both these design codes and the API recommendations include procedures for designing in cohesive and cohesionless siliceous soils. The ARGEMA (1992) and CLAROM (1994) design guides provide specific guidance for calcareous (carbonate) soils.

Recommended design parameters for cohesionless siliceous soil are given in API $(1989,1993)$ for both driven and drilled/grouted piles. The limiting unit endbearing values and limiting skin friction values range from 40 to $250 \mathrm{ksf}$ ( 2 to $12 \mathrm{MPa}$ ) and 1 to $2.4 \mathrm{ksf}(50$ to $115 \mathrm{kPa}$ ), respectively, as the soil density increases from very loose to very dense. In calcareous sands (containing calcium carbonate), driven piles may have substantially lower design strength parameters than drilled and grouted piles.

The design methodology for both driven and drilled piles is similar. It consists of comparing the applied loads to the soil's internal capacity and adjusting these values using applicable safety limits. The ultimate load-carrying capacity is the sum of the pile end-bearing capacity (soil's resistance to bearing) and the pile skin friction capacity (soil's frictional resistance):

$$
Q=Q_{p}+Q_{f}
$$

where

$$
\begin{aligned}
& Q=\text { load-carrying capacity of the pile } \\
& Q_{p}=\text { end-bearing load } \\
& Q_{f}=\text { friction load }
\end{aligned}
$$

and $Q_{p}=q A_{p}$

where

$$
\begin{aligned}
& q=\text { soil's end-bearing capacity } \\
& A_{p}=\text { pile end area }
\end{aligned}
$$

and $Q_{f}=f A_{s}$ 
where

$$
\begin{aligned}
& f=\text { soil's skin friction capacity } \\
& A_{s}=\text { side surface area }
\end{aligned}
$$

The required diameter and length (penetration depth) of the pile are calculated using $\mathrm{A}_{\mathrm{p}}$ and $\mathrm{A}_{\mathrm{s}}$. For given soil values of $q$ and $f$, the ultimate loadcarrying capacity $Q$ increases as pile diameter or penetration depth increases. Ultimate-capacity design uncertainties are usually related to installation uncertainties (plugging and drivability) and soil-capacity uncertainties ( $q$ and $f$ values).

Alternatives - for situations in which design objectives cannot be obtained during the installation of the pile - should be identified and defined in the design process (API 1989). For example, in the event sufficient penetration cannot be achieved, removal of all or part of the soil plug is an option that can be used to permit driving of the pile to the design depth. Care must also be taken when basing pile design on load test correlations using soil properties determined from both in situ tests and the laboratory test results. For example, if the in situ test results yield shear strengths that are higher than those obtained from laboratory samples and the load test correlations were made based upon the laboratory data, using the higher values of shear strengths from in situ tests may lead to an unsafe design (Reese and Isenhower 2000).

Besides designing for ultimate-capacity loading, the pile material must be able to withstand handling and transportation stresses. Wall thicknesses may be governed by the loads developed during installation procedures, especially if the contractor opts to provide single-piece installation instead of making field connections (Will et al. 1999). Column buckling due to unsupported lifting from the horizontal to a vertical orientation or the dead weight of an underwater hammer clamped to the top of a tilted pile undergoing self-penetration is an important design consideration (Doyle 1999). Steel fatigue due to hammer driving is another material design consideration, especially when a large number of blow counts are anticipated in the soil resistance to impact driving analysis.

Varying wall thicknesses along very long offshore pipe pile lengths is a commonly noted design consideration, as some piles extend to about $400 \mathrm{ft}$ $(122 \mathrm{~m})$ in length. Typically, the pile walls are thicker at the mudline due to higher axial and bending stresses in that area (Davies and Srivareerat 1999). Cunningham and Naughton (1977) discussed design aspects for a 1,255-ft (382-m)-long, 4-ft (1.2-m)-diameter, 50-ksi (345-MPa) yield stress pipe pile driven to $375 \mathrm{ft}(114 \mathrm{~m})$ penetration. Wall thickness at the mudline was $3 \mathrm{in}$. $(7.6 \mathrm{~cm})$, decreasing to 1 in. $(2.5 \mathrm{~cm})$ above the mudline depth.

Pile-driving studies are required to determine the soil's resistance to impact driving (SRD) or vibratory driving (SRV). For example, if the pile cannot be driven to the design penetration depth, the pile's designed ultimate capacity may not be achieved. SRD or SRV must be studied as part of the design process since 
these values determine the likelihood of achieving a successful pile installation during the construction phase.

Two aspects of the pile-driving study that should be addressed are (a) selecting the proper pile and hammer and (b) establishing criteria to define a successful installation. Hammer selection may be the most important aspect of pile installation (ASCE 1993). Numerous resources are available for pile-driving equipment selection (Department of the Army 1982). The wave equation analysis provides guidance for items (a) and (b) above and is discussed in detail in Chapter 5. Proof load testing prior to finalizing the design specifications also provides valuable guidance in establishing criteria defining a successful installation. Load testing is also discussed in Chapter 5 of this report.

Self-weight penetration (prior to hammering) as the pile is lowered into the mudline is a design consideration. Self-weight penetration may be calculated by assuming that the penetration resistance is provided by outer circumference skin friction, end bearing at the pile base, and inside skin friction provided by the shoe. The buoyant weight of the pile and attached lifting tools provides the penetration (driving) force. Doyle (1999) noted that unconsolidated-undrained remolded soil strength values were used for skin friction, and undisturbed soil strength values were used for end-bearing resistance in self-weight pile penetration calculations at clay sites in the Gulf of Mexico. At those sites, selfweight penetration was roughly 25 percent of the total pile lengths.

Designing drilled shafts socketed into bedrock generally relies on shaft resistance instead of end bearing, since shaft resistance is fully mobilized at much lower deformation as compared with end-bearing resistance (Becker et al. 1998). For example, the design of the underwater approach piers for the Confederation Bridge was initially based on unit shaft resistance values of 7.5 to $14.1 \mathrm{ksf}$ (360 to $680 \mathrm{kPa}$ ) developing in the mudstone, siltstone, and sandstone layers. Drilled shaft lengths averaging $44 \mathrm{ft}(13.5 \mathrm{~m})$ with $6.5-\mathrm{ft}(2-\mathrm{m})$ diameter were then calculated based on factored design loads up to 6,745 tons $(60 \mathrm{MN})$ vertical, 73,953 ft-tons (200 MN-m) bending, and 2,135 tons (19 MN) horizontal. Design shaft lengths were later reduced to $25 \mathrm{ft}(7.5 \mathrm{~m})$ based on actual (onshore) load tests that indicated much higher shaft resistance values in the rock layers.

Full-scale load tests of drilled shafts using the Osterberg cell method have typically shown that the maximum applied test load is much larger than the design load, including the factor of safety. According to Osterberg (1998), relatively few designers have taken advantage of these results by performing economical redesign efforts. One extreme overdesign example revealed that when a test shaft was loaded to 3,000 tons $(26.5 \mathrm{MN})$ with no sign of failure, the design firm was pleased that the design load of 500 tons $(4.4 \mathrm{MN})$ was validated. No efforts were made to redesign the shaft to a more economical, smaller size.

The effects of scour around pinned foundations requires reducing the effective shaft length to account for reduction in side shear (friction resistance). For example, drilled shaft designs for the Ohio River Bridge (Osterberg 1998) took into account only the bottom $19 \mathrm{ft}(6 \mathrm{~m})$ of shale. The load capacity of the overlying $63 \mathrm{ft}(19 \mathrm{~m})$ of sand and gravel was not considered because of the 
possibility of deep scour. Full-scale load testing (using the Osterberg cell) was tailored to reduce the overburden's load-carrying contribution.

The design criteria for a suction pile is similar to the gravity-based and pinned foundation design methodologies. For the suction pile, the penetration resistance is a function of the soil's resistance to bearing and friction and is calculated as the sum of the shear along the walls and the bearing capacity at the tip. The penetration analysis includes calculation of the underpressure (the difference between the hydrostatic water pressure outside the pile and the water pressure inside the pile cavity). The safety margin against soil heave inside the cavity must be determined to calculate the allowable underpressure (Andersen and Jostad 1999). The calculation of self-weight penetration of the suction pile is a critical design aspect that must be addressed due to its effect on the pile cavity volume.

The bearing capacity and holding (tension) capacity of suction piles are calculated by limit equilibrium methods. The critical failure surface depends on the combination of vertical, horizontal, and moment loads acting on the pile. Andersen and Jostad (1999) provide comments on design concepts and procedures for suction pile (skirted foundations and anchor) design. The following design aspects need to be analyzed for suction piles:

- Penetration

- resistance

- necessary and allowable underpressure

- soil heave inside cavity

- maximum penetration depth

- factor of safety

- removal analysis if needed

- Capacity

- limiting equilibrium modeling

- shear strengths

- soil crack effects

- Displacements

- consolidation

- cyclic and permanent displacements due to cyclic loads

- Soil spring stiffnesses (dynamic analysis)

- Soil-structure interaction

\section{Analysis and verification testing}

Design analysis is conducted during the design phase, and may include numerical and physical modeling. Numerical modeling techniques (such as finite element analysis) and physical modeling techniques (such as model tests) can be used during this phase.

Model tests are geotechnical investigative tools that best document the failure mechanism, deformation patterns, reliability of numerical models, and soundness of the calculated design (Lacasse 1999). Model tests can range from 
full scale to small-scale prototypes and may include the use of centrifuge testing. Figure 41 illustrates model scaling relationships for centrifuge tests.

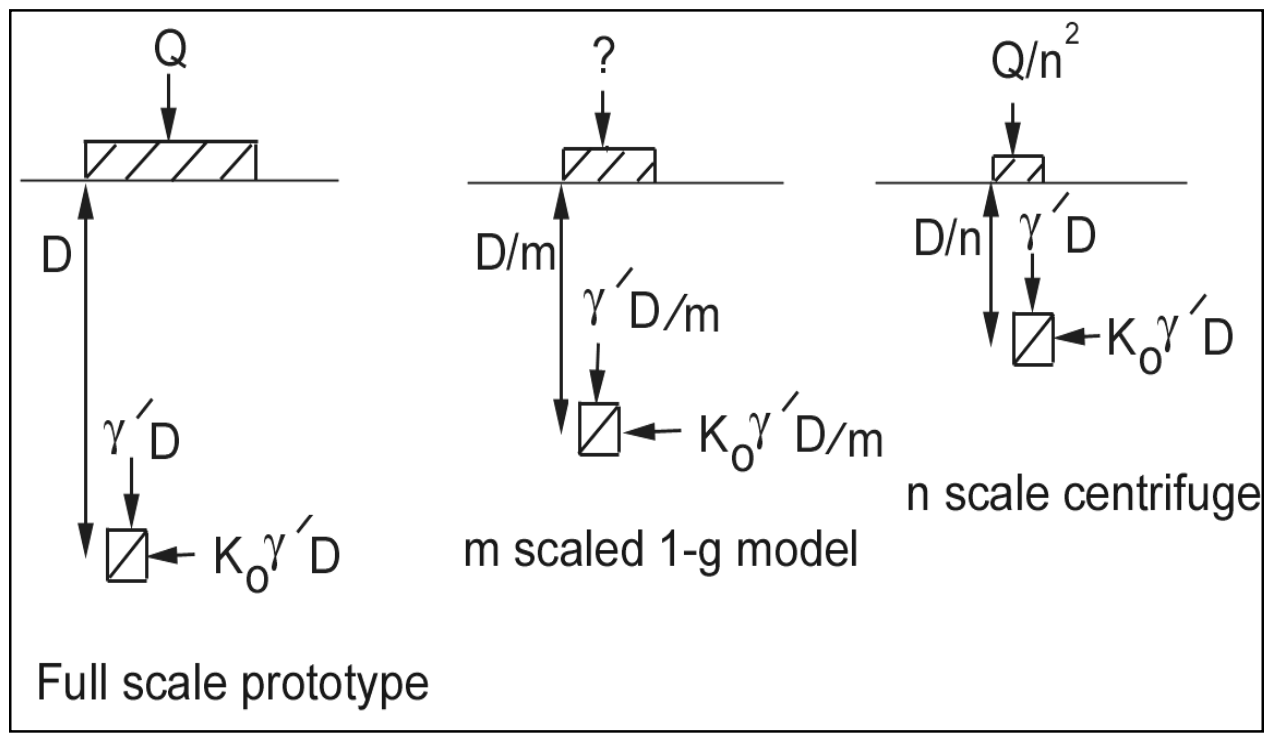

Figure 41. Scaling relationships for 1-g and centrifuge models (after Murff 1996)

When properly designed and conducted, centrifuge testing offers significant advantages compared with 1-g model testing. Centrifuge testing of undrained, partially, or fully drained soils with simplified profiles offers an advantage. The disadvantages include the use of miniature instrumentation, the effects of time scale, and relatively high costs. Murff (1996) presents a discussion of centrifuge testing aspects related to offshore foundation design and analysis that was supplemented with several case histories.

Published examples of centrifuge testing for offshore foundations are not as common as those for onshore applications, perhaps due to the proprietary nature of some tests. Nicola and Randolph (1999) discussed model pile test results compared with current guidelines for offshore pile design. Hu, Randolph, and Watson (1999) discussed centrifuge testing and finite element analysis of offshore skirted gravity-based foundations. Becker et al. (1998) discussed centrifuge testing and finite element analysis of an underwater gravity-based foundation for a bridge pier.

\section{Quality Control and Assurance Issues}

Quality control and quality assurance (QA/QC) are essential in engineering design and construction. Quality control and assurance elements are especially important for in-the-wet construction projects where the foundations are prepared, installed, and tested in an underwater remote location, often from a floating platform on the river or marine surface. Visual inspection of the 
foundation before, during, and after construction is generally not possible, as compared with the onshore process where the aboveground portion of the foundation is easily viewed and accessible. Specialized techniques and equipment are needed to install quality foundations underwater, and adequate QA/QC procedures must be specified and followed to achieve and ensure successful installation.

Quality control and quality assurance are not the same functions, and are more than an inspection process. Quality control refers to setting up and maintaining a system that provides a means to control and measure specified characteristics (of the underwater foundations). Quality assurance verifies that the quality control system is performing adequately. Quality control and assurance operate hand-in-hand to enable the underwater foundation to be constructed in strict accordance with the engineering design and specifications by monitoring, recording, and certifying the entire process. Adequate QA/QC is the collective responsibility of all parties concerned with designing, specifying, manufacturing, purchasing, and installing the various project components (Batten 1987).

Although the QA/QC system applies to the planning, conceptual design, and engineering design phases of a project, its most common and better defined application is in project construction. Constructing the underwater foundation according to the design plans and specifications requires a high degree of QA/QC due to the complexities and variables involved in contractual construction projects. Preventing the introduction of defective materials or poor workmanship in a construction project before these problems occur constitutes an effective quality control and inspection scheme (API 1989).

\section{Engineering design phase}

Design quality is the responsibility of everyone involved in the development of a project (Department of the Army 1994). Several QA steps are involved in the design of Corps projects before plans and specifications are inked, as outlined in Engineer Regulation (ER) 1110-2-1150. Appendix F of the ER is an internal management control checklist to ensure that all engineering functions are conducted in a cost-efficient manner. Adequate coordination, communication, and lessons-learned applications are stressed in order to achieve a high standard of technical quality during the design phase.

Appendix E of ER 1110-2-1150 includes instructions for writing a "report on engineering considerations and instructions for field personnel" who will be responsible for the oversight of the contractors' quality control program. It is stressed that this report should be distributed to appropriate construction field personnel for their suggestions and input prior to completion of the design phase. Field personnel may have a more intimate knowledge of site conditions and potential site-specific design problems than do the engineering design personnel. Hence, the field comments and suggestions should be incorporated early on, especially during the design phase.

The Corps of Engineers has published engineer manuals, technical manuals, and other guidance to ensure consistent criteria and requirements for developing 
design and engineering documents for civil and military projects. ER 1110-345700 covers military and hazardous waste projects. Other regulations are applicable and will not be listed here.

A comprehensive listing of U.S. government standards, design guides, engineer manuals, national standards, building codes, and trade organization

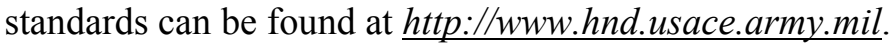

\section{Specifications and contract document phase}

Specifications delineate the project requirements and establish exactly how the designer intends the project drawings to be applied. Specifications form a primary tool for setting up the QA/QC system and must provide enough detail for the construction to proceed in a timely, efficient manner. Specifications also provide a basis for estimating the project costs, which impacts contractor selection during the bidding process.

ER 1110-1-8155 (Department of the Army 1998) prescribes specifications policy for the Corps. The Corps of Engineers Guide Specifications (CEGS) are a system of master guide specifications that define the qualitative requirements for products, materials, and workmanship for repetitive work features occurring on

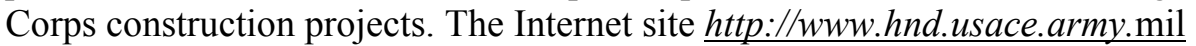
contains the CEGS library and additional specification database links. Although usage of the CEGS system is not mandatory within the Corps, the system is updated and maintained to include lessons learned during design and construction, and thus constitutes a valuable source for technical specifications.

No CEGS documents currently exist for underwater foundation design and construction. Various elements of land-based foundation construction that may be applicable to underwater foundation construction, which are covered in the February 1999 CEGS database, are listed follow:

01270 Measurement and Payment

01451 Contractor Quality Control

02210 Subsurface Drilling, Sampling, and Testing

02217 Foundation Preparation

02251 Foundation Drilling and Grouting

02300 Earthwork

02315 Excavation, Filling, and Backfilling for Buildings

02316 Excavation, Filling, and Backfilling for Utilities

02375 Geogrid Soil Reinforcement

02378 Geotextiles Used as Filters

02453 Prestressed Concrete Piles for Civil Works

02454 Precast Concrete Piling

02455 Cast-In-Place Concrete Piles, Steel Casing

02456 Steel H-Piles

02457 Round Timber Piles

02458 Prestressed Concrete Piling

02459 Piling: Composite, Wood, and Cast-In-Place Concrete 
02461 Round Timber Piles for Hydraulic Structures

02463 Steel H-Piles for Civil Works

02464 Metal Sheet Piling

02465 Auger-Placed Concrete Piles

02466 Drilled Foundation Caissons

02722 Graded, Crushed Aggregate Base

Corps Divisions and Districts are given the flexibility to add non-CEGS specifications within a specific construction project package, but inclusion of those specifications within the CEGS system requires proper submission and Headquarters approval. The specification sections must be properly formatted in accordance with ER 1110-1-8155. The CEGS layout for a construction specification (Construction Specifications Institute 1996) follows:

Part 1 General

1.1 References

1.2 Measurement and payment

1.3 System description

1.3.1 Design requirements

1.3.2 Performance requirements

1.4 Submittals

1.5 Qualifications

1.6 Regulatory requirements

1.7 Field examples

1.8 Mock-ups

1.9 Pre-installation conference

1.10 Delivery, storage, and handling

1.11 Project/site conditions

1.11.1 Environmental requirements

1.11.2 Existing conditions

1.11.3 Field measurement

1.12 Sequencing and scheduling

1.13 Warranty

1.14 Maintenance

1.14.1 Maintenance service

1.14.2 Extra materials

Part 2 Products

2.1 Materials

2.2 Manufactured units

2.3 Equipment

2.4 Components

2.5 Accessories

2.6 Mixes

2.7 Fabrication

2.7.1 Shop assembly

2.7.2 Shop/factory finishing

2.7.3 Tolerances

2.8 Tests, inspections, and verifications 


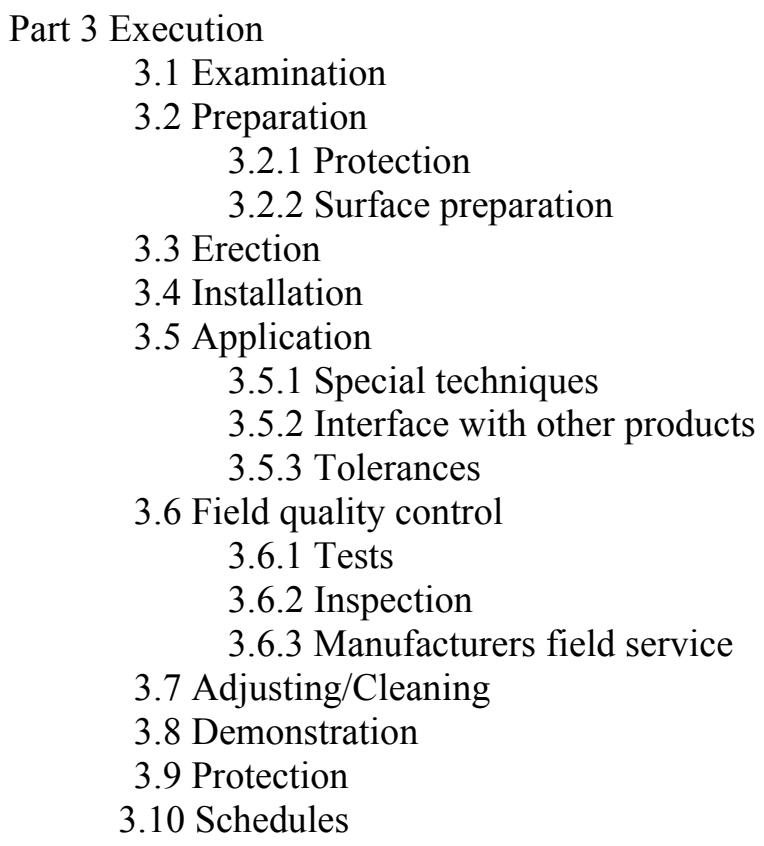

Once the project specifications are sufficiently detailed and written, they are reviewed and approved for inclusion in the project contract documents. During the bidding process and after contract award, conflicts may arise because of problems with the specifications. Based upon one legal firm's breakdown of construction specification conflicts, the following specification problem areas are listed in order of occurrence (Nielsen and Nielsen 1981):

- "Or equal" clauses: These statements lead to the highest occurrence of specification problems (claims and litigation) because of disputes over what is "equal" in a particular situation. This situation occurs mainly in public works contracts in which the specifier wants a particular brand name product but also must comply with Federal contract law to not limit competition.

- Constructibility (defective specifications and tolerances): Constructibililty problems arise when the item cannot be built, installed, or will not perform as specified. Holding the contractor to tighter tolerances than normal industry standards may also lead to conflict.

- Ambiguities (phrasing and typographical errors): These problems refer to interpretation issues.

- Conflicts between plans and specifications (and typographical errors): These conflicts arise from lack of adequate QA/QC during the engineering design phase.

- Inaccurate technical data: This category includes errors and omissions such as specifying subsurface information that does not match the actual conditions (differing site conditions), specifying inadequate quality control standards, and specifying owner-furnished plant and equipment that is not suitable. 
- Product performance deficiencies: These may cause problems when new and relatively untried products are specified. This type of problem has direct applicability to underwater foundations contracted by the Corps because the Corps does not have an extensive experience database gained from in-the-wet construction projects. Special emphasis must be given to prebidding demonstrations of products and equipment and postaward presence of knowledgeable field representatives responsible for implementation of new products, procedures, or equipment to be used for in-the-wet projects.

- Inspection and excessive testing: Overzealous inspection and testing may also cause specification problems and contract conflicts.

\section{Recent Corps of Engineers underwater foundation contracts}

Pittsburgh District. Plans and specifications have been finalized and construction has begun for an innovative Corps in-the-wet float-in construction project. A new gated dam will be constructed at Pittsburgh District's existing Braddock Locks and Dam 2 on the Monongahela River in Pennsylvania (U.S. Army Corps of Engineers 1998). The underwater foundation system consists of a dredged area with sheet-pile cutoff walls in the riverbed alluvium and concrete drilled shafts socketed into bedrock. The precast concrete dam elements will be floated in and ballasted upon and anchored to the drilled shafts. The foundation specifications were custom-written for this unique project and contain numerous non-CEGS specifications. Specifications relating directly to the underwater foundation system include:

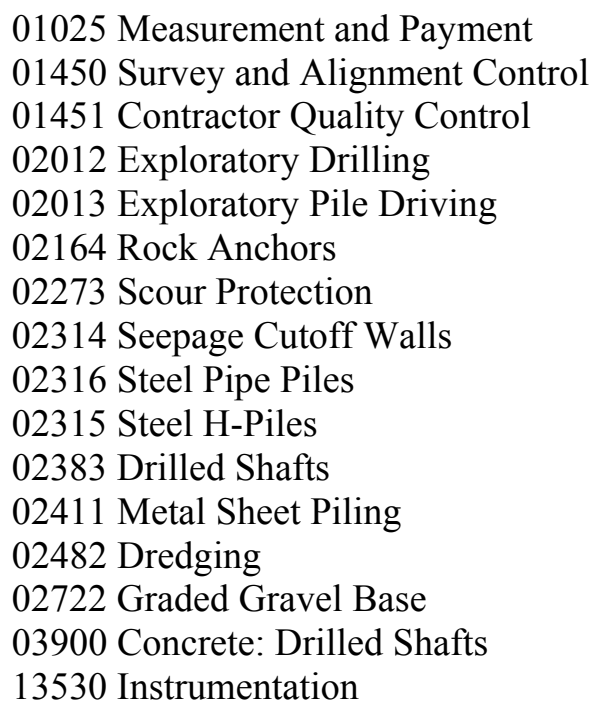

The predominant work feature for the underwater foundation system is drilled shafts, which provide the deep-foundation support for the concrete float-in elements and function as anchor piles for positioning the float-in elements. The drilled shafts (similar to caissons or piers) consist of steel pipe piles (casing) driven with a vibratory hammer to bedrock. Upon completion of the driving of the casing, rotary drilling was conducted through the pile beyond its open bottom 
end and into bedrock (without casing). After the borehole had been advanced to the specified depth in the bedrock, steel reinforcement cages (illustrated in Figure 42) with attached instrumentation tubes (for sonic testing) were to lowered into the casing and through the bedrock to the bottom of the borehole. The borehole and casing were then backfilled with tremie concrete. Foundation details are presented in Figure 43.

Section 01451, Contractor Quality Control, established the baseline requirements for the quality control system to be implemented by the successful bidder. Some of the novel features of this specification section include:

a. Requirement for completion of the "Construction Quality Management for Contractors" training course.

b. Requirement for project management staff to have specialized experience:

(1) Project Engineer: minimum 3 years marine construction experience

(2) Concrete Superintendent: experience in mass concrete operations

(3) Marine Superintendent: minimum 15 years marine project experience

(4) Diving Superintendent: minimum 5 years diving supervision

(5) Chief Surveyor: minimum 5 years marine surveying experience

(6) Project Safety Engineer: minimum 3 years marine construction experience

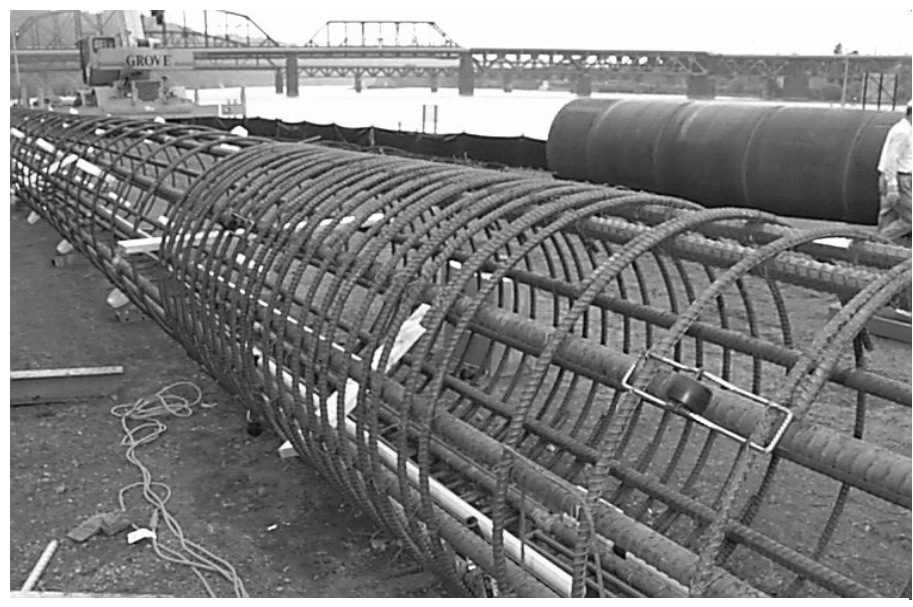

Figure 42. Reinforcing cage for the drilled shaft load test prior to project construction at Braddock Locks and Dam 2

Two additional underwater foundation construction specification sections were added to address specific technical requirements to ensure quality: 


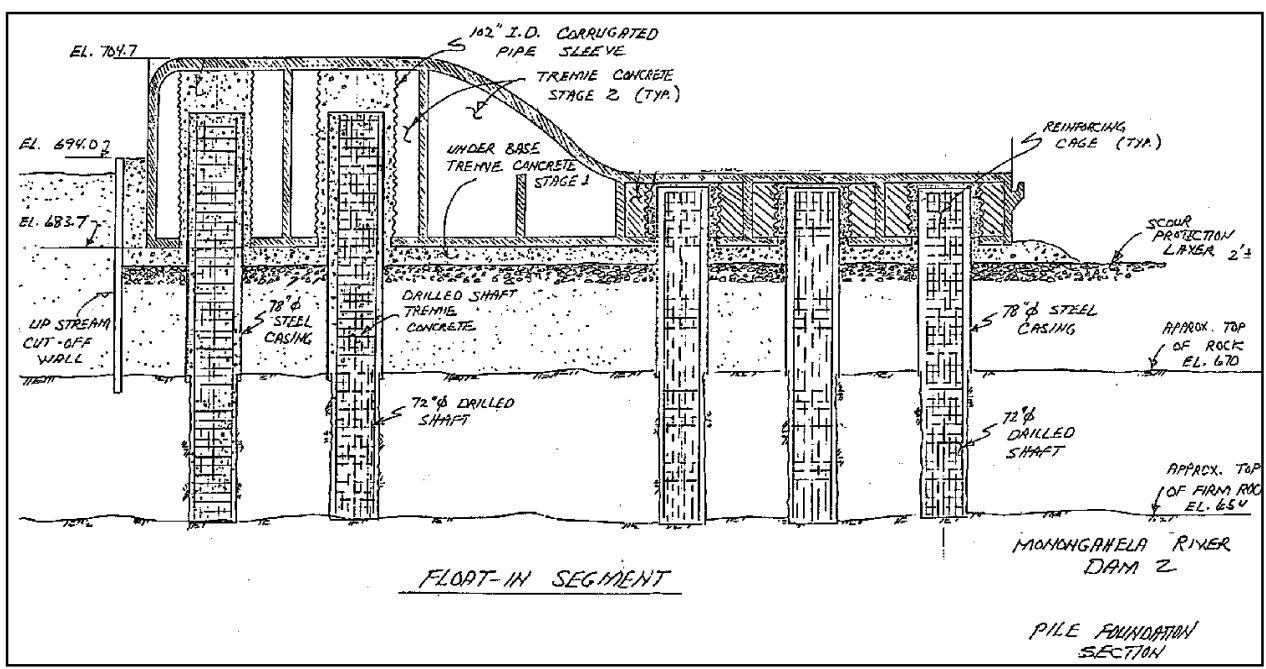

Figure 43. Pinned foundation details, Braddock Locks and Dam 2

Pinned foundation: Exploratory drilling was specified to establish final tip elevations for the bedrock drilled shafts. Exploratory pile-driving served to specify final tip elevations for the alluvium cutoff wall (H-piles, pipe piles, and sheet piles) and to finalize vibratory pile-driving equipment selection for both the cutoff wall piles and the drilled shaft casings. It was specified that these work items were to be completed first, so the contractor would be able to order the correct amount of production piling materials. After the improved-site foundation preparation was completed (i.e., dredging, graded gravel base, and scour protection), a Drilled Shaft Installation Plan was approved. After its approval, a drilled shaft demonstration was conducted to assess and select the equipment and procedures for constructing the production shafts. Previous tests by Pittsburgh District at the site (sheet piles and caissons) provided quality assurance comparisons for both design and construction. Other QC features included the requirement for a fixed-guide pipe pile and casing template and specifying diverless (remote) pipe pile and casing cutoff operations.

Improved-site foundation: Prior to production piling and shaft (caisson) construction, the riverbed was prepared by dredging. Several dredging stages and a graded 12-in. (30-cm) gravel base were specified. Quality control features included surveying specifications and requirements, using a flat-bottom dredging bucket to prevent gouging below final elevation, using a low-velocity suction pump to remove siltation without disturbing the gravel, and diver inspections to ensure siltation removal. Scour protection using specially graded limestone rocks was specified for given areas. Quality control features included laboratory materials testing, diver inspection prior to placement, and disallowing free-fall placement of stones.

New Orleans District. The Inner Harbor Navigation Canal (IHNC) Lock Replacement project will consist of float-in precast concrete elements resting on underwater pinned foundations. Prior to design and construction, a pile load test and installation study contract was awarded. The contract study included installation of nine 48-in. (1.2-m)-diam open-ended steel pipe piles driven to a 
maximum depth of $190 \mathrm{ft}(58 \mathrm{~m})$ below ground surface. Several innovative features for underwater foundation installation were addressed in this contract.

The technical specifications (U.S. Army Corps of Engineers 1999a) included these sections:

02355 Pile Load Test

02451 Steel Pipe Piles

02497 Dynamic Pile Testing

Contractor QC plans were required to address material delivery, storage, handling, installation, testing, and removal procedures. In addition to material specifications meeting American Society for Testing and Materials requirements, the API (1989) RP-2A-LRFD requirements were specified, and only one splice per pile was allowed. Provisions to monitor horizontal and vertical alignments and plumbness during underwater installation were included, with underwater alignment tolerances of 6 in. $(15 \mathrm{~cm})$ vertical, 6 in. $(15 \mathrm{~cm})$ horizontal, and within 1.5 percent of length (plumbness).

Only two of the nine pipe piles were specified to be driven underwater in the navigation channel, which is approximately $30 \mathrm{ft}(9 \mathrm{~m})$ deep. The remaining seven (onshore) piles were driven inside 6-ft (1.8-m)-diam steel casings in which the soil had been excavated and then backfilled with water to simulate underwater pile driving. All piles and casing were driven with submersible impact hydraulic hammers and/or submersible vibratory (electric or hydraulic) hammers (Figure 44). The piles were instrumented and analyzed using the Pile Driving

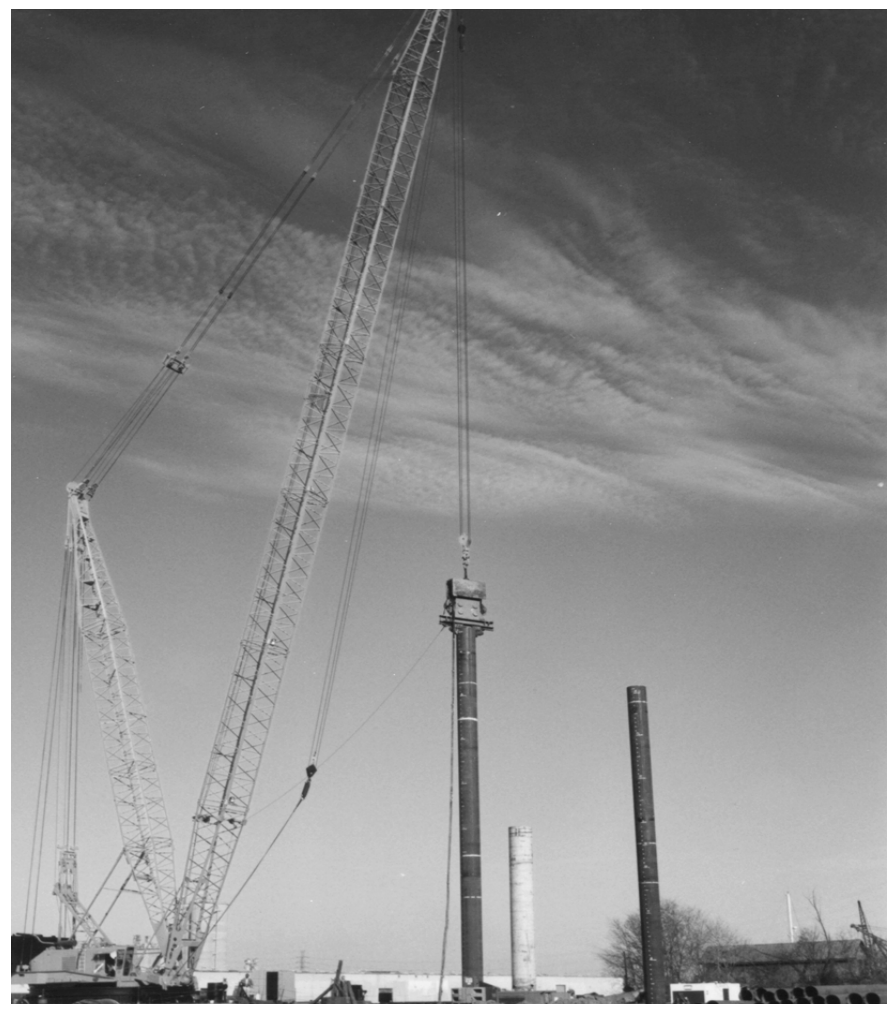

Figure 44. Pile driving with a submersible vibratory hammer, New Orleans IHNC pile test project Analyzer and CAPWAP dynamic load capacity packages.

Restriking and compression load tests were conducted on five of the onshore piles to determine ultimate pile capacity. Noise and vibration measurements (decibels and inches/second) were specified and taken at two locations during driving of the test piles onshore and underwater for comparison with background readings. Upon completion of the driving and testing, it was specified that the piles and casings were to be removed and the voids filled with a tremied cementbentonite-sand mixture. 


\section{Foundation Preparation and Construction}

\section{Quality Control and Quality Assurance Issues}

Quality assurance and verification on a Corps construction project is a Governmental function that consists primarily of maintaining assurance that the contractor has established and is properly executing the project Quality Control Plan. Verification comes from observing the contractor's adherence to the contract plans and specifications, and includes the contract submittal process, preconstruction meetings, visual inspections, and laboratory testing. The most functional quality assurance program is a reflection of a robust quality control program staffed by competent and experienced contractor personnel.

Numerous training courses are available to help field project personnel fulfill their quality assurance responsibilities. No Governmental training is currently available specifically for underwater foundation construction, but modifications to current training topics may be accomplished. Quality assurance representative's guides such as Engineer Pamphlet 415-1-261 (U.S. Army Corps of Engineers 1992) may also be modified to include underwater construction.

Until the Corps acquires a larger database of underwater construction projects, a successful quality assurance program will depend heavily on the constraints in the quality control clauses of the contractual plans and specifications and the degree to which the specialized contractors execute the quality assurance issues.

Inspection and testing requirements and procedures are highly dependent on the type of underwater foundation being constructed. The contract documents and specifications should cover the inspection and testing requirements during all four phases of underwater foundation construction, as described in the following paragraphs.

\section{Preconstruction phase}

After contract award, the preconstruction phase includes specific topics that should be satisfactorily specified, such as preconstruction conferences to establish details of the quality control system, project schedules, and methods for 
resolution of potential problems for each phase of the underwater foundation construction. Discussion of the specified and approved Installation Plan is conducted at this time. Topics that should be addressed include potential sitespecific problems, such as river (or water body) conditions, concurrent work by others, owner-furnished facilities, owner-furnished horizontal and vertical survey control markers, and coordination, sequencing, and safety issues. Inspection and testing topics should be discussed and understood by all parties to minimize misunderstandings and to reduce potential contract conflicts during construction.

\section{Construction phase}

Regardless of the foundation preparation method or the foundation type, a survey positioning system must be established and used throughout the underwater foundation construction phase.

Positional accuracy is required during all phases of the project, from riverbed improvement (including snag removal, dredging, backfill, compaction, leveling, and scour protection activities) to final acceptance. At all locations and during all phases of the construction, three-dimensional (3-D) boundary locations and tolerances must be verified. Floating platforms and supporting items such as drill rigs, pile-driving rigs, and batch plants must be accurately positioned over the foundation site. Mooring with anchor lines or dynamic positioning (propellercontrolled) methods are required to position floating plants and control their locations. The foundation system must be three-dimensionally located and positioned within specified tolerances. Cutoffs, top of surface, and final tip elevations of each foundation element must be accurately measured and recorded. Adequate control measures are required to monitor and control element alignment and plumbness.

Drilled foundations (piles and caissons), especially those that require cast-inplace concrete, require a higher degree of inspection and monitoring because of the high potential for development of unforeseen problems. For drilled foundations, a number of inspection and testing items are important (Greer and Gardner 1986). Items to be considered are listed below and discussed in the following paragraphs.

Cuttings control and disposal

Hole bottom cleanout and stabilization

Subterranean water

Borehole integrity

Proof testing

Reinforcing cage placement

Concrete placement

Load testing

Although the objectives are similar, the inspection and testing of underwater drilled foundations require modification of in-the-dry techniques. Once the uncased borehole has been drilled and cuttings have been properly disposed, a cleanout inspection must be conducted to ensure that the bearing stratum is sound 
and that the hole is stable. A determination and location of subterranean water such as artesian aquifers must be determined during the site investigation phase as their presence may cause stability problems within the boreholes, which may preclude any uncased cast-in-place concrete.

Remote video monitoring for inspecting the finished borehole is possible if the water is not turbid, or divers may be required to monitor the borehole integrity if allowed in the safety plan. If the borehole is in irregularly weathered rock formations, extra attention should be given to proof testing. Proof testing can be performed by drilling a small-diameter exploratory hole through the bottom of the borehole and noting the advance rate for the purpose of detecting subbottom voids. A probe rod may be jiggled in the exploratory hole to allow detection of sidewall fissures and voids.

The reinforcing cage must be placed with proper alignment and plumbness. Concrete placement requires detailed inspection and testing procedures. Load testing of the completed foundation allows for a comparison of the design and actual strength capacities. Although full-scale load testing is time consuming and expensive, the use of an Osterberg cell may be a less expensive option and would permit the drilled shaft to be placed into service upon completion of the testing (Osterberg 1998).

For driven-pile foundations, Fleming et al. (1992) identified a number of inspection and testing items. A discussion of each is presented in the following paragraphs.

Quality of pile materials and connectors

Damage during driving

Pile heave

Ground vibration and movement

Subterranean water

Workmanship and materials during installation

Load testing

Although quality control during fabrication is a separate issue, the piling must be inspected for material defects upon arriving at the jobsite. The piling and associated connectors must also be protected from damage from the time they are offloaded onto the jobsite until they have been installed in the ground. Selection of the proper hammer not only involves matching the required load capacity, soil conditions, and piling properties to the hammer, but also includes a requirement to minimize excessive stresses during driving, to prevent damage to the piling by overdriving.

Driving through saturated clays or dense sands may cause pile heave, which is usually of more concern than ground heave, which is caused by soil compaction and consolidation during driving. The potential effects of ground movement on adjacent structures should be considered and addressed during the design phase. Subterranean water such as artesian aquifers may cause problems due to high pore-water pressures if the aquifer is not discovered during the site investigation phase. 
All materials, methods, and workmanship on piles requiring additions or modifications during installation, such as grouting, concrete, and welding, must be properly inspected and tested according to applicable codes and standards. Pile load testing during construction may be conducted to permit an assessment of the actual factors of safety (designed capacity/actual capacity). Complete and comprehensive records of the testing setup, procedures, calibrations, adjustments, results, and interpretations are required.

\section{Acceptance phase}

Once the foundation system has been constructed, additional inspection and testing should be performed to confirm its acceptance as a finished product. The acceptance phase may be separate or may be conducted during the construction phase, depending on the foundation system. Materials testing conducted during the construction phase may not be finalized until construction is complete (that is, concrete strength tests).

Integrity testing of the completed or installed foundation should be required, and is discussed later in this chapter (see section "Underwater Foundation Testing"). Improved-site integrity testing typically consists of conducting a postconstruction site investigation, which has essentially the same purpose as the preconstruction site investigation.

Gravity-based and pinned foundation integrity testing requires evaluation of the foundation elements (concrete, grout, steel piles, reinforcing, etc.) using standardized material testing methods. The most common integrity testing methods use nondestructive techniques (NDT). For nearly all NDT small-strain integrity testing methods, low-energy ultrasonic pulses or acoustic (sonic) waves are transmitted through the pile materials (concrete, wood, steel, etc.) (Davis and Hertlein 1991).

\section{Postconstruction monitoring phase}

After construction has been completed, ongoing inspection and monitoring activities may be continued. These functions may or may not be regulated, depending on the needs of the owner or operator. The Corps requires periodic inspection activities of its civil works structures during their operation and maintenance phase (Department of the Army 1995). Offshore U.S. structure inspections are regulated by the U.S. Geological Survey and the U.S. Coast Guard.

Rules and guidance are also given by the American Petroleum Institute (API) and the American Bureau of Shipping. European agencies such as the U.K. Department of Energy, Det Norske Veritas, and Lloyd's regulate offshore structure inspections outside the United States (Stern and Alia 1980).

The rules and regulations do not place emphasis solely on the structure's foundation. Focus is instead directed to detecting any changes in the overall 
structural integrity. To the extent that any loss of structural integrity is due to foundation problems, foundation monitoring may then become a critical component of the inspection process. An important aspect of foundation monitoring is evaluating the foundation material integrity, including steel corrosion, steel weld quality, concrete cracks, concrete spalling, soil scouring, etc. It may also be important to evaluate the foundation performance in terms of settlement, inclination, stability, etc. Unique foundations such as suction caissons, which depend on active pore pressure monitoring, may require a special instrumentation and evaluation process (Tjelta 1993; Stock, Jardine, and McIntosh 1993).

Various tools and equipment are available for conducting foundation inspections. Remote visual monitoring may be accomplished with remotely operated vehicle systems (ROVs) or autonomous underwater vehicles similar to those used for underwater site investigations. Diver-equipped tools are also available for material integrity evaluations, including high-pressure waterjets for cleaning steel and concrete and hand-held equipment for inspecting concrete and steel components (Smith 1987).

\section{Foundation Installation and Testing}

A variety of installation procedures and equipment exists for installation of underwater foundations. Testing procedures and equipment are required to validate the foundation design and to ensure foundation integrity.

\section{Improved-site foundations}

Improved-site foundations include those that are modified to increase strength, reduce settlement, and improve stability of the soil or rock. Physical, mechanical, hydraulic, and chemical methods are available to achieve these modification objectives (Hausmann 1990). Physical modification includes excavation, backfilling, and leveling operations. Mechanical methods generally include vibratory compaction, confinement, inclusions, and geotextile reinforcement. Hydraulic methods include the use of vertical and horizontal drainage systems. Chemical modification involves deep cement mixing.

\section{Physical modification.}

Excavation and dredging. Both terms relate to the removal of undesirable soil or rock materials and are often used interchangeably. Excavation generally implies a smaller operation, such as removing soil inside a cofferdam. Dredging implies a larger area operation and is usually required during installation of improved-site foundations and gravity-based foundations. Reasons for excavation and dredging include removing unsuitable materials such as loose/weathered rock or mud overburden, cutting specified depths and slopes in competent materials, retrieving bulk samples, and cleaning (removing) soft bottom 
(sediment) materials after dredging or backfilling operations have been completed (Johnson, Compton, and Ling 1972).

Dredging to remove overlying soft materials may be accomplished using airlifts, suction (hydraulic) dredges, or specialized trenching equipment. Dredging firmer materials may be accomplished using clamshell (orange-peel) draglines (Figure 45) or bucket (dipper) dredges in shallower water. Deepwater dredging is done with continuous dragline, cable with attached cutters, ocean dredging vessels (suction hydraulic or hopper with cutterheads), or ROVs. Explosives are used to remove pinnacles and boulders, and drilling/blasting operations are performed in rocky areas (Gerwick 1974). Harris (1942), Tate (1961), Millard and Hassani (1971), Johnson, Compton, and Ling (1972), and Loeken (1980) describe dredging operations on numerous projects, including the Navy's drydock projects, New York's Yonkers sewage treatment plant, San Francisco's marine terminal, Hong Kong's Plover Cove Dam, Ghana's Akosombo Dam, and offshore borrow areas.

Large-scale dredging and backfilling operations may use oceangoing vessels. Large ocean going trailing suction hopper dredges have been specially designed for removing and backfilling bottom materials

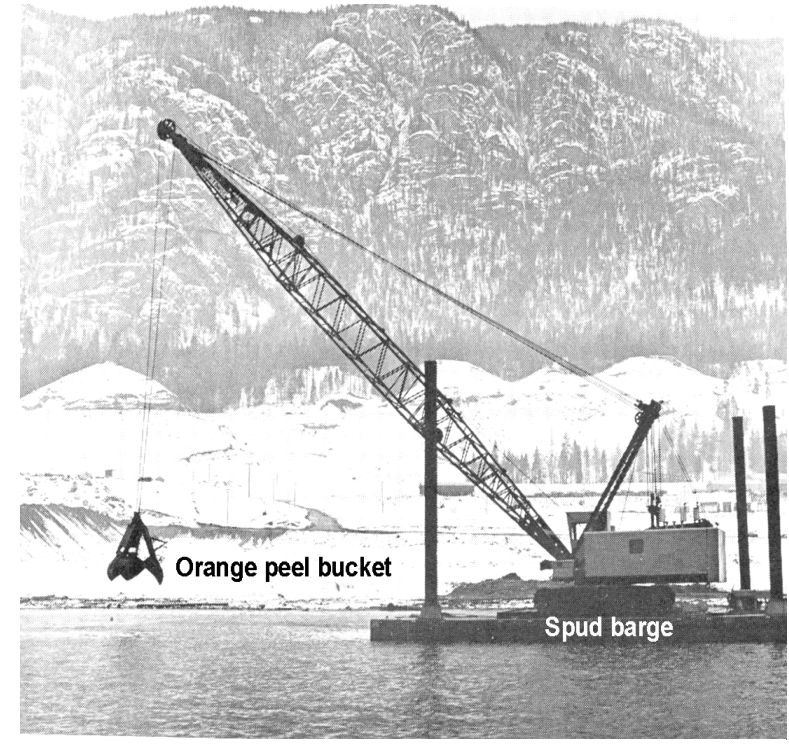

Figure 45. Clamshell excavation and soil sampling in the Columbia River (after Bazett and Foxall 1972) at depths to $430 \mathrm{ft}(130 \mathrm{~m})$. These dredges pump slurried bottom material into vessel hoppers via suction pipes connecting the bottom-trailing dragheads to the vessel's main dredge pumps. The dredge then transports the material to the disposal location, where the hopper load is discharged for placement of underwater fill or is wasted. Currently, the world's largest trailing suction hopper dredger is Belgian Jan De Nul's with 39,200-cu ft (30,000-cu m) hopper capacity (Dredging and Port Construction 1999). Smaller dredges are available for dredging near-offshore and inland rivers to depths necessary for maintaining navigation, usually less than $50 \mathrm{ft}(15 \mathrm{~m})$. Submerged dredging platforms allow access to deeper locations, and are typically used offshore. One Netherlands company has developed an ROV capable of dredging to depths of 3,300 ft $(1,000 \mathrm{~m})$, as illustrated in Figure 46 (Van Oord 1999). Specialized subsea ROV trenchers for pipeline burial are also available (Rushfeldt 1981, Dansette and Robertson 1994).

Positional accuracy for dredging operations has been improving thanks to modern sensor technology and global positioning system (GPS). One example is Prolec's "Digmaster" indication system from the United Kingdom. With its sensors mounted on a bucket (dipper) dredge, the operator can visually monitor in real time where the bucket is, and dredging tolerances to 2 in. $(5 \mathrm{~cm})$ are 


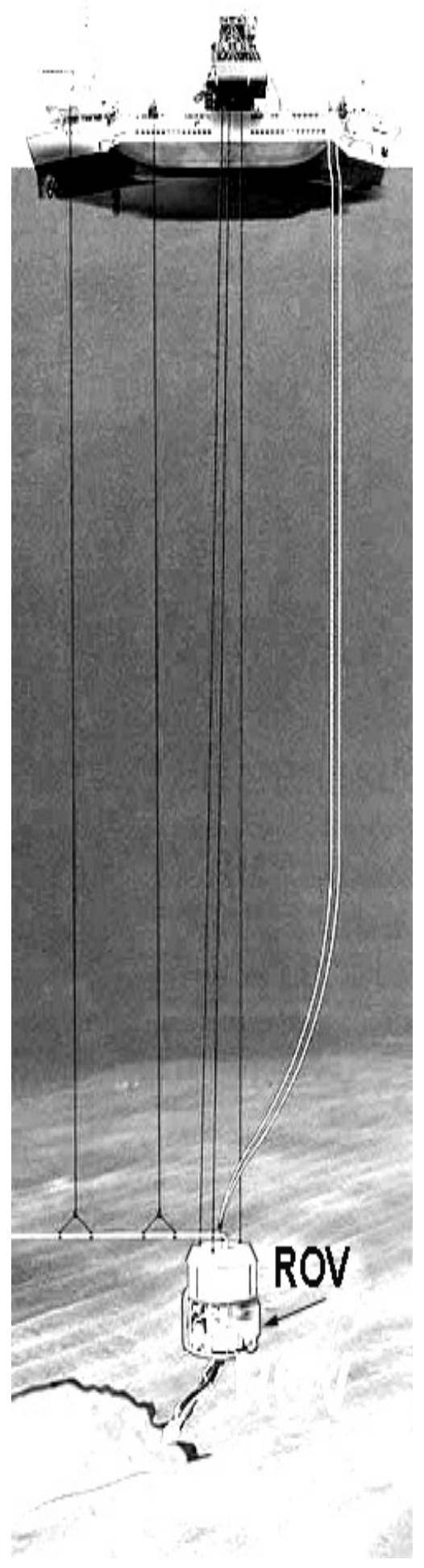

Figure 46. Deep-sea dredging operation possible when dredging at depths to $60 \mathrm{ft}(18 \mathrm{~m})$. Tidal and current fluctuations are automatically taken into account. Prior to the development of this technology, the dredging operator relied on boom markers and hand soundings (World Dredging, Mining, and Construction 1999).

Small quantities of material are removed by mechanical ejectors operated locally by divers or remotely from a work barge. Mechanical ejectors (also called "air lifts") operate using compressed air and water (Figure 47). They work by loosening the material at the base of the excavated area, mixing it with the lighter air bubbles, and discharging it to the surface.

Ejectors do not work well in soft clays or clayey silts as they merely form a hole at the base of the excavated area and extra work is required to slump these materials toward the ejector (Tomlinson 1994). Air lift methods were used on the Thames River flood barrier caissons to remove sediments and excavate chalk that adhered to the cofferdam sheet piles and walers.

Explosives were placed by divers to dislodge the chalk deposits prior to excavation (Gilbert and Horner 1984). A 10-in. (25-cm)-diam airlift operated with a 1,000-cfm (30-cu $\mathrm{m} / \mathrm{min}$ ) air compressor successfully cleared boulder intrusions in rock sockets $100 \mathrm{ft}(30 \mathrm{~m})$ underwater at Bantry Bay (Fox 1970).

Underwater air bubblers were used during underwater backfill operations to prevent "density currents" of suspended fines that flowed upstream and downstream on the river bottom during construction of the submerged foundation for a dam in British Columbia (Bazett and Foxall 1972).

Fill placement. After the unsuitable material has been removed, the site may be further improved by backfilling, leveling, and in situ densification (e.g., soil strengthening).

There are numerous case histories and examples of underwater improved-site foundations using various equipment and methods that can be obtained for additional details.

Underwater fill placement (also called backfill placement if previously dredged or excavated) can be accomplished using several methods (Johnson, Compton, and Ling 1972; Bazett and Foxall 1972; Loeken 1980; Mitchell and McRae 1985; DOSBOUW 1987), as described below. 
Methods for underwater fill placement include:

a. Land-edge dumping by bulldozer, backhoe, or clamshell bucket

b. Placement from deck scow (barge) with buckets or dozer

c. Hydraulic slurry mix pumping or jetting

d. Dumping by bottom-dump scow or vessel

e. Fall-pipe placement

When selecting the optimal method, numerous variables must be considered, including project size, water depth, material type (gradation), final slope requirements, current velocity, environmental considerations, borrow material location, and economic costs.

Figure 48 shows an example of the backfill material gradation curves selected for an underwater pipeline project.

Bottom-dumping scows require a minimum depth of about $15 \mathrm{ft}(5 \mathrm{~m})$ because of scow and tug drafts and propeller disturbance. Material placement is relatively fast, and flat slopes are usually obtained (unless retained). At the Southern Pacific Railroad crossing of the Great Salt Lake, bottom-scow placement of a wellgraded silty sand achieved slopes

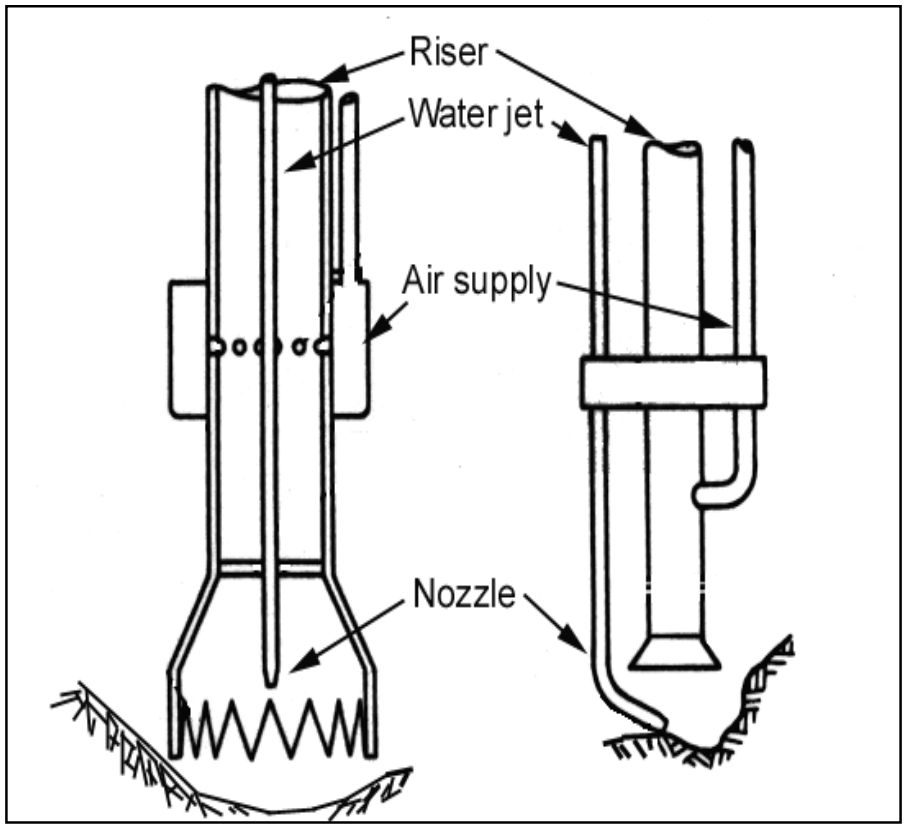

Figure 47. Two types of underwater ejectors (after Tomlinson 1994)

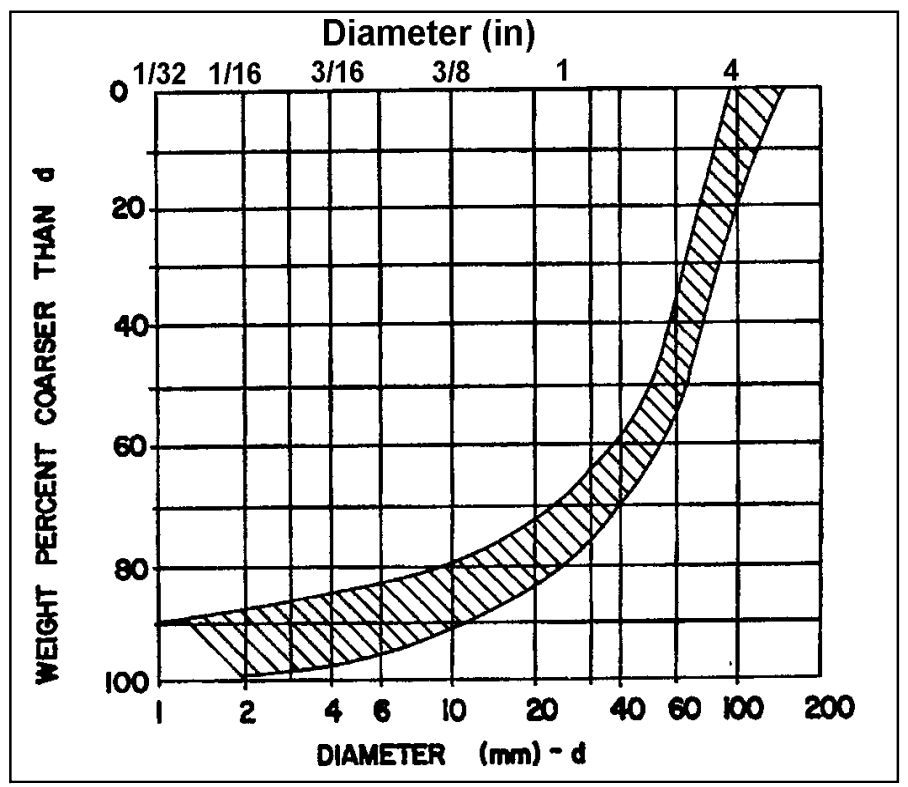

Figure 48. Graduation curve for underwater pipeline stable backfill material inversely proportional to the water depth. Maximum slopes (1:2) were achieved at shallower depths but tapered off to 1:10 slopes at 40-ft (12-m) depths (Johnson, Compton, and Ling 1972). Bottom-scow placement of glacial till material at the Hugh Keenleyside Dam project caused segregation and loss of fines, requiring design changes. Initially, dumping was restricted to river currents 
less than $2 \mathrm{ft} / \mathrm{sec}(0.6 \mathrm{~m} / \mathrm{sec})$ to avoid loss of fines. However, it was determined that suspended fines flowed upstream along the riverbed bottom, and turbidity increased at this low velocity. To help alleviate the problem, dumping in river currents up to $4 \mathrm{ft} / \mathrm{sec}(1.2 \mathrm{~m} / \mathrm{sec})$ was allowed, and underwater dykes were installed (Bazett and Foxall 1972). Materials containing entrapped air and dumped suddenly from bottom-dump scows appear to liquefy as the material hits the bottom. For example, Johnson, Compton, and Ling (1972) observed a rapid bottom-dumped sand spreading horizontally at a rate of $20 \mathrm{ft} / \mathrm{sec}(6 \mathrm{~m} / \mathrm{sec})$.

Deck scows are usable in shallower water and enable steeper backfilled side slopes. Tate (1961) reported that slopes of 1:2 were obtained by hydraulic jetting of well-graded material ( 3 in. down to a maximum of 10 percent finer than the No. 100 sieve) from a deck scow. Johnson, Compton, and Ling (1972) reported the placement of rock by clamshell bucket off a deck scow at the Hong Kong Plover Dam site. The bucket was opened just above the bottom to minimize segregation. Pore-pressure measurements were monitored and indicated a period of 2 months was required for dissipation of pore pressures in the fill materials.

Underwater hydraulic fill placement may cause coarser materials to drop out first, which could lead to unstable slopes. Experiments by Mitchell and McRae (1985) determined that slurry-pipeline placement of sand obtained lower densities that those achieved with bottom-dumping hopper dredge systems. Placing the sand in "layers" and compacting with a special air gun achieved relative density increases up to 80 percent. Without underwater compaction efforts, the relative densities of the sand ranged erratically from about 10 to 70 percent (Johnson, Compton, and Ling 1972). Stewart, Jefferies, and Goldby (1983) reported that the average relative density (without compaction) for a uniform sand ( $\mathrm{D}_{50}$ approximately $0.28 \mathrm{~mm}$ and fines less than 5 percent) placed underwater was about 40 percent.

Underfilling of structures such as immersed tube tunnels and offshore gravity-based structures has been accomplished using hydraulic fill variations. Typically, a mixture of sand and water is pumped between the structure bottom and its supports to (a) provide a good structure/seabed contact and (b) to create a uniform distribution of contact stresses. For offshore structures, a grout mixture is typically used instead of a sand slurry, although a sand slurry underfill enables easier remobilization of the structure. Sand slurry underfill has been used frequently in the Beaufort Sea mobile oil drilling platforms (Buslov et al. 1984).

The fall-pipe placement method generally allows precision placement of coarse materials to deeper depths with minimum segregation. Offshore precision fill placement equipment currently consists of the fall-pipe method used by offshore dredging companies such as Tideway BV, HAM, Ballast Needam, and Boskalis. One earlier project (during the 1970s) that used two types of fall-pipe systems was a North Sea pipeline backfilling operation. A fine sand layer was covered by a gravel layer (4-in. or 10-cm maximum particle size). The materials were placed in water with bottom currents up to $8 \mathrm{ft} / \mathrm{sec}(2.5 \mathrm{~m} / \mathrm{sec})$ at depths up to $230 \mathrm{ft}(70 \mathrm{~m})$. One fall-pipe system had remotely controlled electrohydraulic thruster units attached for accurate placement of the conveyed gravel. The other system pumped hydraulic fill (sand and gravel) through the fall-pipe. The 
positioning of the fall-pipe was accomplished using an underwater acoustic referencing system (Loeken 1980). Stewart, Jefferies, and Goldby (1983) reported another project in which a modified drag arm on a trailing suction hopper dredge was used to discharge a sand slurry $8 \mathrm{ft}(2.5 \mathrm{~m})$ past the arm end to the deposition point. Average slopes of 1:5 were placed in 100-ft $(30-\mathrm{m})$ water depths. Smith (1962) reported that a 2-ft (0.6-m)-diam steel fall-pipe was used to place gravel (8-in. or 20-cm maximum size) at the base of a Mississippi River dam.

Leveling. If the superstructure is founded on an improved-site or gravitybased foundation, the bottom must be leveled to specified tolerances after dredging and/or backfilling. Typical out-of-level tolerances were described by Gerwick (1974) as being about 2 in. $(5 \mathrm{~cm})$ on hard bottoms to 12 in. $(30 \mathrm{~cm})$ on softer bottoms (sand and silt). Gerwick also stated that most leveling sequences include the following steps:

a. Placement of a crushed rock base (similar to the fill placement noted above). A well-graded crushed (not natural gravel) rock base course can be placed by barge bottom-dumping (effective only to about $100-\mathrm{ft}$ (30-m) depths), through a fall-pipe, or lowered in buckets. Natural gravel is not desirable due to its tendency to displace laterally (slide) under load. Typical rock base courses use a maximum aggregate size of about 6 in. $(15 \mathrm{~cm})$.

b. Placement of a "screed course" on top of the rock base. If desired, a smaller layer up to 40-in. (1-m) thickness with maximum aggregate size of 3 in. $(7.5 \mathrm{~cm})$ can be placed on top of the rock base to enable more accurate screeding (of the smaller particle sizes). Typically, the screed course is placed using a tremie pipe (fall-pipe).

c. Level (screed) the aggregate. Many types of screeding devices have been used on various underwater projects. All are designed to provide stable methods for leveling within the specified tolerances. The historical method employed for shallow-water depths used a heavy steel beam that was dragged across the bottom from a surface platform. Other devices are manually operated underwater and require divers. Self-leveling frames with remotely controlled positioning devices are used in deeper water.

Dredging equipment has also been used to provide leveling and trimming of the base course. Boskalis (1999) developed a multipurpose pontoon system ("Scradeway"), which allowed multimillimeter accuracy for placing, leveling, and trimming the gravel bed prior to sinking the Oresund's immersed tube tunnel elements.

Mechanical modification. Mechanical modification by vibrocompaction increases the relative density of granular deposits. To accomplish this increase in density, the vibrating energy is used to rearrange (and density) the soil structure. The vibrating energy is transferred to the soil via a shaft attached to a floating platform system. Typically, inside the shaft is a hydraulic motor driving an 
eccentric (off-centered) mechanism that vibrates due to its eccentricity. The remainder of the shaft is isolated to prevent vibrations beyond the shaft tip. Water may be jetted through the shaft tip to enhance soil consolidation and shaft penetration (vibroflotation). Vibroflotation has been successfully used for increasing the bearing capacity of previously submerged cohesionless materials.

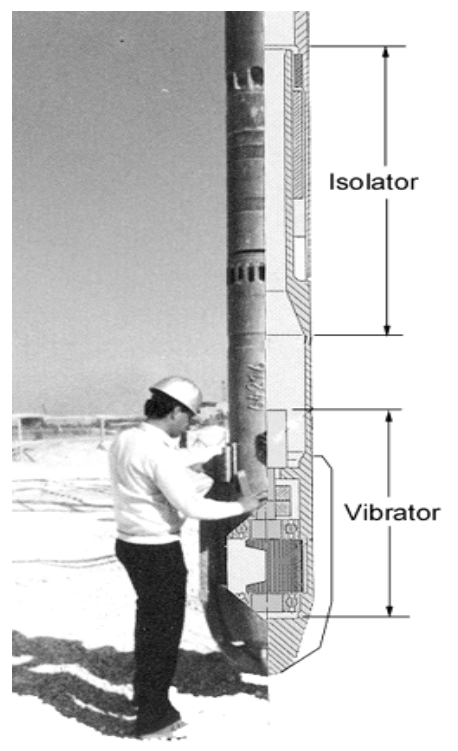

Figure 49. Vibratory compactor (after Bauer, Inc. 1994)

Examples include the underwater placement (but subsequently dewatered) fills such as Wanapum Dam (Engstrom 1963) and Bremerton drydocks (Tate 1961). Vibratory compaction using pipe piles was performed on dewatered fill near Baltimore (Millard and Hassani 1971). Figure 49 shows a vibratory compaction probe. Figure 50 shows a specialty pontoon containing four similar vibratory compaction probes.

Several worldwide contractors use specialized equipment for mechanical modification.

Vibrocompaction equipment may be specified simply to achieve vibratory compaction, or it may be combined with other proprietary systems to construct pinned foundations without soil excavation.

Underwater stone columns have been placed for the purpose of increasing the soil's shear strength and bulk modulus. Pennine, Ltd., (1998) reported the installation of $2.6-\mathrm{ft}(0.8-\mathrm{m})$-diam by $66-\mathrm{ft}(20-\mathrm{m})$-long stone columns in water depths up to $108 \mathrm{ft}(33 \mathrm{~m})$ from a floating barge using vibrocompaction, as illustrated in Figure 51 . The productivity rate was greater than one column per hour, including barge positioning.

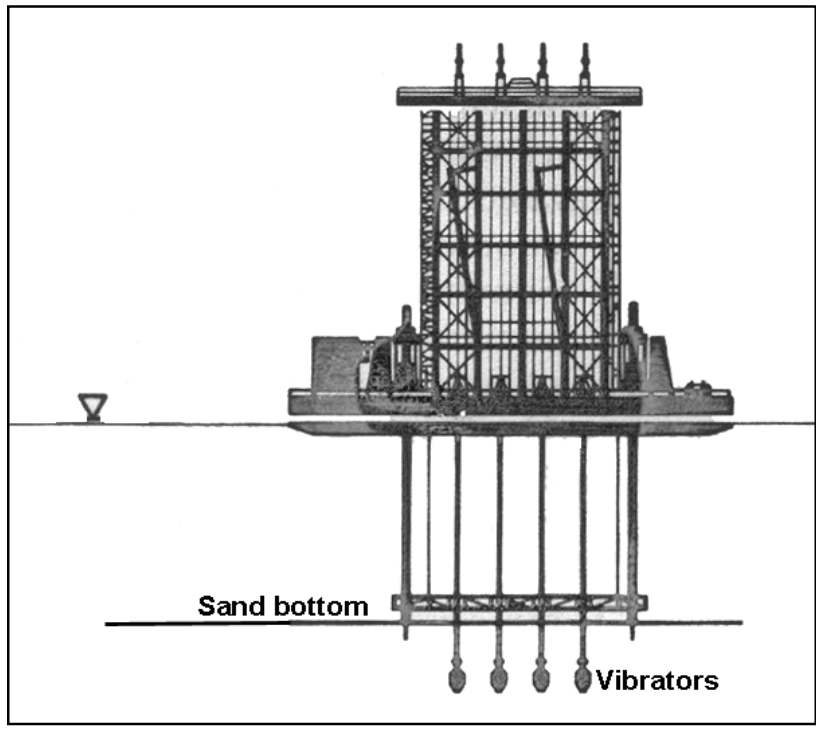

Figure 50. Vibratory compaction pontoon Mytilus used in the Eastern Scheldt project (after DOSBOUW 1987)
Hayward Baker (1999b) reported the installation of 270 stone columns (3-ft (1-m)-diam) using a vibroreplacement method through water depths up to $40 \mathrm{ft}(12 \mathrm{~m})$ to prevent liquefaction damage to existing underwater piles at a Vancouver port facility.

According to Stewart, Jefferies, and Goldby (1983), underwater selfconsolidation of cohesive material (natural or backfilled) is not typically used because of (a) monitoring instrumentation limitations, (b) insufficient experience, especially with hydraulic fill/clay separation, and (c) limited large-scale experience relying on consolidation for strength gain. 
Another mechanical modification technique consists of overlying the soil with prefabricated blankets, mats, or geotextile reinforcement.

Typically, the overlays are constructed of steel, concrete, graded soil materials (sand, fine gravel, and coarse gravel), or synthetic fabrics. The purpose of the blankets is to reduce the induced bearing pressure on the subsoil and to prevent erosion of the subsoil beneath the mat. Prefabricated mats were used extensively in the Eastern Scheldt project (DOSBOUW 1987).

Specialized mat-sinking equipment barges (Figure 52) were required during this operation. Immediately prior to placing the mats, the sand bottom was redredged to remove any silt sedimentation. Bottom compaction was then accomplished with four ICE-815 underwater vibratory hammers each mounted on a perforated 13 - by $13-\mathrm{ft}$ (4- by 4-m) steel plate and dragged in tandem fashion across the dredged surface (Jonker 1987). The prefabricated mats were then placed over the

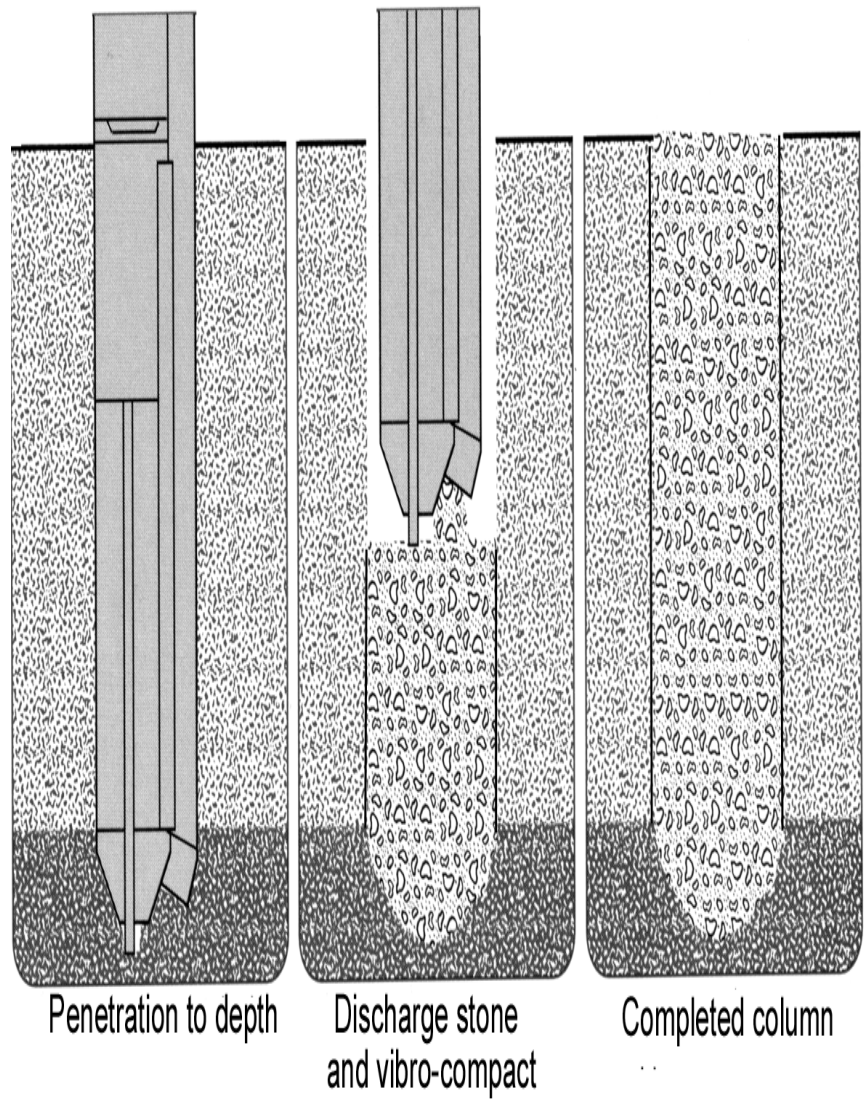

Figure 51. Vibratory stone column installation (after Pennine, Ltd., 1998) vibrocompacted sand.

Abbott and George (1989) selected steel reinforcement meshes for their improved-site foundation. Flat galvanized steel strips were placed 9 in. $(23 \mathrm{~cm})$ on center and covered with granular backfill. Specialized methods were required for the underwater placement of the reinforcement. Onshore reinforced earth applications allowed the reinforcement mesh steel strips to be singularly placed, but underwater installation required a mat arrangement that was constructed onshore and then lowered into the water as a complete mesh mat. Granular backfill (angular coarse to medium sand and gravel) was placed on the mat arrangement.

Steel mudmats have been used offshore to increase the bearing capacity of soft bottom materials and are frequently attached to the base of jacket structures. The thin (typically less than 0.5 -in. or $1.5-\mathrm{cm}$ ) mudmats provide stability and tipover resistance after jacket setdown and prior to pinned foundation installation. Improvements to resist lateral sliding include perimeter skirts and interior ribs. Digre et al. (1989) discussed design details for the Bullwinkle platform skirted mudmats. Lieng and Bjorgen (1995) discussed a release system for mudmats on a Heidrun platform subsea structure. 


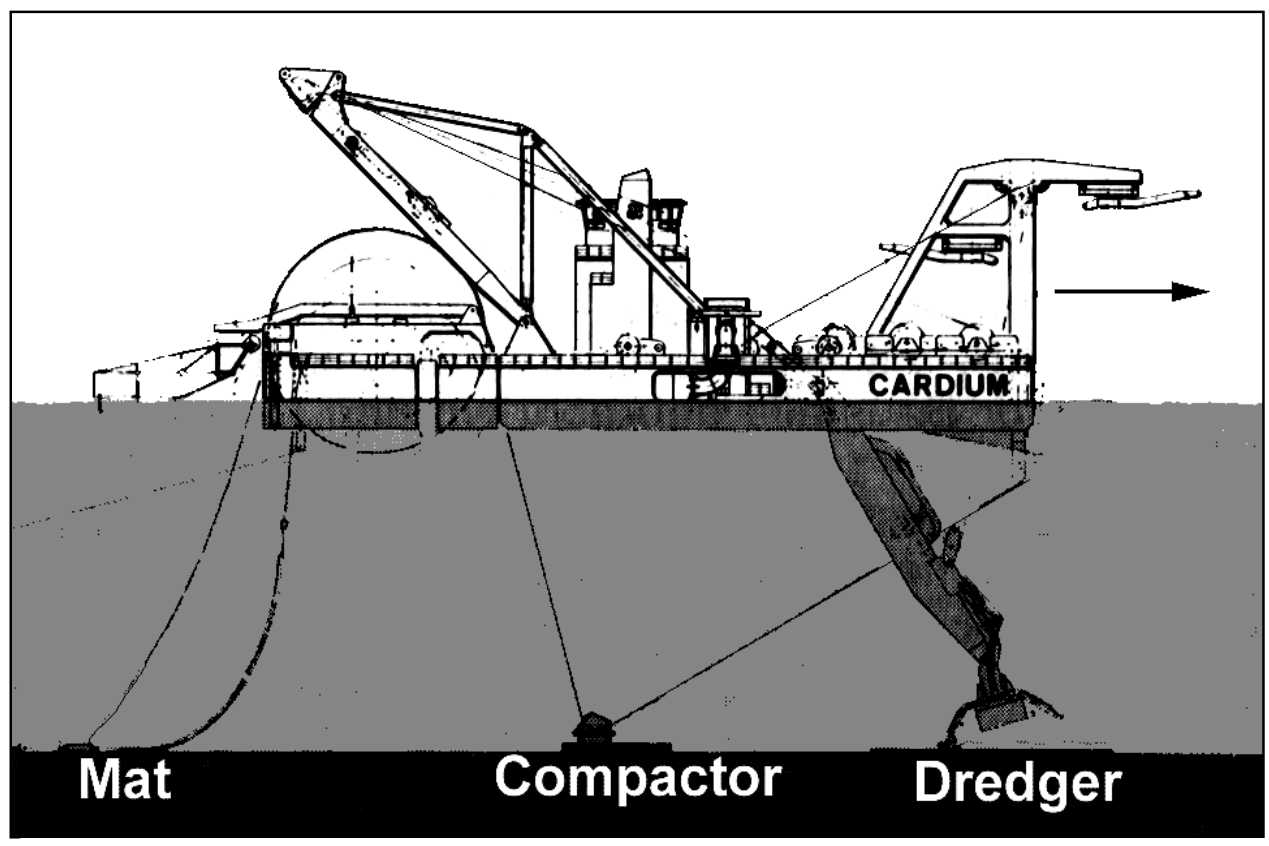

Figure 52. Eastern Scheldt mat-sinking pontoon (after DOSBOUW 1987)

Hydraulic modification. Hydraulic methods use vertical or horizontal drainage systems to remove excess pore fluid from the soil matrix. Vertical drainage systems (wick drains) require a surcharge or overpressure method for generating excess pore-water pressure. Several proprietary wick drain systems are available, including those from the Bauer, Geotechnics America, and American Wick Drain Corporations. Horizontal drains require a vacuum (underpressure) source to remove excess pore-water pressure. For horizontal drains, it is critical that leakage from the overlying water body not be permitted. Water drained as a result of the underpressure method is pumped away from the site (Aerts, Devlieger, and Vandycke 1999).

Chemical modification. Offshore chemical soil modification with deep cement mixing has been successfully used in Japan and the Arctic oil region for several years. It was developed in the United States in 1951 by the U.S. Navy, but was discontinued in the United States for economic reasons (Halebsky and Wetmore 1986). It has been demonstrated to improve soft soil unconfined compressive strengths by up to 700 percent.

Deep cement mixing barge-mounted systems (similar to a system illustrated in Figure 53) have been operated in water depths to $230 \mathrm{ft}(70 \mathrm{~m})$ for mixing soil $165 \mathrm{ft}(50 \mathrm{~m})$ below the mudline. The process consists of pumping cement slurry under pressure into the seabed followed by in situ soil mixing. Each mixer can improve a soil area up to $62 \mathrm{sq} \mathrm{ft}(6 \mathrm{sq} \mathrm{m})$ per penetration. Normal slurry mix is a 0.6 water-cement ratio. Typical cement concentration is about 10 to 20 percent, which is approximately 10 to $20 \mathrm{lb}$ of cement per $100 \mathrm{lb}$ of dry soil (Halebsky and Wetmore 1986). 
Underwater grouting using a barge-mounted drill was described by Hayward Baker (1999b). A 3-in. (7-cm)-diam grout pipe was advanced below a sanitary sewer tunnel under a pond. Compaction grouting strengthened the soft organic soil, allowing tunneling to be completed using a tunnel boring machine.

Quality control. Quality control and quality assurance (QC/QC) testing is conducted to determine the adherence to design requirements, as stated in the contract specifications. For the improved-site foundation, the testing basically consists of comparing the before, during, and after construction conditions

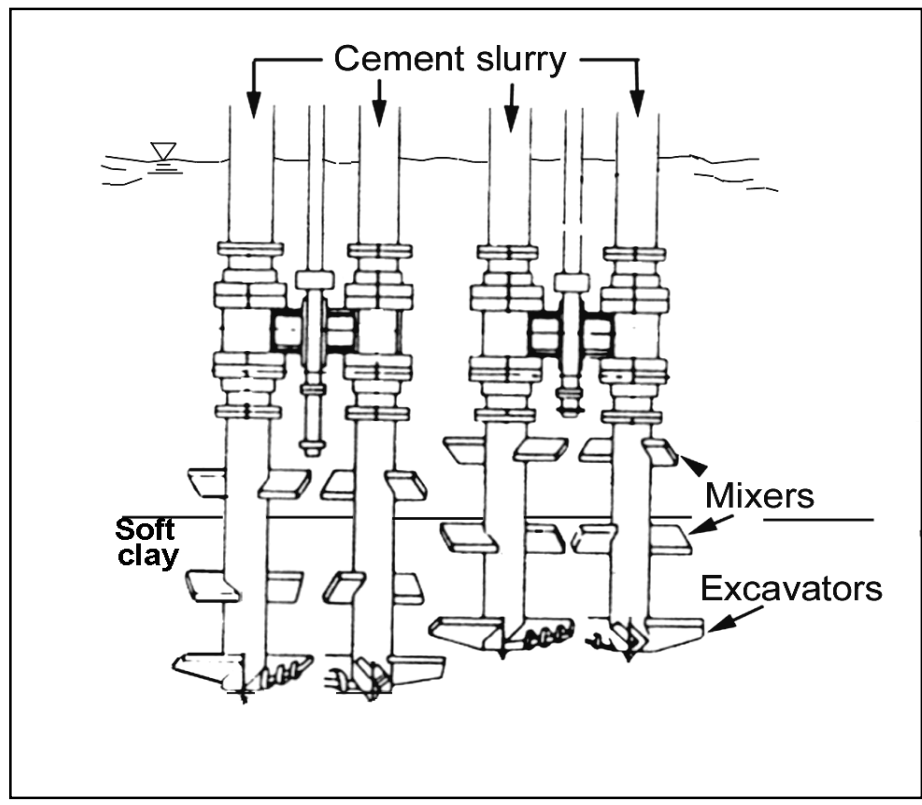

Figure 53. Deep cement mixing system (after Halebsky and Wetmore 1986) to determine if the specified improvements were achieved.

Quality control during dredging for improved-site foundations includes (a) material inspections, (b) surveying for depth, distance, and volume measurements, and (c) postdredging cleanup of any remaining soft sediments (Johnson, Compton, and Ling 1972). Material inspections include bottom examinations by divers or remote monitoring, visual observations of the dredged materials, sampling of the bottom materials and/or the dredged materials, and testing. Site positional control is accomplished by hydrographic surveying methods and is a prerequisite for foundation construction. Ensuring that dimensional tolerances for volumetric quantities, areal extent, and cut slopes are not exceeded is one function of the QC/QA process. It is economically important that accurate surveys are conducted to establish the lateral dredging boundaries and that material inspections are conducted to define the depth of cut, when unsuitable materials are being removed (Johnson, Compton, and Ling 1972). Stewart, Jefferies, and Goldby (1983) discuss quality control methods for dredging operations conducted to remove unsuitable material, including core sampling of the dredged material inside the hoppers.

Postdredging cleanup of remaining soft sediments is a critical element that should always be expected and performed. Inspection by divers or sampling should be conducted to determine the presence and extent of remaining or redeposited sediments (Johnson, Compton, and Ling 1972).

Quality control considerations during fill placement and leveling operations are similar to those for dredging operations. Material inspections and surveying are required to ensure that the proper materials are being deposited at the correct location and are being placed according to specified thickness and side slopes. 
The unforeseen presence of fines (namely, silts) in cohesionless fill materials causes quality control problems and was discussed by Johnson, Compton, and Ling (1972), Bazett and Foxall (1972), Stewart, Jefferies, and Goldby (1983), Buslov et al. (1984), Mitchell and McRae (1985), and Jonker (1987). The loss of fines in cohesive fill materials and corrective measures to control it was discussed by Bazett and Foxall (1972).

Integrity and/or performance tests are necessary to ensure that specified engineering properties such as shear strength and relative density have been met. These should be conducted during and after the fill placement or site modifications, and may include in situ tests and sampling operations. In situ tests include SPT, CPT, PMT, vane shear, and geophysical techniques. Sampling can be accomplished by bucket, probe, cores, or other equipment. Bazett and Foxall (1972), Stewart, Jefferies, and Goldby (1983), Mitchell and McRae (1985), and Jonkers (1987) discussed density measurements and control. Bazett and Foxall (1972), Johnson, Compton, and Ling (1972), and Buslov et al. (1984) discussed aspects of sampling and testing cohesive materials. Figure 54 illustrates the use of the CPT as a measure of in situ density for quality control during construction of the Eastern Scheldt project.

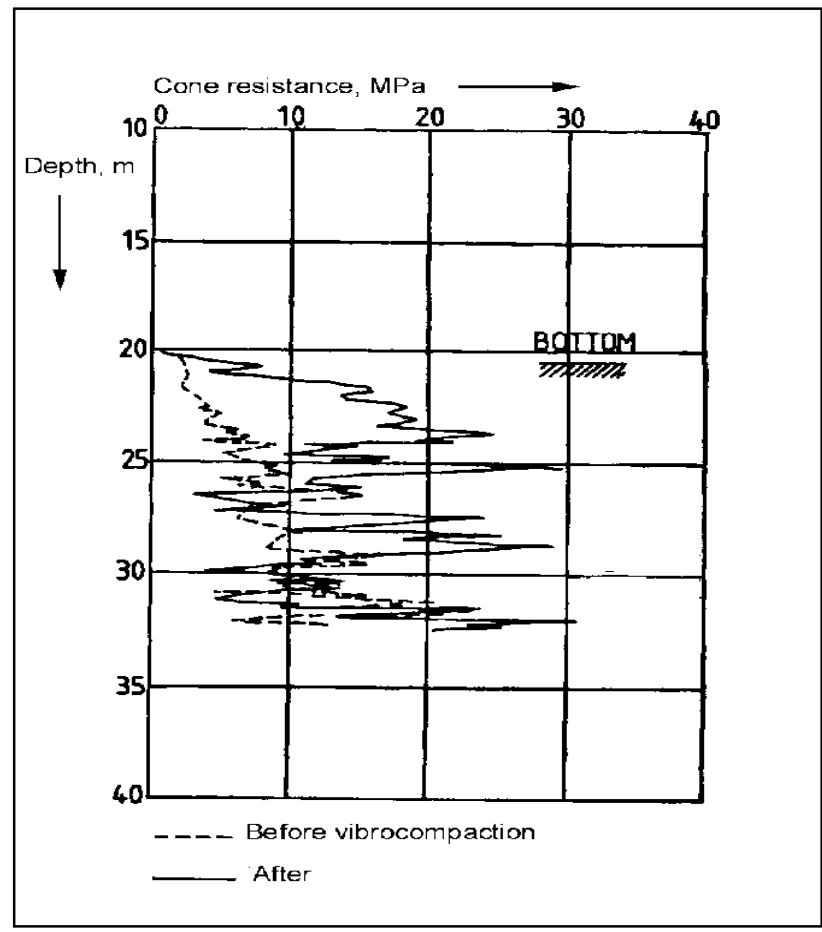

Figure 54. Eastern Scheldt, CPT results-before and after vibrocompaction (after Jonker 1987)

\section{Gravity-based foundations}

Since most gravity-based foundations are floated or lifted in, the installation procedures include towing and positioning concerns (heavy-lifting equipment availability, weather, positioning accuracy, etc.). Once the foundation or structure is positioned for placement, the following concerns become critical (Hove and Foss 1974):

a. Wind, wave, and current limitations.

$b$. Installation sequence.

c. Touch-down load concentrations.

d. Leveling and/or base grouting.

e. Installation mating procedure with superstructure elements.

Numerous case histories are cited in the offshore industry literature which detail installation considerations for float-in and lift-in gravity-based foundations and structures (Gerwick 1974; Hove and Foss 1974; Alloni, D’Agostino, and Priarone 1976; Collipp and Johnson 1979; Noblanc and Schnader 1983; 
Berthin et al. 1985; Tateishi and Watanabe 1986; Tanaka et al. 1987; Broughton and den Hertog 1990; Christophersen 1993; Alm, Bye, and Egeland 1995;

Andenaes, Skomedal, and Lindseth 1996; Waddell 1997).

Gravity-based foundations that are cast in situ (using tremied concrete or grout) also require special installation considerations for the formwork, rebar, and concrete placement. References and case histories for formwork placement and tremie concrete techniques include those from Harris (1942), Tate (1961), Hedefine and Silano (1968), Johnson, Compton, and Ling (1972), Gerwick (1974), Becker et al. (1998), and Yao, Berner, and Gerwick (1999).

\section{Pinned foundations}

Driven piles. Pile foundations are installed using impact-driven, vibrationdriven, jacking, jetting, suction, or drilling techniques, or combinations of these. The most common method of installing onshore piles is dynamic impact from a variety of hammer types. Pile-driving hammers include the simple drop hammer, single-acting hammer, double-acting hammer, differential hammer, and the diesel hammer (ASCE 1984). Hammer energy is supplied by air, steam, hydraulic pressure, diesel, or electricity. Vibratory hammers produce dynamic forces by internal counter-rotating masses using air, steam, electric, or hydraulic energy sources. Jetting, jacking, and screwing methods are specialized, and their usage in underwater piles has not been widely found in the literature. The majority of underwater piles have been installed using impact-driven methods, although vibratory-driven methods are gaining in popularity for offshore operations. The principal reason that offshore vibratory hammers are not as popular as impact hammers is due to the larger offshore pile weights, which require greater vibration energy (Jonker 1987).

Impact hammers. Offshore piles driven with above-water steam-impact hammers dominated through the 1970s. Pipe piles ranging from 30 to 48 in. $(75$ to $120 \mathrm{~cm})$ in diameter with nonsliced lengths from 200 to $350 \mathrm{ft}$ (60 to $110 \mathrm{~m}$ ) were routinely driven (total spliced pile lengths) up to $800 \mathrm{ft}(240 \mathrm{~m})$ below the mudline in the Gulf of Mexico. Offshore pile hammers (typically single-acting steam-driven) with rated energies from 60,000 to $300,000 \mathrm{ft}-1 \mathrm{~b}$ ( 80 to $400 \mathrm{kNm}$ ) were used to drive these piles to their design penetrations. The resulting ultimate pile load capacities were up to 3,500 tons in compression and 2,000 tons tension (Sullivan and Ehlers 1972). Pile-driving experience in the hard clays of the North Sea caused overestimation of pile hammer capabilities and underestimation of the pile bearing capacities (Fox, Parker, and Sutton 1970). Offshore (above-water) pile hammer manufacturers included Vulcan (Figure 55), MKT, Delmag, and Menck. Steam hammer energy capacities increased to $600,000 \mathrm{ft}-\mathrm{lb}(810 \mathrm{kNm})$ by the mid-1970s.

Development of the submersible hammer in the mid-1970s opened up new frontiers in pile-driving history. Pile followers, steam lines, and costly anchored derrick ships were no longer needed. The Hydroblok hydraulic hammer (by HBM, Hollandsche Beton Groep N.V.) operated an internal piston using nitrogen gas supplied through an umbilical cord to the underwater cage attached to the 


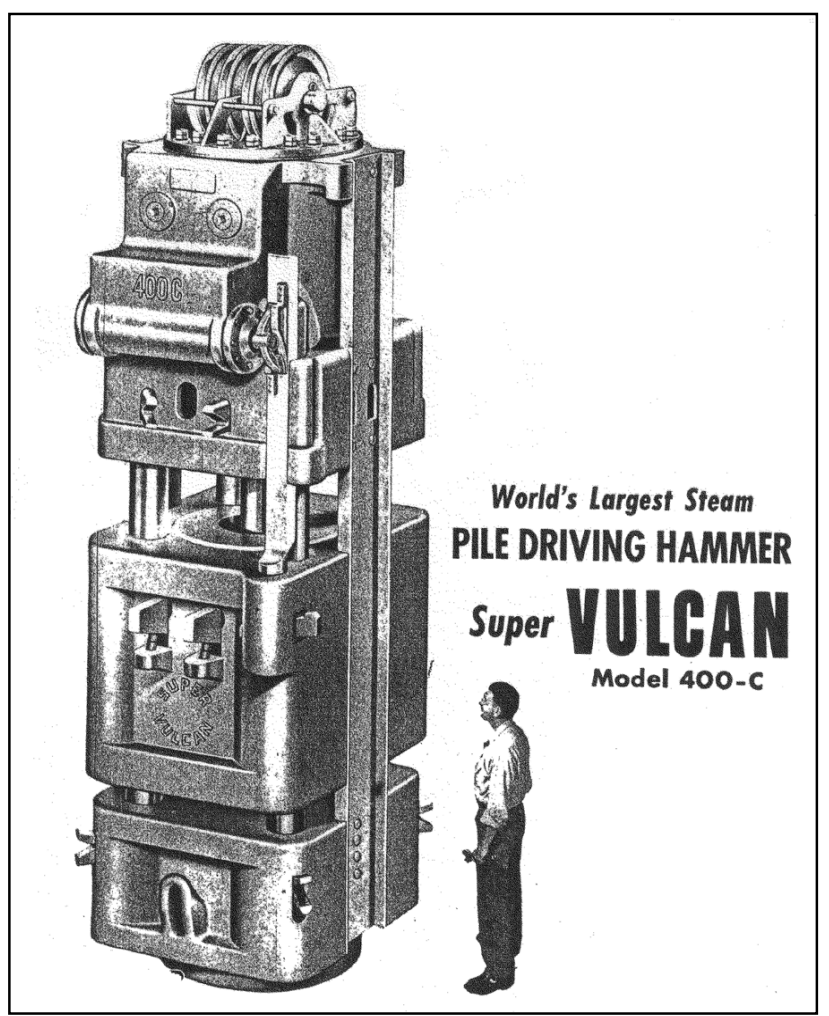

Figure 55. Vulcan steam hammer advertisement from 1957 Civil Engineering magazine

pile top. The rated energy of the HBM 3,000 was $800,000 \mathrm{ft}-\mathrm{lb}$ $(1,080 \mathrm{kNm})$. It could be used to drive an 84-in. (2.1-m)-diam pipe pile (Jansz et al. 1976). Cox and Christy (1976) and Jansz (1977) reported that this underwater hydraulic hammer successfully drove piles in the Gulf of Mexico and the North Sea. In hard clay locations, a method to vertically align piles topped with the HBM hammer was devised.

Alignment and lateral support problems of submerged pile hammers were addressed (Jansz and Brockhoff 1979). For the Eastern Scheldt project, an HBM 1500 hammer was used for driving mooring anchor piles. Sitter (1980) reported the development of an underwater hammer (HBM 4000) with rated capacity of over 1 million $\mathrm{ft}-\mathrm{lb}$ $(1,350 \mathrm{kN}-\mathrm{m})$ of energy. The Menck company, which previously had made steam hammers, began making underwater hammers (such as the

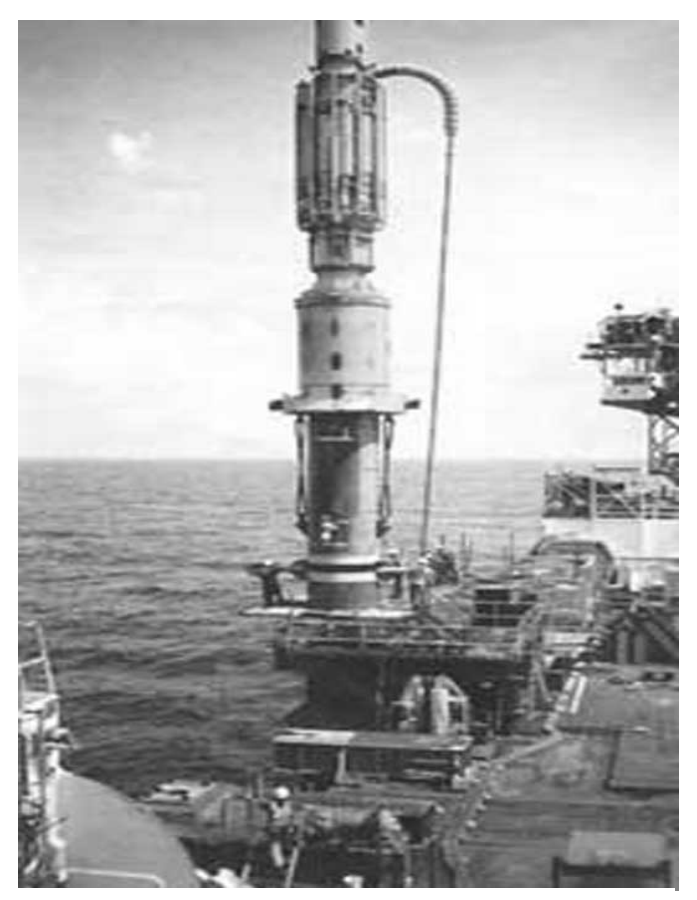

Figure 56. Menck 500T underwater hammer (after Menck 1999) model shown in Figure 56). Heerema (1980) reported that a patent conflict developed in the late 1970s between HBM and Menck.

Another submersible hammer was manufactured by the Raymond Company (RU-300). Its rated energy was 300,000 ft-lb (404 kNm). Its first offshore assignment was off the coast of New Zealand on the Maui jacket platforms that have 48-in. (1.2-m)-diam open-ended pipe piles driven $230 \mathrm{ft}(70 \mathrm{~m})$ below the mudline (Gendron, Holland, and Ranft 1978; Rennie and Fried 1979).

Several other innovative pile-driving methods were introduced during the late 1970s. These developments include the submerged water hammer pile driver, which used seawater pressure to create a cyclic waterdriven impact mechanism to drive the pile (Wisotsky 1978), and electro-osmosis, which used direct current and achieved considerable pile-driving resistance reduction in clay 
deposits due to the soil chemistry bond force reduction (Rose and Grubbs 1979).

Slender hydraulic underwater hammers (Figure 57) were introduced in 1980 by Menck, Inc. By 1983, the hammers were instrumented with an adequate internal monitoring system comparable to the above-water hammers (Van Zandwijk 1986). Slender hammers proved to be much more versatile for offshore jacket pinning than were the larger diameter first generation of underwater hammers. Currently, underwater hammers manufactured by Menck $\mathrm{GmbH}$ (Germany) and IHC Hydrohammer BV (Netherlands) are used for offshore applications.

Both manufacturers build hydraulic hammers for underwater applications. Menck's largest hydraulic hammer (MHU 3000T) has a rated energy of 2.4 million ft-lb $(3,300 \mathrm{kNm})$ and weighs 400 tons. IHC's largest hydraulic hammer (the S-2300, shown in Figure 58) has a rated energy of 1.7 million $\mathrm{ft}-\mathrm{lb}(2,300 \mathrm{kNm})$ and weighs 260 tons. Piles up to 102 in. $(2.5 \mathrm{~m})$ outside diameter may be driven with these hammers (Menck 1999, IHC 1999).

Soil resistance to impact-driven piles. Driving piles to their designed penetration lengths may not always be possible due to the inadequacy of the pile-driving equipment in overcoming soil resistance. The analyses of

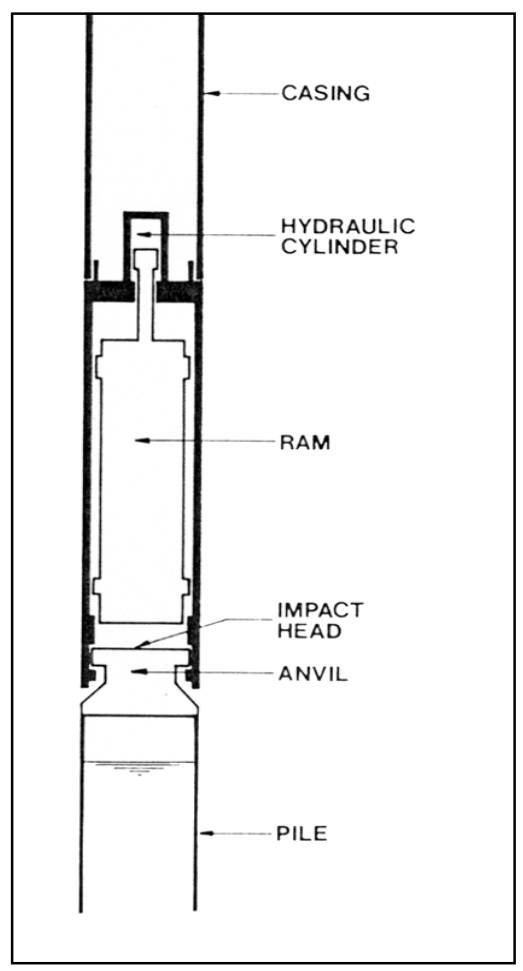

Figure 57. Underwater hydraulic slender hammer (after Van Zandwijk 1986)

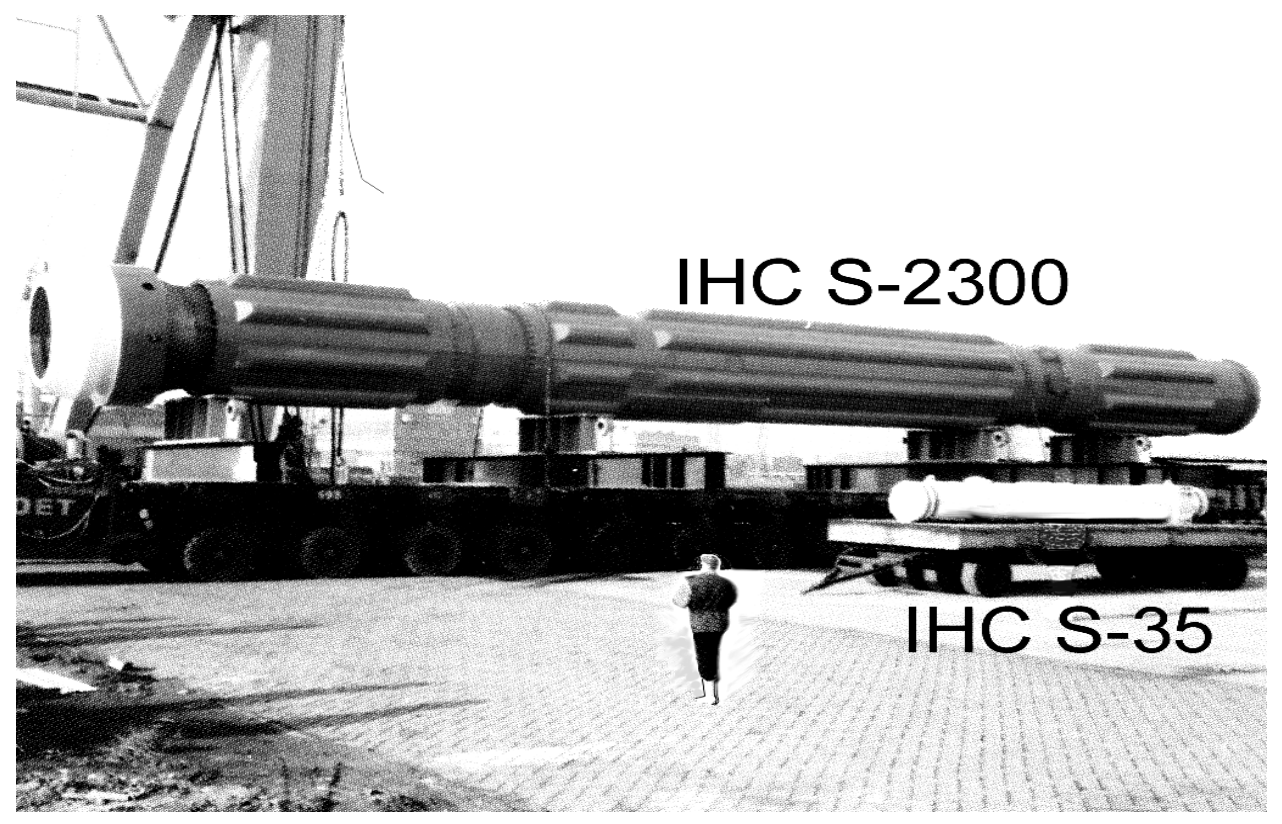

Figure 58. IHC underwater hammers (after IHC 1999) 
pile drivability evolved from simply pounding the pile to refusal using the biggest available hammer to using mathematical models depicting the real-time pile-driving resistance.

The mathematical model concept is based upon the solution of the 1-D wave propagation equation. It allows the determination of the pile-driver adequacy and the soil's resistance to driving. The original development of the model wave equation concept began in the 1950s. In the 1960s, computer solutions to the 1-D wave equation were further detailed and refined. Applications to offshore piles (using above-water hammers) commenced in the 1960s (Bender et al. 1969) and led toward the analyses of different elements of the pile-driving process. Besides the hammer and the pile, accessories were analyzed during the actual pile-driving process. The contributions of pile leads (cradle), cushions, anvil, follow block (helmet or pile cap), and followers (chasers) to driving resistance were analyzed. The application of the wave equation to long piles unsupported through the water column was analyzed and found to accurately predict the behavior on several projects (Lowery, Edwards, and Finley 1969; Engeling 1974; Cunningham and Naughton 1977).

By incorporating the wave equation analysis during the early stages of the pile design process, preliminary selection of the pile hammer can be ascertained. During the pile-driving process, the wave equation analysis can be used to predict the pile's ultimate axial capacity (Hirsch, Koehler, and Sutton 1975; Porter and Ingram 1989). The wave propagation method was further refined to include computerized instrumentation, data acquisition, and data analysis thanks to electronic technology developments (Rausche, Goble, and Moses 1971).

Other wave propagation numerical solution techniques have also been proposed (Fischer 1975; Foo, Matlock, and Meyer 1977). During the 1980s, many case histories of pile-drivability analyses were conducted by the offshore industry, including hammer types (steam versus hydraulic) (Heerema 1980); hammer location (above-water versus submerged) (Aurora 1984); soil conditions (sands, clays, carbonate soils, weak rocks, layer conditions, etc.) (Agarwal, Rawat, and Paintal 1978; Tagaya et al. 1979; Aurora 1980; Stevens, Wiltsie, and Turton 1982; Stockard 1979, 1986); pile size (Lang 1980); and analysis methods (Holloway, Audibert, and Dover 1978; Van Zandwijk, van Dijk, and Heerema 1983). Additional computer codes that perform numerical integration of the wave equation were developed by offshore companies and universities. The universitydeveloped codes include TTI, OCEANWAVE, TIDYWAVE, DIESEL1, WEAP, CAPWAP, DUKFOR, and PSI. The latest version of the WEAP series is GRLWEAP (Holloway, Audibert, and Dover 1978; Porter and Ingram 1989). Recent literature suggests that GRLWEAP accurately predicts pile drivability (Dutt et al. 1995, Doyle 1999).

Vibratory hammers. An alternate method of installing piles is pile advancement (driving) using vibratory methods. Vibratory hammer technology was developed by the Russians for onshore applications in the 1960s. The Japanese foundation industry quickly embraced this technology and developed an extensive array of vibratory hammers. The Americans became interested in vibratory hammers in the early 1970s. 
Vibratory hammer power is supplied by electricity or hydraulics. The vibratory hammers that use hydraulic power normally use a diesel engine to drive the hydraulic pump, which in turn drives the excitation motor on the vibratory hammer. In the United States, hydraulic vibratory hammer systems have become dominant. The major manufacturers, including Vulcan, ICE, and MKT, offer hydraulic systems exclusively (Warrington 1989).

The vibratory hammer (one model shown in Figure 59) does not incrementally impart energy to the pile-soil system as does an impact hammer, but instead provides a rapidly alternating dynamic force to the pile. The hammers are designed to impart this dynamic force to the pile at a range of frequencies, i.e., from approximately 300 to about 7,200 rpm ( 5 to $120 \mathrm{~Hz}$ ), depending on the type of pile to be driven. Frequencies above $30 \mathrm{~Hz}$ are considered to be "high frequency." These hammers generally provide for lowered transmission of ground excitation to neighboring structures. Hammers weighing greater than 12 tons with the capability of transferring dynamic force greater than 200 tons to the pile are available. Pile Buck, Inc., (1999) maintains a comprehensive list of manufacturers and equipment capabilities.

Case histories of offshore vibratory-driven piles are not as numerous as those for impact-driven piles, especially before the late 1980s. The evolution from above-water to underwater vibratory hammer usage occurred much faster than did the impact hammer evolution. It was soon realized that the benefits of underwater vibratory hammers outweighed the abovewater benefits. Use of the underwater hammers began at offshore locations in the North Sea and Adriatic (Jonker 1987, 1988; Ligterink, Van Zandwijk, and Middendorp 1990; Ligterink and Martin 1992).

Pile drivability using a vibratory hammer is analyzed using the same 1-D wave propagation concept as for impact hammers. The model is somewhat different for vibratory hammers as compared to impact hammers, including modifications to wave equation computer programs. Chua, Gardner, and Lowery (1987) showed the applicability of the wave equation approach to vibratory hammer driving by modifying the TTI program

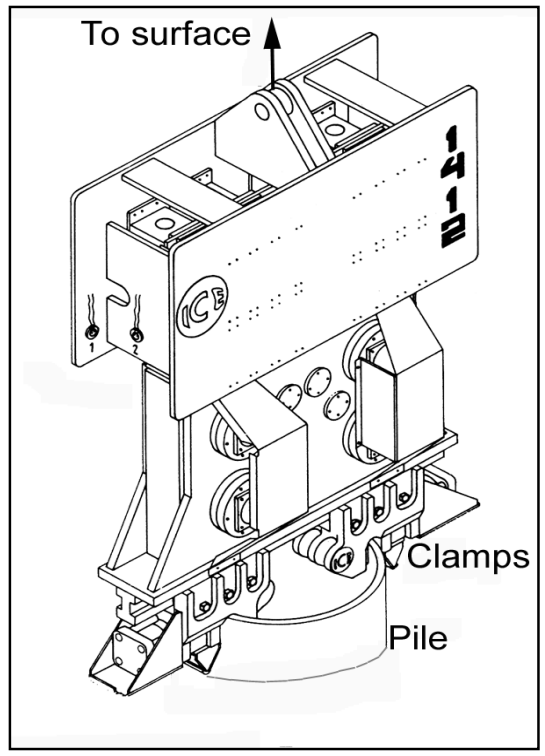

Figure 59. ICE 1412 hydraulic vibratory pile hammer (after Jonker 1987) (VIBEWAVE). Jonker (1988) adapted the TNOWAVE program to vibratory driving. Ligterink, Van Zandwijk, and Middendorp (1990) used the adapted TNOWAVE program to analyze the soil's resistance to vibratory driving during installation of 42 -in. $(1.07-\mathrm{m})$ piles. The vibratory piledriving analyzer (VPDA) finite difference model was developed by MoulaiKhatir, O'Neill, and Vipulanandan (1994). The Wisconsin Vibratory Pile Driving Analyzer (WiscVPDA) was developed by Bosscher et al. (1998).

A list of considerations for selecting impact versus vibratory underwater hammers follows: 
a. No pile followers (chasers) are needed for underwater driving with either hammer.

$b$. The vibratory hammer and pile are clamped together and are handled as one unit.

c. The vibratory hammer can be activated prior to the pile tip touching the seabed. The methodology avoids the need for a temporary guide template (illustrated in Figure 60).

d. The use of impact hammers is more common for offshore applications. Consequently, they have been used for a larger variety of soil types and pile sizes.

e. Soil frictional resistance may be overestimated when using vibratory hammers.

f. Vibratory hammers are used with piles requiring a minimum vertical tolerance, which allows easier realignment during penetration.

g. A combination of hammers allows faster installation of a pile. The vibratory hammer can be used for initial positioning followed by limited driving to achieve lateral support, whereas the impact hammer can be used for the remainder of penetration.

$h$. Above-water impact hammers generally have higher vibration and noise levels than vibratory hammers. Hydraulic impact hammers generally have lower vibration levels than diesel hammers.

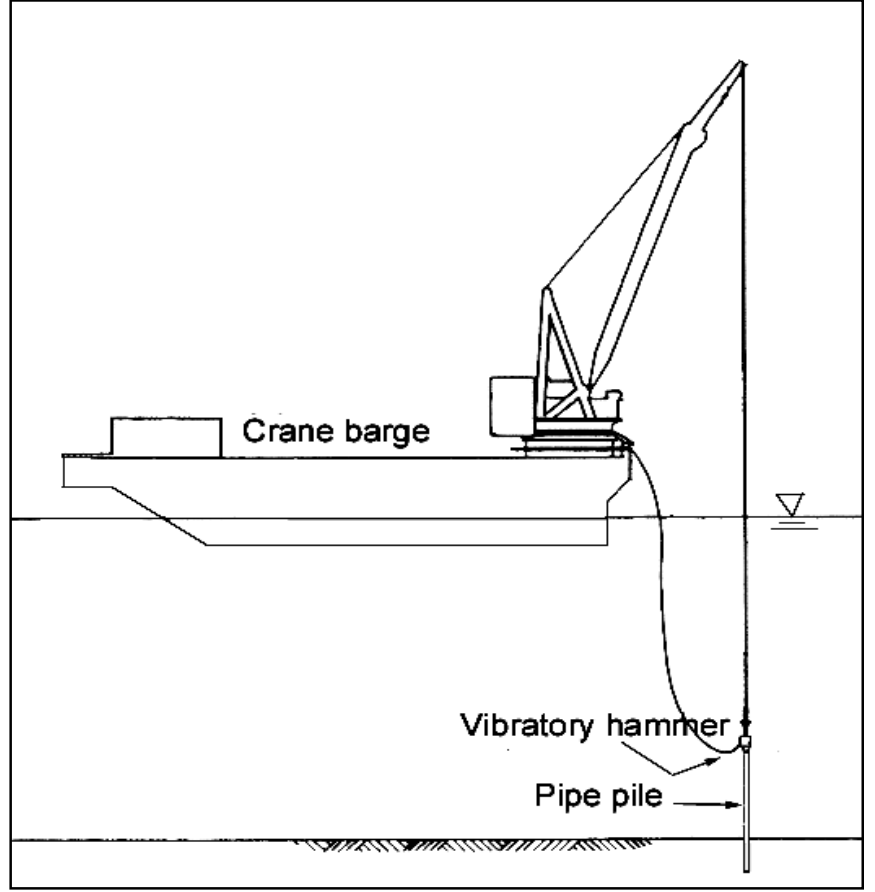

Figure 60. Vibratory-driven pipe pile without an underwater template (after Jonker 1988)
Technology is now available to reduce noise levels during abovewater impact driving. Numerous manufacturers offer protective shields or encapsulation modules as noise mufflers. For example, one onshore contractor designed and built a hydraulic impact piledriver that was about $12 \mathrm{db}$ quieter than an equivalent system for driving concrete precast piles near an urban development. Totally enclosing all moving parts and eliminating all metal-to-metal contact reduced the noise level to the point at which the ropes flapping against the rig's mast was the only appreciable noise (Ground Engineering 1999). For driving tubular and standard steel sheet piles, a Japanese company has recently demonstrated in the 
United States a hydraulic pile-driving system that operates at less than $60 \mathrm{db}$ of noise and is virtually vibration free (Phair 2000).

Drilled shafts. Drilled shafts (also called drilled piers, drilled caissons, largediameter bored piles, or rock sockets) can be installed by a variety of onshore drilling rigs. Offshore equipment is generally the same with the exception of being mounted on a barge or other floating platform. Casing is driven or drilled past the mudline. If the casing can be sealed into an impervious stratum, it can then be dewatered and drilled. Otherwise, drilling is conducted through casing using the mud-drilling technique. Cuttings are removed using air or water ejectors or by mud circulation techniques. After cleanout and inspection, steel reinforcing and concrete are then placed into the casing to form the shaft (Greer and Gardner 1986).

A more common offshore method that does not use reinforced concrete is typically used on steel jacket platforms sited on rock regardless of whether soil overburden is present. Instead, a steel pipe pile is lowered into the bored or cased opening, and then the annulus is grouted to provide a "pinned" pile system.

When casing is used, it is advanced by spinning the casing with a drill bit attached at its lower end or by guiding a smaller diameter casing through a jacket pipe sleeve or spud pile and then advancing the casing by use of a pilot drill bit. Grouting of the casing may or may not be conducted prior to insertion of the inner pipe pile. Final grouting is accomplished after the inner pipe pile is advanced to its target depth. The drill rig may be operated from a support barge or may operate directly on top of the outer casing.

Steinke and Strasser (1978) discussed drilling techniques for the Valdez terminal where piles up to $3.5 \mathrm{ft}(1.1 \mathrm{~m})$ in diameter were placed in $43-\mathrm{ft}$ (13-m)-deep boreholes located up to 1,500 ft (456 m) from shore, on steep 60-deg underwater rock slopes. Fox (1970) discussed rotary drilling through driven 40-in. (101-cm)-diam steel pipe piles with an 18-in. $(46-\mathrm{cm})$ tri-cone bit on a 7 -in. $(18-\mathrm{cm})$-diam drill stem to clear out boulder clay overburden prior to rock drilling. Drill water pumped at 2,100 gpm $(8,400 \mathrm{~L} / \mathrm{m})$ helped to clean the soil cuttings as the bit advanced into the rock, although boulder inclusions caused problems during the drilling operations. After achieving the design depth, each pile was then filled with reinforcing bars and concrete. Chamberlin (1970) discussed drilling 42-in. (107-cm)-diam holes in layered limestone using a 24 -in. (61-cm) tri-cone bit, a 32-in. (81-cm) hole opener, and a 42-in. (107-cm) underreamer (shown in Figure 61). A 36-in. (91-cm)-diam pipe pile was then lowered into each socket during

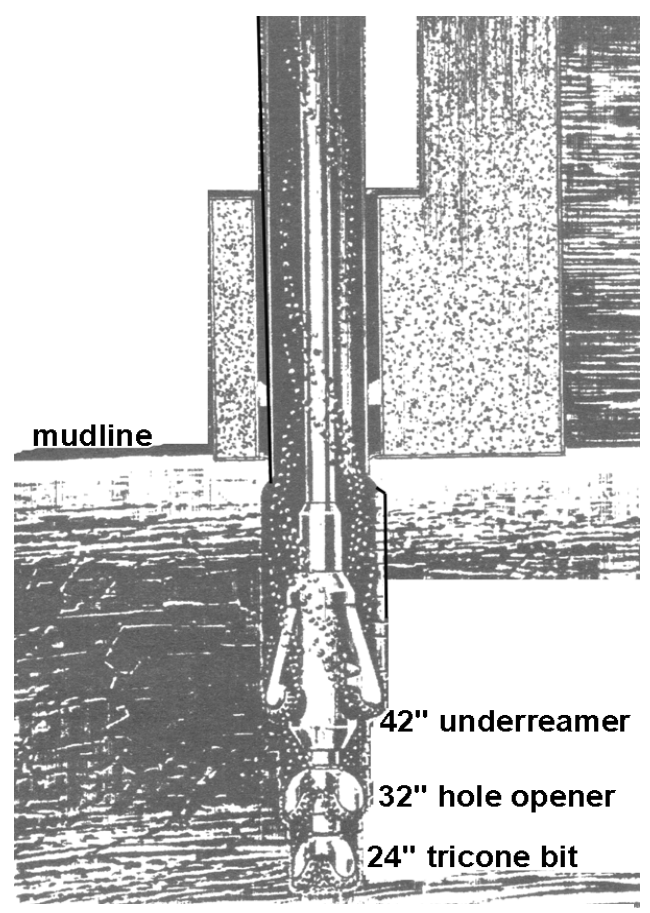

Figure 61. Offshore rotary drilling operation for grouted pipe piles in limestone (after Chamberlin 1970) drilling and was grouted inside and out. Santiago et al. (1986) discussed drilling techniques used at an offshore platform in 350-ft 
(106-m) water depth to install 4.5-ft (1.37-m)-diam pipe piles $82 \mathrm{ft}(25 \mathrm{~m})$ into claystone and gravel deposits.

Suction caissons. Suction caissons (also called suction piles, buckets, skirts, skirted foundations, or anchors) are installed by self penetration into the seabed, similar to the illustration shown in Figure 62.

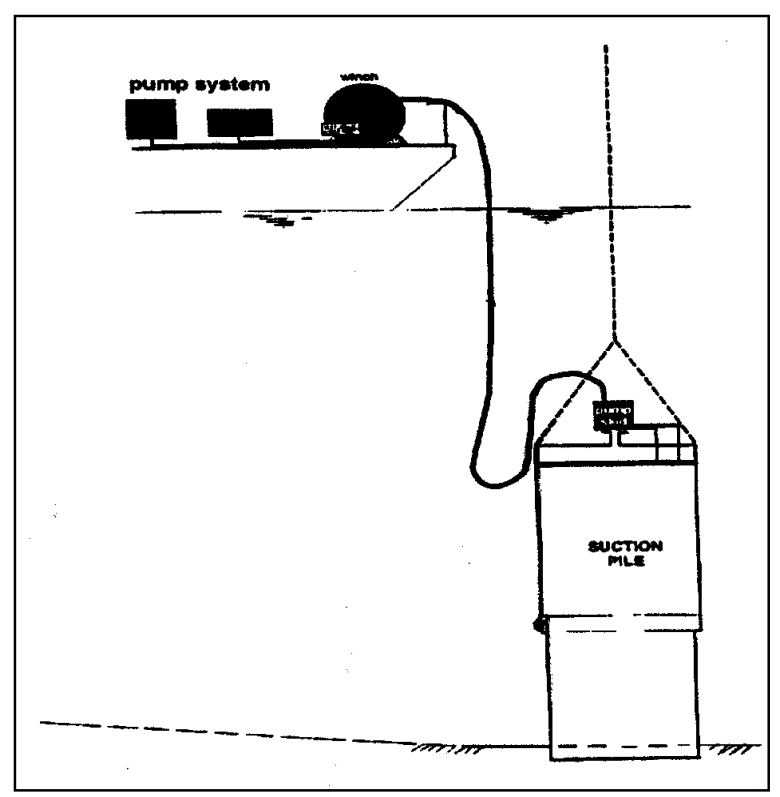

Figure 62. Suction caisson (pile) installation (after Senpere and Auvergne 1982)

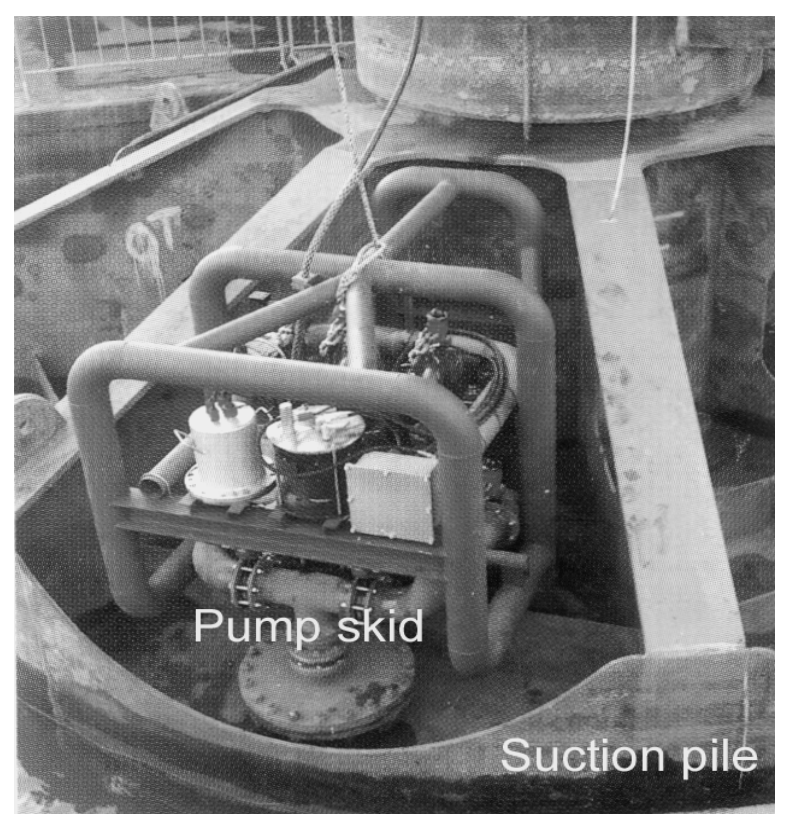

Figure 63. Pile-mounted suction pump skid (after Suction Pile Technology, Inc. 1999)
The initial phase is self-weight penetration as the caisson is lowered onto the seabed and allowed to "sink" under its own weight into the mudline. Further penetration requires an underpressure in the cavity of the suction caisson, which creates an additional driving force. As underpressure is applied (usually by a skid-mounted pump on top of the caisson, shown in Figure 63), the caisson tends to penetrate the soil until the pressure inside the skirt walls tends to equalize with the external pressures. The rate at which the pore pressures tend to equalize and mechanisms by which the underlying soil tends to fail are due to the material and strength properties of the soil. Set-up effects (time-dependent properties) are similar to those found in pile driving (Andersen and Jostad 1999).

Placement positioning. Proper 3-D positioning of the foundation is required during the installation process. The installation procedures must be consistent with the design criteria, and advance planning for alternate or supplemental procedures should be made prior to mobilization of the marine construction equipment (Sullivan and Ehlers 1972). Tanaka et al. (1987) studied the installation procedures for placing a gravity-based foundation on an offshore Japan seabed. Model testing and numerical simulation confirmed the technical feasibility and provided recommendations prior to actual installation.

For typical offshore oil and gas structures, foundation positioning is intricately linked to the exploration and drilling process. Elaborate computerized 
positioning procedures are followed, which have been discussed in the offshore literature for the largest, most complex, or deepest structures from subsea risers to surface platforms.

For example, positioning and installation procedures for Shell's Cognac jacket platform are detailed by Collipp and Johnson (1979), Simpson (1979), Mayfield, Strohbeck, and Wilkins (1979), and Sterling et al. (1979). Since the foundation pile-driving guide or "template" was integral to the jacket structure, no positioning of a separate pile-driving template was required. During the positioning and placement of the 84 -in. $(2.1-\mathrm{m})$-diam by 615 -ft $(187-\mathrm{m})$ pipe piles, an acoustic positioning system composed of multiple transponders (beacons and hydrophones) communicated with a computerized referencing system. Hydrophones were mounted on the pile-lowering system, which received sequenced pulses from oceanfloor and surface-barge beacons. Three-dimensional computer-assisted pile-maneuvering was performed to guide the platform jacket stab guides onto the piles. A pile-mounted TV camera system and a video ROV provided video monitoring capabilities. After pile positioning and stabbing were completed, the pile hammer monitoring and control system was implemented.

Three operators were positioned at separate computer/TV consoles to control and monitor the pile elevator depth, the hammer depth, and the hammer operation. Although the installation schedule allowed 3 days per pile, the installation of the final 18 piles (out of 24 total) required a total of only 22 days.

Pile-driving templates that are not preattached to the structure require separate positioning and placement efforts. Ulbricht et al. (1994) discuss positioning efforts for Shell's Auger Tension Leg Platform (TLP) foundation template, which is shown in Figure 64. The foundation template was placed at a depth of 2,860-ft $(870 \mathrm{~m})$ in the Gulf of Mexico to within tolerances of $2 \mathrm{ft}$ radial offset, 2 deg heading offset, and 2 deg horizontal offset.

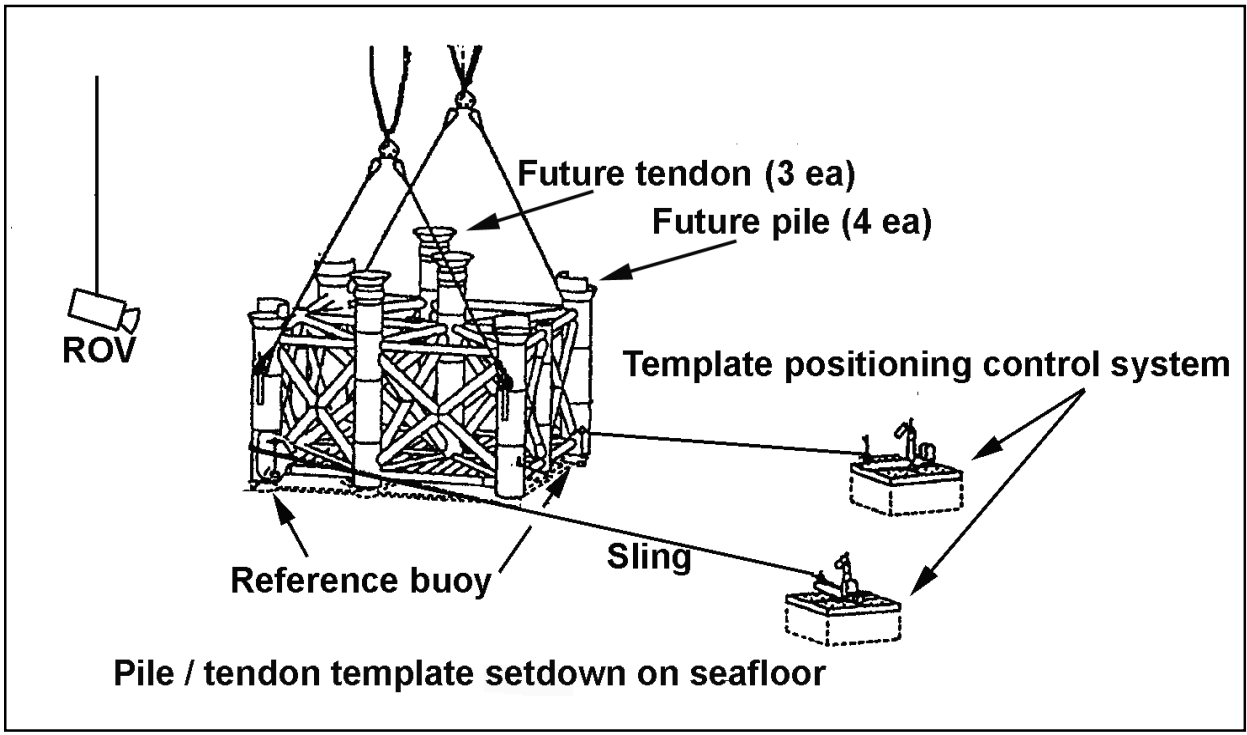

Figure 64. Pile template positioning for Shell's Auger TLP (after Ulbricht et al. 1994) 
The installation vessel (a semisubmersible crane vessel) experienced lowfrequency surface excursions between 15 and $35 \mathrm{ft}(5$ and $11 \mathrm{~m})$ while setting the 60 - by 60 - by $48-\mathrm{ft}$ (18- by 18 - by $15-\mathrm{m}), 611$-ton steel template on a slightly sloping, soft clay site. Specially designed "clump weights" were acoustically positioned on the seabed prior to lowering the template. Near- and far-field acoustic transponder arrays on the seabed provided positional references to the template-mounted Sonardyne MicroNav acoustic monitoring system. A dual-axis inclinometer was attached to the template and was acoustically monitored during lowering. Template position, heading, inclination, and water depths were monitored relative to the crane vessel's position. As the template neared the seabed, ROV-connected slings attached to the "clump weights" corrected and stabilized its position prior to setdown. Pile stabbing and hammer operations were monitored using acoustic positioning equipment.

Offshore pile-handling operations have improved as more experience has been gained in deepwater pile transporting, offloading, upending, and lowering. Converse et al. (1990) discussed a newer, more mechanized method for handling large, one-piece piles while reducing the requirement for specialized rigging.

With experience, positioning tolerances have also become tighter. In 1979, the accuracy using the computerized positioning system was within a radius of about $15 \mathrm{ft}(4.5 \mathrm{~m})$ at a depth of 1,000 ft (304 m) for Shell's Cognac platform. By 1999 , piles were positioned within $1 \mathrm{ft}(0.3 \mathrm{~m})$ of the target with less than $1 \mathrm{deg}$ of final tilt in 3,800-ft $(1,160-\mathrm{m})$-deep water for the Shell Mars, Ram-Powell, and Ursa TLPs (Doyle 1999).

For positioning a drilled shaft casing, differential GPS (DGPS) surveying was demonstrated at the Corp's Lock and Dam 24 on the Mississippi River. Rotary-drilled casings were monitored for DGPS positional accuracy and compared to standard surveying methods (U.S. Army ERDC 1999).

\section{Foundation-structure connections}

The design and installation of mating connections between an underwater foundation and its supported structure are not within the scope of this study and, hence, are not specifically addressed in this report. For the improved-site foundation, there usually is no distinct connection to the structure. Gravity-based and pinned foundations typically require connection to their structures, and their installation must be considered during the design phase.

Various connection configurations are available, including shear pins, stabbed or embedded mating connections, and grouted connections. Some connection details are included in offshore design guidance (American Petroleum Institute 1993). Several offshore examples include the discussion of mating details and installation procedures for jacket structures on piles by Allen et al. (1990); a procedure to mechanically connect piles to an underwater structure using hydraulic swaging equipment by Ulbricht et al. (1994); the use of pile stabbing guides by Birdwell and Jordan (1994); and a Smart Leg system by 
LabbJ, Legras, and Standing (1999) for float-over installations on piles. Sele and Skjolde (1993) and Welham and Gilfrin (1993) discuss grouted connections.

\section{Underwater Foundation Testing}

Underwater foundation tests may be of two types: integrity testing and performance testing. Integrity testing seeks to determine the quality of the constructed foundation material, i.e., to determine if the concrete in the drilled shaft is honeycombed. Performance testing seeks to determine the adequacy of the foundation to withstand the design loading (i.e., the expected range of deflections imposed by lateral loading on a drilled shaft) and the capacity of the soil to resist the shaft (or pile) loads.

The type and degree of testing usually depends upon the type of foundation and economics. The general trends for underwater foundation site testing are listed below.

\begin{tabular}{|l|l|l|}
\hline Foundation & Integrity Tests & Performance Tests \\
\hline Improved-site & Material-dependent & Intrusive (sampling, etc.) and NDT \\
\hline Gravity-based & NDT & Long-term monitoring \\
\hline Pinned & NDT & NDT, large-strain tests or load tests \\
\hline
\end{tabular}

Intrusive or destructive tests commonly refer to invasive techniques such as soil/rock coring, sample retrieval and laboratory tests, or in situ techniques such as cone penetrometer and shear vane tests. These are the same tests that are used in geotechnical site investigations to determine the soil/rock properties including shear strength, friction angle, relative density, RQD, etc. Intrusive testing may also be required in gravity-based and pinned foundations to determine strength of (cored) concrete specimens.

Nondestructive tests (NDT) cover a broad range of techniques. Integrity testing using NDT is primarily concerned with cast-in-place concrete or grout materials found in gravity-based and pinned foundations. Flaws in steel and timber piles may also be detected using NDT during or after pile-driving. Performance testing of driven piles to determine their drivability and ultimate capacity may also be accomplished with NDT methods. According to Chernauskas and Paikowsky (1999), the NDT methods of integrity testing are categorized as small-strain testing and large-strain testing.

\section{Small-strain integrity testing}

Small-strain test methods generate stress waves that are interpreted to provide shaft or pile integrity information, such as concrete or grout integrity. Small-strain integrity testing includes direct transmission techniques, including crosshole sonic logging (CSL), single-hole sonic logging (SSL), and parallel 
seismic logging, as well as surface reflection techniques, such as pulse echo method (or sonic echo), transient dynamic response (impulse response), and electromagnetic techniques (electromagnetic induction (EM), X-ray, radar, and magnometer).

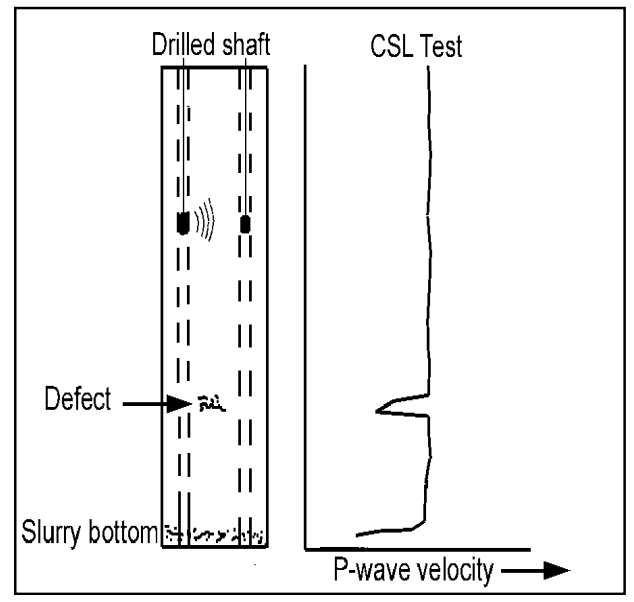

Figure 65. Crosshole sonic logging (CSL) integrity test
The most common integrity testing technique is the CSL, which is conducted within preinstalled tubes in cast-in-place piles or drilled shafts (illustrated in Figure 65). A transducer is lowered into one water-filled tube and emits an acoustic signal that is received by a hydrophone (geophone) transducer in a separate tube. The signal's compression (P-) wave is detected and compared to the transit time of a signal transmitted through intact material with a given modulus of elasticity. If material defects are present, the wave speed will be reduced relative to that of intact material. Accurate transducer positioning helps to pinpoint the location of a defect. For accurate P-wave transmission, the concrete material must be fully cured. Chernauskas and Paikowsky (1999) describe the first use of a portable personal computer-based

CSL test on concrete drilled shafts in the United States with the Pile Integrity Sonic Analyzer software package.

Single-hole sonic logging uses only one tube in the drilled shaft. This method is normally used after construction is completed and it has been determined that there is a need to check the shaft integrity by coring a single hole through the shaft.

Parallel seismic logging (as illustrated in Figure 66) is similar to geophysical cross-hole seismic testing in that holes are drilled into the surrounding soil. A PVC (polyvinyl chloride) casing is inserted into each

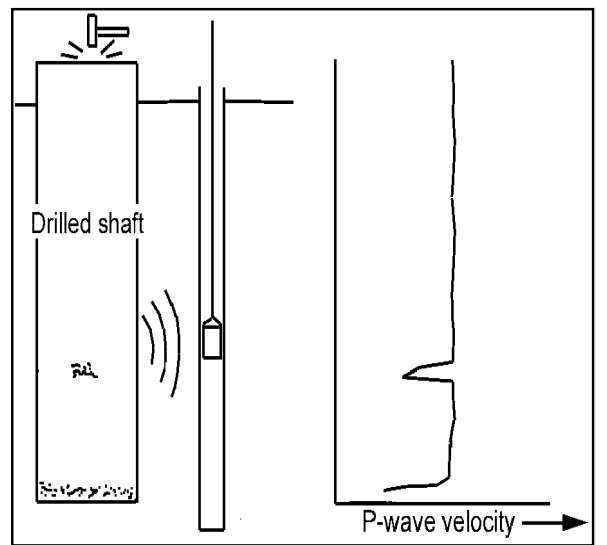

Figure 66. Parallel seismic integrity test hole, the annulus is grouted, and the casing is filled

with water. Both SSL and parallel logging use equipment and interpretation procedures similar to those used in the CSL test.

The pulse echo method (PEM) requires an external hammer source and an accelerometer transducer mounted on the drilled shaft (or pile), as shown in Figure 67. The hammer impact causes small strains, which induce stress waves in the shaft that are transmitted to the accelerometer. The accelerations are integrated with respect to time, to obtain velocity profiled as a function of shaft length. The presence and location of defects are interpreted from the velocity record. The effectiveness of this technique is limited to depths up to 20 to 30 pile diameters. 
The transient dynamic response (TDR) method (not to be confused with time domain reflectometry) requires an external instrumented hammer. The impact force of the hammer is recorded and combined with the acceleration record, similar to the PEM method. The shaft's velocity response due to the induced excitation force can be interpreted to indicate the presence and location of defects.

In general, electromagnetic techniques are not commonly applied in pile integrity testing. However, two manufacturers of equipment and software specifically designed for pile integrity testing using surface reflection methods (low strain) are PileTestCom (Israel) Ltd.'s Pile Integrity Sonic Analyzer and Pile Dynamics (U.S.A.) Inc.'s Pile Integrity Tester.

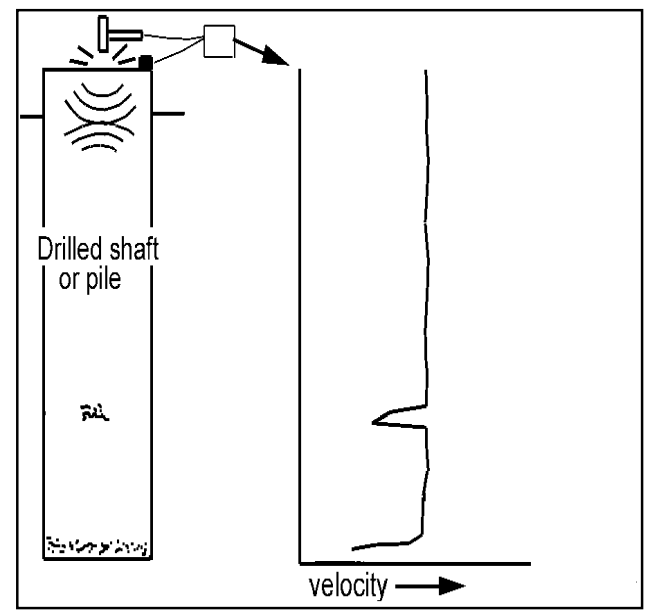

Figure 67. Pulse echo method integrity test

\section{Large-strain testing}

Large-strain testing is typical of the integrity/performance testing conducted during pile driving. Large strains induced during pile driving generate large stress waves that mobilize the shaft or pile resistance against the surrounding soil. Large-strain methods (also referred to as "dynamic testing") allow interpretation of both material integrity and performance. The ability to determine the shaft or pile performance allows one to evaluate drivability as well as load carrying capacity. One example of a large strain test is the surface reflection method, which is similar to the pulse echo and transient dynamic response methods.

Large-strain methods are primarily used for driven (impact and vibratory hammered) piles. When the hammer strikes (or vibrates) the pile head, a large strain wave is initiated and propagates down the pile. External soil resistance or changes in the pile's impedance (due to variations in the material or geometry of the pile) initiate reflection waves that are recorded.

Typical dynamic pile testing instrumentation requires two accelerometers and two strain transducers mounted on opposite sides near the pile top. The strains are converted to forces according to the theory of elasticity while the accelerations are converted to velocities. Although numerous interpretation methods are available to assess the pile's integrity and performance characteristics, all are generally based upon 1-D stress wave propagation theory. The U.S. standard for high-strain dynamic testing of piles is ASTM Standard D4945 (ASTM 1993). One of the most common wave equation software packages is GRLWEAP for Windows. A U.S. company that offers it, as well as other proprietary pile testing systems, is Pile Dynamics, Inc., of Cleveland, $\mathrm{OH}$. The PDA (Pile Driving Analyzer) and the PIT (Pile Integrity Tester) systems are also sold by this company. 
The PDA systems (PAK and PAL) monitor acceleration and strain sensors attached to the impact-hammered pile and process these signals (using GRLWEAP) after each blow of the hammer during driving or restriking to investigate hammer performance, driving stresses, and pile integrity and to provide an estimate of static bearing capacity (Pile Dynamics, Inc. (PDI) 1999).

The PAK collects up to four channels of strain and four channels of acceleration (two piezoelectric and two piezoresistive). Compared with PAL, which is a smaller unit that can capture only two channels of data for each of strain and acceleration, PAK has superior data collection and processing capabilities. Remote data collection using a cell phone modem is also possible, and underwater transducers are available. Figure 68 illustrates a PDA test example.

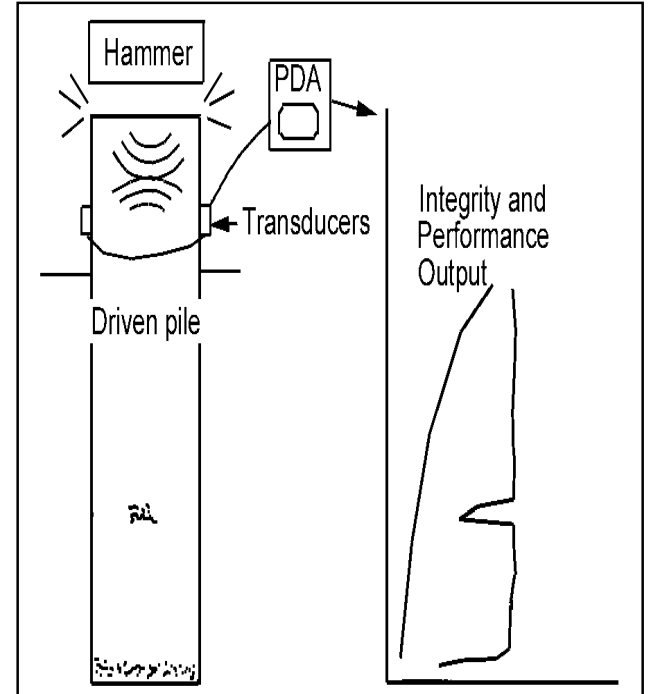

Figure 68. Pile dynamic analysis (PDA) test
Using the software program CAPWAP (CAse Pile Wave Analysis Program), which was developed by Goble Rausche Likins and Associates, Inc. (GRL), and marketed by PDI, Inc., the soil response is expressed in terms of total capacity and its distribution along the shaft and at the toe. Damping factors and quakes are also modeled. CAPWAP users are required to have approved training. GRL and PDI regularly offer seminars and workshops.

Performance testing of vibratory-driven piles is generally based upon the same principles as large-strain dynamic testing of impact-driven piles. The impact-hammer equations are modified to account for the dynamic properties of the vibrating energy source. Computer models based upon finite difference or finite element methods for solution of the wave equation have been proposed and are similar to those models previously developed for impact-driven piles.

The computer programs VIBEWAVE and TNOWAVE were developed to predict pile-driving performance and the soil's resistance to vibratory driving. TNOWAVE can also be used to analyze the performance of the vibratory hammer as well as to predict several parameters, including maximum stress in the pile, amplitude of vibration at different levels in the pile, penetration rate, and nearby building vibrations. TNOWAVE is especially useful for matching vibratory hammer size to the soil conditions and preventing pile damage due to overloading. The computer model VPDA was developed to predict the pile bearing capacity in addition to predicting the pile-driving performance (MoulaiKhatir, O'Neill, and Vipulanandan 1994). The predicted bearing capacity is input into the program and compared to the observed penetration rate. When model parameters match, the actual bearing capacity of the pile is calculated.

Bosscher et al. (1998) used VPDA and field (onshore) load tests to develop the computer model WiscVPDA, which estimates the ultimate bearing capacity 
as the pile is being driven. WiscVPDA was developed and refined by comparing the predicted (VPDA) bearing capacity to the full-scale load test ultimate bearing capacity results (illustrated in Figure 69). Steel pipe piles and H-piles at one chosen site were vibratory driven and load tested for statistical correlations. Significant correlations were noted for pile parameters such as type, diameter, perimeter, and cross-sectional area. Significant vibratory hammer correlations, i.e., driver parameters such as driving frequency, eccentric acceleration, and delivered power, were noted and incorporated into the program.

\section{Load testing}

Static load tests are conducted to determine the shaft (or pile) performance and the soil response in resisting applied axial and lateral loads. A load test is usually made for one or more of the following reasons (Whitaker 1976): (a) to obtain a loadsettlement or load-displacement relationship, (b) to obtain or validate the design safety factor against failure, and (c) to determine the true ultimate bearing capacity as a check on the design value.

Pile load test configurations are axial (compression, tension, and quick load), monotonic lateral, and cyclic lateral. These test configurations are detailed in ASTM Standard

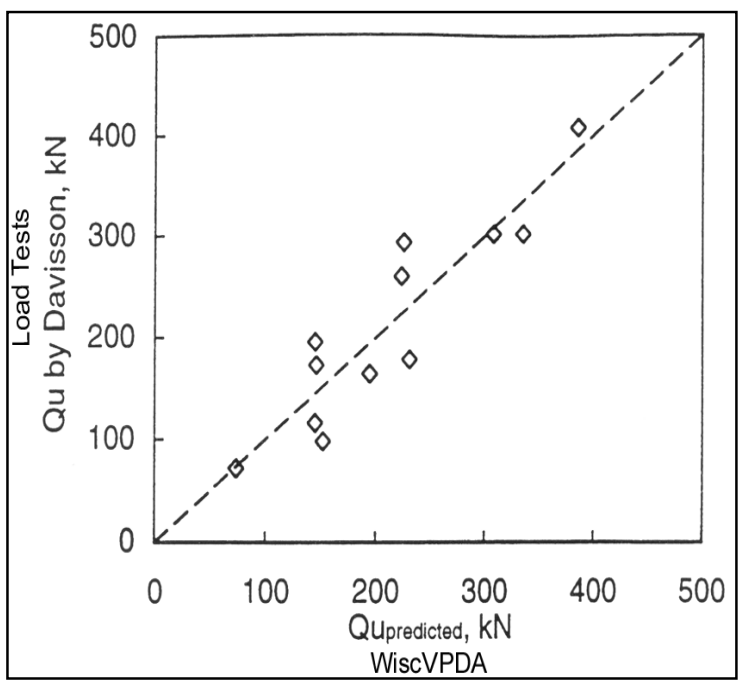

Figure 69. Comparison of actual pile load test results to WiscVPDA predictions (after Bosscher et al. 1998) D 1143 (axial compression and quick load), ASTM Standard D 3689 (axial tension), and ASTM Standard D 3966 (lateral loading) (ASTM 1993).

The quick load test is permitted as a faster alternative. Its two loading configurations are the constant-rate-of-penetration (CRP) and the quick maintained-load test (ASCE 1993). The CRP test was developed in the United Kingdom by Whitaker (1976) and is not as popular in the United States as is the maintained-load test (ASCE 1993). In the maintained-load test, the load is applied in increments of 10 percent of the proposed design load and is maintained for a constant time interval of a few minutes. In the CRP test, the load is applied to cause pile head settlement at a predetermined constant rate, usually 0.01 to $0.1 \mathrm{in}$./minute. Several static bearing capacity determination methods (including the Corps of Engineers method) are listed in ASCE (1993).

Axial pile load tests conducted in the past used superimposed dead weights. Current practice includes the use of a hydraulic ram that is jacked against a loaded platform or against a test frame anchored by reaction piles (ASCE 1993).

Load tests conducted onshore are much more numerous and are relatively less costly than those conducted offshore. The offshore industry literature contains several references to offshore load tests, especially for research purposes 
or in riskier environments such as calcareous soils. For example, load tests conducted from both a fixed offshore platform and a floating vessel are described by Angemeer, Carlson, and Klick (1973) and Angemeer et al. (1975) for offshore Australian sites containing calcareous soils. Dutt and Cheng (1984) conducted pullout load tests on 2-ft (0.66-m)-diam pipe piles in offshore carbonate sands. A research program described by Matlock, Bogard, and Chan (1998) conducted load tests on pipe piles from a fixed platform in the Gulf of Mexico. Jardine and Overy (1996) conducted load tests on 2-ft (0.66-m)-diam pipe piles in dense sand from a fixed platform in the North Sea.

The majority of referenced offshore load tests are performed under axial tension loading (monotonic pullout tests) to enable determination of skin friction capacity. An offshore load test for bending, tension, and compression of pipe piles driven into carbonate bedrock was detailed by Settgast (1980). Vines and Hong (1984) reported tests on large-diameter laterally loaded pipe piles in coral at an offshore port site in Saudi Arabia.

Load tests conducted onshore with the results applied to offshore structures have also been conducted. Tension and compression loading tests were conducted on 2-ft (0.66-m)-diam pipe piles in stiff clay in Belgium (Heerema 1979). Grosch and Reese (1980) performed cyclic axial loading tests on smallscale (1-in.-diam) piles pushed beyond the end of shallow boreholes in soft clay. $\mathrm{Lu}$ (1986) evaluated small-scale pile models in carbonate sands while Karlsrud and Nadim (1990) reported tests on small-scale (6-in.-diam) piles subjected to tension and compression loadings in clay. Zuidberg and Vergobbi (1996) discussed load tests on 30-in. (0.76-m)-diam pipe piles in dense silica sand for

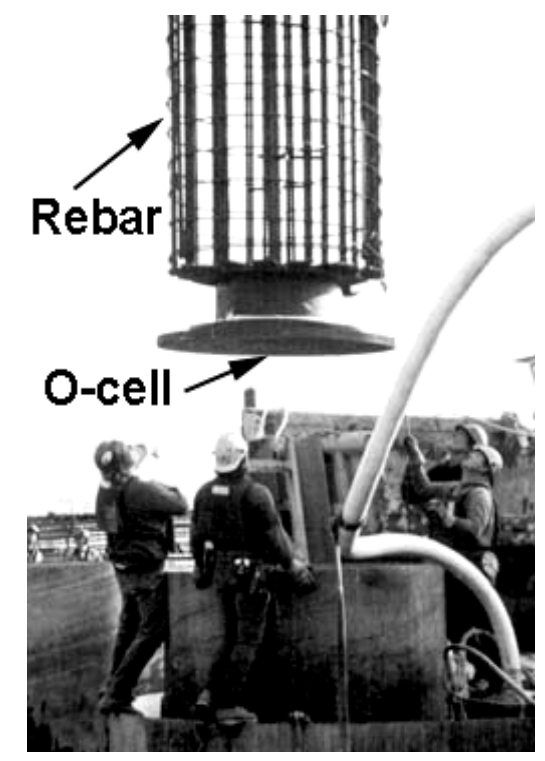

Figure 70. Osterberg cell at the rebar cage bottom (after DiMillio 1999) the European Initiative on Piles in Dense Sands (EURIPIDES) Project. Onshore testing of pipe piles driven and grouted in calcareous soils was performed by Randolph et al. (1996). Onshore axial load tests on 4-ft (1.2-m)-diam pipe piles in clay were conducted for the Corp's future in-the-wet IHNC project in New Orleans (U.S. Army Corps of Engineers 1999a).

Load tests conducted on drilled shafts sometimes use the Osterberg load cell (Figure 70). As compared to conventional load tests conducted with a reaction load or hold-down shafts with a heavy reaction beam, the load test employing the Osterberg load cell is relatively easy and inexpensive (Greer and Gardner 1986).

The Osterberg method, which was developed in 1984, allows separate measurements of end-bearing and friction loads versus deflection for each load increment.

Typically, a flat pressure cell that covers the bottom of the shaft hole is hydraulically pressed simultaneously against both the bottom of the shaft hole and the bottom of the shaft. Depending upon the cell placement within the drilled shaft, gauges can be used to measure the cell's downward movement 
against the soil and its upward movement against the shaft. From these data, load-deflection curves are generated. The most common loading sequence is the ASTM Quick Test Method D 1143 (Osterberg 1998). After the testing is completed, the cell can be grouted in place, and the test shaft can be used as a production shaft.

Drilled shaft (caisson) load tests were conducted in 1998 at the Corp's Monongahela River Braddock Dam site to provide axial and lateral load data for design of the production shafts (Figure 71).

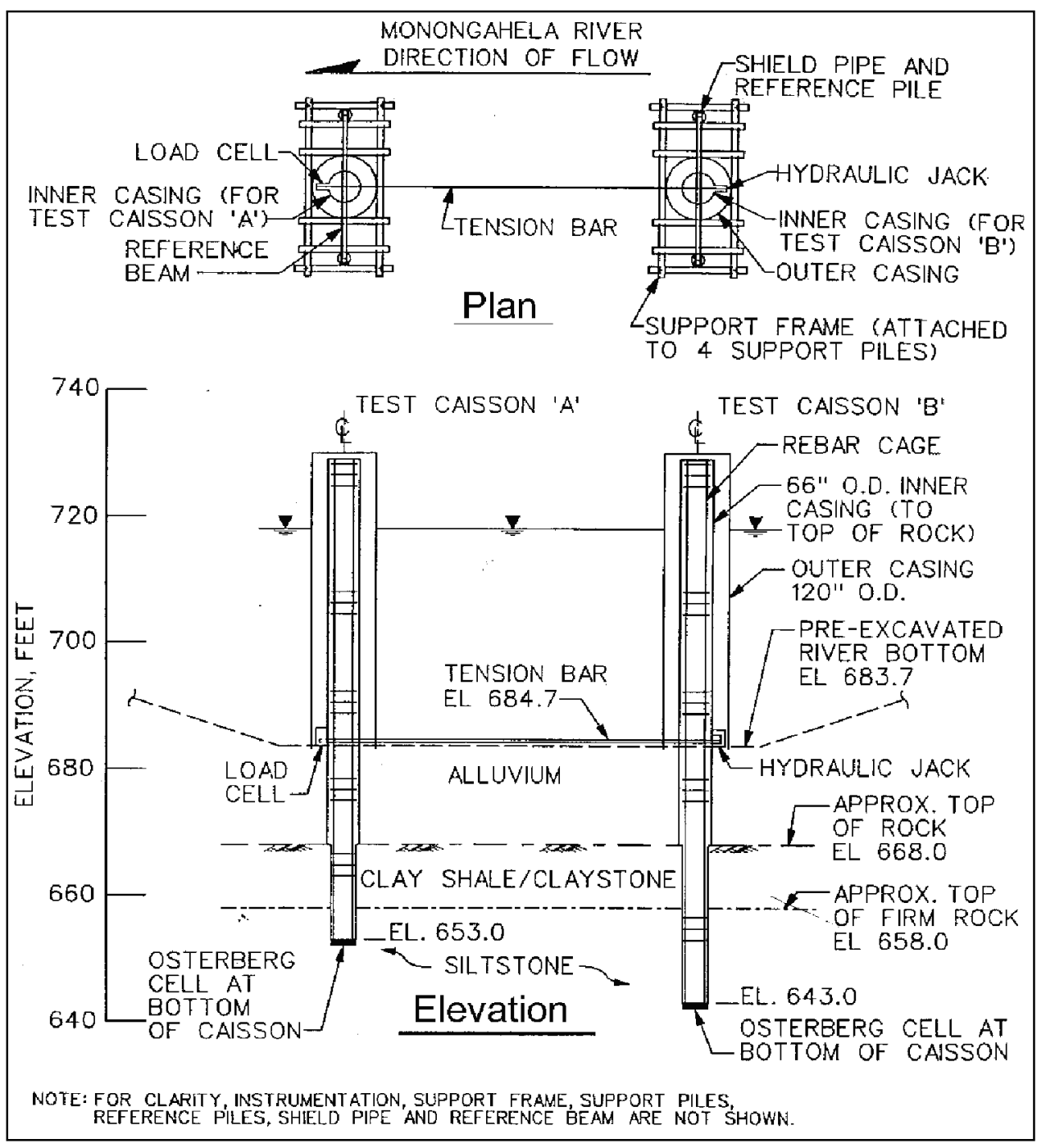

Figure 71. Braddock Locks and Dam 2 drilled shaft load test configuration (after Wahl 1999)

Two 5-ft (1.5-m)-diam concrete-reinforced shafts were embedded 15 and $25 \mathrm{ft}$ (5.1 and $7.6 \mathrm{~m})$, respectively, into the claystone/siltstone bedrock. To the rebar cages for each $70-\mathrm{ft}(21-\mathrm{m})$-long shaft, strain gauges, telltale tubes, CSL tubes, inclinometer tubes, and an Osterberg cell (at its bottom) were attached. The rebar cage was lowered through the casing, and then the casing was 
backfilled with tremied concrete. After the concrete had cured, integrity and performance tests were conducted. Integrity testing was conducted using CSL. Performance testing was conducted using the Osterberg cell for application of axial loads and hydraulic jacks for application of lateral loads. Axial loaddeflection curves were generated to provide end-bearing and side-wall friction resistance design data, while bending moments were generated from the lateral load-deflection curves (Wahl 1999).

Full-scale load tests of underwater drilled shafts have also been conducted at the Ohio River (Kentucky), St. Mary's River (Georgia), and the Apalachicola River (Florida) bridges using the Osterberg cell (Osterberg 1998). Load tests on shafts up to $9 \mathrm{ft}(2.7 \mathrm{~m})$ in diameter were conducted in water depths to $27 \mathrm{ft}$ (8 m).

Over 300 load tests using Osterberg cells have been conducted in over 10 countries. Drilled shafts (bored piles or caissons), driven pipe piles, and driven precast concrete piles up to $10 \mathrm{ft}(3 \mathrm{~m})$ in diameter, driven to depths up to $300 \mathrm{ft}(90 \mathrm{~m})$, have been tested. Loads up to 15,000 tons (135 MN) have been applied using Osterberg cells. Osterberg (1998) lists several installation methods and cell locations for determining side shear resistance and end-bearing values. As an example, Figure 72 shows the test configuration on a drilled shaft subjected to deep scouring.

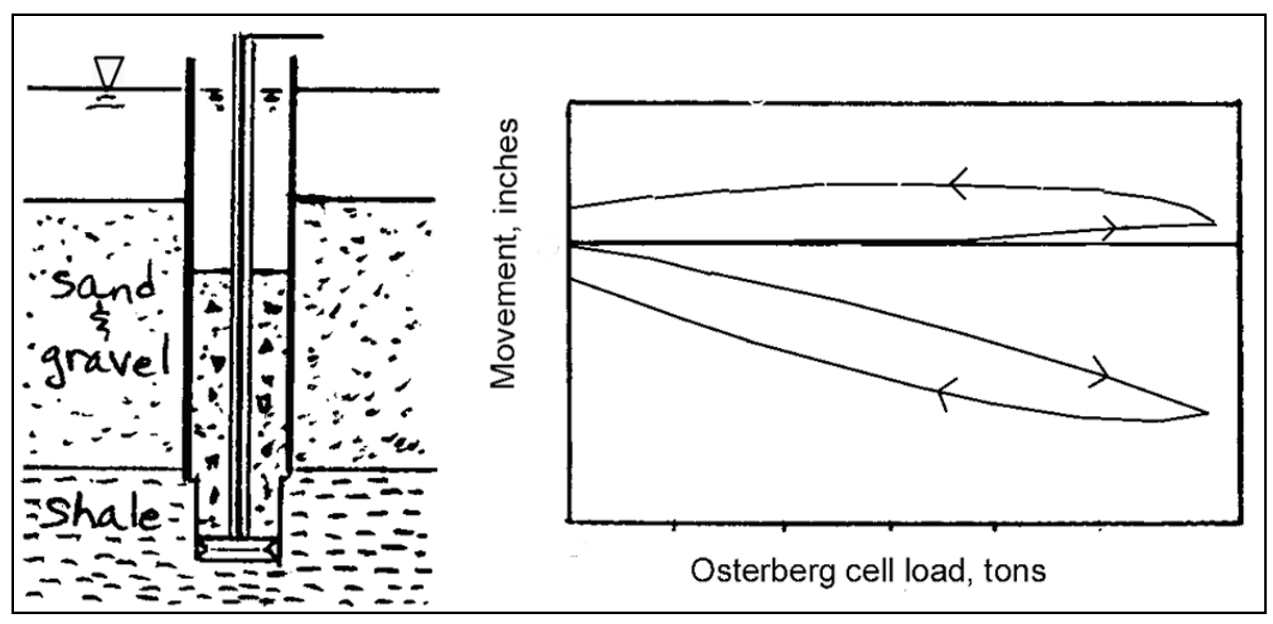

Figure 72. Load test on an underwater drilled shaft showing a test configuration for scour design with load/deflection curve results (after Osterberg 1998)

\section{Long-Term Considerations}

Underwater foundations are designed and constructed for durability and long-term integrity during their service life. After construction is completed, important considerations should include protecting the foundation from scour, corrosion, and deleterious environmental effects and ensuring that the foundation performs as designed. 


\section{Deleterious effects}

Constructed foundations are exposed to swift currents, shifting mudline soils, corrosion, and other (harmful) environmental conditions. Each foundation type is susceptible to any of these conditions to a varying degree.

For example, an improved-site foundation is susceptible to scouring, but corrosion is generally not a consideration. A steel pipe pile foundation exposed above the mudline will be more susceptible to corrosion than a submerged concrete gravity-based foundation. A harmful effect that does not discriminate by foundation materials or foundation types is mudline erosion (scouring), as illustrated in Figure 73.

Scouring. Scouring or erosion is caused by unidirectional water currents, oscillatory waves, and tidal currents. Scouring is the result of the interaction between the water flow field, the obstruction to this flow field (the foundation), and the sediment bed (Machemehl and Abad 1975). The scouring phenomenon has been researched for different foundation types, and several technological advances have been developed to reduce scouring action.

Ninomiya, Tagaya, and Murase (1972) studied the scouring of gravity-based foundations (cylindrical

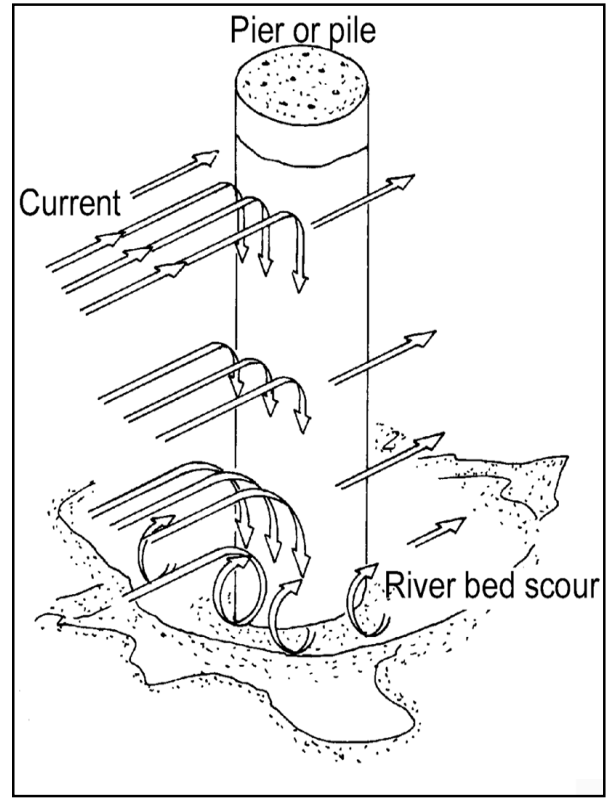

Figure 73. Scour development around a pinned foundation (after Abad and Machemehl 1974) shapes) placed on soft cohesive and sandy soils. Model testing using square foundation shapes resulted in formulas for scouring depth and pattern due to currents. Correlations with other foundation geometry shapes were also made. It was concluded that a skirted hemispheric shape was the most effective shape to resist scouring. Scouring characteristics were also quantified.

For pile foundations, Abad and Machemehl (1974) and Machemehl and Abad (1975) researched the effects of scour caused by oscillatory wave motion and unidirectional currents in a laboratory wave flume. The parameter volumetric scour, rather than scour depth, was studied based upon the controlling factors, which included current velocity, water depth, wave characteristics, and pile diameter. These researchers were able to predict the scour patterns and the magnitude of the scour when the geometric and dynamic similarities of a given foundation were matched to the research results.

Chow and Herbich (1978) studied sand scour due to oscillatory wave motions around a pile group in a laboratory wave flume. Fifteen variables controlling the ultimate scour depth were analyzed. The variables were water depth, density, viscosity, and free stream velocity; wave height, period, and length; sand density, diameter, and friction angle; elapsed time and gravity acceleration; pile diameter and distance between piles; and ultimate scour depth. 
Maidl and Schiller (1979) conducted field research at a gravity-based platform in the North Sea to investigate scour phenomena and protection techniques. The protection techniques included (a) precast slabs hinged to the gravity-based foundation, (b) sandbags in nylon netting, (c) nylon mats filled with colcrete grout, and (d) mats studded with artificial seaweed. Costs, installation techniques, and recommendations were discussed for the first three techniques. It was concluded that the sandbags in nylon netting had the lowest service life and efficiency rating, while the nylon bags filled with colcrete rated the highest.

Sheppard, Niedoroda, and Karanumuni (1990) compiled all previously researched scour phenomena and synthesized the data. These researchers compiled 98 data sets from five investigations of steady flow around vertical cylinders in cohesionless granular soil. They proposed an equation to predict the erosion depth in a scour hole formed by a steady current passing a vertical cylinder.

Scour induced during pipeline installation was addressed by Bijker et al. (1991). Scour induced during cyclic lateral loading of piles was described by Reese, Wang, and Long (1989).

The installation of scour protection consists of side- or fall-pipe dumping, or individually placing selected fill material (rocks and gravel). The most common offshore methods are side-dumping and fall-pipe placement, largely due to the massive quantities of materials that are required around some of the platform foundations (Figure 74) and for seafloor trenched pipelines. For precision placement, the fall-pipe method is most frequently used.

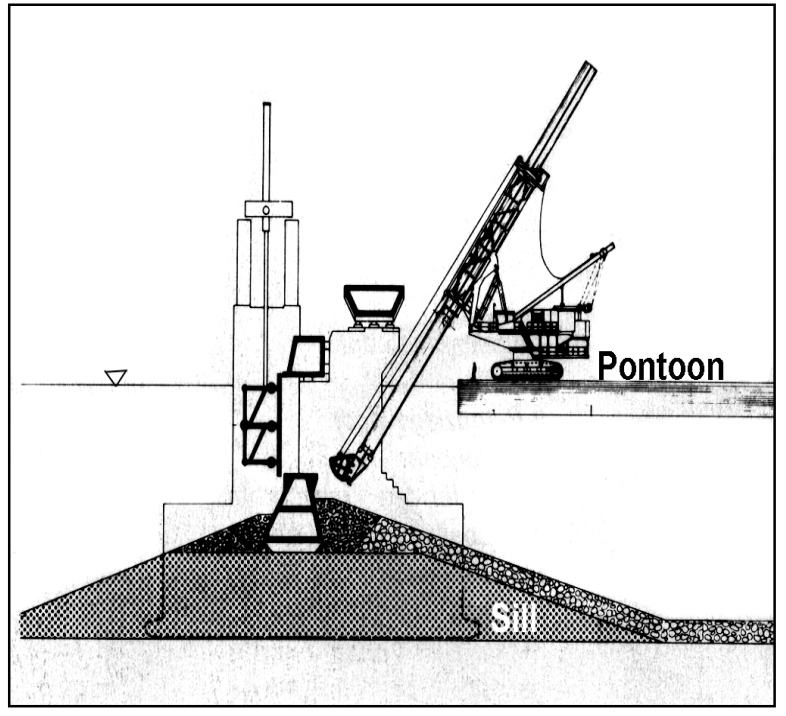

Figure 74. Offshore fall-pipe rock dumping (after Tideway BV 1999)
Specialized vessels are available to place offshore scour protection. For example, Tideway BV (Dredging International NV, Netherlands) has a dynamically positioned (no tug assistance needed) fall-pipe vessel capable of placing 12,000 tons of rock within a $1,644-\mathrm{ft}(500-\mathrm{m})$ zone to a depth of $986 \mathrm{ft}(300 \mathrm{~m})$. Its survey system includes a multibeam echosounder and an ROV that is heavecompensated to within 4 in. $(10 \mathrm{~cm})$ vertical movement. Other large offshore vessels with rock-dumping capabilities are owned by HAM (Hollandsche Beton Groep NV, Netherlands), Ballast Needam NV (Netherlands), and Boskalis Offshore BV (Netherlands).

Precision-placement may also be accomplished by individual rock placement. A specially adapted barge (pontoon) crane deposited rocks weighing 
more than 1 ton on the Oosterschelde project (shown in Figure 75). Basalt rocks weighing 5 to 9 tons (6 to 10 metric tons) were placed as the top layer of scour protection on the submerged pier sills. Rocks weighing less than 1 ton were placed by side-dumping vessels (DOSBOUW 1987).

Corrosion. Corrosion is caused by numerous environmental factors. Its prevention is an important topic, especially to the metallurgical industry. Substantial research has been conducted regarding marine corrosion and fouling, and several organizations, including the National Association of Corrosion Engineers, American Society of Mechanical Engineers, and American Concrete Institute, and publications including Corrosion and Materials Performance have addressed these issues. Steel pilings are especially susceptible to corrosion. For example, the average

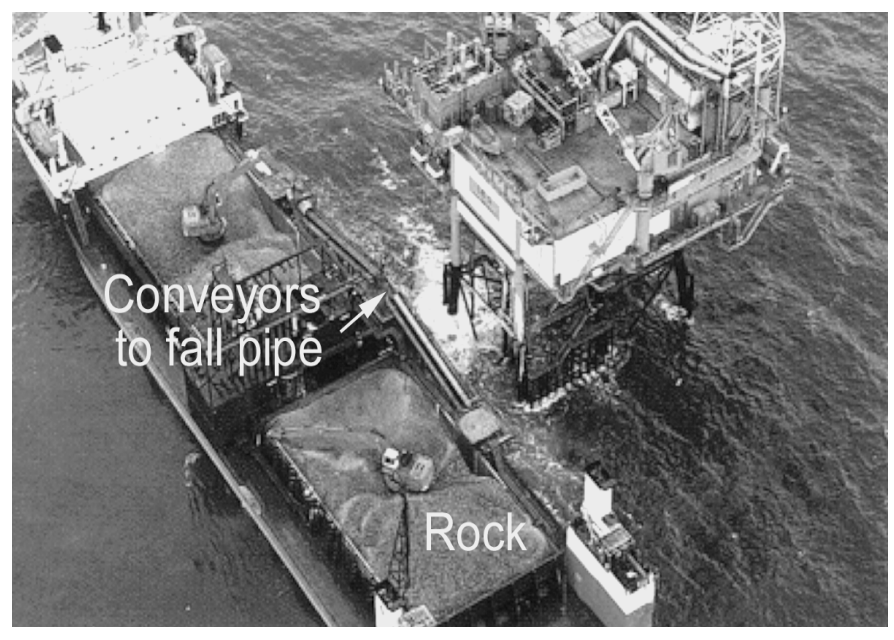

Figure 75. Precision rock placement (after DOSBOUW 1987) general corrosion rate of marine structures in European countries is approximately 5 mils $(0.125 \mathrm{~mm})$ per year (Van Damme and Vrelust 1999).

As illustrated in Figure 76, the corrosion and biological fouling exposure zones on a typical pile include the lower erosion zone, the biological fouling zone, the splash zone, and the atmospheric zone (Escalante and Iverson 1978).

Although each zone has a different corrosion profile, the highest corrosion rate occurs in a narrow band just below the splash zone and is aggravated by fluctuating water levels (Van Damme and Vrelust 1999).

Environmental factors influencing corrosion include dissolved oxygen, temperature, salinity, $\mathrm{pH}$, currents, pressure, and biological fouling (Thomason and Fischer 1991). Corrosion prevention methods for steel piles include barrier type coatings, anodic coatings, cathodic protection, or combinations of these (Escalante and Iverson 1978).

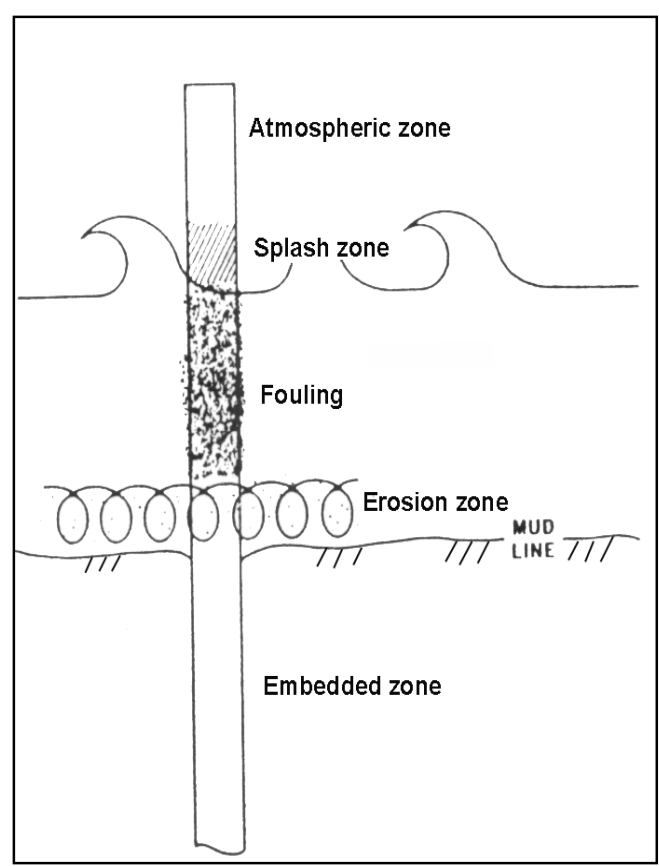

Figure 76. Exposure zones for piling (after Escalante and Iverson 1978)

Escalante et al. (1977) evaluated a variety of coatings and cathodic protection systems on steel piles located off the Atlantic coast over a 15-year period. Van Damme and 
Vrelust (1999) investigated the effects of a two-component coal tar and epoxy coating system over a 15 -year period.

Cathodic protection is needed for long-term corrosion protection of subsea components. The offshore industry has successfully used cathodic protection measures over the last several decades, and reliable systems have been optimized for water depths less than $986 \mathrm{ft}(300 \mathrm{~m})$. For example, North Sea experience has shown that inducing a high current density (e.g., $320 \mathrm{~mA} / \mathrm{sq} \mathrm{m}$ ) on steel piles immediately upon immersion promotes rapid cathodic polarization and formation of high-quality calcareous deposits. The calcareous deposits reduce the dissolved oxygen diffusion rate and thus reduce the long-term current density requirements for cathodic polarization (Thomason and Fischer 1991).

Combination cathodic protection and multicoat paint systems offer greater corrosion resistance. Shell's Gulf of Mexico Auger TLP pile template and piles have a three-coat paint system in addition to cathodic protection with aluminum/zinc/mercury-type anodes. The corrosion protection system was designed in accordance with National Association of Corrosion Engineers (NACE) RP-01-76 for a targeted fatigue life of 1,200 years (Ulbricht et al. 1994).

\section{Foundation behavior monitoring}

Long-term monitoring is required to detect changes in the structure's foundation that may affect the structure's life cycle performance. Periodic inspections and permanent instrumentation are needed to achieve monitoring programs. Offshore regulations list permanent instrumentation requirements

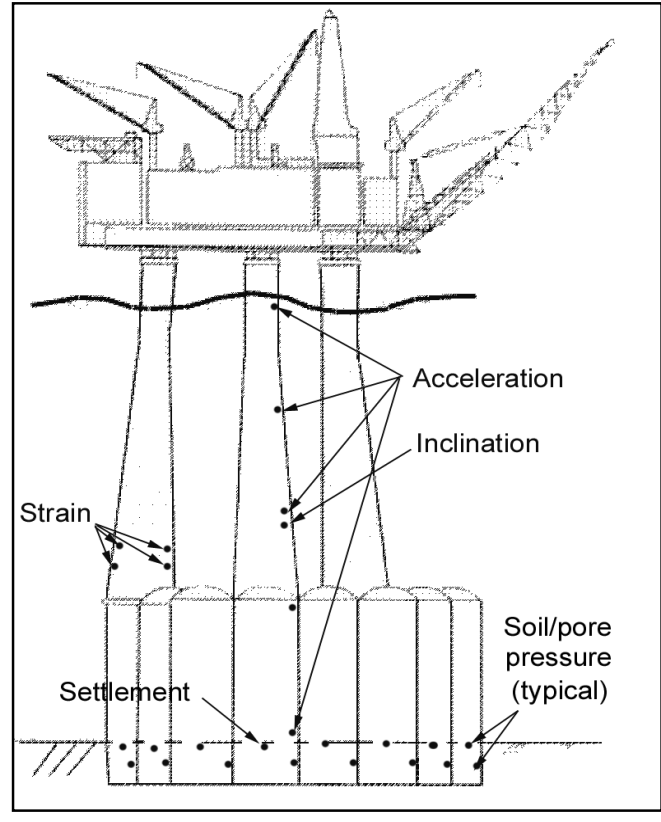

Figure 77. Foundation monitoring sensors on the Gullfaks C platform (after Tjelta 1993) when (a) the foundation depends on an active operation such as drainage systems, (b) design conditions are different or unusual, and (c) foundation settlement, tilt, or penetration need to be monitored (Tjelta 1993).

The skirted gravity-based foundations have a special need for long-term monitoring due to their reliance on active drainage inside the suction skirts. Filters placed on the inside walls of the skirts allow pumping to reduce pore-water pressures. Pressure transducers, accelerometers, settlement gauges, inclinometers, and/or strain gauges are permanently mounted at various locations on the foundations. Tjelta (1993) details the long-term monitoring instrumentation program for the North Sea's Gullfaks platform, shown in Figure 77.

The foundation monitoring system of the North Sea's Hutton TLP includes unique settlement monitoring gauges. Basically, manometer tubes were connected to both the 
piling structure and the adjacent seabed. It was reported by Stock, Jardine, and McIntosh (1993) that the tubes contained pressure transducers capable of detecting differential displacements within an accuracy of $0.1 \mathrm{~mm}$. The transducer outputs were acoustically transmitted to the surface, where settlements were recorded and integrated into the performance monitoring system.

Long-term monitoring of a pile foundation for a jacket platform was detailed by Sharp and Kenley (1993). Strain gauges and accelerometers mounted on the piles and pressure transducers placed beneath the mudmat were monitored beginning with the installation of the platform. Loading variations were recorded as a function of short-term events (such as high wave loading) and long-term performance. 


\section{Summary and Conclusions}

This report provides a general overview and description of geotechnical foundations constructed in the wet (underwater). Case histories of selected (published) in-the-wet foundation projects were chosen. Since the largest quantity of in-the-wet foundations have been constructed offshore, most of the detailed information regarding foundation design and installation was taken from published offshore industry sources.

Three generalized underwater foundation types are described (improved-site, gravity-based, and pinned). Design, installation, and testing considerations are discussed for each foundation type. Site assessment principles remain the same as for onshore foundation sites, but the equipment technology for underwater site investigations may be more innovative and unique. For example, remotely controlled equipment is not commonly used for onshore site investigations. Sampling techniques and equipment may also differ from those used onshore.

Focus is placed on two of the most common pinned foundation types (pipe piles and drilled shafts) for design and installation considerations. The use of the suction pile, which has not been used for onshore applications, is also discussed. Foundation connections (interface between the foundation and structure) are not discussed since they are highly structure-specific.

Installation equipment and procedures are discussed, and differences between onshore and underwater foundation construction techniques are highlighted. Inspection and testing procedures are similar to those onshore, with the exception of pile load test frequency and configurations.

In conclusion, underwater foundations constructed in the wet may allow an alternative to expensive in-the-dry cofferdam construction. Underwater foundations have been used extensively offshore, since in-the-dry installations are not an option in deeper water and, consequently, much of the offshore expertise and technology developed over the last 50 years may be directly applied to the Corps of Engineers shallow (in-the-wet) sites. As the Corps and its contractors develop more experience regarding design and construction of in-thewet foundations (especially for navigation and flood control structures on inland waterways), the innovative in-the-wet construction approach may offer a significantly beneficial alternative to typical in-the-dry construction. 


\section{References}

Abad, G. N., and Machemehl, J. L. (1974). "An experimental study of scour around marine foundations due to oscillatory waves and unidirectional currents," Report 74-5, North Carolina Center for Marine and Coastal Studies, Raleigh, NC.

Abbott, E. L., and George, S. J. (1989). "Underwater foundations for a jack-up barge." Proceedings, ASCE Congress on foundation engineering: Current principles and practice. American Society of Civil Engineers, New York. 2, 1498-1504.

Aerts, F., Devlieger, H., and Vandycke, S. (1999). "Building on soft soils," Bulletin of the International Navigation Association, No. 101 (Apr), 23-25.

Agarwal, S. L., Rawat, P. C, and Paintal, S. S. (1978). "Problems encountered in installation of offshore piles for fixed platforms," OTC 3274. Proceedings, 10th annual offshore technology conference. 3, 1925-31.

Acker, W. L., Jr. (1974). Basic procedures for soil sampling and core drilling, Acker Drill Company, Scranton, PA.

Allen, A. P., Bjorke, M., Saetrevic, T., and Auraaen, E. G. (1990). "The installation design and analysis of the Oseberg 'C' jacket," OTC 6475. Proceedings, 22nd annual offshore technology conference. 4, 463-76.

Alloni, C., D’Agostino, A., and Priarone, R. (1976). "Design, analysis, and construction of the Loango steel gravity platforms," OTC 2437. Proceedings, 8th annual offshore technology conference. 1, 149-64.

Alm, T., Bye, A., and Egeland, S. (1995). "The Draugen platform and subsea structures, installation and foundation aspects," OTC 7670. Proceedings, 27th annual offshore technology conference. 1, 281-87.

American Petroleum Institute. (1989). "Recommended practice for planning, designing, and constructing fixed offshore platforms," API Recommended Practice 2A (RP 2A), 18th ed., Washington, DC.

. (1993). "Recommended practice for planning, designing, and constructing fixed offshore platforms - Load and resistance factor design," API Recommended Practice 2A (RP 2A-LRFD), 1st ed., Washington, DC. 
American Society for Testing and Materials. (1991). Annual book of ASTM standards, 04.08. Philadelphia, PA, 439-44.

. (1993). Annual book of ASTM standards. 04.08, ASTM D4945, Philadelphia, PA, 1146-52.

American Society of Civil Engineers. (1981). "Drilled piers and caissons." Proceedings, Engineering Division, ASCE, National Convention (October 28).

. (1984). Practical guidelines for the selection, design, and installation of piles. Committee on Deep Foundations, New York, 50-70.

. (1992). "Spin-fin piles gain in application," Civil Engineering$A S C E, 62(1), 12-13$.

. (1993). Design of pile foundations, New York.

. (1998). Inland navigation: Locks, dams, and channels. ASCE

Manuals and Reports on Engineering Practice, No. 94. Reston, VA, 295-306.

. (1999a). "Corps chooses 'in-the-wet' technique for replacement project," Civil Engineering, 69(11), 26.

. (1999b). "Sister bridge to resist maximum credible earthquake," Civil Engineering, 69(9), 20.

Andenaes, E., Skomedal, E., and Lindseth, S. (1996). "Installation of the Troll Phase I GBS," OTC 8122. Proceedings, 28th annual offshore technology conference. 3, 57-70.

Andersen, K. H., and Jostad, H. P. (1999). "Foundation design of skirted foundations and anchors in clay," OTC 10824. Proceedings, 31st annual offshore technology conference. 1.

Andersen, K. H., and Lauritzsen, R. (1988). "Bearing capacity for foundations with cyclic loads," ASCE Journal of Geotechnical Engineering 114(5), 540-55.

Andersen, K. H., Kleven, A., and Heien, D. (1988). "Cyclic soil data for design of gravity structures," ASCE Journal of Geotechnical Engineering 114(5), 517-39.

Anderson, V. C., Clinton, J. R., Gibson, D. K., and Kirsten, O. H. (1972). "Instrumenting RUM for in situ subsea soil surveys." Underwater soil sampling, testing, and construction control, ASTM STP 501. American Society for Testing and Materials, Philadelphia, PA, 216-31.

Angelo, W. J. (2000). "Giant concrete tube is sunk to form new road link in Boston," Engineering News-Record, 244(2), 14. 
Angemeer, J. (1972). "Foundation investigations for drilling platforms in Cook Inlet." Underwater soil sampling, testing, and construction control, ASTM STP 501. American Society for Testing and Materials, Philadelphia, PA, 232-41.

Angemeer, J., Carlson, E. D., and Klick, J. H. (1973). "Techniques and results of offshore pile load testing in calcareous soils," OTC 1894. Proceedings, 5th annual offshore technology conference. 2, 679-82.

Angemeer, J., Carlson, E. D., Stroud, S., and Kurzeme, M. (1975). "Pile load tests in calcareous soils conducted in 400 feet of water from a semisubmersible exploration rig," OTC 2311. Proceedings, 7th annual offshore technology conference. 2, 657-63.

Antonakis, C. J. (1972). "A problem of designing and building for a structure at sea," Proceedings of the Institution of Civil Engineers 52(1), 95-126.

Appert, O., and Burger, J. (1997). "France's forty years of experience in offshore technology," OTC 8330. Proceedings, 29th annual offshore technology conference. 4, 553-560.

ARGEMA (Association de Recherche en Geotechnique Marine). (1992). Offshore pile design. Pierre Le Tirant, ed., Editions Technip Publishers, Paris, France.

Armour, T., and Groneck, P. (1998). "Micropile design and construction guidelines and implementation manual," Report FHWA-SA-97-070, Federal Highway Administration.

Audibert, J. M. E., and Hamilton, T. K. (1998). "West Delta 58A site selection and characterization," OTC 8764. Proceedings, 30th annual offshore technology conference.

Aurora, R. P. (1980). "Case studies of pile set-up in the Gulf of Mexico," OTC 3824. Proceedings, 12th annual offshore technology conference. 3, 281-84.

. (1984). "Experience with driving 84-in. piles with underwater and abovewater hammers at the South Brae Platform, North Sea," OTC 4803. Proceedings, 16th annual offshore technology conference. 3, 237-41.

Babcock, F. M., and Miller, H. J. (1972). "Correlation of Standard Penetration Test results with Vibracore sampler penetration rates." Underwater soil sampling, testing, and construction control, ASTM STP 501. American Society for Testing and Materials, 81-89.

Baerheim, M., Hoberg, L., and Tjelta, T. I. (1995). "Development and structural design of the bucket foundations for the Europipe jacket," OTC 7792. Proceedings, 27th annual offshore technology conference. 2, 859-65. 
Baker, C. N., Parikh, G., Briaud, J. L., Drumright, E. E., and Mensah, F. (1993). "Drilled shafts for bridge foundations," Report FHWA-RD-92-004, Federal Highway Adminstration.

Bardgette, J. J., and Irick, J. T. (1977). "Construction of the Hondo platform in 850 feet of water in the Santa Barbara Channel," OTC 2959. Proceedings, 9th annual offshore technology conference. 2, 7-16.

Barksdale, R. D., and Bachus, R. C. (1983). "Design and construction of stone columns," Report FHWA-RD-83-026 and 027 (Vols 1 and 2), Federal Highway Administration.

Barton, N., Lien, R., and Lunde, J. (1974). "Engineering classification of rock masses for the design of tunnel support," Journal of Rock Mechanics 6, 189236.

Batten, P. R. (1987). "Quality assurance for subsea installations." Advances in underwater technology, ocean science, and offshore engineering; Vol 2, Underwater construction: Development and potential. Society for Underwater Technology (Graham \& Trotman), 177-90.

Bauer, Inc. (1994). Information brochure, Schrobenhausen, Germany, http://www.bauer.de.

Bazett, D. J. and Foxall, R. G. (1972). "Control of underwater earthwork at Hugh Keenleyside (Arrow) Dam." Underwater soil sampling, testing, and construction control, ASTM STP 501. American Society for Testing and Materials, Philadelphia, PA, 187-203.

Beasley, C. J., Chambers, R. E., Workman, R. L., Craft, K. L., and Meister, L. J. (1997a). "Repeatability of 3D ocean bottom cable seismic surveys," OTC 8310. Proceedings, 29th annual offshore technology conference. 1, 309-12.

. (1997b). "Repeatability of 3D ocean bottom cable seismic surveys," EdgeNet Online 16(9). Society of Exploration Geophysics, Tulsa, OK. http://www.edge-online.org.

Becker, D. E. (1996). "18th Canadian geotechnical colloquium: Limit states design for foundations, Parts 1 and 2," Canadian Geotechnical Journal 33(6), 956-1007.

Becker, D. E., Burwash, W. J., Montgomery, R. A., and Liu, Y. (1998). "Foundation design aspects of the Confederation Bridge," Canadian Geotechnical Journal 35, 750-68.

Bender, C. H., Jr., Lyons, C. G., and Lowery, L. L., Jr. (1969). “Applications of wave-equation analysis to offshore pile foundations," OTC 1055.

Proceedings, 1st annual offshore technology conference. 1, 575-86. 
Berthin, J. C., Hudson, W. L., Doris, C. G., and Myrabo, D. O. (1985). "Installation of Maureen gravity platform over a template," OTC 4876. Proceedings, 17th annual offshore technology conference. 1, 321-28.

Bieniawski, Z. T. (1974). "Geomechanics classification of rock masses and its application in tunneling. Proceedings of the Third Congress, ISRM, Denver, CO. 2A, 27.

Bijker, R., Staub, C., Silvis, F., and Bruschi, R. (1991). "Scour-induced free spans," OTC 6762. Proceedings, 23rd annual offshore technology conference. 4, 583-88.

Birdwell, J. R., and Jordan, J. E. (1994). "Mobile Bay Project float-on deck installation." Proceedings, 26th annual offshore technology conference. 3 , 323-32.

Bjerrum, A., and Krogh, B. (1998). "Martin 200," Hydro International (May/June).

Bomba, J. G., and Seeds, K. J. (1970). "Pipelining in $600 \mathrm{ft}$ of water: A case study of Washington Natural Gas Company's Puget Sound crossing," OTC 1188. Proceedings, 2nd annual offshore technology conference. 2, I-379-390.

Booth, J. S. and Garrison, L. E. (1978). "A geologic and geotechnical analysis of the upper continental slope adjacent to the Mississippi Delta," OTC 3165. Proceedings, 10th annual offshore technology conference. 2, 1019-28.

Boskalis, Inc. (1999). "Tunnel under the Oresund," The Netherlands, http://www.boskalis.com/ projects/oresund.htm.

Bosscher, P. J., Menclova, E., Russell, J. S., and Wahl, R. E. (1998). "Estimating bearing capacity of piles installed with vibratory drivers," Technical Report CPAR-GL-98-2, U.S. Army Engineer Waterways Experiment Station, Vicksburg, MS.

Bowles, J. E. (1988). Foundation analysis and design. 4th ed., McGraw-Hill, 161-63.

Briaud, J. -L., Riner, K. B., and Ohya, S. (1984). "Cyclic pressuremeter tests for cyclic lateral loads," OTC 4678. Proceedings, 16th annual offshore technology conference. 1, 275-82.

Briaud, J. -L., Smith, T. D., and Meyer, B. J. (1983). "Using the pressuremeter curve to design laterally loaded piles," OTC 4501. Proceedings, 15th annual offshore technology conference. 1, 495-502. 
Broughton, P., and den Hertog, P. D. (1990). "The foundation stability analysis of the Ekofisk Protective Barrier for both the installation and operational conditions," OTC 6240. Proceedings, 22nd annual offshore technology conference. 1, 357-72.

Brown, P. P. (1972). "Construction beyond the Continental Shelf." Underwater soil sampling, testing, and construction control, ASTM STP 501. American Society for Testing and Materials, Philadelphia, PA, 122-80.

Bruce, D. A. (1992). "Recent advances in pinpiling practice." Piling: European practice and worldwide trends. M.J. Sands, ed., Institution of Civil Engineers, Thomas Telford, London, 123-30.

Bruce, D. A. and Juran, I. (1997). "Drilled and grouted micropiles: State of the practice review," Reports FHWA-RD-96-016, 017, 018, and 019, Federal Highway Administration.

Brudno, A. A., and Lancellotti, A. R. (1992). "New concept for designing and constructing immersed tube tunnels without using ballast," Civil Engineering Practice (Fall 1992), 49-58.

Bugge, William A. (1974). "BART in operation-Innovations in rapid transit," ASCE Transportation Engineering Journal 100(TE2), 335-52.

Burt, N. J., and Harris, R. P. (1980). "Design, installation, and testing of belled pile foundations," OTC 3872. Proceedings, 12th annual offshore technology conference. $4,175-85$.

Buslov, V. M., Williams, D. R., Hayes, R. A., and Bivens, H. R. (1984). "Bottom preparation for gravity structures in the Beaufort Sea," OTC 4696.

Proceedings, 16th annual offshore technology conference. 2, 423-32.

Carter, Carol. "Built to last, fast—Confederation Bridge," Ingersoll-Rand (U.S.), Woodcliff Lake, NJ, http://www.irco.com.

Chamberlin, R. S. (1970). "Khazzan Dubai 1: Design, construction, and installation," OTC 1192. Proceedings, 2nd annual offshore technology conference. 2, I-339-350.

Chernauskas, L. R., and Paikowsky, S. G. (1999). "Deep foundations integrity testing: Techniques and case histories," Civil Engineering Practice 14(1), 3955 .

Chow, W. and Herbich, J. B. (1978). "Scour around a group of piles," OTC 3308. Proceedings, 10th annual offshore technology conference. 4, 2243-46.

Christophersen, H. P. (1993). "The non-piled foundation systems of the Snorre Field," Proceedings, international conference on offshore site investigation and foundation behaviour. Society of Underwater Technology, London. 28, 433-47. 
Chua, K. M., Gardner, S., and Lowery, L. L. (1987). "Wave equation analysis of a vibratory hammer-driven pile," OTC 5396. Proceedings, 19th annual offshore technology conference. 1, 339-45.

CIRIA (Construction Industry Research and Information Association). (1993). "The design and construction of sheet-piled cofferdams," Special Publication 95, Thomas Telford Publications, London.

CLAROM (Club des Actions de Recherche sur les Ouvrages en Mer). (1994). "Foundations in carbonate soils." Design Guides for Offshore Structures. Pierre LeTirant and Jean-Francois Nauroy, ed., Editions Technip Publishers, Paris.

Construction Methods and Equipment. (1957). "Pacific Ocean outfall pulled 7 miles in 7 days," August, 140-70.

Construction Specifications Institute (CSI). (1996). Manual of Practice, Alexandria, VA.

Collipp, B. G., and Johnson, P. (1979). "Marine equipment and procedures for the Cognac platform installation," OTC 3498. Proceedings, 11th annual offshore technology conference. 2, 1233-38.

Converse, R. M., Bhattacharjee, S., Chen, J., Windus, J. W., and Raymond, K. G. (1990). "An economical pile-handling technique using dynamic upend," OTC 6397. Proceedings, 22nd annual offshore technology conference. 3, 473-80.

Cox, B. E., and Christy, W. W. (1976). "Underwater pile driving test offshore Louisiana," OTC 2478. Proceedings, 8th annual offshore technology conference. 1, 611-13.

Cunningham, G. R., and Naughton, H. R. (1977). "Design and installation of the piling foundation for the Hondo platform in 850 feet of water in the Santa Barbara Channel," OTC 2843. Proceedings, 9th annual offshore technology conference. 2, 291-96.

Danish Wind Turbine Manufacturers Association (DWTMA). (1998). Copenhagen, Denmark, http://www.windpower.dk.

D’Appolonia, E. (1972). "Introduction." Underwater soil sampling, testing, and construction control, ASTM STP 501. American Society for Testing and Materials, Philadelphia, PA, 1-3.

Dansette, N., and Robertson, N. C. (1994). "Subsea flexible pipeline burial using a lightweight pipeline trencher," OTC 7600. Proceedings, 26th annual offshore technology conference. IV, 847-50. 
Davie, J. R., Ehlers, C. J., and Antes, R. E. (1978). "Properties of Celtic sea chalk," OTC 3211. Proceedings, 10th annual offshore technology conference. 3, 1381-89.

Davies, K. B., and Srivareerat, M. (1999). "Morpeth SeaStar: Foundation and tendon system," OTC 10856. Proceedings, 31st annual offshore technology conference.

Davis, A. G., and Hertlein, B. H. (1991). "Development of nondestructive smallstrain methods for testing deep foundations: A review." Integrity testing of foundations 1991, Transportation Research Record No. 1331. Transportation Research Board of the National Research Council, Washington, DC, 15-20.

Delaney, P. E. (1983). Sandhogs: A history of the tunnel workers of New York, Longfield Press, New York.

Demsky, E. C., and Moore, B. H. (1989). "Design, construction, and load testing of a high capacity caisson." Foundation engineering: Current principles and practices; Proceedings, ASCE Congress. American Society of Civil Engineers, New York. 2, 1486-97.

Department of Energy, United Kingdom. (1986). "Guidance on the design and construction of offshore structures," EMSO, London.

Department of the Army. (1982). "Pile driving equipment," Army Technical Manual 5-849-1, Washington, DC.

. (1983). "Soils and geology procedures for foundation design of buildings and other structures (except hydraulic structures)," Army Technical Manual 5-818-1. Departments of the Army and Air Force, Washington, DC.

. (1992). "Quality assurance representative's guide; 1 , General information and sitework," Engineer Pamphlet 415-1-261, Washington, DC.

. (1994). "Engineering and design for civil works projects," Engineer Regulation 1110-2-1150, Washington, DC.

. (1995). "Periodic inspection and continuing evaluation of completed civil works structures," Engineer Regulation 1110-2-100, Washington, DC.

. (1998). "Specifications," Engineer Regulation 1110-1-8155, Washington, DC.

Det Norske Veritas (1989). "Rules for classification of fixed offshore installations," Oslo, Norway, http://www.dnv.com.

Digre, K. A., Kipp, R. M., and Hunt, R. J. (1999). "Ursa TLP, tendon and foundation design, fabrication, transportation, and TLP installation," OTC 10756. Proceedings, 31 st annual offshore technology conference. 2. 
Digre, K. A., Pelletier, J. H., Larrabee, R. D., Marshall, P. W., and Piter, E. S. (1989). "Design consideration for the Bullwinkle jacket mudmats," OTC 6097. Proceedings, 21st annual offshore technology conference. 2, 489-98.

DiMillio, A. (1999). "A quarter century of geotechnical research," FHWA-RD98-13X, Federal Highway Administration, U.S. Department of Transportation, Washington, DC, http://www.tfhrc.gov/structur/gtr/century.

Dorgant, P. L., Hansen, M. C., Sgouros, G. E., Sezer, F., and Steege, G. T. (1998). "Design and construction of a two-piece lifted jacket for the Enchilada development," OTC 8824. Proceedings, 30th annual offshore technology conference. 2.

DOSBOUW v.o.f. (1987). The storm surge barrier in the Eastern Scheldt. Drukkerij, Lakenman, and Ochtman b.v., Zierikzee, Netherlands.

Dowse, B. E. W. (1979). "Design of hydrostatically supported sand islands for arctic drilling," OTC 3634. Proceedings, 11 th annual offshore technology conference. IV, 2399-2403.

Doyle, E. H. (1999). "Pile installation performance for four TLP's in the Gulf of Mexico," OTC 10826. Proceedings, 31st annual offshore technology conference.

Doyle, E. H., McClelland, B., and Ferguson, G. H. (1971). "Wire-line vane probe for deep penetration measurements of ocean sediment strength," OTC 1327. Proceedings, 3rd annual offshore technology conference. I, 21-32.

Dredging and Port Construction. (1999). "World's largest dredger begins new voyage of discovery," Dredging and Port Construction 26(11).

Dutt, R. N., and Cheng, A. P. (1984). "Frictional response of piles in calcareous deposits," OTC 4838. Proceedings, 16th annual offshore technology conference. 3, 527-34.

Dutt, R. N., and Ingram, W. R. (1988). "Bearing capacity of jack-up footings in carbonate granular sediments," Proceedings, international conference on calcareous sediments, Perth, 291-96.

Dutt, R. N., and Teferra, W. (1986). "CAPWAP analyses increase ability to properly design piles in calcareous soils," OTC 5147. Proceedings, 18th annual offshore technology conference. 1, 569-78.

Dutt, R. N., Doyle, E. H., Nandlal, S., and Ingram, W. B. (1986). "Frictional characteristics of calcareous sands from offshore Florida," OTC 5149. Proceedings, 18th annual offshore technology conference. 1, 589-600. 
Dutt, R. N., Doyle, E. H., Collins, J. T., and Ganguly, P. (1995). “A simple model to predict soil resistance to driving for long piles in deepwater normally consolidated clays," OTC 7668. Proceedings, 27th annual offshore technology conference.

Dutt, R. N., Rainey, W. S., Hamilton, T. K., Pelletier, J. H., and Doyle, E. H. (1997). "Recent advances in deepwater Gulf of Mexico geotechnical investigations," OTC 8303. Proceedings, 29th annual offshore technology conference. 1, 249-57.

Engeling, P. (1974). "Drivability of long piles," OTC 2084. Proceedings, 6th annual offshore technology conference. 2, 521-26.

Engstrom, U. V. (1963). "Innovations at Wanapum Dam," Civil Engineering (Oct), 43-45.

Engineering News-Record. (1996). "Consultant picked to recommend innovative construction methods," 237(10), 18.

Escalante, E., and Iverson, W. P. (1978). "The protection of steel piles by selected coatings in a natural sea water environment," OTC 3190.

Proceedings, 10th annual offshore technology conference. 2, 1215-22.

Escalante, E., Iverson, W. P., Gerhold, W. F., Sanderson, B. T., and Alumbaugh, R. L. (1977). "Corrosion and protection of steel piles in a natural sea water environment," Monograph 158, National Bureau of Standards.

Federal Highway Administration. (1978). "Guidelines for cone penetration test performance and design," FHWA-TS-78-209, U.S. Department of Transportation, Washington, DC.

Ferguson, George H., McClelland, Bramlette, and Bell, Wiley D. (1977). "Seafloor cone penetrometer for deep penetration measurements of ocean sediment strength," OTC 2787. Proceedings, 9th anuual offshore technology conference. 1, 471-78.

Fischer, F. J. (1975). "Driving analysis for initially curved marine conductors," OTC 2309. Proceedings, 7th annual offshore technology conference. 2, 63340 .

Fleming, W. G. K., Weltman, A. J., Randolph, M. F., and Elson, W. K. (1992). Piling engineering. Wiley Publishing, New York.

Focht, J. A., and Kraft, L. M., Jr. (1977). "Progress in marine geotechnical engineering," Journal of the Geotechnical Engineering Division ASCE 103(10), 1097-1118.

Focht, J. A., Jr., Johnson, G. W., and Rivette, C. A. (1986). "Results of recent cone penetrometer testing in the Gulf of Mexico," OTC 5104. Proceedings, 18th annual offshore technology conference. 1, 213-24. 
Foo, S. H. C., Matlock, H., and Meyer, P. L. (1977). "Analysis of driving of foundation piles." Proceedings, 9th annual offshore technology conference. $2,281-86$.

Fountain, J. D. (1979). "Foundation information from exploration seismic data," OTC 3663. Proceedings, 11th anuual offshore technology conference. 4, 2677-82.

Fox, V. S. (1970). "Constructing tanker terminal in 100 feet of water," Civil Engineering (June), 63-65.

Fox, D. A., Parker, G. F., and Sutton, V. J. R. (1970). "Pile driving into North Sea boulder clays," OTC 1200. Proceedings, 2nd annual offshore technology conference. 1, 535-45.

Gemeinhardt, J. P., and Yan, W. K. (1978). "Progress of consolidation of a marine clay in Borneo," OTC 3209. Proceedings, 10th annual offshore technology conference. 3, 1361-66.

Gendron, G. J., Holland, H. A. N., and Ranft, E. V. (1978). “Underwater pile driving hammer at the Maui Field," OTC 3270. Proceedings, 10th annual offshore technology conference. 3, 1887-92.

Geotronics. Sunnyvale, CA, http://www.trimble.com/.

Gerwick, B. C. (1971). "Techniques for increasing the capacities of pin piles in new and existing offshore construction," OTC 1473. Proceedings, $3 r d$ annual offshore technology conference. 1. . (1974). "Preparation of foundations for concrete caisson sea structures," OTC 1946. Proceedings, 6th annual offshore technology conference. 1.

Gerwick News. Ben C. Gerwick, Inc., San Francisco, CA. http://www.gerwick.com/.

(1990, Oct). "Benicia-Martinez Bridge, preliminary foundation design."

(1992, Oct). "Great Belt Eastern Bridge."

(1993, Apr). "Grouting considerations for the drilled insert piles of the Goodwyn 'A' steel jacket offshore platform."

(1996, May). "Tremie concrete restoration of a Florida Keys reef."

(1998, Nov). "Evaluation of lift-in technologies for in-the-wet construction of navigation structures."

(1999, May). "Braddock Dam--construction phase services." 
Gilbert, Stuart, and Horner, Ray. (1984). The Thames Barrier. Thomas Telford, Ltd., London.

Goodman, R. E. (1989). Introduction to rock mechanics. 2nd ed., John Wiley, New York.

Green, Peter. (1996). "Digging it in Boston," Engineering News-Record 237(8), 24-30.

Greer, D. M., and Gardner, W. S. (1986). Construction of drilled pier foundations. Wiley Publishing, New York, 102-35.

Grosch, J. J., and Reese, L. C. (1980). "Field tests of small-scale pile segments in a soft clay deposit under repeated axial loading," OTC 3869. Proceedings, 12th annual offshore technology conference. 4, 143-51.

Ground Engineering. (1999). "Quiet hammer cushions the blow," 32(11), 18.

Halebsky, M., and Wetmore, S. B. (1986). "Seabed strengthening by deep cement mixing," OTC 5108. Proceedings, 18th annual offshore technology conference. 1, 253-59.

Hannigan, P. J., Goble, G. G., Thendean, G., Likins, G. E., and Raushe, F. (1997). "Design and construction of driven pile foundations," Report FHWA-HI-97-013, Federal Highway Administration.

Harris, F. R. (1942). "Evolution of tremie-placed concrete dry docks," Civil Engineering 12(6), 309-14.

Harris, M. (1999). “NRL's improved multibeam system on ORCA," Sea Technology 40(3), 85-88.

Hausmann, M. R. (1990). Engineering principles of ground modification, McGraw-Hill, New York.

Haynes, R., Davis, A. M., Reynolds, J. M., and Taylor, D. I. (1993). "The extraction of geotechnical information from high-resolution seismic reflection data." Proceedings, international conference on offshore site investigation and foundation behaviour, Society of Underwater Technology, London. 28, 215-27.

Hayward Baker. (1999a). "Vibro-Compaction," ISSMFE-TC-17, http://www.haywardbaker.com/compac.html. . (1999b). "Project summaries," Odenton, MD, http://www.haywardbaker.com/project.html.

Hedefine, A., and Silano, L. G. (1968). "Newport Bridge foundations," Civil Engineering 38(11), 37-43. 
Heerema, E. P. (1979). "Pile driving and static load tests on piles in stiff clay," OTC 3490. Proceedings, 11th annual offshore technology conference. 2 , $1135-45$

. (1980). "An evaluation of hydraulic vs. steam pile driving hammers," OTC 3829. Proceedings, 12th annual offshore technology conference. 3, 321-27.

Heijnen, W. J., and Vermeiden, J. (1979). "Site investigation in the Eastern Scheldt, Netherlands." Offshore site investigation (Proceedings of the conference sponsored by the Society for Underwater Technology, The Geological Society of London, and the Institution of Civil Engineers). D.A. Ardus, ed. Graham and Trotman, Ltd., London, 183-93.

Herrmann, G., Raecke, D. A., and Albertsen, N. D. (1972). "Selection of practical seafloor foundation systems," Technical Report R-761, Naval Facilities Engineering Command, Port Hueneme, CA.

Hight, D. W. (1993). "A review of sampling effects in clays and sands." Proceedings, international conference on offshore site investigation and foundation behaviour, Society of Underwater Technology, London. 28, 139-45.

Hironaka, M. C., and Green, W. C. (1971). "A remote controlled seafloor incremental corer," OTC 1325. Proceedings, 3rd annual offshore technology conference. I, 13-20.

Hirsch, T. J., Koehler, A. M., and Sutton, V. J. R. (1975). "Selection of pile driving equipment and field evaluation of pile bearing capacity during driving for the North Sea Forties Field," OTC 2247. Proceedings, 7th annual offshore technology conference. 2, 37-42.

Hirst, T. J., Richards, A. F., and Inderbitzen, A. L. (1972). "A static cone penetrometer for ocean sediments." Underwater soil sampling, testing, and construction control, ASTM STP 501. American Society for Testing and Materials, Philadelphia, PA, 69-80.

Hitchings, G. A., Bradshaw, H., and Labiosa, T. D. (1976). "The planning and execution of offshore site investigations for a North Sea gravity platform." OTC 2430. Proceedings, 8th annual offshore technology conference. 1, 61-72.

Hollingsworth, J. R., and Imbo-Burg, R. M. (1992). "The Atlas screw pileConstruction, design, and performance. Piling: European practice and worldwide trends. M.J. Sands, ed., Institution of Civil Engineers, Thomas Telford Publisher, London, 170-75.

Holloway, D. M., Audibert, J. M. E., and Dover, A. R. (1978). "Recent advances in predicting pile driveability," OTC 3273. Proceedings, 10th annual offshore technology conference. 3, 1915-22. 
Honshu-Shikoku Bridge Authority. (1996). "Substructure construction," Osaka, Japan, http://www.hsba.go.jp/technolo/d-sekou.htm.

Hove, K., and Foss, I. (1974). "Quality assurance for offshore concrete gravity structures," OTC 2113. Proceedings, 6th annual offshore technology conference. 2, 830-41.

Hu, Y., Randolph, M. F., and Watson, P. G. (1999). "Bearing response of skirted foundation on nonhomogeneous soil," Journal of Geotechnical and Geoenvironmental Engineering 125(11), 924-35.

Humphrey, G. D., and Adams, J. B. (1995). "TSP-New solution for geotechnical studies in deep water environments," OTC 7673. Proceedings, 27th annual offshore technology conference. 1, 309-17.

Hunt, M., and Gary, L. (2000). "Gulf of Mexico fabrication yards build 5,500 platforms over 50 years," Offshore 60(1), 94.

Hunteman, J. E., Anastasio, F. L., Jr., and Deshazer, W. A. (1979). "Concrete gravity platform in shallow offshore Louisiana water," OTC 3473. Proceedings, 11th annual offshore technology conference. 2, 1003-06.

IHC Foundation Equipment, B. V. (1999). "IHC Hydrohammer," technical specifications brochure, Kinderdijk, Netherlands.

Inderbitzen, A. L., and Simpson, F. (1972). "A study of the strength characteristics of marine sediments utilizing a submersible." Underwater soil sampling, testing, and constructioncsontrol, ASTM STP 501. American Society for Testing and Materials, 204-15.

James, E. L. (1987). "Geotechnical influences on subsea installations." Advances in underwater technology-Ocean science and offshore engineering; 2,Underwater construction: Development and potential. Society for Underwater Technology, London, 191-202.

Jansz, J. W. (1977). "North Sea pile driving experience with a hydraulic hammer," OTC 2840. Proceedings, 9th annual offshore technology conference. 2, 267-79.

Jansz, J. W., and Brockhoff, H. S. T. (1979). "A simple way to drive freestanding subsea anchor piles," OTC 3439. Proceedings, 11th annual offshore technology conference. 2, 697-705.

Jansz, J. W., Voitus van Hamme, G. E. J. S. L., Gerritse, A., and Bomer, H. (1976). "Controlled piledriving above and under water with a hydraulic hammer," OTC 2477. Proceedings, 8th annual offshore technology conference. 1, 593-603. 
Jardine, R. J., and Overy, R. F. (1996). "Axial capacity of offshore piles driven in dense sand," OTC 7973. Proceedings, 28th annual offshore technology conference. 1, 161-70.

Jeanjean, P., Andersen, K. H., and Kalsnes, B. (1998). "Soil parameters for design of suction caissons for Gulf of Mexico deepwater clays," OTC 8830. Proceedings, 30th annual offshore technology conference. 1.

Johnson, S. J., Compton, J. R., and Ling, S. C. (1972). "Control for underwater construction." Underwater soil sampling, testing, and construction control, ASTM STP 501. American Society for Testing and Materials, Philadelphia, PA, 122-80.

Jonker, G. (1987). "Vibratory pile driving hammers for pile installations and soil improvement projects," OTC 5422. Proceedings, 19th annual offshore technology conference. 2, 549-60.

. (1988). "Subsea installations using vibratory piling hammers," OTC 5776. Proceedings, 20th annual offshore technology conference. 2, 291-304.

Kajima Corporation. (1998). "The Akashi Kaiyo Bridge," Kajima News and Notes, Tokyo, Japan, http://www.kajima.co.jp/topics/news_notes/vol6/v6a.

Karlsrud, K., and Nadim, F. (1990). "Axial capacity of offshore piles in clay," OTC 6245. Proceedings, 22nd annual offshore technology conference. 1, 405-16.

Kobus, L. C. S., and Whittington, L. V. (1978). "Jack-up operational guidelines," OTC 3243. Proceedings, 10th annual offshore technology conference. 3, 1647-56.

Kosowatz, John J. (1995). “Chek Lap Kok airport special report,” Engineering News-Record, 235(25), 24-28.

Kussel, Thomas R., (1986). "Immersed tube tunnels: Concept, design, and construction," Civil Engineering Practice 1(1), 57-78.

Kutter, B. L., Arulanandan, K., and Dafalias, Y. F. (1979). "A comparison of electrical and penetration methods of site investigation," OTC 3488. Proceedings, 11th annual offshore technology conference. 2, 1105-10.

Labbé, J. P., Legras, J. L., and Standing, R. G. (1996). "Smart”Leg: A new method for heavy deck offshore installation,"OTC 8120. Proceedings, 28th annual offshore technology conference. 3, 31-43.

Lacasse, S. (1999). "Ninth OTRC honors lecture: Geotechnical contributions to offshore development," OTC 10822. Proceedings, 31st annual offshore technology conference. 2. 
Lam, I. P., and Martin, G. R. (1986). "Seismic design of highway bridge foundations," Reports FHWA-RD-86-101, 102, and 103, Federal Highway Administration.

Lang, G. R., Jr. (1980). "Predicting the driveability of large diameter offshore piling," OTC 3827. Proceedings, 12th annual offshore technology conference. 3, 301-05.

LeTirant, P., and Nauroy, J. F. (1994). Foundations in carbonate soils; Design guides for offshore structures. CLAROM, Paris, 172.

Liedtke, E. A., and Wright, S. G. (1999). "Computation of slope stability over large areas of the seafloor with variable topography," OTC 10829.

Proceedings, 31 st annual offshore technology conference. 2.

Lieng, J. T., and Bjorgen, H. P. (1995). "New flow-through mudmat design for Heidrun subsea structure," OTC 7671. Proceedings, 27th annual offshore technology conference. 2, 289-99.

Ligterink, A., and Martin, R. (1992). "Field experience installing A-shape piles with a vibratory hammer," OTC 6842. Proceedings, 24th annual offshore technology conference. 1, 301-10.

Ligterink, A., van Zandwijk, C., and Middendorp, P. (1990). "Accurate vertical pile installation by using a hydraulic vibratory hammer on the Arbroath Project," OTC 6236. Proceedings, 22nd annual offshore technology conference. 1, 315-26.

Ling, S. C. (1978). "Four offshore-piled structures installed on Outer Continental Shelf of the Atlantic coast of the United States," OTC 3088. Proceedings, 10th annual offshore technology conference. 2, 345-52.

Loeken, P. A. (1980). "Engineered backfilling on the 36-in. Ekofisk-Emden gas pipeline," OTC 3741. Proceedings, 12th annual offshore technology conference. 1, 53-58.

Lowery, L. L., Jr., Edwards, T. C., and Finley, J. R., Jr. (1969). "Increasing the ability to drive long off-shore piles," OTC 1064. Proceedings, 1st annual offshore technology conference. 1, 681-86.

Lu, B. T. D. (1986). "Axial behavior and capacity of driven piles in calcareous sands," OTC 5248. Proceedings, 18th annual offshore technology conference. 1, 579-88.

Lunne, T., and Powell, J. J. M. (1993). "Recent developments in in-situ testing in offshore soil investigations." Proceedings, international conference on offshore site investigation and foundation behaviour. Society of Underwater Technology, London. 28, 148-80. 
Machemehl, J. L., and Abad, G. (1975). "Scour around marine foundations," OTC 2313. Proceedings, 7th annual offshore technology conference. 2, 692-96.

Mahmood, A., and Hough, J. C. (1978). "Seabottom soil properties and acoustic characteristics," OTC 3208. Proceedings, 10th annual offshore technology conference. 3, 1353-60.

Mahmood, A., and Reifel, A. (1978). "Foundation conditions in outer banks area offshore southern California," OTC 3213. Proceedings, 10th annual offshore technology conference. 3, 1401-08.

Maidl, B., and Schiller, W. (1979). "Testing and experiences of different scour protection technologies in the North Sea," OTC 3470. Proceedings, 11th annual offshore technology conference. 2, 981-84.

Marr, L. S., and Endley, S. N. (1982). "Offshore geotechnical investigation using a cone penetrometer," OTC 4298. Proceedings, 14th annual offshore technology conference. 2, 783-98.

Matlock, H., Bogard, D., and Chan, J. (1998). "Technical program; Tension pile study," OTC 8763. Proceedings, 30th annual offshore technology conference. 2.

Mayfield, J. G., Strohbeck, E. E., and Wilkins, J. R. (1979). "Installation of the pile foundation for the Cognac platform," OTC 3497. Proceedings, 11th annual offshore technology conference. 2, 1221-27.

McCoy, F. W., Jr. (1972). "An analysis of piston coring through corehead camera photography." Underwater soil sampling, testing, and construction control, ASTM STP 501. American Society for Testing and Materials, Philadelphia, PA, 42-54.

McMillin, K. (1999). "Deepwater generates interest in seismic-while-drilling technology," Offshore 59(3).

Menck, Inc. (1999). Kaltenkirchen, Germany, http://www.jraymcdermott.com/ menck/menck_mhut.htm.

Meyer, B. J., Harman, D. E., and King, P. G. (1982). "Introduction of a new offshore cone penetrometer (CPT) device for the Gulf of Mexico," OTC 4299. Proceedings, 14th annual offshore technology conference. 2, 799-808.

Millard, C. F., and Hassani, J. J. (1971). "Graving dock for 300,000-ton ships," Civil Engineering 41(6), 71-74.

Mitcha, J. L., Morrison, C. E., and Oliveira, J. G. (1997). "Concrete colossus," Civil Engineering 67(3), 37-39. 
Mitchell, D. E., and McRae, T. E. (1985). "Densification of submarine hydraulic fills," OTC 4920. Proceedings, 17th annual offshore technology conference, 2, 229-38.

Mosher, D. C., Currie, R. G., and Sullivan, D. (1997). "Monitoring of ocean disposal using side-scan mosaicing," EdgeNet Online, Society of Exploration Geophysicists electronic magazine, http://www.edge-online.org.

Moulai-Khatir, R., O’Neill, M. W., and Vipulanandan, C. (1994). "Program VPDA: Wave equation analysis for vibratory driving of piles," prepared by University of Houston for U.S. Army Engineer Waterways Experiment Station, Vicksburg, MS.

Munn, W. D. (1989). "Wick drains placed underwater." Highway and heavy construction. Cahners Publishing (reprint by Geotechnics America, Inc., Peachtree City, GA).

Murff, J. D. (1996). "The geotechnical centrifuge in offshore engineering," OTC 8265. Proceedings, 28th annual offshore technology conference. 1, 675-89.

Nakayama, J. (1992). "Multi-head hammer drill makes advances in rock socket drilling function for large diameter bored piling." Piling: European practice and worldwide trends. M.J. Sands, ed., Institution of Civil Engineers, Thomas Telford Publishers, London, 342-44.

Narver, D. L., and Graham, E. H. (1958). "Two long ocean outfalls constructed," Civil Engineering 28(1), 38-43.

Nauroy, J. F., and Meunier, J. (1993). "Geosis project: Integration of geotechnical and geophysical data." Proceedings, International conference on offshore site investigation and foundation behaviour. Society of Underwater Technology, London. 28, 107-13.

Neate, J. J. (1989). “Augered cast-in-place piles.” Foundation engineering: Current principles and practices, Proceedings, ASCE Congress. American Society of Civil Engineers, New York. 2, 970-78.

New York State Thruway Internet Site. (1999). "The Governor Malcom Wilson Tappan Zee Bridge," Albany, NY, http://www.thruway.state.ny.us/ factbook/tz.

Nicola, A. D., and Randolph, M. F. (1999). "Centrifuge modelling of pipe piles in sand under axial loads," Geotechnique 49(3), 295-318.

Nielsen, M. J., and Nielsen, K. R. (1981). "Risks and liabilities of specifications." Proceedings, specialty conference: Reducing risk and liability through better specifications and inspection. Construction Division, American Society of Civil Engineers, New York, 4-19. 
Ninomiya, K., Tagaya, K., and Murase, Y. (1972). "A study on suction and scouring of sit-on-bottom type offshore structure," OTC 1605. Proceedings, 4th annual offshore technology conference. 1, 869-78.

Noblanc, A., and Schnader, H. -E. (1983). "Precise seabed emplacement of an articulated loading platform in the North Sea," OTC 4571. Proceedings, 15th annual offshore technology conference. 2, 481-88.

Noorany, I. (1972). "Underwater soil sampling and testing - A state-of-the-art review." Underwater soil sampling, testing, and construction control, ASTM STP 501. American Society for Testing and Materials, Philadelphia, PA, $3-41$.

Norwesco Marine. (1999). "Diving projects," International Journal on Hydropower and Dams 6(3), 45-46.

Offshore Technology. (1999). London, U.K., http://www.offshoretechnology.com/ projects/hibernia/index.html.

O’Neill, M. W. (1988). "Drilled shafts: Construction procedures and design methods," Report FHWA-HI-88-042, Federal Highway Administration.

ORE Offshore Division. (1999). East Falmouth, MA, http://www.ore.com.

Orenberg, P., True, D., Bowman, L, Herrmann, H., and March, R. (1996). "Use of a dropped dynamic penetrometer in cohesionless soil," OTC 8027. Proceedings, 28th annual offshore technology conference. 1, 639-48.

Oresundskonsortiet. (1999). Copenhagen, Denmark, http://www.oresundskonsortiet.com (copyright, 1996, LinneData Oresund $\mathrm{AB})$.

Osterberg, J. O. (1998). "The Osterberg load test method for bored and driven piles, the first ten years." Proceedings, 7th international conference and exhibition on piling and deep foundations. Vienna, Austria. Deep Foundation Institute, Englewood Cliffs, NJ. 1.28.1-1.28.11.

Palmer, W. F., and Roberts, K. C. (1975). "Developments in trench-type tunnel construction." Journal of the Construction Division ASCE 101(CO1), 37-49.

Parkhill, S. T. (1998). "Geotechnical design and construction from 1848 to 1998," Civil Engineering Practice (Fall/Winter), 2.

Parkin, A. K., Yee, Y. W., Tan, C. P., and Willoughby, D. R. (1990). "Driven model piles tested in calcareous sand in a large calibration chamber," OTC 6242. Proceedings, 22nd annual offshore technology conference. 1, 389-97.

Paulson, B. C. (1980). “Tokyo's Dainikoro underwater tube tunnel," Journal of the Construction Division ASCE 106(CO4), 489-97. 
Pearlman, S. L., Richards, T. D., Wise, J. D., and Vodd, W. F. (1997). "Pin piles for bridge foundations - A five year update," Technical Paper, Nicholson Construction Company, Cuddy, PA, http://www.nicholson-rodio.com/papers/ papers.html.

Pelletier, J. H., Murff, J. D., and Young, A. G. (1993). "Historical development and assessment of the current API design methods for axially loaded piles," OTC 7157. Proceedings, 25th annual offshore technology conference. 25382.

Pennine Ground Engineering, Ltd. (1998). "Batu Hijau Project, Sumbawa, Indonesia." Ground Modification Techniques (brochure), Lancashire, England.

Perlow, M., and Richards, A. F. (1972). "In-place geotechnical measurements from submersible ALVIN in Gulf of Maine soils," OTC 1543 (preprint). Proceedings, 4th annual offshore technology conference. 1, I-333-340.

Phair, M. (2000). "Hydraulically powered pile-driving system lands in Florida," Engineering News-Record 244(4), 45.

Pile Buck, Inc. (1999). Palm City, FL, http://www.pilebuck.com.

Pile Dynamics, Inc. (1999). Information brochures, Cleveland, OH, http://web.pile.com.

Ping, W. C. V., Locke, G. E., de Mello, J. R., and de Matos, S. F. D. (1984). "Performance assessment of deep penetration offshore piles driven into calcareous soils," OTC 4836. Proceedings, 16th annual offshore technology conference. 3, 513-26.

Porter, B. W., and Ingram, W. B. (1989). "Post driving prediction of pile capacity," OTC 6003. Proceedings, 21st annual offshore technology conference. 2, 367-72.

Powers, M. B. (1997). "Long, deep, Puerto Rico outfall throws a few placement curves," Engineering News-Record 239(21), 52-54.

Preslan, W. L., and Babb, L. (1979). "Piezometer measurement for deep penetration marine applications," OTC 3461. Proceedings, 11th annual offshore technology conference. 2, 901-08.

Puech, A., Bustamante, M., and Auperin, L. (1990). "Foundation problems in coral soils: A case history- the oil terminal of Matanzas, Cuba," OTC 6238. Proceedings, 22nd annual offshore technology conference. 1, 335-44.

Randolph, M. F., Joer, H. A., Khorshid, M. S., and Hyden, A. M. (1996). "Field and laboratory data from pile load tests in calcareous soil," OTC 7992. Proceedings, 28th annual offshore technology conference. 1, 327-36. 
Rausche, F., Goble, G. G., and Moses, F. (1971). "A new testing procedure for axial pile strength," OTC 1481. Proceedings, 3rd annual offshore technology conference. 2, 633-40.

Raushe, F., Thendean, G., Abou-Matar, H., Likens, G. E., and Goble, G. G. (1997). "Determination of pile driveability and capacity from penetration tests," Reports FHWA-RD-96-179, 180, and 181, Federal Highway Administration.

Redfern, I. J., Calkins, D. E., and Matten, R. B. (1999). "Morpeth SeaStar installation," OTC 10857. Proceedings, 31st annual offshore technology conference. 2.

Reese, L. C. (1984). "Handbook on design of piles and drilled shafts under lateral loads," Report FHWA-IP-84-11, Federal Highway Administration, Washington, DC.

Reese, L. C., and Isenhower, W. M. (2000.) "Deep foundations in the future," Civil Engineering 70(2), A2-A9.

Reese, L. C., Wang, S. T., and Long, J. H. (1989). "Scour from cyclic lateral loading of piles," OTC 6005. Proceedings, 21st annual offshore technology conference. 2, 395-402.

Reid, W. M., Fyffe, S., St. John, H. D., and Rigden, W. J. (1982). "The push-inpressuremeter," Symposium on the pressuremeter and its marine applications. Paris.

Reina, Peter. (1996). "Potsdamer Platz revival begins," Engineering NewsRecord 237(17), 30-34.

Rennie, I. A., and Fried, P. (1979). "An account of the piling problems encountered and the innovative solutions devised during the installation of the Maui 'A' tower in New Zealand," OTC 3442. Proceedings, 11th annual offshore technology conference. 2, 723-30.

Reson, Inc. (1999). Goleta, CA, http://www.reson.com/resnfaq.htm.

Richards, A. F., McDonald, V. J., Olson, R. E., and Keller, G. H. (1972). "Inplace measurement of deep sea soil shear strength." Underwater soil sampling, testing, and construction control, ASTM STP 501. American Society for Testing and Materials, Philadelphia, PA. 55-68.

Rose, W. L., and Grubbs, B. R. (1979). "Field applications of electro-osmosis to increase offshore pile driveability," OTC 3444. Proceedings, 11th annual offshore technology conference. 2, 747-50.

Rushfeldt, P. D. (1981). "Control system for an intelligent underwater trencher," OTC 3985. Proceedings, 11th annual offshore technology conference. 1, 311-18. 
Sangrey, D. A. (1972). "Obtaining strength profiles with depth for marine soil deposits using disturbed samples." Underwater soil sampling, testing, and construction control, ASTM STP 501. American Society for Testing and Materials, Philadelphia, PA, 106-21.

Sangrey, D. A., Clukey, E. C., and Molnia, B. F. (1979). “Geotechnical engineering analysis of underconsolidated sediments from Alaska coastal waters," OTC 3426. Proceedings, 11th annual offshore technology conference. 1, 677-82.

Santiago, J. L., Fragio, A. G., Mingo, J. A., and Charlesworth, P. C. (1986). "Installation of the Gaviota Platform foundation," OTC 5329. Proceedings, 18th annual offshore technology conference. 2, 341-47.

Schwank, S. K. (1997). "Large size sampling tools for offshore exploration," OTC 8283. Proceedings, 29th annual offshore technology conference. 1, $312-22$.

Sea Technology. (1999). "MARSCO conducts deepwater tests using DeepSea Vane," Sea Technology 40(5).

Sele, A., and Skjolde, M. (1993). "Design provisions for offshore grouted construction," OTC 7150. Proceedings, 25th annual offshore technology conference. 2, 165-79.

Senner, D. W. F., and Cathie, D. N. (1993). "Offshore pile design for sites with complex soil conditions," OTC 7197. Proceedings, 25th annual offshore technology conference. 2, 687-94.

Senpere, D., and Auvergne, G. A., (1982). "Suction anchor piles-A proven alternative to driving or drilling," OTC 4206. Proceedings, 14th annual offshore technology conference. 1, 483-87.

Settgast, R. H. (1980). "Marine pile load testing in carbonate rocks," OTC 3868. Proceedings, 12th annual offshore technology conference. 4, 131-41.

Sharp, D. E., and Kenley, R. M. (1993). "Magnus foundation monitoring project: Summary of static and dynamic behaviour." Offshore site investigation and foundation behaviour; Advances in underwater technology, ocean science and offshore engineering, Society for Underwater Technology, London, U.K. 28, 493-98.

Sharples, B. P., Bennett, W. T., and Trickey, J. C. (1989). "Risk analysis of jackup rigs." Second international conference on jack-up drilling platform: Design, construction, and operation. City University, London, 101-23.

Shephard, L. E., Bryant, W. R., and Dunlap, W. A. (1978). "Consolidation characteristics and excess pore water pressures of Mississippi Delta sediments," OTC 3167. Proceedings, 10th annual offshore technology conference. 2, 1037-48. 
Sheppard, D. M., Niedoroda, H., and Karanumuni, A. (1990). "Structure-induced seafloor scour," OTC 6366. Proceedings, 22nd annual offshore technology conference. 3, 213-222.

Simpson, W. F. (1979). "The instrumentation system for the Cognac platform," OTC 3499. Proceedings, 11th annual offshore technology conference. 2, $1245-51$

Sitter, W. R. (1980). "Special offshore piledriving test," OTC 3828. Proceedings, 12th annual offshore technology conference. 3, 313-17.

Smith, A. P. (1987). "New tools and techniques for the underwater inspection of waterfront structures," OTC 5390. Proceedings, 19th annual offshore technology conference. 1, 291-98.

Smith, G. R. (1962). "Carefully placed rock dams," Construction Methods (Nov), 76-79.

Sonsub. (1999). Houston, TX, http://www.sonsub.com/rovs.htm.

Steinke, J. F., and Strasser, R. L. (1978). "Novel approach to construction pile drilling for Alaska Valdez Terminal," OTC 3271. Proceedings, 10th annual offshore technology conference. 3, 1895-99.

Sterling, G. H., Casbarian, A. O. P., Dodge, N. L., and Godfrey, D. G. (1979). "Construction of the Cognac platform, Gulf of Mexico," OTC 3493. Proceedings, 21 st annual offshore technology conference. 1, 465-69.

Stern, I. L., and Alia, B. L. (1980). "Materials, fabrication and inspection requirements for offshore fixed structures," OTC 3743. Proceedings, 12th annual offshore technology conference. 2, 71-78.

Stevens, R. S., Wiltsie, E. A., and Turton, T. H. (1982). "Evaluating pile driveability for hard clay, very dense sand, and rock," OTC 4205. Proceedings, 14th annual offshore technology conference. 2, 1169-73.

Stewart, H. R., Jefferies, M. G., and Goldby, H. M. (1983). "Berm construction for the Gulf Canada Mobile Arctic Caisson," OTC 4552. Proceedings, 15th annual offshore technology conference. 2, 339-46.

Stock, P. J., Jardine, R., and McIntosh, W. (1993). "Foundation monitoring on the Hutton tension leg platform." Offshore site investigation and foundation behaviour: Advances in underwater technology, ocean science and offshore engineering. Society for Underwater Technology, London, U.K. 28, 469-91.

Stockard, D. M. (1979). "Case histories: pile driving in the Gulf of Mexico," OTC 3443. Proceedings, 11th annual offshore technology conference. 2, $737-40$. 
Stockard, D. M. (1986). "Case histories: pile driving offshore India," OTC 5227. Proceedings, 18th annual offshore technology conference. 3, 55-58.

Stokoe, K. H., and Rosenblad, B. L. (1999). "Offshore geotechnical investigation with shear waves," OTC 10823. Proceedings, 31st annual offshore technology conference. 1.

Suction Pile Technology, Inc. (1999). Product brochure, The Netherlands, http://www.suctionpile.com.

Sullivan, R. A., and Ehlers, C. J. (1972). "Practical planning for driving offshore pipe piles," OTC 1600. Proceedings, 4th annual offshore technology conference. 1, 806-14.

Sullivan, R. A., Wright, S. J., and Senner, D. W. F. (1980). "Evaluation of design parameters from laboratory tests." Offshore site investigation (proceedings of the conference sponsored by the Society for Underwater Technology, The Geological Society of London, and the Institution of Civil Engineers). D.A. Ardus, ed., Graham and Trotman, Ltd., London, 201-15.

Suyama, K., Ohya, S., and Imai, T. (1982). "Development of the LLT Pressuremeter and its application in prediction of pile behavior under horizontal loads." Symposium on the pressuremeter and its marine applications. Paris.

Tagaya, K., Heerema, E.P., Uchino, T., and Kusaka, T. (1979). "Pile driveability test on actual offshore platform in calcareous clay for Qatar NGL offshore project," OTC 3440. Proceedings, 11th annual offshore technology conference. 2, 713-16.

Tan, C. P., Parkin, A. K., and Yee, Y. W. (1990). "Monotonic testing of a model pile driven in a calcareous sandy silt," OTC 6243. Proceedings, 22nd annual offshore technology conference. 1, 399-404.

Tanaka, K., Ikejiri, K., Kobayashi, A., Tsuchiya, M., and Nakatsuka, K. (1987). "A study on the installation of a submerged caisson in deep waters," OTC 5606. Proceedings, 19th annual offshore technology conference. 4, 481-88.

Tate, T. N. (1961). "World's largest drydock," Civil Engineering 31(12), 33-37.

Tateishi, H., and Watanabe, Y. (1986). "Leg penetration monitor system to avoid the punch-through accidents of jackup rigs," OTC 5223. Proceedings, 18th annual offshore technology conference. 3, 19-30.

Thomason, W. H., and Fischer, K. P. (1991). "Cathodic protection of steel structures in deep water: A review," OTC 6588. Proceedings, 23rd annual offshore technology conference. 2, 243-52. 
Thornton, P. (1992). “Keynote paper: UK and Eire.” Piling: European practice and worldwide trends. M.J. Sands, ed., Institution of Civil Engineers, Thomas Telford Publisher, London, 6-16.

Tideway BV. (1999). Information brochure, The Netherlands, http://www.tideway.nl.

Tirey, G. B. (1972). "Recent trends in underwater soil sampling methods." Underwater soil sampling, testing, and construction control, ASTM STP 501, American Society for Testing and Materials, Philadelphia, PA, 42-54.

Tjelta, T. I. (1993). "Foundation behaviour of Gullfaks C." Offshore site investigation and foundation behaviour; Advances in underwater technology, ocean science and offshore engineering. Society for Underwater Technology, London, U.K. 28, 451-67.

Tomlinson, M. J. (1994). Pile design and construction practice. 4th ed., E\&FN Spon Publishers, London.

Toolan, F. E., and Horsnell, M. R. (1993). "The evolution of offshore pile design codes and future developments." Offshore site investigation and foundation behaviour: Advances in underwater technology, ocean science and offshore engineering. Society for Underwater Technology, London, U.K. 28, 751-72.

Toppler, J. F., Harris, F. R., and Maaten, R. (1971). "Design of piled breakwater structure for new port of Manfredonia, Italy," OTC 1454. Proceedings, 13th annual offshore technology conference. 2.

Toth, T., Vida, R., and Horvath, F. (1997). "Shallow-water single and multichannel seismic profiling in a riverine environment," EdgeNet Online, Society of Exploration Geophysicists electronic magazine, http://www.edgeonline.org (Nov 1997).

Tsien, S. I. (1986). "Shaft frictional resistance of long pipe piles driven into dense sands," OTC 5150. Proceedings, 18th annual offshore technology conference. 1, 601-10.

Tsinker, Gregory P. (1988). "Pile jetting," ASCE Journal of Geotechnical Engineering 114(3), 326-34.

Ulbricht, W. R., Ripping, M. A., Doyle, E. H., Stevens, J. W., and Mayfield, J. G. (1994). "Design, fabrication, and installation of the Auger TLP foundation system," OTC 7626. Proceedings, 26th annual offshore technology conference. 2, 589-98.

Ultra Electronics. (1999). Greenford, Middlesex, U.K., http://www.ultraelectronics.co.uk/.

U.S. Army Corps of Engineers. (1991). Design of pile foundations, Engineer Manual 1110-2-2906, Washington, DC. 
U.S. Army Corps of Engineers. (1992). "Quality assurance representative's guide," Engineer Pamphlet 415-1-261, Washington, DC.

. (1994). Rock foundations, Engineer Manual 1110-1-2908, Washington, DC.

. (1996). Soil sampling engineer manual, Engineer Manual 1110-11906, Washington, DC.

. (1998). "Construction of new gated dam, Braddock Locks and Dam, Monongahela River, PA," Advertised Solicitation DACW59-99-R0003, Pittsburgh District, PA.

. (1999a). "Inner Harbor Navigation Canal Lock Replacement pile load test and pile installation study," Advertised Solicitation DACW29-99-B0085, New Orleans District, LA.

. (1999b). "Use of single-head multi-beam surveying on Corps of Engineers navigation projects in the Los Angeles District," Engineering and Construction News 1(6), http://www.usace.army.mil/inet/functions/cw/ cecwe/notes/1999/jun99.pdf.

U.S. Army ERDC (Engineer Research and Development Center). (1999). "Monitoring steel cell placement using differential GPS at Lock and Dam 24, Mississippi River," http://crunch.tec.army.mil/information/ publications/Lock_Dam24/cell.htm.

Van Damme, L., and Vrelust, W. (1999). "Low water corrosion of steel pilings," Bulletin of the International Navigation Association 101, 17-20.

Van Oord ACZ. (1999). Newbury, Berkshire, U.K., http://www.voacz.com.

Van Zandwijk, K. (1986). "The effect of deepwater on the performance of slender underwater hammers," OTC 5326. Proceedings, 18th annual offshore technology conference. 4, 313-22.

Van Zandwijk, C., van Dijk, B. P., and Heerema, E. P. (1983). "An improved pile driveability theory for Gulf of Mexico soils," OTC 4503. Proceedings, 15th annual offshore technology conference. 1, 509-15.

Vijayvergiya, V. N., Cheng, A. P., and Kolk, H. J. (1977). "Design and installation of piles in chalk," OTC 2938. Proceedings, 9th annual offshore technology conference. 1, 459-64.

Vines, W. R., and Hong, I. S. (1984). "Lateral load tests on large pipe piles in coral," OTC 4839. Proceedings, 16th annual offshore technology conference. $3,535-38$.

Waddell, J. W. (1997). "Self installing gravity platform concept," OTC 8446. Proceedings, 29th annual offshore technology conference. 3, 99-107. 
Wahl, R. (1999). "Caisson load tests at Monongahela River Locks and Dam 2," Draft report, U.S. Army Engineer Research and Development Center, Vicksburg, MS.

Warrington, D. C. (1989). "Theory and development of vibratory pile-driving equipment," OTC 6030. Proceedings, 21 st annual offshore technology conference. 2, 541-50.

Welham, T. R., and Gilfrin, J. A. (1993). "Installation of grouted pile-sleeve connections: A state-of-the-art review," OTC 7195. Proceedings, 25th annual offshore technology conference. 2, 667-75.

Whitaker, T. (1976). The design of piled foundations. 2nd ed., Pergamon Press, New York.

White, E. I., and Drake, K. R. (1994). "The design, fabrication, and installation of the Alba Northern jacket," OTC 7467. Proceedings, 26th annual offshore technology conference. 2, 467-75.

Will, S. A. (1999). "Compliant towers: The next generation," Offshore (July), 8284.

Will, S. A., Edel, J. C., Kallaby, J., and des Deserts, L. D. (1999). "Design of the Baldplate compliant tower," OTC 10915. Proceedings, 31st annual offshore technology conference. 2.

Wisotsky, S. (1978). "Water hammer pile driver," OTC 3272. Proceedings, 10th annual offshore technology conference. 3, 1905-11.

World Dredging, Mining, and Construction. (1999). "Underwater excavation," June, 4.

Yao, S. X., Berner, D. E., and Gerwick, B. C. (1999). "Assessment of underwater concrete technologies for in-the-wet construction of navigation structures," Technical Report INP-SL-1, U.S. Army Engineer Research and Development Center, Vicksburg, MS, 50.

Young, A. G., Kraft, L. M., and Focht, J. A. (1975). "Geotechnical considerations in foundation design of offshore gravity structures," OTC 2371. Proceedings, 7th annual offshore technology conference. 2, 367-80.

Zuidberg, H. M., and Vergobbi, P. (1996). "EURIPIDES, load tests on large driven piles in dense silica sands," OTC 7977. Proceedings, 28th annual offshore technology conference. 1, 193-206. 


\section{Appendix A}

\section{Underwater Foundation References by Topic}

\section{Case Histories-Bridges}

Becker, D.E., Burwash, W.J., Montgomery, R.A., and Liu, Y. (1998).

"Foundation design aspects of the Confederation Bridge," Canadian Geotechnical Journal 35, 750-768.

Carter, C. (1998). "Built to last, fast--Confederation Bridge," from Internet site http://www.irco.com.

Delaney, P.E. (1983). Sandhogs: a history of the tunnel workers of New York. Longfield Press, New York.

Gerwick, B.C., and Bach, P.E. (1992). "Great Belt Eastern Bridge Foundations," Gerwick News Internet site http://www.gerwick.com.

Gilmour, R., Sauvageot, G., Tassin, D., and Lockwood, J.D. (1997).

"Northumberland's Ice Breaker," American Society of Civil Engineers, Civil Engineering 67(1), 35-37.

Hedefine, A., and Silano, L.G. (1968). "Newport Bridge foundations," American Society of Civil Engineers, Civil Engineering 38(11), 37-43.

Honshu-Shikoku Bridge Authority. (1996). "Substructure construction," Osaka, Japan, http://www.hsba.go.jp/technolo/d-sekou.htm.

Kajima Corp. (1998). "The Akashi Kaiyo Bridge," Kajima News and Notes, Tokyo, Japan, http://www.kajima.co.jp/topics/news_notes/vol6/v6a.

New York State Thruway Internet site. (1999). "The Governor Malcom Wilson

Tappan Zee Bridge,” Albany, NY, http://www.thruway.state.ny.us/ factbook/tz. 


\section{Case Histories-Immersed Tube Tunnels and Pipelines}

Angelo, W.J. (2000). "Giant concrete tube is sunk to form new road link in Boston," Engineering News-Record 244(2), 14.

Boskalis, Inc. (1999). "Tunnel under the Oresund," http://www.boskalis.com/ projects/oresund.htm.

Brudno, A.A., and Lancellotti, A.R. (1992). "New concept for designing and constructing immersed tube tunnels without using ballast," American Society of Civil Engineers, Civil Engineering Practice, Fall 1992, pp 49-58.

Bugge, William A. (1974). "BART in operation-Innovations in rapid transit," ASCE Transportation Engineering Journal 100(TE2), May, 335-352.

Construction Methods and Equipment. (1957). "Pacific Ocean outfall pulled 7 miles in 7 days," Construction Methods and Equipment, August, pp 140-170.

Green, Peter. (1996). “Digging it in Boston,” Engineering News-Record 237(8), 24-30.

Kosowatz, John J. (1995). “Chek Lap Kok airport special report,” Engineering News-Record 235(25), 24-28.

Kussel, Thomas R. (1986). "Immersed tube tunnels: concept, design, and construction," Boston Society of ASCE, Civil Engineering Practice 1(1), $57-78$.

Narver, D.L., and Graham, E.H. (1958). "Two long ocean outfalls constructed," American Society of Civil Engineers, Civil Engineering 28(1), 38-43.

Oresundskonsortiet. (1999). Internet site http://www.oresundskonsortiet.com, copyright 1996, LinneData Oresund AB.

\section{Case Histories-Navigation, Flood Control, and Dam Structures}

Abbott, E.L., and George, S.J. (1989). "Underwater foundations for a jack-up barge." Proceedings, ASCE Congress on Foundation Engineering: Current Principles and Practice, Vol 2, American Society of Civil Engineers, New York, pp 1498-1504.

Adee, Bruce H. (1976). "A review of developments and problems in using floating breakwaters," Proceedings, 8th Annual Offshore Technology Conference. 2, 225-236. 
American Society of Civil Engineers (ASCE). (1998). Inland navigation: locks, dams, and channels. ASCE Manuals and Reports on Engineering Practice No. 94, ASCE, Reston, VA, pp 295-306.

(1999). "Corps chooses 'in-the-wet' technique for replacement project," Civil Engineering 69(11), 26.

Demsky, E.C., and Moore, B.H. (1989). "Design, construction, and load testing of a high capacity caisson," Foundation Engineering: Current Principles and Practices, Proceedings, ASCE Congress, Vol 2, ASCE, New York, pp 14861497.

DOSBOUW v.o.f. (1987). The storm surge barrier in the Eastern Scheldt, printed by Drukkerij, Lakenman, and Ochtman b.v., Zierikzee, Netherlands.

Engstrom, U.V. (1963). "Innovations at Wanapum Dam," Civil Engineering, American Society of Civil Engineers, October, pp 43-45.

ENR. (1996). "Consultant picked to recommend innovative construction methods," Engineering News-Record 237(10), 18.

Gerwick, B.C. (1998). Gerwick News Internet site http://www.gerwick.com/ News.

Gilbert, Stuart, and Horner, Ray. (1984). The Thames_Barrier, Thomas Telford Ltd. publishers, London, England.

Smith, G.R. (1962). "Carefully placed rock dams," Construction Methods, November, pp 76-79.

Steinke, J.F., and Strasser, R.L. (1978). "Novel approach to construction pile drilling for Alaska Valdez Terminal," OTC 3271. Proceedings, 10th Annual Offshore Technology Conference. 3, 1895-1899.

U.S. Army Corps of Engineers. (1998). "Construction of new gated dam, Braddock Locks and Dam, Monongahela River, PA," Advertised Solicitation DACW59-99-R-0003, Pittsburgh District, PA.

(1999). "Inner Harbor Navigation Canal Lock Replacement pile load test and pile installation study," Advertised Solicitation DACW29-99-B0085, New Orleans District, LA.

\title{
Case Histories-Offshore Oil Platform Structures
}

\author{
Albert, L.F., Holtz, R.D., and Magris, E. (1987). "The superpile system: A \\ feasible alternate foundation for TLP in deep water," OTC 5392. \\ Proceedings, 19th Annual Offshore Technology Conference. 1, 307-314.
}


Allen, A. P., Bjorke, M., Saetrevic, T., and Auraaen, E.G. (1990). "The installation design and analysis of the Oseberg 'C' jacket," OTC 6475. Proceedings, 22nd Annual Offshore Technology Conference. 4, 463-476.

Alm, T., Bye, A., Sandvik, K., and Egeland, S. (1995). "The Draugen platform and subsea structures, installation and foundation aspects," OTC 7670. Proceedings, 27th Annual Offshore Technology Conference. 1, 281-287.

Appert, O., and Burger, J. (1997). "France's forty years of experience in offshore technology," OTC 8330. Proceedings, 29th Annual Offshore Technology Conference. 4, 553-560.

Baerheim, M., Hoberg, L., and Tjelta, T.I. (1995). "Development and structural design of the bucket foundations for the Europipe jacket," OTC 7792. Proceedings, 27th Annual Offshore Technology Conference. 2, 859-865.

Baerheim, M., Fossan, T.I., and Eriksen, K. (1990). "Design and installation of the Veslefrikk jacket," OTC 6307. Proceedings, 22nd Annual Offshore Technology Conference. 2, 331-340.

Bardgette, J.J., and Irick, J.T. (1977). "Construction of the Hondo platform in 850 feet of water in the Santa Barbara Channel," OTC 2959. Proceedings, 9th Annual Offshore Technology Conference. 2, 7-16.

Berner, D.E., and Dahlgren, Thomas. (1992). "Concrete platforms in the North Sea," Gerwick News (Oct 1992). http://www.gerwick.com.

Beskow, R.H., Dunn, P.J., Metcalf, M.F., and Benoit, P.S. (1987). “A removable bottom-founded structure for iceberg-infested waters," OTC 5425. Proceedings, 19th Annual Offshore Technology Conference. 2, 19-30.

Bowman, L.E., Forrest, J., Taylor, R.J., and Seelig, B. (1994). "Pile-driven plate anchors for fleet moorings," OTC 7490. Proceedings, 26th Annual Offshore Technology Conference. 3, 225-232.

Broughton, P., and Koenekoop, C. (1989). "Detailed design and installatin aspects of the protective barrier to surround the Ekofisk 2/4 Storage Tank," OTC 5907. Proceedings, 21 st Annual Offshore Technology Conference. 1, 235-262.

Chamberlin, R.S. (1970). "Khazzan Dubai 1: Design, construction, and installation," OTC 1192. Proceedings, 2nd Annual Offshore Technology Conference. 2, I-339-I-350.

Christian, John T., Taylor, Peter K., Ten, John K.C., and Erali, David R. (1974). "Large diameter underwater pipeline for nuclear power plant designed against soil liquefaction," OTC 2094. Proceedings, 6th Annual Offshore Technology Conference. 2, 597-606. 
Christophersen, H.P. (1993). "The non-piled foundation systems of the Snorre Field." Proceedings of International Conference on Offshore Site Investigation and Foundation Behaviour, Vol 28, Society of Underwater Technology, London, pp 433-447.

Collipp, B.G., and Johnson, P. (1979). "Marine equipment and procedures for the Cognac platform installation," OTC 3498. Proceedings, 11th Annual Offshore Technology Conference. 2, 1233-1244.

Cunningham, Gerald R., and Naughton, Henry R. (1977). "Design and installation of the piling foundation for the Hondo platform in 850 feet of water in the Santa Barbara Channel," OTC 2843. Proceedings, 9th Annual Offshore Technology Conference. 2, 291-298.

Davies, K.B., and Srivareerat, M. (1999). "Morpeth SeaStar: Foundation and tendon system," OTC 10856. Proceedings, 31st Annual Offshore Technology Conference. 2.

Digre, K.A., Brasted, L.K., and Marshall, P.W. (1989). "The design of the Bullwinkle Platform," OTC 6050. Proceedings, 21st Annual Offshore Technology Conference. 3, 63-80.

Digre, K.A., Kipp, R.M., and Hunt, R.J. (1999). "Ursa TLP, tendon and foundation design, fabrication, transportation, and TLP installation," OTC 10756. Proceedings, 31st Annual Offshore Technology Conference. 2.

Enze, C.R., Brasted, L.K., Arnold, J.S., Breaux, J.N., and Luyties, W.H. (1994). "Auger TLP design, fabrication, and installation overview," OTC 7615. Proceedings, 26th Annual Offshore Technology Conference. 3, 379-387.

Fines, S., Stove, O.J., and Guldberg, F. (1991). "Snorre TLP tethers and foundation," OTC 6623. Proceedings, 23rd Annual Offshore Technology Conference. 2, 587-598.

Fjeld, S., Hall, M.E., Hoff, G.C., Michel, D., Robberstad, L.,Vegge, A., and Warland, T.A. (1994). "The North Sea concrete platforms: 20 years of experience," OTC 7462. Proceedings, 26th Annual Offshore Technology Conference. 2, 427-441.

Gerwick News. (1993). "Grouting considerations for the drilled insert piles of the Goodwyn 'A' platform," Gerwick News (Apr 1993).

http://www.gerwick.com.

Godfrey, D.G., and Huete, D.A. (1979). "Measurement techniques and misalignment analysis for the three-part Cognac platform installation," OTC 3495. Proceedings, 11 th Annual Offshore Technology Conference. 2, 1199-1208. 
Goepfert, B.L. (1969). "An Engineering Challenge: Cook Inlet, Alaska," OTC 1048. Proceedings, 1st Annual Offshore Technology Conference. 1, $511-524$

Howe, R.J. (1986). "Evolution of offshore drilling and production technology," OTC 5354. Proceedings, Eighteenth Annual Offshore Technology Conference. 4, 593-603.

Hunt, M., and Gary, L. (2000). "Gulf of Mexico fabrication yards build 5,500 platforms over 50 years," Offshore 60(1), 94.

Hunteman, J. E., Anastasio, F. L. Jr., Deshazer, W. A. (1979). "Concrete gravity platform in shallow offshore Louisiana water," OTC 3473. Proceedings, 11th Annual Offshore Technology Conference. 2, 1003-1008.

Javanmardi, K., Froster, L.D., Flodberg, K.D., Simon, B.W., Marsh, G.L., Gonzalez, R., Michel, D.L., and Travis, T.R. (1994). "Auger predrill challenges and innovations," OTC 7618. Proceedings, 26th Annual Offshore Technology Conference. 4, 903-912.

Knudsen, A., Skjaeveland, H., Lindseth, S., and Høklie, M. (1994). "Recordbreaking water depth for fixed concrete platforms," OTC 7463. Proceedings, 26th Annual Offshore Technology Conference. 2, 443-454.

Kobus, L.C.S., and Whittington, L.V. (1978). "Jack-up operational guidelines," OTC 3243. Proceedings, 10th Annual Offshore Technology Conference. 3, 1647-1656.

Korsgaard, J., and Hutter, L. (1995). "The suction mooring, a new type of offshore single point mooring," OTC 7711. Proceedings, 27th Annual Offshore Technology Conference. 2, 177-190.

Lacasse, S. (1999). "Ninth OTRC honors lecture: Geotechnical contributions to offshore development," OTC 10822. Proceedings, 31st Annual Offshore Technology Conference. 2.

Lacasse, S., Goulois, A., Robberstad, L., Andersen, E., and Boisard, P. (1991). "The foundation of the Frigg CDP1 gravity platform: A case study," OTC 6512. Proceedings, 23rd Annual Offshore Technology Conference. 1, $125-132$.

Lecourt, E.J., Jr., and Williams, D.W. (1971). "Deep ocean mining-New application for oil field and marine equipment," OTC 1412. Proceedings, Third Annual Offshore Technology Conference. I, 859-874.

Ling, S.C. (1978). "Four offshore-piled structures installed on outer continental shelf of the Atlantic coast of the United States," OTC 3088. Proceedings, 10th Annual Offshore Technology Conference. 1, 345-352. 
Lohse, Alan, and Crump, Joseph R. (1974). "International inventory and forecast of ocean offshore drilling rigs, surface vessels, and certain undersea apparatus owned by U. S. petroleum and mining companies and foreign subsidiaries, Year-End 1972 to Year 1985," OTC 2088. Proceedings, 6th Annual Offshore Technology Conference. 2, 561-574.

Mancini, C.V., Dowse, B.E.W., and Chevallier, J-M. (1983). "Caisson retained island for Canadian Beaufort Sea: Geotechnical design and construction considerations," OTC 4581. Proceedings, 15th Annual Offshore Technology Conference. 3, 17-22.

Masuda, Y., Cruickshank, M.J., and Mero, J.L. (1971). "Continuous bucket-line dredging at 12,000 feet," OTC 1410. Proceedings, Third Annual Offshore Technology Conference. I, 837-858.

Mayfield, J. G., Strohbeck, E. E., Oliver, J. C., and Wilkins, J. R. (1979). "Installation of the pile foundation for the Cognac platform," OTC 3497. Proceedings, 11th Annual Offshore Technology Conference. 2, 1221-1232.

Mitcha, J.L., Morrison, C.E., and Oliveira, J.G. (1997). "Concrete colossus," ASCE, Civil Engineering 67(3), 37-39.

Noble, H. (1976). "Use of Wave-Maze Flexible Floating Breakwater to Protect Offshore Structures and Landings," OTC 2542. Proceedings, 9th Annual Offshore Technology Conference. 2, 215-224.

Offshore Technology. (1999). Internet site http://www.offshoretechnology.com/projects.

Puech, A., Bustamante, M., and Auperin, L. (1990). "Foundation problems in coral sands: Case history - the oil terminal of Matanzas, Cuba," OTC 6238. Proceedings, 22nd Annual Offshore Technology Conference. 1, 335-344.

Picard, Jacques, and Agnes, H., (Buck). (1976). "G. B. S. A new design of gravity platform with structure in steel," OTC 2432. Proceedings, 9th Annual Offshore Technology Conference. 1, 83-88.

Piter, E. S., Sterling, G. H., and Cox, B. E. (1979). "Development of an alignment system for the three-part Cognac platform jacket," OTC 3496. Proceedings, 12th Annual Offshore Technology Conference. 2, 1209-1220.

Rennie, I. A., and Fried. (1979). "An account of the piling problems encountered and the innovative solutions devised during the installation of the Maui A Tower In New Zealand," OTC 3442. Proceedings, 12th Annual Offshore Technology Conference. 2, 723-736.

Riles, W.G., and Thornton, W.L. (1988). "The pre-installed foundation concept jacket: A case history," OTC 5639. Proceedings, 20th Annual Offshore Technology Conference. 1, 207-214. 
Rusaas, P., Giske, S.R., Barrett, G., Christiansen, P.E., and Baerheim, M. (1995). "Design, operations, planning, and experience from the marine operations for the Europipe jacket with bucket foundation," OTC 7794. Proceedings, 27th Annual Offshore Technology Conference. 2, 885-895.

Santiago, J.L., Fragio, A.G., Mingo, J.A., and Charlesworth, P.C. (1986).

"Installation of the Gaviota Platform foundation," OTC 5329. Proceedings, 18th Annual Offshore Technology Conference. 4, 341-347.

Senpere, D., and Auvergne, G.A. (1982). "Suction anchor piles-a proven alternative to driving or drilling," OTC 4206. Proceedings, 14th Annual Offshore Technology Conference. 1, Houston, May, 483-487.

Stepanek, O., Ahlers, E., and Mckee, K.E. (1969). "Comparison of offshore airport construction," OTC 1129. Proceedings, 1st Annual Offshore Technology Conference. 2, 465-470.

Sterling, G.H., Casbarian, A.O.P., Dodge, N.L., and Godfrey, D.G. (1979). "Construction of the Cognac platform, 1025 feet of water, Gulf Of Mexico," OTC 3493. Proceedings, 11th Annual Offshore Technology Conference. 2, 1169-1184.

Sterling, G.H., Cox, B.E., and Warrington, R.M. (1979). "Design of the Cognac platform for 1025 feet water depth, Gulf Of Mexico," OTC 3494.

Proceedings, 11th Annual Offshore Technology Conference. 2, 1185-1198.

Stockard, D.M. (1979). "Case histories: pile driving in the Gulf of Mexico," OTC 3443. Proceedings, 11th Offshore Technology Conference. 2, 737-740. . (1986). "Case histories: pile driving offshore India," OTC 5227. Proceedings, 18th Offshore Technology Conference. 3, 55-58.

Sybert, J.H., Meith, R.M., and Gass, J.D. (1978). "A drilling platform for a soft foundation location," OTC 3048. Proceedings, 10th Offshore Technology Conference. 1, 49-54.

Synodis, Steve T., and Flory, John F. (1977). "Six years experience with the Brega Single Anchor Leg Mooring," OTC 2824. Proceedings, 9th Annual Offshore Technology Conference. 2, 135-140.

Toppler, J.F., and Maaten, R. (1971). "Design of piled breakwater structure for New Port of Manfredonia, Italy," OTC 1454. Proceedings, Third Annual Offshore Technology Conference. II, 369-384.

Ulbricht, W.R., Ripping, M.A., Doyle, E.H., Stevens, J.W., and Mayfield, J.G. (1994). "Design, fabrication, and installation of the Auger TLP foundation system," OTC 7626. Proceedings, 26th Annual Offshore Technology Conference. 2, 589-598. 
White, E.I., and Drake, K.R. (1994). "The design, fabrication, and installation of the Alba Northern jacket," OTC 7467,. Proceedings, 26th Annual Offshore Technology Conference. 2, 467-475.

White, G.J., Preston, S., and McKenzie, R.H. (1985). "The Hutton TLP foundation installation," OTC 4949. Proceedings, 17th Annual Offshore Technology Conference. 2, 457-468.

Will, S.A. (1999). "Compliant towers: the next generation," Offshore, July, pp 82-84.

Will, S.A., Edel, J.C., Kallaby, J., and des Deserts, L.D. (1999b). "Design of the Baldplate compliant tower," OTC 10915. Proceedings, 31st Annual Offshore Technology Conference. 2.

\section{Case Histories-Other Underwater-Founded Structures}

Bomba, J.G., and Seeds, K.J. (1970). "Pipelining in $600 \mathrm{ft}$ of water: a case study of Washington Natural Gas Company's Puget Sound crossing," OTC 1188. Proceedings, 2nd Annual Offshore Technology Conference. 2, I-379-I-390.

Bruce, D.A. (1992). "Recent advances in pinpiling practice," Piling: European Practice and Worldwide Trends, edited by M.J. Sands, Institution of Civil Engineers, Thomas Telford, London, pp 123-130.

DWTMA. (1998). Internet site of the Danish Wind Turbine Manufacturers Association (DWTMA), http://www.windpower.dk, February.

Fox, V.S. (1970). "Constructing tanker terminal in 100 feet of water," American Society of Civil Engineers, Civil Engineering, June, pp 63-65.

Gerwick News. (1996). "Tremie concrete restoration of a Florida Keys reef," Gerwick News (May 1996). http://www.gerwick.com.

Harris, F.R. (1942). "Evolution of tremie-placed concrete dry docks," American Society of Civil Engineers, Civil Engineering 12(6), 309-314.

Ling, S.C. (1978). "Four offshore-piled structures installed on Outer Continental Shelf of the Atlantic coast of the United States," OTC 3088. Proceedings, 10th Annual Offshore Technology Conference. 2, 345-352.

Loeken, P.A. (1980). "Engineered backfilling on the 36," Ekofisk-Emden gas pipeline," OTC 3741. Proceedings, 12th Annual Offshore Technology Conference. 1, 53-58.

Millard, C.F., and Hassani, J.J. (1971). "Graving dock for 300,000-ton ships," American Society of Civil Engineers, Civil Engineering 41(6), 71-74. 
Nakayama, J. (1992). "Multi-head hammer drill makes advances in rock socket drilling function for large diameter bored piling," Piling: European Practice and Worldwide Trends, edited by M.J. Sands, Institution of Civil Engineers, Thomas Telford Publishers, London, pp 342-344.

Norwesco Marine. (1999). "Diving projects," Intl. Journal on Hydropower and Dams 6(3), 45-46.

Powers, M. B. (1997). "Long, deep, Puerto Rico outfall throws a few placement curves," Engineering News-Record 239(21), 52-54.

Reina, Peter. (1996). "Potsdamer Platz revival begins," Engineering News-Record 37(17) 30-34.

Tate, T.N. (1961). "World's largest drydock," American Society of Civil Engineers, Civil Engineering 31(12), 33-37.

Toppler, J.F., Harris, F.R., and Maaten, R. (1971). "Design of piled breakwater structure for new port of Manfredonia, Italy," OTC 1454. Proceedings, 13th Offshore Technology Conference, Vol 2, Houston, Texas.

\section{Design Considerations}

Agarwal, S.L., Malhotra, A.K., and Barnerjee, R. (1977). "Engineering properties of calcareous soils affecting the design of deep penetration piles for offshore structures," OTC 2792. Proceedings, 9th Annual Offshore Technology Conference. 1, 503-512.

Agaskar, V.L., and Metcalf, M.F. (1971). "Interaction between structure and pile foundation of offshore platforms," OTC 1484. Proceedings, Third Annual Offshore Technology Conference. II, pp 663-676.

Alhayari, S. (1998). "Innovative developments in suction pile technology," OTC 8836. Proceedings, 30th Annual Offshore Technology Conference. II.

American Petroleum Institute. (1989). "Recommended practice for planning, designing, and constructing fixed offshore platforms," API Recommended Practice 2A (RP 2A), 18th Edition, Washington, DC.

. (1993). "Recommended practice for planning, designing, and constructing fixed offshore platforms - Load and resistance factor design," API Recommended Practice 2A (RP 2A-LRFD), 1st Edition, Washington, DC.

American Society of Civil Engineers (ASCE). (1981). "Drilled piers and caissons," Proceedings of Geotechnical Engineering Division, ASCE National Convention, October 28, 153 p. 
American Society of Civil Engineers (ASCE). (1984). Practical guidelines for the selection, design, and installation of piles, Committee on Deep Foundations, ASCE, New York, pp 50-70.

. (1992). "Spin-fin piles gain in application," Civil EngineeringASCE 62(1), January 12-13.

. (1993). Design of pile foundations, New York, 97 p.

Andersen, K.H., and Jostad, H.P. (1999). "Foundation design of skirted foundations and anchors in clay," OTC 10824. Proceedings, 31st Annual Offshore Technology Conference. 1.

Andersen, K.H., and Lauritzsen, R. (1988). "Bearing capacity for foundations with cyclic loads," ASCE Journal of Geotechnical Engineering 114(5), 540-555.

Andersen, K.H., Kleven, A., and Heien, D. (1988). "Cyclic soil data for design of gravity structures," ASCE Journal of Geotechnical Engineering. 114(5), May, 517-539.

Antonakis, C.J. (1972). "A problem of designing and building for a structure at sea." Proceedings, Institution of Civil Engineers 52, Part 1, 95-126.

Arango, Ignacio. (1977). "The effects of cyclic loading on the behavior of anisotropically loaded soft clay," OTC 2789. Proceedings, 9th Annual Offshore Technology Conference. 1, 489-494.

ARGEMA (Association de Recherche en Geotechnique Marine). (1992). Offshore pile design, Pierre Le Tirant, editor, Editions Technip Publishers, Paris, $291 \mathrm{p}$

Armour, T., and Groneck, P. (1998). "Micropile design and construction guidelines and implementation manual," Report No. FHWA-SA-97-070, December.

Arnold, Peter, Bea, R.G., Idriss, I.M., Reimer, R.B., and Marshall, P.W. (1977). "A study of soil-pile-structure systems in severe earthquakes," OTC 2749. Proceedings, 9th Annual Offshore Technology Conference. 1, 189-202.

Arz, P. (1992). "Keynote paper: Germany, Austria, and Switzerland," Piling: European Practice and Worldwide Trends, edited by M.J. Sands, Institution of Civil Engineers, Thomas Telford, London, pp 44-50.

Baerheim, M. (1994). "Structural and installation design of plate foundations for jackets." OTC 7452. Proceedings, 26th Annual Offshore Technology Conference. 2, 313-322. 
Baerheim, M., Hoberg, L., and Tjelta, T.I. (1995). "Development and structural design of the bucket foundations for the Europipe jacket." OTC 7792.

Proceedings, 27th Annual Offshore Technology Conference. 2, 859-867.

Baker, C.N., Parikh, G., Briaud, J.L., Drumright, E.E., and Mensah, F. (1993). "Drilled shafts for bridge foundations," Report No. FHWA-RD-92-004, August.

Barthelemy, H.C., Martin, R., Le Tirant, P.M., Nauroy, J.F., and de Medeiros, J.C. (1987). "Grouted driven piles: an economic and safe alternate for pile foundations," OTC 5409. Proceedings, 19th Annual Offshore Technology Conference. 1, 427-436.

Barton, N., Lien, R., and Lunde, J. (1974). "Engineering classification of rock masses for the design of tunnel support," Journal of Rock Mechanics 6, 189-236.

Bea, R.G. (1975). "Parameters affecting axial capacity of piles in clays." OTC 2307. Proceedings, Seventh Annual Offshore Technology Conference. II, 611-623.

(1996). "Evaluation of the reliability of a conventional platform installed in South Pass Block 47 of the Mississippi River Delta." OTC 8035. Proceedings, 28th Annual Offshore Technology Conference. 2, 59-70.

Bea, R.G., Audibert, J.M.E., and Dover, A.R. (1980). "Dynamic response of laterally and axially loaded piles," OTC 3749. Proceedings, 12th Annual Offshore Technology Conference. 2, 129-140.

Bea, R.G., Vahdani, S., Guttman, S.I., Meith, R.M., and Paulson, S.F. (1986). "Analysis of the performance of piles in silica sands and carbonate formations." OTC 5145. Proceedings, Eighteenth Annual Offshore Technology Conference. 1, pp 551-560.

Becker, D.E. (1996). "18th Canadian Geotechnical Colloquium: Limit states design for foundations, Parts 1 and 2," Canadian Geotechnical Journal 33(6), 956-1007.

Becker, D.E., Burwash, W.J., Montgomery, R.A., and Liu, Y. (1998). "Foundation design aspects of the Confederation Bridge," Canadian Geotechnical Journal 35, 750-768.

Berzins, W.E., and Hewitt, K.J. (1984). "The use of hydraulically placed sand in island construction," OTC 4671. Proceedings, 16th Annual Offshore Technology Conference. 1, 213- 222. 
Bieniawski, Z.T. (1974). "Geomechanics classification of rock masses and its application in tunneling,. Proceedings, 3rd Congress, ISRM, Denver. 2A, p 27.

Bjordal, B.N., and Hagen, Ø. (1994). “ Mating of large integrated decks to concrete gravity structures.” OTC 7502. Proceedings, 26th Annual Offshore Technology Conference. 3, 357-365.

Boer, S., Hulsbergen, C.H., Richards, D.M., Klok, A., and Biaggi, J.P. (1986). "Buckling considerations in the design of the gravel cover for a hightemperature oil line." OTC 5294. Proceedings, Eighteenth Annual Offshore Technology Conference. 4, 9-26.

Bogard, D. (1991). "Nonlinear bending of deep foundation piles," OTC 6668. Proceedings, 21st Annual Offshore Technology Conference. 3, 205-212.

Bonin, J.P., Deleuil, G., and Doris, C.G. (1976). "Foundation analysis of marine gravity structures submitted to cyclic loading," OTC 2475. Proceedings, 8 th Annual Offshore Technology Conference. 1, 571-584.

Borgman, Leon E. (1977). "Some new techniques for hurricane risk analysis," OTC 2848. Proceedings, 9th Annual Offshore Technology Conference. 2, 331-338.

Bradshaw, H., Barton, R.R., and McKenzie, R.H. (1984). “The Hutton TLP foundation design," OTC 4807. Proceedings, 16th Annual Offshore Technology Conference. 3, pp 263-274.

Briaud, J.-L., and Felio, G.Y. (1986). "Analysis of existing cyclic vertical load tests for piles in clay." OTC 5224. Proceedings, Eighteenth Annual Offshore Technology Conference. 3, pp 31-37.

Briaud, J.-L., Riner, K.B., and Ohya, S. (1984). "Cyclic pressuremeter tests for cyclic lateral loads," OTC 4678. Proceedings, 16th Annual Offshore Technology Conference. 1, pp 275-282.

Briaud, J.-L., Smith, T.D., and Meyer, B.J. (1983). "Using the pressuremeter curve to design laterally loaded piles," OTC 4501. Proceedings, 15th Annual Offshore Technology Conference. 1, pp 495-502.

Brockett, F.H., Petters, R.A., and White, G.M. (1979). "Designing an ocean mining collector system," OTC 3368. Proceedings, 11th Annual Offshore Technology Conference. 1, 95-100.

Brod, E.J., Fowler, J.N., and Boston, L.A. (1975). "A unified technique for the analysis of structure-soil-pile systems." OTC 2262. Proceedings, Seventh Annual Offshore Technology Conference. II, pp 199-208. 
Broughton, P., and den Hertog, P.D. (1990). "The foundation stability analyses of the Ekofisk protective barrier for both the installation and operational conditions," OTC 6240. Proceedings, 22nd Annual Offshore Technology Conference. 1, 357-372.

Bruce, D.A., and Juran, I. (1997). "Drilled and grouted micropiles: State of the practice review," Report Nos. FHWA-RD-96-016, 017, 018, and 019.

Bryant, L.M., and Hall, R.A. (1979). "Design for complex foundation configurations and submarine mudslide conditions," OTC 3403. Proceedings, 11th Annual Offshore Technology Conference. 1, 405-412.

Budhu, M., and Davies, T.G. (1986). "Nonlinear analysis of piles in stiff clays.”OTC 5225. Proceedings, Eighteenth Annual Offshore Technology Conference. 3, pp 39-44.

Burt, N.J., and Harris, R.P. (1980). "Design, installation and testing of belled pile foundations," OTC 3872. Proceedings, 12th Annual Offshore Technology Conference. 4, 175-186.

Bury, M.R.C., and Domone, P.L. (1974). "The role of research in the design of concrete offshore structures," OTC 1949. Proceedings, 6th Annual Offshore Technology Conference. 1, 155-168.

Bye, A., Erbrich, C., Rognlien, B., and Tjelta, T.I. (1995). "Geotechnical design of bucket foundations," OTC 7793. Proceedings, 27th Annual Offshore Technology Conference. 2, pp 869-883.

Byrne, B.W., and Houlsby, G.T. (1999). "Drained behaviour of suction caisson foundations on very dense sand," OTC 10994. Proceedings, 31st Annual Offshore Technology Conference. 2.

Carnahan, N.F., Zimmer, R.A., and Carnahan, F.L. (1975). "Anchor-pile design for ocean-floor environments using finite-element analysis," OTC 2308. Proceedings, Seventh Annual Offshore Technology Conference. II, pp 625-632.

CIRIA. (1993). The design and construction of sheet-piled cofferdams, Construction Industry Research and Information Association Special Publication 95, Thomas Telford Publications, London, 198 p.

CLAROM (Club des Actions de Recherche sur les Ouvrages en Mer).(1994). Foundations in carbonate soils, Design Guides for Offshore Structures, Pierre LeTirant and Jean-Francois Nauroy, editors, Editions Technip Publishers, Paris. 
Clukey, E.C., Morrison, M.J., Garnier, J., and Corté, J.F. (1995). "The response of suction caissons in normally consolidated clays to cyclic TLP loading conditions," OTC 7796. Proceedings, 27th Annual Offshore Technology Conference. 2, pp 909-918.

Colliat, J-L., Boisard, P., Andersen K., and Schroeder, K. (1995). "Caissons foundations as alternative anchors for permanent mooring of a process barge offshore congo," OTC 7797. Proceedings, 27th Annual Offshore Technology Conference. 2, pp 919-929.

Colliat, J.L., Boisard, P., Gramet, J.C., and Sparrevik, P. (1996). "Design and installation of suction anchor piles at a soft clay site in the Gulf of Guinea," OTC 8150. Proceedings, 28th Annual Offshore Technology Conference. 3, pp 325-337.

Colp, J.L. (1975). "Inclined pullout forces for embedded plate anchors," OTC 2182. Proceedings, Seventh Annual Offshore Technology Conference. I, pp 333-342.

Coyle, H.M., and Castello, R.R. (1979). "A new look at bearing capacity factors for piles," OTC 3405. Proceedings, 11 th Annual Offshore Technology Conference. 1, 427-436.

Cristopher, B.R., Gill, S.A., Juran, I., and Mitchel, J.K. (1990). "Reinforced soil structures, Design and construction guidelines," Report Nos. FHWA-RD-89043 and 044, Vols 1 and 2.

Cruickshank, Michael J., and Collions, Ian J. (1969). "Design of a facility for marine mining systems research," OTC 1034. Proceedings, 1st Annual Offshore Technology Conference. 1, 305-316.

Cunningham, G.R., and Naughton, H.R. (1977). "Design and installation of the piling foundation for the Hondo platform in 850 feet of water in the Santa Barbara Channel," OTC 2843. Proceedings, 9th Annual Offshore Technology Conference. 2, 291-296.

Dahlberg, R. (1998). "Design procedures for deepwater anchors in clay," OTC 8837. Proceedings, 30th Annual Offshore Technology Conference. 2.

Daidola, John C., and Maniar, Naresh M. (1976). "Design considerations for stability of drill ships," OTC 2507. Proceedings, 8th Annual Offshore Technology Conference. 1, pp 873-888.

Darr, K.A., Reese, L.C., and Wang, S.T. (1990). "Coupling effects of uplift loading and lateral loading on capacity of piles," OTC 6320. Proceedings, 22nd Annual Offshore Technology Conference. 2, pp 443-450. 
Datta, M., Gulhati, S.K., and Rao, G.V. (1980). "An appraisal of the existing practice of determining the axial load capacity of deep penetration piles in calcareous sands," OTC 3867. Proceedings, 12th Annual Offshore Technology Conference. 4, pp 119-130.

Delgado, C. (1992). “Keynote paper: Spain and Portugal,” Piling: European practice and worldwide trends, edited by M.J. Sands, Institution of Civil Engineers, Thomas Telford Publishers, London, pp 32-37.

Department of Energy (UK). (1986). "Guidance on the design and construction of offshore structures," EMSO, London.

Department of the Army. (1983). "Soils and geology procedures for foundation design of buildings and other structures (except hydraulic structures)," Army Technical Manual TM 5-818-1, Depts. of the Army and Air Force, Washington, DC.

. (1994). "Engineering and design for civil works projects," Engineer Regulation ER 1110-2-1150, U.S. Army Corps of Engineers CECW-EP, Washington, DC.

. (1997). "Design analysis, drawings, and specifications," Engineer Regulation ER 1110-345-700, U.S. Army Corps of Engineers CEMP-EA, Washington, D.C.

Digre, K.A., Kenney, J.J., and Simic, R. (1989). "Design considerations for the Bullwinkle Jacket mudmats," OTC 6097. Proceedingsof the 21st Annual Offshore Technology Conference. 3, 489-500.

Digre, K.A., Kipp, R.M., and Hunt, R.J. (1999). "Ursa TLP, tendon and foundation design, fabrication, transportation, and TLP installation," OTC 10756. Proceedings, 31st Annual Offshore Technology Conference. 2.

DiMillio, A. (1999). "A quarter century of geotechnical research," FHWA, U.S. DOT internet site http://www.tfhrc.gov/structur/gtr/century, $18 \mathrm{p}$.

Dorgant, P.L., Hansen, M.C., Sgouros, G.E., Sezer, F., and Steege, G.T. (1998). "Design and construction of a two-piece lifted jacket for the Enchilada development," OTC 8824. Proceedings, 30th Annual Offshore Technology Conference. 2.

Dowse, B.E.W. (1979). "Design of hydrostatically supported sand islands for arctic drilling," OTC 3634. Proceedings, 11th Annual Offshore Technology Conference. IV, 2399-2403.

Dunnavant, T.W., and Kwan, C-T.T. (1993). "Centrifuge modelling and parametric analyses of drag anchor behavior." OTC 7202. Proceedings, 25th Annual Offshore Technology Conference. 3, 29-39. 
Dutt, R.N., and Ingram, W.R. (1988). "Bearing capacity of jack-up footings in carbonate granular sediments." Proceedings, Intl Conference on Calcareous Sediments, Perth, pp 291-296.

(1991). "Significance of in-situ and laboratory tests for design of foundations in granular carbonate soil," OTC 6515. Proceedings, $23 \mathrm{rd}$ Annual Offshore Technology Conference. 1, 155-164.

El-Gharbawry, S.L., Iskander, M.G., and Olson, R.E. (1998). "Application of suction caisson foundations in the Gulf of Mexico," OTC 8832. Proceedings, 30th Annual Offshore Technology Conference. 2.

Esrig, M. I., and Kirby, R. C. (1979). "Advances in general effective stress method for the prediction of axial capacity for driven piles in clay," OTC 3406. Proceedings, 11th Annual Offshore Technology Conference. 1, 437-448.

Esrig, M.I., Ladd, R.S., and Bea, R.G. (1975). "Material properties of submarine Mississippi Delta sediments under simulated wave loadings," OTC 2188. Proceedings, Seventh Annual Offshore Technology Conference. I, 399-411.

Feibusch, Robert, J., and Keith, Edward J. (1969). "Analysis of offshore structures including coupled structure, pile and inelastic soil properties," OTC 1054. Proceedings, 1st Annual Offshore Technology Conference. 1, $567-574$

Ferguson, M.C. (1990). "A comparative study using API RP2A-LRFD," OTC 6308. Proceedings, 22nd Annual Offshore Technology Conference. 2 , 341-352.

Fern, D.T., and Waddell, J.W. (1987). "A new compliant pile design and its application to compliant towers," OTC 5539. Proceedings, 19th Annual Offshore Technology Conference. 3, 475-484.

Finch, M. (1999). "Upheaval buckling and flotation of rigid pipelines: The influence of recent geotechnical research on the current state-of-the-art," OTC 10713. Proceedings, 31st Annual Offshore Technology Conference. 2.

Finn, W.D.L., Lee, M.K.W., and Martin, G.R. (1978). "Application of effective stress methods for offshore seismic design in cohesionless seafloor soils," OTC 3112. Proceedings, 10th Annual Offshore Technology Conference. 1, $521-528$

Fjeld, S., and Andreasson, B. (1982). "Soil-structure interaction of multifooting gravity structures," OTC 4413. Proceedings, 14th Annual Offshore Technology Conference. 4, 435-442.

Fleming, W.G.K., Weltman, A.J., Randolph, M.F., and Elson, W.K. (1992). Piling engineering. Wiley Publishing, New York, 384 p. 
Foray, P.Y., Colliat, J.L., and Nauroy, J.F. (1993). "Bearing capacity of driven model piles in dense sands from calibrated chamber tests," OTC 7194. Proceedings, 25th Annual Offshore Technology Conference. 2, 655-665.

Foss, I., Dahlberg, R., and Kvalstad, T. (1978). "Foundation design for gravity structures with respect to failure in cyclic loading," OTC 3114. Proceedings, 10th Annual Offshore Technology Conference. 1, 535-546.

Fuller, J.T. (1975). "Behavior of mechanical elements in submerged clays of low shear strength," OTC 2242. Proceedings, Seventh Annual Offshore Technology Conference. I, pp 933-942.

Galambos, T.V. (1975). "The state-of-the-art of metal column design," OTC 2203. Proceedings, Seventh Annual Offshore Technology Conference. I, 571-581.

Gandais, M. (1992). "Keynote paper: France," Piling: European Practice and Worldwide Trends, edited by M.J. Sands, Institution of Civil Engineers, Thomas Telford Publishers, London, pp 38-43.

Gerwick, B.C. (1971). "Techniques for increasing the capacities of pin piles in new and existing offshore construction," OTC 1473. Proceedings, 3rd Annual Offshore Technology Conference. 2, 543-552.

Ghazzaly, O.T., and Lim, S.J. (1975). "Experimental investigation of pipeline stability in very soft clay," OTC 2277. Proceedings, Seventh Annual Offshore Technology Conference. II, 315-326.

Gidwani, J.M., and Renault, J-P. (1990). "Boat impact ultimate capacity analyses of jacket structures," OTC 6484. Proceedings, 22nd Annual Offshore Technology Conference. 4, 543-550.

Gifford, D.G. Wheeler, J.R., Kraemer, S.R., and McKown, A.F. (1987). "Spread footings for highway bridges," Report No. FHWA-RD-86-185, March.

Gilbert, R.B., and Tang, W.H. (1995). "Model uncertainty in offshore geotechnical reliability," OTC 7757. Proceedings, 27th Annual Offshore Technology Conference. 2, 557-567.

Gilbert, R.B., Gambino, S.J., and Dupin, R.M. (1999). "Reliability-based approach for foundation design without site-specific borings," OTC 10927. Proceedings, 31st Annual Offshore Technology Conference. II.

Golightly, C.R., and Nauroy, J.F. (1990). "End-bearing capacity of piles in calcareous sands," OTC 6239. Proceedings, 22nd Annual Offshore Technology Conference. 1, 345-356. 
Gu, G.Z., Parsley, M.A., Berek, E.P., Calvo, J.J., Johnson, R.C., and Petruska, D.J. (1996). "Model test of wave forces on a structurally dense jacket platform," OTC 8065. Proceedings, 28th Annual Offshore Technology Conference. 2, 341-347.

Gunasena, U., Joer, H.A., and Randolph, M.F. (1995). "Design approach for grouted driven piles in calcareous soil," OTC 7669. Proceedings, 27th Annual Offshore Technology Conference. 1, 271-280.

Hagen, D., Andenaes, E., and Korstad, G.M. (1998). "Innovative suction anchor design and installation," OTC 8833. Proceedings, 30th Annual Offshore Technology Conference. 2.

Hagenaar, J., Chandrasekhar, C.S., and Waanaders, A.J. (1986). "Lateral loading tests on large-diameter steel pipe piles installed in carbonate rock and soils," OTC 5146. Proceedings, Eighteenth Annual Offshore Technology Conference. 1, 561-568.

Hamilton, J.M., and Murff, J.D. (1995). "Ultimate lateral capacity of piles in clay," OTC 7667. Proceedings, 27th Annual Offshore Technology Conference. 1, 241-255.

Hanna, S.Y. (1989). "Load transfer mechanism to offshore jackets during pile driving," OTC 5913. Proceedings, 21st Annual Offshore Technology Conference. 1, 321-330.

Hannigan, P.J., Goble, G.G., Thendean, G., Likins, G.E., and Raushe, F. (1997). "Design and construction of driven pile foundations," Report No. FHWA-HI97-013, January.

Helfrich, S.C., Brazill, R.L., and Richards, A.F. (1976). "Pullout characteristics of a suction anchor in sand," OTC 2469. Proceedings, 8th Annual Technology Conference. 1, 501-506.

Herrmann, H.G., and Houston, W.N. (1976). "Response of seafloor soils to combined static and cyclic loading," OTC 2428B. Proceedings, 8th Annual Offshore Technology Conference. 1, 53-60. . (1978). "Behavior of seafloor soils subjected to cyclic loading," OTC 3260. Proceedings, 10th Annual Offshore Technology Conference. 3, 1797-1808.

Herrmann, G., Raecke, D.A., and Albertsen, N.D. (1972). "Selection of practical seafloor foundation systems," Technical Report R-761, Naval Facilities Engineering Command, Port Hueneme, CA. 
Hight, D.W., Lawrence, D.M., Farquhar, G.B., Miligan, G.W.E., Gue, S.S., Potts, D.M. (1996). "Evidence for scale effects in the end bearing capacity of openended piles in sand," OTC 7975. Proceedings, 28th Annual Offshore Technology Conference. 1, 181-192.

Hollingsworth, J.R. (1992). "The Atlas screw pile- construction, design, and performance," Piling: European Practice and Worldwide Trends, edited by M.J. Sands, Institution of Civil Engineers, Thomas Telford Publisher, London, pp 170-175.

Holloway, D.M., Clough, G.W., and Vesic, A.S. (1978). "The effects of residual driving stresses on pile performance under axial loads," OTC 3306.

Proceedings, 10th Annual Offshore Technology Conference. 4, 2225-2236.

Holm, G. (1992). "Keynote paper: Sweden, Denmark, Norway and Finland," Piling: European practice and worldwide trends, edited by M.J. Sands, Institution of Civil Engineers, Thomas Telford Publisher, London, pp 25-31.

Holmquist, Darrel V., and Matlock, Hudson. (1976). "Resistance-displacement relationships for axially-loaded piles in soft clay," OTC 2474. Proceedings, 8th Annual Offshore Technology Conference. 1, 553-570.

Horsnell, M.R., and Toolan, F.E. (1996). "Risk of foundation failure of offshore jacket piles," OTC 7997. Proceedings, 28th Annual Offshore Technology

Conference. 1, 381-392.

Horsnell, M.R., Aldridge, T.R., and Erbrich, C. (1990). "Lateral group behaviour of piles in offshore soil conditions," OTC 6246. Proceedings, 22nd Annual Offshore Technology Conference. 1, pp 417-424.

Hulsbergen, C.H. (1986). "Spoilers for stimulated self-burial of submarine pipelines," OTC 5339. Proceedings, Eighteenth Annual Offshore Technology Conference. 4, 441-444.

Hwong, S.T., Ghazzaly, O.I., and O’Neill, M.W. (1978). "Pile response to dynamic lateral loading," OTC 3309. Proceedings, 10th Annual Offshore Technology Conference. 4, 2255-2260.

Ichiye, Taskashi, and Carnes, Michael. (1977). "Modeling of sediment dispersion during deep ocean mining operations," OTC 2778. Proceedings, 9th Annual Offshore Technology Conference. 1, 421-432.

Jardine, R.J., and Overy, R.F. (1996). "Axial capacity of offshore piles driven in dense sand," OTC 7973. Proceedings, 28th Annual Offshore Technology Conference. 1, 161-170. 
Jeanjean, P., Andersen, K.H., and Kalsnes, B. (1998). "Soil parameters for design of suction caissons for Gulf of Mexico deepwater clays," OTC 8830.

Proceedings, 30th Annual Offshore Technology Conference. 1, pp

Johanson, Edward E. (1976). "Predicting dredge material dispersion in open water dumping as a function of the material physical characteristics," OTC 2589. Proceedings, 8th Annual Offshore Technology Conference. 2, 675-682.

Kagawa, T. (1990). "Soil reaction to axially loaded piles," OTC 6491. Proceedings, 22nd Annual Offshore Technology Conference. 4, 605-615.

Kagawa, T., and Kraft, L.M. Jr. (1980). "Soil-pile-structure interaction of offshore structures during an earthquake," OTC 3820. Proceedings, 12th Annual Offshore Technology Conference. 31, 235-246.

Kallaby, Joseph 1977). "Considerations for analysis and design of piled offshore structures in severe earthquake environment," OTC 2748. Proceedings, 9th Annual Offshore Technology Conference. 1, 185-188.

Karlsrud, K., and Nadim, F. (1990). "Axial capacity of offshore piles in clay," OTC 6245. Proceedings, 22nd Annual Offshore Technology Conference. 1, 405-416.

Kerr, Neil. (1976). "A self-burying anchor of considerable holding power," OTC 2466. Proceedings, 8th Annual Offshore Technology Conference. 1, 447-458.

Kint, T.E., and Morrison, D.G. (1990). "Dynamic design and analysis methodology for deepwater bottom-founded structures," OTC 6343. Proceedings, 22nd Annual Offshore Technology Conference. 2, 607-614.

Kobayashi, H., and Nagatsuka, M. (1978). "Experimental study on the liquefaction of sandy seabed under offshore oil storage tanks," OTC 3258. Proceedings, 10th Annual Offshore Technology Conference. 3, 1779-1788.

Kobayashi, H., Iida, Y., Mori, N., Kawanishi, T., and Hirakawa, S. (1990). "A new concept of TLP with gravity-type template," OTC 6350. Proceedings, 22nd Annual Offshore Technology Conference. 3, 47-54.

Kolk, H.J., and van der Velde, E. (1996). " A reliable method to determine friction capacity of piles driven into clays," OTC 7993. Proceedings, 28th Annual Offshore Technology Conference. 1, 337-346.

Kraft, L.M., Jr., and Lyons, C.G. (1974). "State-of-the-Art: Ultimate axial capacity of grouted piles," OTC 2081. Proceedings, 6th Annual Offshore Technology Conference. 2, 485-504. 
Lalani, M., and Shuttleworth, E.P. (1990). "The ultimate limit state of offshore platforms using reserve and residual strength principles," OTC 6309.

Proceedings, 22nd Annual Offshore Technology Conference. 2, 353-364.

Lalli, D. (1971). "Pile analysis by large deflection matrix method," OTC 1483. Proceedings, Third Annual Offshore Technology Conference. II, 653-662.

Lam, I.P., and Martin, G.R. (1986). "Seismic design of highway bridge foundations," Report Nos. FHWA-RD-86-101, 102, and 103.

Larsen, P. (1989). "Suction anchors as an anchoring system for floating offshore constructions," OTC 6029. Proceedings, 21st Annual Offshore Technology Conference. 2, 535-540.

Lauritzen, Rolf, and Schjetne, Knut. (1976). "Stability calculations for offshore gravity structures," OTC 2431B. Proceedings, 8th Annual Offshore Technology Conference. 1, 75-82.

Lee, K.L., and Focht, J.A., Jr. (1975). "Cyclic testing of soil for ocean wave loading problems," OTC 2183. Proceedings, Seventh Annual Offshore Technology Conference. I, 343-354.

Lee, P.Y., and Gilbert, L.W. (1979). "Behavior of laterally loaded piles in very soft clay," OTC 3401. Proceedings, 11th Annual Offshore Technology Conference. 1, 387-396.

LeTirant, P., and Nauroy, J.F. (1994. Foundations in carbonate soils; Design Guides for Offshore Structures, CLAROM, Paris, pg. 172.

Liedtke, E.A., and Wright, S.G. (1999). "Computation of slope stability over large areas of the seafloor with variable topography," OTC 10829. Proceedings, Offshore Technology Conference. 2.

Lieng, J.T., and Bjørgen, H.P. (1995). "New flow-through mudmat design for Heidrun subsea structure," OTC 7671in Proceedings, 27th Annual Offshore Technology Conference. 1, 289-299.

Ling, Shun Chin. (1977). "Dynamic behavior of a Northeast Pacific clay," OTC 2790. Proceedings, 9th Annual Offshore Technology Conference. 1, 495-502.

Little, R.L., Moore, G.H., and Templeton, J.E. (1991). "Subsidence-induced sediment motion: Foundation design criteria for platforms at Main Pass 299," OTC 6665. Proceedings, 23rd Annual Offshore Technology Conference. 3, 171-180. 
Lu, B.T.D. (1986). "Axial behavior and capacity of driven piles in calcareous sands," OTC 5148. Proceedings, Eighteenth Annual Offshore Technology Conference. 1, 579-588.

Lupini, J.F., Chacín, M.E., Furiol, A., Troconis, C.M., and Vargas, F. (1995). "Lateral loading on piles due to slope instability," OTC 7664. Proceedings, 27th Annual Offshore Technology Conference. 1, 221-231.

Meyer, P.L., Holmquist, D.V., and Matlock, H. (1975). "Computer predictions for axially-loaded piles for nonlinear supports," OTC 2186. Proceedings, Seventh Annual Offshore Technology Conference. I, 375-387.

Miller, B.L., Frieze, P.A., Lai, P.S.K., Lewis, T.C., and Smith, I.A.A. (1993). "Motion and impact responses of jackups moving onto location," OTC 7301. Proceedings, 25th Annual Offshore Technology Conference. 4, 389-398.

Miller, T.W., Murff, J.D., and Kraft, L.M. (1978). "Critical state soil mechanics model of soil consolidation stresses around a driven pile," OTC 3307. Proceedings, 10th Annual Offshore Technology Conference. 4, 2237-2242.

Mongal, J.K., and Houlsby, G.T. (1999). "Partially-drained loading of shallow foundations on sand," OTC 10991. Proceedings, 31st Annual Offshore Technology Conference. 2.

Murff, J.D. (1996). "The geotechnical centrifuge in offshore engineering," OTC 8265. Proceedings, 28th Annual Offshore Technology Conference. 1, 675-689.

Murff, J.D., Raines, R.D., and Randolph, M.F. (1990). "Soil plug behaviour of piles in sand," OTC 6421. Proceedings, 22nd Annual Offshore Technology Conference. 4, 25-32.

Neate, J.J. (1989). "Augered cast-in-place piles," Foundation Engineering: Current Principles and Practices, Proceedings, ASCE Congress, ASCE, New York. 2, 970-978.

Nelson, W.E., Murphy, B.S., and Stahl, B. (1983). "Bumper pile design for mating platform and subsea drilling template," OTC 4572. Proceedings, 15th Annual Offshore Technology Conference. 2, 489-496.

Olson, R.E. (1990). "Axial load capacity of steel pipe piles in sand," OTC 6421. Proceedings, 22nd Annual Offshore Technology Conference. 4, 17-24.

O’Neill, M.W. (1988). "Drilled shafts: construction procedures and design methods," Report No. FHWA-HI-88-042, July. 
O’Neill, M.W., Ghazzaly, O.I., and Ha, H.B. (1977). “Analysis of threedimensional pile groups with non-linear soil response and pile-soil-pile interaction," OTC 2838. Proceedings, 9th Annual Offshore Technology Conference. 2, 245-256.

Osterberg, J. O. (1998). "The Osterberg load test method for bored and driven piles, the first ten years," Proc., 7th Int. Conf. and Exhibition on Piling and Deep Foundations. Vienna, Austria, June 15-17, Deep Foundation Institute, Englewood Cliffs, N.J., 1.28.1-1.28.11.

Paikowsky, S.G. (1990). "The mechanism of pile plugging in sand," OTC 6490. Proceedings, 22nd Annual Offshore Technology Conference. 4, 593-604.

Parkhill, S. T. (1998). "Geotechnical design and construction from 1848 to 1998," Civil Engineering Practice, ASCE, Fall/Winter, Vol 2.

Pearlman, S.L., Richards, T.D., Wise, J.D., and Vodd, W.F. (1997). "Pin piles for bridge foundations-A five-year update," Nicholson Company Technical Paper on Internet site http://www.nicholson-rodio.com/papers/papers.html.

Pelletier, J.H., and Sgouros, G.E. (1987). "Shear transfer behavior of a 30-in. Pile in silty clay," OTC 5407. Proceedings, 19th Annual Offshore Technology Conference. 1, 417-426.

Pelletier, J.H., Murff, J.D., and Young, A.G. (1993). "Historical development and assessment of the current API design methods for axially loaded piles," OTC 7157. Proceedings, 25th Annual Offshore Technology Conference, pp 253-282.

Prevost, J.H., and Hughes, T.J.R. (1978). "Analysis of gravity offshore structure foundations subjected to cyclic wave loading," OTC 3261. Proceedings, 10th Annual Offshore Technology Conference. 3, 1809-1818.

Puech, A., and Jezequel, J.F. (1980). "The effects of long time cyclic loadings on the behavior of a tension pile," OTC 3870. Proceedings, 12th Annual Offshore Technology Conference. 4, 153-162.

Puech, A., Meunier, J., and Pallard, M. (1978). "Behavior of anchors in different soil conditions," OTC 3204. Proceedings, 10th Annual Offshore Technology Conference. 3, 1321-1330.

Ramzan, F.A., and Robinson, R.W. (1989). "Prediction of jacket to template docking forces during installation," OTC 5915. Proceedings, 21 st Annual Offshore Technology Conference. 1, 343-356.

Randolph, M.F., Joer, H.A., Khorshid, M.S., Hyden, A.M. (1996). "Field and laboratory data from pile load test in calcareous soil," OTC 7992. Proceedings, 28th Annual Offshore Technology Conference. 1, 327-336. 
Randolph, M.F., O'Neill, M.P., and Stewart, D.P. (1998). "Performance of suction anchors in fine-grained calcareous soils," OTC 8831. Proceedings, 30th Annual Offshore Technology Conference. 2.

Reese, L.C. (1984). "Handbook on design of piles and drilled shafts under lateral loads,” Report No. FHWA-IP-84-11, July.

Reese, L.C., and Isenhower, W.M. (2000). "Deep foundations in the future," American Society of Civil Engineers, Civil Engineering 70(2), A2- A9.

Reese, Lymon C., Cox, William, R., and Koop, Francis D. (1974). "Analysis of laterally loaded piles in sand," OTC 2080. Proceedings, 6th Annual Offshore Technology Conference. 2, 473-484.

Ross, H.E. (1971). "Dynamic response of offshore piling," OTC 1480. Proceedings, Third Annual Offshore Technology Conference, TX. II, 619632.

Sangrey, D. A., Clukey, E. C., and Molnia, B. F. (1979). "Geotechnical engineering analysis of underconsolidated sediments from Alaska coastal waters," OTC 3436. Proceedings, 11th Annual Offshore Technology Conference. 1, 677-682.

Schuëller, G.I. (1971). "Reliability of circular piles subjected to ocean waves," OTC 1508. Proceedings, Third Annual Offshore Technology Conference. II, 920-928.

. (1975). "On the risk assessment of offshore structures," OTC 2334. Proceedings, Seventh Annual Offshore Technology Conference. II, 903-908.

Scott, R. F. (1979). "Cyclic static model pile test in a centrifuge," OTC 3492. Proceedings, 11th Annual Offshore Technology Conference. 2, 1159-1168.

Sele, A., and Skjolde, M. (1993). "Design provisions for offshore grouted construction," OTC 7150. Proceedings, 25th Annual Offshore Technology Conference. 2, 165-179.

Senner, D.W.F., and Cathie, D.N. (1993). "Offshore pile design for sites with complex soil conditions," OTC 7197. Proceedings, 25th Annual Offshore Technology Conference. 2, 687-694.

Seymour, Richard J. (1976). "Tethered float breakwater: A temporary wave protection system for open ocean contruction," OTC 2545. Proceedings, 8th Annual Offshore Technology Conference. 2, 253-264.

Sharples, B.P., Bennett, W.T., and Trickey, J.C. (1989). "Risk analysis of jackup rigs," Second Intl Conf on Jack-Up Drilling Platform:Design, Construction, and Operation, City University, London, pp 101- 123. 
Silence, P.G. (1992). "Keynote paper: Luxembourg, Belgium, and Holland," Piling: European Practice and Worldwide Trends, edited by M.J. Sands, Institution of Civil Engineers, Thomas Telford Publisher, London, pp 1-5.

Smith, J.E. (1971). "Explosive anchor for salvage operations-Progress and status," OTC 1504. Proceedings, Third Annual Offshore Technology Conference. II, 859-872.

Spidsoe, N., and Skjåstad, O. (1986). "Measured soil-structure interaction properties of a gravity platform," OTC 5222. Proceedings, Eighteenth Annual Offshore Technology Conference. 3, 9-17.

Stevens, J. B., and Audibert, J.M.E. (1979). "Re-examination of P-Y curve foundations," OTC 3402. Proceedings, 11th Annual Offshore Technology Conference. 1, 397-404.

Stevens, J.B. (1978). "Prediction of pile response to vibratory loads," OTC 3305. Proceedings of the 10th Annual Offshore Technology Conference. 4, 22132224.

Sulaiman, I.H., and Coyle, H.M. (1971). "Predicted behavior of axially loaded piles in sand," OTC 1482. Proceedings, Third Annual Offshore Technology Conference. II, 643-652.

Tang, W.H., and Gilbert, R.B. (1993). "Case study of offshore pile system reliability," OTC 7196. Proceedings, 25th Annual Offshore Technology Conference. 2, 677-686.

Thornton, P. (1992). "Keynote paper: UK and Eire," Piling: European Practice and Worldwide Trends, edited by M.J. Sands, Institution of Civil Engineers, Thomas Telford Publisher, London, pp 6-16.

Tjelta, T-I. (1994). "Geotechnical aspects of bucket foundations replacing piles for the Europipe 16/11-E jacket," OTC 7379. Proceedings, 26th Annual Offshore Technology Conference. 1, 73-82.

Tomlinson, M.J. (1994. Pile design and construction practice, 4th edition, E \& FN Spon Publishers, London, 411 pp

Toolan, F.E., and Horsnell, M.R. (1993). "The evolution of offshore pile design codes and future developments," Offshore Site Investigation and Foundation Behaviour: Advances in Underwater Technology, Ocean Science and Offshore Engineering, Vol 28, Society for Underwater Technology, London, U.K., pp 751-772.

Trevisani, G. (1992). "Keynote paper: Italy and Greece," Piling: European Practice and Worldwide Trends, edited by M.J. Sands, Institution of Civil Engineers, Thomas Telford Publisher, London, pp 17-24. 
Tsien, S.I. (1986). "Shaft frictional resistance of long pipe piles driven into dense sands," OTC 5150. Proceedings, Eighteenth Annual Offshore Technology Conference. 1, 601-610.

Ugaz, O.G., Nowacki, F., and Harvik, L. (1997). "Foundation analysis of the Hibernia GBS," OTC 8403. Proceedings, 29th Annual Offshore Technology Conference. 2, 447-454.

U.S. Army Corps of Engineers. (1991). Design of pile foundations, Engineer Manual 1110-2-2906, CECW-ED, Washington, DC.

(1994). Rock foundations, Engineer Manual 1110-1-2908, CECWEG, Washington, DC.

van Langen, H., Swee, J.L.K., Efthymiou, M., and Overy, R. (1995). "Integrated foundation and structural reliability analysis of a North Sea structure," OTC 7758. Proceedings, 27th Annual Offshore Technology Conference. 2, 809820.

Veletsos, A.S., and Boaz, I.B. (1979). "Effects of soil-structure interaction on seismic response of a steel gravity platform," OTC 3404. Proceedings, 11th Annual Offshore Technology Conference. 1, 413-426.

Vesic, A.S. (1977). "Design of pile foundations," National Cooperative Highway Research Program, Synthesis of Highway Practice 42, Transportation Research Board, National Research Council, Washington, DC.

Waddell, J.W. (1997). "Self installing gravity platform concept," OTC 8446. Proceedings, 29th Annual Offshore Technology Conference. 3, 99-107.

Wang, M.C., Demars, K.R., and Nacci, V.A. (1978). "Applications of suction anchors in offshore technology," OTC 3203. Proceedings, 10th Annual Offshore Technology Conference. 3, 1311-1320.

Wantland, G.M., O'Neill, M.W., and Kalajian, E.H. (1979). "Lateral stability of pipelines in clay," OTC 3477. Proceedings, 11th Annual Offshore Technology Conference. 2, 1025-1034.

Wathugala, G.W., and Desai, C.S. (1989). "An analysis of piles in marine clay under cyclic axial loading," OTC 6002. Proceedings, 21st Annual Offshore Technology Conference. 2, 359-366.

Weatherby, D.E. (1998). "Design manual for permanent ground anchor walls," Report No. FHWA-RD-97-130, September.

Whitaker, T. (1976). The design of piled foundations, 2nd edition, Pergamon Press, New York, 218 p. 
Wisch, D.J. (1999). "Fixed steel offshore structure design: Past, present, and future," OTC 8822. Proceedings, 31st Annual Offshore Technology

Conference. 2.

Wung, C.C., Litton, R.W., Mitwally, H.M., Bang, S., and Taylor, R.J. (1995). "Effect of soil on mooring system dynamics," OTC 7672. Proceedings, 27th Annual Offshore Technology Conference. 1, 301-307.

Yao, S.X., Berner, D.E., and Gerwick, B.C. (1999). "Assessment of underwater concrete technologies for in-the-wet construction of navigation structures," Technical Report INP-SL-1, U.S. Army Corps of Engineers ERDC, Vicksburg, MS, page 50.

\section{Foundation Monitoring and Long-Term Considerations}

\section{Corrosion}

Blume, W.J., and Kirk, B.J. (1982). "An electrolytic system for controlling marine growth and corrosion in sea water service systems," OTC 4364. Proceedings, 14th Annual Offshore Technology Conference. 3, 755-768.

Britton, J.N. (1991). "Monitoring offshore cathodic protection systems in the Gulf of Mexico: A review of available technologies and regulatory requirements," OTC 6601. Proceedings, 23rd Annual Offshore Technology Conference. 2, 373-382.

Crawford, D.W. (1972). "A history of protective coatings for the offshore industry: 1947-1972," OTC 1582. Proceedings, 4th Annual Offshore Technology Conference. 1, 671-676.

Ellor, J.A., and Gehring, G.A. Jr. (1991). "Galvanic corrosion of CuNi-sheathed steel pilings in sea water," OTC 6589. Proceedings, 23rd Annual Offshore Technology Conference. 2, 253-260.

Escalante, E., and Iverson, W.P. (1978). "The protection of steel piles by selected coatings in a natural sea water environment," OTC 3190. Proceedings, 10th Annual Offshore Technology Conference. 2, 1215-1222.

Escalante, E., Iverson, W.P., Gerhold, W.F., Sanderson, B.T., and Alumbaugh, R.L. (1977). Corrosion and protection of steel piles in a natural sea water environment, Monograph 158, National Bureau of Standards.

Evans, S. (1990). "The TLWP cathodic protection system," OTC 6276. Proceedings, 22nd Annual Offshore Technology Conference. 2, 75-80. 
Melton, D.G. (1991). "Review of five-year exposure data for CuNi-sheathed steel pilings," OTC 6586. Proceedings, 23rd Annual Offshore Technology

Conference. 2, 221-234.

Sharma, J.N. (1983). "Marine growth on the Hondo Platform in the Santa Barbara Channel," OTC 4569. Proceedings, 15th Annual Offshore Technology Conference. 2, 469-474.

Thomason, W.H., and Fischer, K.P. (1991). "Cathodic protection of steel structures in deep water: A review," OTC 6588. Proceedings, 23rd Annual Offshore Technology Conference. 2, 243-252.

Van Damme, L., and Vrelust, W. (1999). "Low water corrosion of steel pilings," Bulletin of the International Navigation Association, No. 101, pp 17-20.

Wolfson, S.L., and Kenney, J.J. (1989). "Cathodic protection monitoring: Bullwinkle," OTC 6053. Proceedings, 21st Annual Offshore Technology Conference. 3, 101-106.

\section{Monitoring}

Berzins, W.E., Melrose, G.R., and Mitchell, D.E. (1984). "Geotechnical monitoring systems and performance in dynamic ice environments," OTC 4697. Proceedings, 16th Annual Offshore Technology Conference. 1, 433-442.

Coffman, V.T. (1975). "Instrumentation system for installation of the North Sea Forties Field program." OTC 2249. Proceedings, Seventh Annual Offshore Technology Conference. II, 67-76.

Erb, P.R., Finch, C.L., and Manley, G.R. (1985). "The Hutton TLP performance monitoring and verification program," OTC 4951. Proceedings, 17th Annual Offshore Technology Conference. 2, 485-492.

Lamb, W.C. Jr., Hibbard, H.C., James, A.L., Koerner, W.A., and Rothberg, R.H. (1984). "Instrumentation for monitoring behavior of Lena Guyed Tower," OTC 4684. Proceedings, 16th Annual Offshore Technology Conference. 1, 329-338.

Luyties, W.H. (1993). "An update on allowable fatigue stresses in API RP2A." OTC 7154. Proceedings, 25th Annual Offshore Technology Conference. 2, 213-228.

Sharp, D.E., and Kenley, R.M. (1993). "Magnus foundation monitoring project: summary of static and dynamic behaviour," Offshore Site Investigation and Foundation Behaviour: Advances in Underwater Technology, Ocean Science and Offshore Engineering, Vol 28, Society for Underwater Technology, London, U.K., pp 493-498. 
Simpson, W. (1979). "The instrumentation system of the Cognac platform," OTC 3499. Proceedings, 11th Annual Offshore Technology Conference. 2, $1245-1258$.

Stock, P.J., Jardine, R., and McIntosh, W. (1993). "Foundation monitoring on the Hutton tension leg platform," Offshore Site Investigation and Foundation Behaviour: Advances in Underwater Technology, Ocean Science and Offshore Engineering, Vol 28, Society for Underwater Technology, London, U.K. , pp 469-491.

Tateishi, H., and Watanabe, Y. (1986). "Leg penetration monitor system to avoid the punch-through accidents of jackup rigs." OTC 5223. Proceedings, Eighteenth Annual Offshore Technology Conference. 3, 19-30.

Titlow, J.D. (1971). "An earthquake/wave instrumentation system for offshore platforms." OTC 1443. Proceedings, Third Annual Offshore Technology Conference. II, 277-288.

Tjelta, T.I. (1993. "Foundation behaviour of Gullfaks C," Offshore Site Investigation and Foundation Behaviour: Advances in Underwater Technology, Ocean Science and Offshore Engineering, Vol 28, Society for Underwater Technology, London, U.K., pp 451-467.

\section{Scouring}

Abad, G.N., and Machemehl, J.L. (1974). "An experimental study of scour around marine foundations due to oscillatory waves and unidirectional currents," Report No. 74-5, North Carolina Center for Marine and Coastal Studies, Raleigh, NC, 91 p.

Chesnutt, C.B., and Schiller, R.E., Jr. (1971). "Scour of Gulf Coast beached due to wave action." OTC 1352. Proceedings, Third Annual Offshore Technology Conference. I, 269-278.

Chow, W., and Herbich, J.B. (1978). "Scour around a group of piles," OTC 3308. Proceedings, 10th Annual Offshore Technology Conference. 4, 2243-2246.

Hansen, E.A., Yde, L., and Jacobsen, V. (1991). "Simulated turbulent flow and forces around groups of cylinders," OTC 6577. Proceedings, 23rd Annual Offshore Technology Conference. 2, 143-154.

Hnatiuk, J., and Wright, B.D. (1983). "Sea bottom scouring in the Canadian Beaufort Sea," OTC 4584. Proceedings, 15th Annual Offshore Technology Conference. 3, 35-40. 
Machemehl, J.L., and Abad, G. (1975). "Scour around marine foundations," OTC 2313. Proceedings, 7th Annual Offshore Technology Conference. 2, 692-696.

Machemehl, J.L., and Herbich, J.B. (1971). "Wave run-up on composite beachesEffect of roughness." OTC 1431. Proceedings, Third Annual Offshore Technology Conference. II, 179-190.

Maidl, B., and Schiller, W. (1979). "Testing and experiences of different scour protection technologies in the North Sea," OTC 3470. Proceedings, 11th Annual Offshore Technology Conference. 2, 981-984.

Ninomiya, K., Tagaya, K., and Murase, Y. (1972). "A study on suction and scouring of sit-on-bottom type offshore structure," OTC 1605. Proceedings, 4th Annual Offshore Technology Conference. 1, 869-878.

Reese, L.C., Wang, S.T., and Long, J.H. (1989). "Scour from cyclic lateral loading of piles," OTC 6005. Proceedings, 21 st Annual Offshore Technology Conference. 2, 395-402.

Sheppard, D.M., Niedoroda, H., and Karanumuni, A. (1990). "Structure-induced seafloor scour," OTC 6366. Proceedings, 22nd Annual Offshore Technology Conference. 3, 213-222.

Susbielles, G.G., Van Den Bunt, J.R., Deleuil, G., and Michel, D. (1971). "Wave forces on pile selections due to irregular and regular waves." OTC 1379. Proceedings, Third Annual Offshore Technology Conference. I, 525-536.

Sweeney, M., Webb, R.M., and Wilkinson, R.H. (1988). "Scour around jackup rig footings," OTC 5764. Proceedings, 20th Annual Offshore Technology Conference. 3, 171-180.

Vick, D.M. (1984). "Concrete revetment mat systems for shore erosion control on offshore embankments," OTC 4673. Proceedings, 16th Annual Offshore Technology Conference. 1, 229-238.

Wright, Stephen G. (1976). "Analyses for wave induced sea-floor movements," OTC 2427B. Proceedings, 8th Annual Offshore Technology Conference. 1, 41-52.

\section{Inspection, Testing, and Quality Assurance Considerations}

\section{Construction quality assurance}

Brown, G.A., and Nacci, V.A. (1971). "Performance of hydrostatic anchors in granular soils," OTC 1472. Proceedings, Third Annual Offshore Technology Conference. II, 533-540. 
Cox, B.E., and Christy, W.W. (1976). "Underwater pile driving test offshore Lousiana," OTC 2478. Proceedings, 8th Annual Offshore Technology Conference. 1, 611-613.

Davis, A. G., and Hertlein, B. H. (1991). "Development of nondestructive smallstrain methods for testing deep foundations: a review," Integrity Testing of Foundations 1991, Transportation Research Record No. 1331, Transportation Research Board of the National Research Council, Washington, DC, 15-20.

Dunegan, Harold L. (1977). "Acoustic emission: New inspection technique," OTC 2851. Proceedings, 9th Annual Offshore Technology Conference. 2, 349-356.

Johnson, S.J., Compton, J.R., and Ling, S.C. (1972). "Control for underwater construction," Underwater Soil Sampling, Testing, and Construction Control, ASTM STP 501, American Society for Testing and Materials, pp 122-180.

Osterberg, J. O. (1998). "The Osterberg load test method for bored and driven piles, the first ten years," Proc., 7th Int. Conf. and Exhibition on Piling and Deep Foundations. Vienna, Austria, June 15-17, Deep Foundation Institute, Englewood Cliffs, N.J., 1.28.1-1.28.11.

Porter, B.W., and Ingram, W.B. (1989). "Post driving prediction of pile capacity," OTC 6003. Proceedings, 21st Annual Offshore Technology Conference. 2, pp 367-372.

Raushe, F., Thendean, G., Abou-Matar, H., Likens, G.E., and Goble, G.G. (1997). "Determination of pile driveability and capacity from penetration tests," Report Nos. FHWA-RD-96-179, 180, and 181.

U.S. Army Corps of Engineers. (1992). "Quality assurance representative's guide,” EP 415-1-261, Washington, DC.

\section{Inspection equipment and techniques}

Bitting, K.R. (1989). “Advancements in underwater inspection,” U.S. Coast Guard, DOT Office of Engineering and Development, Report no. CG-D-1289, Washington, DC.

Black, S.A., Thomson, H.G., Farber, B.W., and Inouye, A. (1986). "Development of underwater construction tools and equipment for U.S. Navy divers," OTC 5262. Proceedings, Eighteenth Annual Offshore Technology Conference. 3, 339-351.

Collins, K. (1993). "Untethered AUVs can reduce costs for offshore inspection jobs," OTC 7114. Proceedings, 25th Annual Offshore Technology Conference. 1, 299-309. 
Department of the Army. (1995). "Periodic inspection and continuing evaluation of completed civil works structures," Engineer Regulation ER 1110-2-100, U.S. Army Corps of Engineers CECW-EP, Washington, DC.

Engels, M., and Huis int Veld, J.C. (1982). "Underwater inspection system for the Eastern Scheldt Barrier," OTC 4363. Proceedings, 14th Annual Offshore Technology Conference. 3, 739-754.

Felio, G.Y., and Berthold, C.S. (1989). "A new rod shear device for the measurement of the degradation of soil-pile interfaces," OTC 6188. Proceedings, 21st Annual Offshore Technology Conference. 2, 655-664.

Miller, J.C. (1986). "Construction diver navigation system," OTC 5264. Proceedings, Eighteenth Annual Offshore Technology Conference. 3, 353361.

Smith, A.P. (1987). "New tools and techniques for the underwater inspection of waterfront structures," OTC 5390. Proceedings, 19th Annual Offshore Technology Conference. 1, 291-298.

Stern, I.L., and Alia, B.L. (1980). "Materials, fabrication and inspection requirements for offshore fixed structures," OTC 3743. Proceedings, 12th Offshore Technology Conference. 2, 71-78.

U.S. Army Corps of Engineers. (1996a). "Diving Regulations," USACE Safety and Occupational Health Manual EM 385-1-1 Section 30.

Watt, A., Smith, G., and Goldberg, L. (1986). "ROV involvement during installation, inspection, maintenance, and repair of offshore structures," OTC 5170. Proceedings, Eighteenth Annual Offshore Technology Conference. 2, 167-172.

\section{Integrity and load tests}

Angemeer, J., Carlson, E.D., and Klick, J.H. (1973). "Techniques and results of offshore pile load testing in calcareous soils," OTC 1894. Proceedings, 5th Annual Offshore Technology Conference. 2, 679-682.

Angemeer, J., Carlson, E.D., Stroud, S., and Kurzeme, M. (1975). "Pile load tests in calcareous soils conducted in 400 feet of water from a semi-submersible exploration rig," OTC 2311. Proceedings, 7th Annual Offshore Technology Conference. 2, 657-663.

Bogard, J.D., and Matlock, H. (1990). "In-situ pile segment model experiments at Empire, Louisiana," OTC 6323. Proceedings, 22nd Annual Offshore Technology Conference. 2, 459-468. 
Bogard, J.D., and Matlock, H. (1998). "Static and cyclic load testing of a 30-inch diameter pile over a 2.5-year period," OTC 8767. Proceedings, 30th Annual Offshore Technology Conference. 2.

Bogard, D., Matlock, H., and Chan, J.H.C. (1991). "In-situ model pile experiments at West Delta 58A," OTC 6513. Proceedings, 23rd Annual Offshore Technology Conference. 1, 133-144.

Briaud, J-L., and Dupin, R.M. (1990). "Integrity testing of three drilled and grouted piles," OTC 6322. Proceedings, 30th Annual Offshore Technology Conference. 2, 451-458.

Briaud, J-L., Anderson, J., and Perdomo, D. (1987). "Evaluation of API Method using 98 vertical pile load tests," OTC 5411. Proceedings, 19th Annual Offshore Technology Conference. 2, 447-452.

Cox, W.R., Kraft, L.M., and Venger, E.A. (1979). "Axial load test on 14-inch pipe piles in clay," OTC 3491. Proceedings, 11th Annual Offshore Technology Conference. 2, 1147-1158.

Cox, W.R., and Reese, L.C. (1976). "Pullout of grouted piles in stiff clay," OTC 2473. Proceedings, 8th Annual Offshore Technology Conference. 1, $539-552$.

Cox, W.R., Reese, L.C., and Grubbs, B.R. (1974). "Field testing of laterally loaded piles in sand," OTC 2079. Proceedings, 6th Annual Offshore Technology Conference. 2, 459-472.

Digre, K.A., Kenney, J.J., and Simic, R. (1989). "Full-scale load test of pile gripper for Bullwinkle," OTC 6098. Proceedings, 21st Annual Offshore Technology Conference. 2, 501-512.

Fragio, A.G., Santiago, J.L., and Sutton, V.J.R. (1985). "Load tests on grouted piles in rock," OTC 4851. Proceedings, 17th Annual Offshore Technology Conference. 1, 93-104.

Gouvenot, Daniel, and Grimault, Othmar. (1976). "Offshore test on jetted piles," OTC 2476. Proceedings, 8th Annual Offshore Technology Conference. 1, 585-592.

Heerema, E. P. (1979). "Pile driving and static load test on piles in stiff clay," OTC 3490. Proceedings, 11 th Annual Offshore Technology Conference. 2, 1135-1146.

Helfrich, S.C., Wiltsie, E.A., Cox, W.R., and Al Shafie, K.A. (1985). "Pile load tests in dense sand: Planning, instrumentation, and results," OTC 4847. Proceedings, 17th Annual Offshore Technology Conference. 1, 55-64. 
Lamport, W.B., Jirsa, J.O., and Yura, J.A. (1987). "Grouted pile-to-sleeve connection tests," OTC 5485. Proceedings, 19th Annual Offshore Technology Conference. 3, 19-26.

Matlock, H., Bogard, D., and Chan, J. (1998). "Technical program: tension pile study," OTC 8763. Proceedings, 30th Annual Offshore Technology

Conference. 2.

Matlock, H., Ingram, W.B., Kelly, A.E., and Bogard, D. (1980). "Field tests of the lateral-load behavior of pile groups in soft clay," OTC 3871. Proceedings, 12th Annual Offshore Technology Conference. 4, 163-174.

Pile Dynamics, Inc. (1999). Information brochures and Internet site http://web.pile.com.

Rausche, F., Goble, G.G., and Moses, F. (1971). "A new testing procedure for axial pile strength," OTC 1481. Proceedings, 3rd Annual Offshore Technology Conference. 2, 633-640.

Reese, L.C., and Cox, W.R. (1975). "Field testing and analysis of laterally loaded piles in stiff clay," OTC 2312. Proceedings, Seventh Annual Offshore Technology Conference. II, 671-690.

. (1976). "Pullout tests of piles in sand," OTC 2472. Proceedings, 8th Annual Offshore Technology Conference. 1, 527-538.

Settgast, R.H., and Sutcliffe, G. (1980). "Marine pile load testing in carbonate rocks," OTC 3868. Proceedings, 12th Annual Offshore Technology Conference. 4, 131-142.

Sitter, W.R. (1980). "Special offshore piledriving test," OTC 3828. Proceedings, 12th Annual Offshore Technology Conference. 3, 313-317.

Sutton, V.J., Rigden, W.J., James, E.L., St. John, H.D., and Poskit, R.J. (1979). "A full scale instrumented pile test in the North Sea," OTC 3489. Proceedings, 11th Annual Offshore Technology Conference. 2, 1117-1134.

Tagaya, K., Heerema, E.P., Uchino, T., and Kusaka, T. (1979). "Pile driveability test on actual offshore platform in calcareous clay for Qatar NGL offshore project," OTC 3440. Proceedings, 11th Offshore Technology Conference. 2, 713-716.

Tan, C.P., Parkin, A.K., and Yee, Y.W. (1990). "Monotonic testing of a model pile driven in a calcareous sandy silt," OTC 6243. Proceedings, 22nd Annual Offshore Technology Conference. 1, 399-404.

Vines, W.R., and Hong, I.S. (1984). "Lateral load tests on large pipe piles in coral," OTC 4839. Proceedings, 16th Annual Offshore Technology Conference. 3, 535-538. 
Wahl, R. (1999). "Caisson load tests at Monongahela River Locks and Dam 2," U.S. Army Engineer Waterways Experiment Station, Vicksburg, MS.

Withers, N.J., Kolk, Lewis, W.M., and Hyden, A.M. (1986). "Grouted section tests in calcareous soils," OTC 5328. Proceedings, 18th Annual Offshore Technology Conference. 4, 333-339.

Zuidberg, H.M., and Vergobbi, P. (1996). "EURIPIDES, load tests on large driven piles in dense silica sands," OTC 7977. Proceedings, 28th Annual Offshore Technology Conference. 1, 193-206.

\section{Modeling, design, and specification considerations}

ASTM. (1991). Annual book of ASTM standards. 04.08:439-444, American Society for Testing and Materials, Philadelphia, PA.

Barton, Y.O., Finn, W.D.L., Parry, R.H.G., and Towhata, I. (1983). "Lateral pile response and p-y curves from centrifuge tests," OTC 4502. Proceedings, 15th Annual Offshore Technology Conference. 1, 503-508.

Batten, P.R. (1987). "Quality assurance for subsea installations," Advances in Underwater Technology, Ocean Science, and Offshore Engineering, Vol 2, Underwater Construction: Development and Potential, Society for Underwater Technology (Graham \& Trotman), pp 177-190.

Blazy, J.P., Quichaud, C., and Leturcq, M. (1971). "ELFOCEAN-Full scale tests and mathematical model," OTC 1401. Proceedings, Third Annual Offshore Technology Conference. I, 751-762.

Bogard, J.D., and Matlock, H. (1990). "Applications of model pile tests to axial pile design," OTC 6376. Proceedings, 22nd Annual Offshore Technology Conference. 3, 271-278.

Brannon, H.R. (1977). "Platform verification: A view from a member of industry," OTC 2809. Proceedings, 9th Annual Offshore Technology Conference. 2, 21-32.

Brennodden, H., Sveggen, O., Wagner, D.A., and Murff, J.D. (1986). "Full-scale pipe-soil interaction tests," OTC 5338. Proceedings, Eighteenth Annual Offshore Technology Conference. 4, 433-440.

Cassidy, M.I., and Houlsby, G.T. (1999). "On the modeling of foundations for jack-up units on sand," OTC 10995. Proceedings, 31st Annual Offshore Technology Conference. II. 
Chernauskas, L.R., and Paikowsky, S.G. (1999). "Deep foundations integrity testing: techniques and case histories," Journal of the Boston Society of Civil Engineers/ASCE, Civil Engineering Practice 14(1), 39-55.

Construction Specifications Institute (CSI). (1996). Manual of Practice, Alexandria, VA.

Cronk, P.J., and Bishop, K.F. (1977). "Development and application of Coast Guard regulations for mobile offshore drilling units," OTC 2860. Proceedings, 9th Annual Offshore Technology Conference. 2, 423-430.

Department of the Army. (1998). "Specifications," Engineer Regulation ER 11101-8155, U.S. Army Corps of Engineers, Washington, DC.

Det Norske Veritas. (1989). "Rules for classification of fixed offshore installations," Oslo, Norway, http://www.dnv.com.

Dutt, R.N., and Teferra, W. (1986). "CAPWAP analysis increase ability to properly design piles in calcareous sands," OTC 5147. Proceedings, Eighteenth Annual Offshore Technology Conference. 1, 569-578.

Finn, W.D.L., Siddharthan, R., Lee, F., and Schofield, A.N. (1984). "Seismic response of offshore drilling islands in a centrifuge including soil-structure interaction," OTC 4693. Proceedings, 16th Annual Offshore Technology Conference. 1, 399-406.

Finn, W.D.L., Steedman, R.S., Yogendrakumar, M., and Ledbetter, R.R. (1985). "Seismic response of gravity structures in a centrifuge," OTC 4885. Proceedings, 17th Annual Offshore Technology Conference. 1, 389-394.

George, P. J., and Shaw, P. G. H. (1976). "Certification of concrete gravity platforms in the North Sea," OTC 2436. Proceedings, 8th Annual Offshore Technology Conference. 1, 131-148.

Gerwick, Ben. (1977). "Verification of offshore platform design and installation: The Marine Board panel view," OTC 2807. Proceedings, 9th Annual Offshore Technology Conference. 2, 7-14.

Hove, K., and Foss, I. (1974). "Quality assurance for offshore concrete gravity structures," OTC 2113. Proceedings, 6th Annual Offshore Technology Conference. 2, 830-841.

Jardine, R.J., and Soldivar, E. (1999). "An alternative interpretation of the West Delta 58A tension pile research results," OTC 10827. Proceedings, 31st Annual Offshore Technology Conference. 2.

Lee, Griff C. (1977). "Verification of platform design and installation : A contractor's view," OTC 2808. Proceedings, 9th Annual Offshore Technology Conference. 2, 15-20. 
Leung, P.K., Schiffman, R.L., Ko, H.Y., and Pane, V. (1984). "Centrifuge modeling of shallow foundation on soft soil," OTC 4808. Proceedings, 16th Annual Offshore Technology Conference. 3, 275-282.

Murff, J.D. (1996). "The geotechnical centrifuge in offshore engineering," OTC 8265. Proceedings, 28th Annual Offshore Technology Conference. 1, 675-689.

Murff, J.D., Hamilton, J.M., Dean, E.T.R., James, R.G., Kusakage, O., and Schofield, A.N. (1991). "Centrifuge testing of foundation behavior using full jackup rig models," OTC 6516. Proceedings, 23rd Annual Offshore Technology Conference. 1, 165-178.

Nicola, A.D., and Randolph, M.F. (1999). "Centrifuge modelling of pipe piles in sand under axial loads," Geotechnique 49(3), 295-318.

Nielsen, M. J., and Nielsen, K. R. (1981). "Risks and liabilities of specifications"in Proceedings, Specialty Conference: Reducing Risk and Liability through Better Specifications and Inspection, Construction Division of the American Society of Civil Engineers, New York, pp 4-19.

Parkin, A.K., Yee, Y.W., Tan, C.P., and Willoughby, D.R. (1990). "Driven model piles tested in calcareous sand in a large calibration chamber," OTC 6242. Proceedings, 22nd Annual Offshore Technology Conference. 1, 389-398.

Rajabi, F., and Mangiavacchi, A. (1988). "Model test of a pile-founded guyed tower," OTC 5675. Proceedings, 20th Annual Offshore Technology Conference. 1, 531-542.

Shaw, P. (1974). "Quality assurance for offshore gravity structures," Symposium on Ocean Engineering, Royal Institution of Naval Architects, London, pp 105-111.

Tannahill, C.A. (1971). "Methods of strengthening existing offshore structures," OTC 1488. Proceedings, Third Annual Offshore Technology Conference. II, 699-704.

\section{Installation Considerations}

\section{Gravity-based foundations}

Alloni, C., D'Agostino, A., and Priarone, R. (1976). "Design, analysis, and construction of the Loango steel gravity platforms," OTC 2437. Proceedings, 8th Annual Offshore Technology Conference. 1, 149-164. 
Alm, T., Bye, A., and Egeland, S. (1995). "The Draugen platform and subsea structures, installation and foundation aspects," OTC 7670. Proceedings, 27th Annual Offshore Technology Conference. 1, 281-287.

Andenaes, E., Skomedal, E., and Lindseth, S. (1996). "Installation of the Troll Phase I GBS," OTC 8122. Proceedings, 28th Annual Offshore Technology Conference. 3, 57-70.

Berthin, J.C., Hudson, W.L., Doris, C.G., and Myrabo, D.O. (1985). "Installation of Maureen Gravity Platform over a template," OTC 4876. Proceedings, 17th Annual Offshore Technology Conference. 1, 321-328.

Broughton, P., and den Hertog, P.D. (1990). "The foundation stability analysis of the Ekofisk Protective Barrier for both the installation and operational conditions," OTC 6240. Proceedings, 22nd Annual Offshore Technology Conference. 1, 357-372.

Collipp, B.G., and Johnson, P. (1979). "Marine equipment and procedures for the Cognac platform installation," OTC 3498. Proceedings, 11th Annual Offshore Technology Conference. 2, 1233-1238.

Gerwick, B.C. (1974). "Preparation of foundations for concrete caisson sea structures," OTC 1946. Proceedings of 6th Annual Offshore Technology Conference. 1, 119-130.

Hu, Y., Randolph, M.F., and Watson, P.G. (1999). "Bearing response of skirted foundation on nonhomogeneous soil," Journal of Geotechnical and Geoenvironmental Engineering. 125, No. 11, American Society of Civil Engineers, pp 924-935.

Kriebel, D.L., Berek, E.P., Chakrabarti, S.K., and Waters, J.K. (1996). "Wavecurrent loading on a shallow water caisson," OTC 8067. Proceedings, 28th Annual Offshore Technology Conference. 2, 349-358.

Noblanc, A., and Schnader, H.-E. (1983). "Precise seabed emplacement of an articulated loading platform in the North Sea," OTC 4571. Proceedings, 15th Annual Offshore Technology Conference. 2, 481-488.

O'Riordan, N.J., and Clare, D.G. (1990). "Geotechnical considerations for the installation of gravity base structures," OTC 6381. Proceedings, 22nd Annual Offshore Technology Conference. 2, 309-316.

Sterling, G.H., Casbarian, A.O.P., Dodge, N.L., and Godfrey, D.G. (1979). "Construction of the Cognac platform, Gulf of Mexico," OTC 3493. Proceedings, 21st Annual Offshore Technology Conference. 1, 465-469. 
Tanaka, K., Ikejiri, K., Kobayashi, A., Tsuchiya, M., and Nakatsuka, K. (1987). "A study on the installation of a submerged caisson in deep waters," OTC 5606. Proceedings, 19th Annual Offshore Technology Conference. 4, 481488.

Tateishi, H., and Watanabe, Y. (1986). "Leg penetration monitor system to avoid the punch-through accidents of jackup rigs," OTC 5223. Proceedings, 18th Annual Offshore Technology Conference. 3, 19-30.

Waddell, J.W. (1997). "Self installing gravity platform concept," OTC 8446. Proceedings, 29th Annual Offshore Technology Conference. 3, 99-107.

Yao, S.X., Berner, D.E., and Gerwick, B.C. (1999). "Assessment of underwater concrete technologies for in-the-wet construction of navigation structures," Technical Report INP-SL-1, U.S. Army Corps of Engineers ERDC, Vicksburg, MS, p 50.

\section{Improved-site foundations}

Aerts, F., Devlieger, H., and Vandycke, S. (1999). "Building on soft soils," Bulletin of the International Navigation Association, No. 101, April, pp 23-25.

Agerton, D.J. (1983). "Construction of an arctic offshore gravel island in $39 \mathrm{ft}$ of water during winter and summer," OTC 4548. Proceedings of the 15th Annual Offshore Technology Conference. 2, 309-316.

Barksdale, R.D., and Bachus, R.C. (1983). "Design and construction of stone columns," Report No. FHWA-RD-83-026 and 027. 1 and 2.

Bazett, D.J., and Foxall, R.G. (1972). "Control of underwater earthwork at Hugh Keenleyside (Arrow) Dam," Underwater Soil Sampling, Testing, and Construction Control, ASTM STP 501, American Society for Testing and Materials, pp 187-203.

Brown, P.P. (1972). "Construction beyond the Continental Shelf," Underwater Soil Sampling, Testing, and Construction Control, ASTM STP 501, American Society for Testing and Materials, pp 122-180.

Buslov, V.M., Williams, D.R., Hayes, R.M., and Bivens, H.R. (1984). "Bottom preparation for gravity structures in the Beaufort Sea," OTC 4696. Proceedings, 16th Annual Offshore Technology Conference. 1, 423-432.

Dansette, N., and Robertson, N.C. (1994). " Subsea flexible pipeline burial using a lightweight pipeline trencher," OTC 7600. Proceedings, 26th Annual Offshore Technology Conference. 4, 847-850. 
Digre, K.A., Pelletier, J.H., Larrabee, R.D., Marshall, P.W., and Piter, E.S. (1989). "Design consideration for the Bullwinkle jacket mudmats," OTC 6097. Proceedings, 21 st Annual Offshore Technology Conference. 2, 489-498

Dikken, J.J., and Brakel, J. (1982). "Dredging and construction techniques for steep slopes on artificial drilling islands in the Canadian Arctic," OTC 4225. Proceedings, 14th Annual Offshore Technology Conference. 1, 713-720.

Dredging and Port Construction. (1999). "World's largest dredger begins new voyage of discovery," Dredging and Port Construction. 26, No. 11.

Fitzmaurice, S.J., Williams, S.E., Moore, R.H., and Moir, J.R. (1985).

"Construction of steep, sloped underwater berms by bottom dumping using trailer suction hopper dredges," OTC 4921. Proceedings of the17th Annual Offshore Technology Conference. 2, 239-246.

Halebsky, M., and Wetmore, S.B. (1986). "Seabed strengthening by deep cement mixing," OTC 5108. Proceedings of the 18th Annual Offshore Technology Conference. 1, 253-259.

Hausmann, M.R. (1990). Engineering principles of ground modification, McGraw-Hill Publishing Co., New York, 632 p.

Hayward Baker. (1999a). "Vibro-Compaction," ISSMFE-TC-17, http://www.haywardbaker.com/compac.html.

\section{project.html.}

(1999b). "Project summaries," http://www.haywardbaker.com/

Johnson, S.J., Compton, J.R., and Ling, S.C. (1972). "Control for underwater construction," Underwater Soil Sampling, Testing, and Construction Control, ASTM STP 501, American Society for Testing and Materials, pp 122-180.

Jolliffe, I.P. (1974). "Beach-offshore dredging: Some environmental consequences," OTC 2056. Proceedings of 6th Annual Offshore Technology Conference. 2, 257-268.

Kraemer, S.R., and Smith, A.D. (1986). "Geocomposite drains: Volume 1, Engineering assessment and preliminary guidelines," Report No. FHWA-RD86-171, August (NTIS PB87-154993/AS).

Leidersdorf, C.B., Potter, R.E., Gerwick, B.C., and Hsu, Y.-Y. (1982). "Modular slope protection for the arctic environment," OTC 4223. Proceedings, 14th Annual Offshore Technology Conference. 1, 689-704.

Lieng, J.T., and Bjorgen, H.P. (1995). "New flow-through mudmat design for Heidrun subsea structure," OTC 7671. Proceedings, 27th Annual Offshore Technology Conference. 2, 289-299. 
Loeken, P.A. (1980). "Engineered backfilling on the 36-in Ekofisk-Emden gas pipeline," OTC 3741. Proceedings, 12th Annual Offshore Technology Conference. 2, 53-58.

Mitchell, D.E., and McRae, T.E. (1985). "Densification of submarine hydraulic fills," OTC 4920. Proceedings of 17th Annual Offshore Technology Conference. 2, 229-238.

Mortensen, P., Fredsoe, J., and Damsgaard, A. (1978). "Natural backfilling of pipeline trenches," OTC 3073. Proceedings of the 10th Annual Offshore Technology Conference. 1, 225-232.

Munn, W.D. (1989). "Wick drains placed underwater," Highway and Heavy Construction, Cahners Publishing. (Reprint by Geotechnics America, Inc., Peachtree City, GA.)

Pennine Ground Engineering, Ltd. (1998). "Batu Hijau Project, Sumbawa, Indonesia," Ground Modification Techniques brochure, Lancashire, England.

Rixner, J.J., Kraemer, S.R., and Smith, A.D. (1986). "Prefabricated vertical drains: Volume 1, Engineering Guidelines, Report No. FHWA-RD-86-168, August (NTIS PB87-155008/AS)

Roderick, G.L., and Lubbad, A. (1975). "Effect of object in-situ time on bottom breakout," OTC 2184. Proceedings of Seventh Annual Offshore Technology Conference. I, 355-362.

Rose, W.L., and Grubbs, B.R. (1979). "Field applications of electro osmosis to increase offshore pile driveability," OTC 3373. Proceedings, 11th Annual Offshore Technology Conference. 2, 747-754.

Ross, C.M. (1995). "New tool designs for high rate gravel pack operations," OTC 7891. Proceedings, 27th Annual Offshore Technology Conference. 4, 217-227.

Stamatopoulos, A.C., and Kotzias, P.C. (1971). "Embankment construction on yielding sea bottom," OTC 1470. Proceedings of Third Annual Offshore Technology Conference. II, 503-524.

Stewart, H.R., Jefferies, M.G., and Goldby, H.M. (1983). "Berm construction for the Gulf Canada Mobile Arctic Caisson," OTC 4552. Proceedings, 15th Annual Offshore Technology Conference. 2, 339-346.

Usami, T., Saito, T., and Oba, S. (1982). "Lifting characteristics of solid particles by air-lift pump," OTC 4297. Proceedings, 14th Annual Offshore Technology Conference. 2, 763-782. 
Van Oord ACZ. http://www.voacz.com.

Van Steveninck, J. (1975). "Pipeline burial by fluidisation," OTC 2276. Proceedings of Seventh Annual Offshore Technology Conference. II, 313-314.

Wilson, James F., Preston, Lowery D., and Millan, John D. (1976). "Dredging with tidal-powered scouring jets," OTC 2585. Proceedings, 8th Annual Offshore Technology Conference. 2, 611-620.

World Dredging, Mining, and Construction. (1999a). "Backhoe dredge 'New York',"World Dredging, Mining, and Construction, August, p 8.

. (1999b). "Underwater excavation," World Dredging, Mining, and Construction, June, p 4.

\section{Pinned foundations}

Agarwal, S.L., Rawat, P.C, and Paintal, S.S. (1978). "Problems encountered in installation of offshore piles for fixed platforms," OTC 3274. Proceedings, 10th Annual Offshore Technology Conference. 3, 1925-1931.

Aurora, R.P. (1980). "Case studies of pile set-up in the Gulf of Mexico," OTC 3824. Proceedings, 12th Annual Offshore Technology Conference. 3, 281-284.

(1984). "Experience with driving 84-in. piles with underwater and abovewater hammers at the South Brae Platform, North Sea," OTC 4803. Proceedings, 16th Annual Offshore Technology Conference. 3, 237-241.

Barton, Charles E. (1976). "Heave compensated system for determining return mud flowrate aboard floating drilling vessels," OTC 2618. Proceedings, 8th Annual Offshore Technology Conference. 2, 997-1002.

Bender, Carl H., Jr., Lyons, Charles G., Lt., and Lowery, Lee L., Jr. (1969). "Applications of wave-equation analysis to offshore pile foundations," OTC 1055. Proceedings, 1st Annual Offshore Technology Conference. 1, 575-586.

Bosscher, P.J., Menclova, E., Russell, J.S., and Wahl, R.E. (1998). "Estimating bearing capacity of piles installed with vibratory drivers," Technical Report CPAR-GL-98-2, Construction Productivity Advancement Research Program, U.S. Army Engineer Waterways Experiment Station, Vicksburg, MS, 171 p.

Chua, K.M., Gardner, S., and Lowery, L.L. (1987). "Wave equation analysis of a vibratory hammer-driven pile," OTC 5396. Proceedings, 19th Annual Offshore Technology Conference. 1, 339-345. 
Collins, G.J., and Bennett, R.D. (1994 "Field testing a downhole multiwell drilling template: A unique approach to individually drill, case, and complete two separate wells from one,"OTC 7548. Proceedings, 26th Annual Offshore Technology Conference. 4, 369-376.

Cox, B. E., and Christy, W. W. (1976 "Underwater pile driving test offshore Louisiana," OTC 2478. Proceedings of 8th Annual Offshore Technology Conference. 1, 611-616.

Department of the Army. (1982). "Pile driving equipment," Army Technical Manual TM 5-849-1, Washington, DC.

Doyle, E.H. (1999). "Pile installation performance for four TLP's in the Gulf of Mexico," OTC 10826. Proceedings of 1999 Offshore Technology Conference, TX.

Dutt, R.N., Doyle, E.H., Collins, J.T., and Ganguly, P. (1995). “A simple model to predict soil resistance to driving for long piles in deepwater normally consolidated clays," OTC 7668. Proceedings of 27th Annual Offshore Technology Conference.

Engeling, Paul. (1974). "Drivability of long piles," OTC 2084. Proceedings, 6th Annual Offshore Technology Conference. 2, 521-526.

Erbrich, C.T., and Tjelta, T.I. (1999). "Installation of bucket foundations and suction caissons in sand- geotechnical performance," OTC 10990.

Proceedings, 31st Annual Offshore Technology Conference. 2.

Esrig, M.I. (1978). "Increasing offshore pile driveability through electroosmosis," OTC 3269. Proceedings, 10th Annual Offshore Technology Conference. 3, 1877-1886.

Foo, Stephen H. C., Matlock, Hudson, and Meyer, Patrick L. (1977). "Analysis of driving of foundation piles," OTC 2842. Proceedings of 9th Annual Offshore Technology Conference. 2, 281-290.

Fox, D.A., Parker, G.F., and Sutton, V.J.R. (1970). "Pile driving into North Sea boulder clays," OTC 1200. Proceedings of 2nd Annual Offshore Technology Conference. 1, 535-545.

Gendron, G.J., Holland, H.A.N., and Ranft, E.V. (1978). "Underwater pile driving hammer at the Maui Field," OTC 3270. Proceedings of 10th Annual Offshore Technology Conference. 3, 1887-1892.

Greer, D. M., and Gardner, W. S. (1986. Construction of drilled pier foundations, Wiley Publishing, New York, pp 102-135. 
Ground Engineering, 1999). "Quiet hammer cushions the blow," Ground engineering 32(11), 18.

Harris, L. M., and Ilfrey, W. T. (1969). " Drilling in 1300 Feet of water in Santa Barbara Channel, California," OTC 1018. Proceedings of 1st Annual Offshore Technology Conference. 1, 167-182.

Heerema, E.P. (1980). "An evaluation of hydraulic vs. steam pile driving hammers," OTC 3829. Proceedings of 12th Annual Offshore Technology Conference. 3, 321-327.

Hirsch, T.J., Koehler, A.M., and Sutton, V.J.R. (1975). "Selection of pile driving equipment and field evaluation of pile bearing capacity during driving for the North Sea Forties Field," OTC 2247. Proceedings of 7th Annual Offshore Technology Conference. 2, 37-42.

Holloway, D.M., Audibert, J.M.E., and Dover, A.R. (1978). "Recent advances. Predicting pile driveability," OTC 3273. Proceedings of 10th Annual Offshore Technology Conference. 3, 1915-1922.

Hruska, S.J., Koehler, A.M., Shaw, L.K., and Bourne, M.J. (1975). "Engineering the procedure for installing the North Sea Forties Field platforms,"'OTC 2248. Proceedings of Seventh Annual Offshore Technology Conference. II, 51-65.

IHC Foundation Equipment. (1999). "IHC Hydrohammer," Technical specifications brochure, Kinderdijk, Netherlands.

Jansz, J.W. (1977). "North Sea pile driving experience with a hydraulic hammer," OTC 2840. Proceedings of 9th Annual Offshore Technology Conference. 2, 267-279.

Jansz, J.W., and Brockhoff, H.S.T. (1979). "A simple way to drive free-standing subsea anchor piles," OTC 3439. Proceedings of 11th Annual Offshore Technology Conference. 2, 697-705.

Jansz, J.W., Voitus van Hamme, G.E.J.S.L., Gerritse, A., and Bomer, H. (1976). "Controlled piledriving above and under water with a hydraulic hammer," OTC 2477. Proceedings of 8th Annual Offshore Technology Conference. 1, 593-603.

Jonker, G. (1987). "Vibratory pile driving hammers for pile installations and soil improvement projects," OTC 5422. Proceedings of 19th Annual Offshore Technology Conference. 2, 549-560.

. (1988). "Subsea installations using vibratory piling hammers," OTC 5776. Proceedings of 20th Annual Offshore Technology Conference. 2, 291-304. 
Lang, G.R. Jr. (1980). "Predicting the driveability of large diameter offshore piling," OTC 3827. Proceedings of 12th Annual Offshore Technology Conference. 3, 301-305.

Lenihan, J.E., Austin, R.T.C., and Flanagan, P.J. (1984). "The rapid installation of a large North Sea jacket over a subsea template," OTC 4759. Proceedings, 16th Annual Offshore Technology Conference. 2, 419-430.

Ligterink, A., and Martin, R. (1992). "Field experience installing A-shape piles with a vibratory hammer," OTC 6842. Proceedings of 24th Annual Offshore Technology Conference. 1, 301-310.

Ligterink, A.A., van Zandwijk, C., and Middendorp, P. (1990). "Accurate vertical pile installation using a hydraulic vibratory hammer on the Arbroath Project," OTC 6236. Proceedings, 22nd Annual Offshore Technology Conference. 1, 315-326.

Lowery, Lee L. Jr., Edwards, Thomas C., and Finley, James R. Jr. (1969). "Increasing the ability to drive long off-shore piles," OTC 1064. Proceedings, 1st Annual Offshore Technology Conference. 1, 681-686.

Mayfield, J.G., Strohbeck, E.E., and Wilkins, J.R. (1979). "Installation of the pile foundation for the Cognac platform," OTC 3497. Proceedings, 11th Annual Offshore Technology Conference. 2, 1221-1227.

Menck, Inc. (1999). Internet site http://www.jraymcdermott.com/menck/ menck_mhut.htm.

Moulai-Khatir, R., O’Neill, M.W., and Vipulanandan, C. (1994). "Program VPDA: Wave equation analysis for vibratory driving of piles," Department of Civil and Environmental Engineering, University of Report for U.S. Army Engineer Waterways Experiment Station, Vicksburg, MS.

Parker, E.J., Jardine, R.J., Standing, J.R., and Jullian, X. "Jet grouting to improve offshore pile capacity: GOPAL Project," OTC 10828. Proceedings, 31st Annual Offshore Technology Conference. 2.

Phair, M. (2000). "Hydraulically powered pile-driving system lands in Florida," Engineering News-Record 244(4), 45.

Phares, Lindsey J. (1974). “Grouting piles while driving,” OTC 2083. Proceedings, 6th Annual Offshore Technology Conference. 2, 513-520.

Pile Buck, Inc. (1999). Internet site http://web.pilebuck.com. 
Puech, A., Poulet, D., and Boisard, P. (1990). "A procedure to evaluate pile drivability in the difficult soil conditons of the southern part of the Gulf of Guinea," OTC 6237. Proceedings, 22nd Annual Offshore Technology Conference. 1, 327-334.

Redfern, I.J., Calkins, D.E., and Matten, R.B. (1999). "Morpeth SeaStar installation," OTC 10857. Proceedings of 31st Annual Offshore Technology Conference, Vol 2.

Rennie, I.A., and Fried, P. (1979). "An account of the piling problems encountered and the innovative solutions devised during the installation of the Maui 'A' tower in New Zealand," OTC 3442. Proceedings of 11th Annual Offshore Technology Conference. 2, 723-730.

Shirley, Kirk R. (1976). "The underreamer: Its versatility in offshore drilling and construction," OTC 2619. Proceedings, 8th Annual Offshore Technology Conference. 2, 1003-1006.

Steinke, J.F., and Strasser, R.L. (1978). "Novel approach to construction pile driving for Alaska pipeline terminal, Valdez, Alaska," OTC 3271. Proceedings, 10th Annual Offshore Technology Conference. 3, 1895-1904.

Stevens, R.S., Wiltsie, E.A., and Turton, T.H. (1982). "Evaluating pile driveability for hard clay, very dense sand, and rock," OTC 4205. Proceedings, 14th Offshore Technology Conference. 2, 1169-1173.

Sullivan, R.A., and Ehlers, C.J. (1972). "Practical planning for driving offshore pipe piles," OTC 1600. Proceedings, 4th Offshore Technology Conference. 1, 806-814.

Tagaya, K., Heerema, E. P., Uchino, T., and Kusaka, T. (1979). “Pile driveability test on actual offshore platform In calcareous clay for Qatar NGL offshore project," OTC 3440. Proceedings, 11th Annual Offshore Technology Conference. 2, 713-722.

Tang, W.H., Woodford, D.L., and Pelletier, J.H. (1990). "Performance reliability of offshore piles," OTC 6379. Proceedings, 22nd Annual Offshore Technology Conference. 2, 299-308.

Taylor, Robert J., and True, Daniel G. (1976). "Use of propellant-actuated anchors in underwater construction," OTC 2465. Proceedings, 8th Annual Offshore Technology Conference. 1, 431-436.

Tjelta, T.I. (1995). "Geotechnical experience from the installation of the Europipe jacket with bucket foundations," OTC 7795. Proceedings, 27th Annual Offshore Technology Conference. 2, 897-908. 
Tjelta, T.I., Aas, P.M., Hermstad, J., and Andenaes, E. (1990). "The skirt piled Gullfaks C Platform installation," OTC 6473. Proceedings, 22nd Annual Offshore Technology Conference. 4, 453-462.

Tragesser, Arthur F., Dalton, Charles, and Kay, Franklin J. (1974). "Pressure grouting: An improved method of offshore structure grouting," OTC 2082. Proceedings, 6th Annual Offshore Technology Conference. 2, 505-512.

Tsinker, Gregory P. (1988). "Pile jetting," ASCE Journal of Geotechnical Engineering 114(3), March, 326-334.

Van Luipen, P. (1987). "The application of the hydraulic underwater hammer in slender and free-riding mode with optional underwater powerpack," OTC 5423. Proceedings, 19th Annual Offshore Technology Conference. 1, 561570.

Van Zandwijk, K. (1986). "The effect of deepwater on the performance of slender underwater hammers," OTC 5326. Proceedings of Eighteenth Annual Offshore Technology Conference. 4, 313-322.

Van Zandwijk, C., van Dijk, B.P., and Heerema, E.P. (1983). "An improved pile driveability theory for Gulf of Mexico soils," OTC 4503. Proceedings of 15th Annual Offshore Technology Conference. 1, 509-515.

Warrington, D.C. (1989). "Theory and development of vibratory pile-driving equipment," OTC 6030. Proceedings of 21 st Annual Offshore Technology Conference. 2, 541-550.

Welham, T.R., and Gilfrin, J.A. (1993). "Installation of grouted pile-sleeve connections: A state-of-the-art review," OTC 7195. Proceedings of 25th Annual Offshore Technology Conference. 2, 667-675.

Williams, M., Wharton, R., Horlin, H., and Jegou, A. (1975). "Underwater construction work in Forties Field and Argyll Field,"OTC 2166. Proceedings of Seventh Annual Offshore Technology Conference. I, 201-209.

Wisotsky, S. (1978). "Water hammer pile driver," OTC 3272. Proceedings of 10th Annual Offshore Technology Conference. 3, 1905-1911.

\section{Positioning}

Batten, P.R. (1987). "Quality assurance for subsea installations," Advances in Underwater Technology, Ocean Science, and Offshore Engineering, Vol 2, Underwater Construction: Development and Potential, Society for Underwater Technology (Graham \& Trotman), pp 177-190. 
Benington, C.K., and Stevenson, W.D. (1975). "A servo-controlled motion compensator for the offshore drilling industry," OTC 2231. Proceedings of Seventh Annual Offshore Technology Conference. I, 818-827.

Birdwell, J.R., and Jordan, J.E. (1994). "Mobile Bay project float-on deck installations," OTC 7499. Proceedings, 26th Annual Offshore Technology Conference. 3, 323-332.

Bos, A.J., and van den Hoonaard, A.H. (1996). "The "Marine quality kit": a Tool to monitor accelerations, velocities, and motions in arbitrary locations on floating objects,"OTC 8161. Proceedings, 28th Annual Offshore Technology Conference. 4, 109-114.

Boyadjieff, George, House, Horace, and Roussel, Herbert. (1977). "A new offshore pile aligning system," OTC 2839. Proceedings of 9th Offshore Technology Conference. 2, 257-266.

Burns, J. Q., and Suh, S. L. (1979). "Design and analysis of hydraulic lift systems for deep ocean mining," OTC 3366. Proceedings of 11th Offshore Technology Conference. 1, 73-84.

Butler, B., and Larralde, E. (1971). "Motion compensation on drilling vessels,"OTC 1335. Proceedings of Third Annual Offshore Technology Conference. I, 113-124.

Calcar, Henry Van 1969). "Acoustic position reference methods for offshore drilling operations," OTC 1141. Proceedings of 1st Annual Offshore Technology Conference. 2, 567-582.

Cathie, D.N., Machin, J.B., and Overy, R.F. (1996). "Engineering appraisal of pipeline floatation during backfilling,"OTC 8136. Proceedings, 28th Annual Offshore Technology Conference. 3, 197-206.

Christensen, D. R., and Richey, E. P. (1976). "Prototype performance characteristics of two floating breakwaters," OTC 2544. Proceedings of 8 th Annual Offshore Technology Conference. 2, 237-252.

Converse, R.M., Bhattacharjee, S., Chen, J., Windus, J.W., and Raymond, K.G. (1990). "An economical pile-handling technique using dynamic upend," OTC 6397. Proceedings, 22nd Annual Offshore Technology Conference. 3 , 473-480.

Delerno, Joseph, and Marchal, A.W. (1969). "Offshore radiopositioning systems," OTC 1099. Proceedings of 1st Annual Offshore Technology Conference. 2, 217-222.

Drouin, Andre H. (1974). "Design and field operation of an underwater acoustic telemetry system," OTC 1965. Proceedings of 6th Annual Offshore Technology Conference. 1, 319-332. 
Fischer, F.J. (1975). "Driving analysis for initially curved marine conductors," OTC 2309. Proceedings of Seventh Annual Offshore Technology Conference. II, 633-644.

Goren, Y., and McMillan, B. (1971). "A vessel for offshore construction in heavy seas," OTC 1489. Proceedings of Third Annual Offshore Technology Conference. II, 705-720.

Hartell, W.D., and Beattie, S.M. (1996). "Integrated, float-over deck design considerations," OTC 8119. Proceedings, 28th Annual Offshore Technology Conference. 3, 15-30.

Labbé, J.P., Legras, J.L., and Standing, R.G. (1996). “Smart'Leg: A new method for heavy deck offshore installation,"OTC 8120. Proceedings, 28th Annual Offshore Technology Conference. 3, 31-43.

Leonard, J.W. (1971). “Inflatable shells for underwater use,"OTC 1404. Proceedings of Third Annual Offshore Technology Conference. I, 789-806.

Ligterink, A., van Zandwijk, C., and Middendorp, P. (1990). "Accurate vertical pile installation by using a hydraulic vibratory hammer on the Arbroath Project," OTC 6236. Proceedings of 22th Annual Offshore Technology Conference. 1, 315-326.

Loth, W. D., Burkhardt, J. A., and Covellone. (1976). "Template structure and installation- A subsystem of the submerged production system," OTC 2532. Proceedings, 8th Annual Offshore Technology Conference. 2, 83-94.

Mukerji, P.K. (1993). "Application of expert systems in offshore structure installation," OTC 7226. Proceedings of 25th Annual Offshore Technology Conference. 3, 215-221.

Peterson, D.C. (1979). "Cognac positioning system," OTC 3500. Proceedings, 11th Annual Offshore Technology Conference. 2, 1259-1270.

Schneider, W.P. (1969). "Dynamic positioning systems," OTC 1094. Proceedings, 1st Annual Offshore Technology Conference. 2, 183-190.

Sigrist, J.H., Thomas, P.A., and Naudin, J.C. (1998). "Experience in float over integrated deck: Flexibility of the concept," OTC 8616. Proceedings, 30th Annual Offshore Technology Conference. 3.

Sigrist, J.H., and Naudin, J.C. (1996). "Experience in float over integrated deckdesign and installation," OTC 8121. Proceedings, 28th Annual Offshore Technology Conference. 3, 45-56. 
Simpson, W.F. (1979). "The instrumentation system for the Cognac platform," OTC 3499. Proceedings, 11th Annual Offshore Technology Conference. 2, 1245-1251.

U.S. Army. (1999). "Monitoring steel cell placement using differential GPS at Lock and Dam 24, Mississippi River," INP Internet site http://crunch.tec.army.mil/ information/publications/Lock_Dam24/cell.htm.

\section{Site Assessment Considerations}

\section{Geophysics and surveying methods}

Antoine, J.W. (1975). "Advances in the interpretation of high resolution seismic data," OTC 2178. Proceedings, Seventh Annual Offshore Technology Conference. I, 313-320.

Arnold, M. E. (1976). "Pressure amplitude of seismic signals in offshore Louisiana," OTC 2512. Proceedings, 6th Annual Offshore Technology Conference. 1, 925-936.

Badger, A. S. (1969). "A variable area recorder for offshore seismic data," OTC 1126. Proceedings, 1st Annual Offshore Technology Conference. 2, 453-460.

Beasley, C.J., Chambers, R.E., Workman, R.L., Craft, K.L., and Meister, L.J. (1997). "Repeatability of 3D ocean bottom cable seismic surveys," OTC 8310. Proceedings, 29th Annual Offshore Technology Conference. 1, 309312.

. (1997). "Repeatability of 3-D ocean-bottom cable seismic surveys," EdgeNet Online 16(9). Society of Exploration Geophysicists, Tulsa, OK. http://www.edge-online.org.

Bouma, A.H., Ferebee, T.W.,Jr., Chmelik, F.B., and Huebner, G.H., Jr. (1975). "Electrical logging systems and results of unconsolidated marine sediments," OTC 2157. Proceedings, Seventh Annual Offshore Technology Conference. I, 753-759.

Bouma, A.H., Sweet, W.E., Jr., Chmelik, F.B., and Huebner, G.L. (1971). "Shipboard and in-situ electrical resistivity logging of unconsolidated marine sediments," OTC 1351. Proceedings, Third Annual Offshore Technology Conference. I, 253-268.

Campbell, K.J. (1997). "Fast-track development: The evolving role of 3D seismic data in deepwater hazards assessment and site investigation," OTC 8306. Proceedings, 29th Annual Offshore Technology Conference. 1, pp 277-292. 
Chernof, Joseph. (1969). "New developments in satellite navigation equipment for offshore exploration," OTC 1103. Proceedings, 1st Annual Offshore Technology Conference. 2, 245-252.

Ciani, J.B., and Malloy, R.J. (1975). "Seafloor surveying in the nearshore zone," OTC 2221. Proceedings, Seventh Annual Offshore Technology Conference. I, 743-751.

Coles, B.W. (1995). "Recent field demonstrations of the capabilities of an underwater laser line scan imaging system in environmental survey and pipeline inspection applications," OTC 7678. Proceedings, 27th Annual Offshore Technology Conference. 1, 355-362.

Delflache, A.P., Bryant, W.R., and Cernock, P.J. (1971). "Determination of compressibility of marine sediments from compressional-wave velocity measurements," OTC 1328. Proceedings, Third Annual Offshore Technology Conference. I, 33-42.

Demars, K.R., Charles, R.D., and Richter, J.A. (1979). "Geology and geotechnical features of the Mid-Atlantic Shelf," OTC 3397. Proceedings, 11th Annual Offshore Technology Conference. 1, 343-354.

Denham, L.R. (1993). "Why that great discovery wasn't so great: The limitations of 2D seismic," OTC 7076. Proceedings, 25th Annual Offshore Technology Conference. 1, 9-15.

Dennis, A.R. (1975). "Satellite positioning and navigation for offshore application: Past, present, and future," OTC 2170. Proceedings, Seventh Annual Offshore Technology Conference. I, 243-254.

Dennis, A.R. (1976). "Methods for calibrating offshore navigation systems via satellite," OTC 2463. Proceedings, 8th Annual Offshore Technology Conference. 1, 421-430.

Downey, M.W. (1996). " Understanding the value of 3-D seismic for exploration," OTC 7954. Proceedings, 28th Annual Offshore Technology Conference. 1, 27-28.

Ejezie, S.U. (1986). "Geotechnical potentials of seismic profiling in the Niger Delta," OTC 5107. Proceedings, Eighteenth Annual Offshore Technology. 1, 245-252.

Erchul, Ronald A. (1974). "Ocean engineering applications for electrical resistivity techniques," OTC 2012. Proceedings, 6th Annual Offshore Technology Conference. 1, 733-746.

Exploration Geophysicists Society. Electronic magazine EdgeNet Online. http://www.edge-online.org. 
Furlow, W. (1999). “Subsea/surface systems technology,” Offshore, July 1999, p 22.

Gassaway, G.S., Brown, R.A., and Bennett, L.E. (1986). "Pitfalls in seismic amplitude vs offset analysis: Case histories," OTC 5279. Proceedings, Eighteenth Annual Offshore Technology Conference. 3, 481-487.

Gealy, E.L. (1971). "A new look at marine sediments in the light of deep ocean drilling," OTC 1350. Proceedings, Third Annual Offshore Technology Conference. I, 243-252.

Greene, D.C., and Hildebrand, B.P. (1969). "Applications of acoustical holography to underwater viewing," OTC 1096. Proceedings, 1st Annual Offshore Technology Conference. 2, 201-212.

Hampton, M.A., Bouma, A.H., Pulpan, H., and Huene, R. von. (1979). "GeoEnvironmental assessment of the Kodiak Shelf, Western Gulf Of Alaska," OTC 3399. Proceedings, 11th Annual Offshore Technology Conference. 1, 365-376.

Harrington, Patrick K., and Moody, C. Douglas. (1976). "A deep-tow multipurpose sparker system," OTC 2614. Proceedings of the8th Annual Offshore Technology Conference. 2, 967-980.

Harris, M. (1999). "NRL's improved multibeam system on ORCA," Sea Technology 40(3), 85-88.

Hawes, W.S. (1975). "Marine seismic survey problems resulting from "hard bottom," OTC 2224. Proceedings, Seventh Annual Offshore Technology. I, 773-782.

Haynes, R., Davis, A.M., Reynolds, J.M., and Taylor, D.I. (1993). "The extraction of geotechnical information from high-resolution seismic reflection data." Proceedings of International Conference on Offshore Site Investigation and Foundation Behaviour, Vol 28, Society of Underwater Technology, London, pp 215-227.

Hazelwood, D.T. (1975). "Acoustic re-entry concepts for subsea exploration drilling and production platforms," OTC 2152. Proceedings, Seventh Annual Offshore Technology Conference. I, 25-36.

Henderson, R.F. (1975). "Recent developments in side scan sonar and applications in the offshore oil field," OTC 2220. Proceedings, Seventh Annual Offshore Technology Conference. I, 733-742.

Herbich, J.B., and Hales, Z.L. (1971). "Remote sensing techniques used in determining changes in coastlines," OTC 1448. Proceedings, Third Annual Offshore Technology. II, 319-334. 
Hess, W.N., and Nelson, T.A. (1975). "A test particle dispersion study in Massachusetts Bay," OTC 2160. Proceedings, Seventh Annual Offshore Technology Conference. I, 119-132.

Hitchings, G.A., Bradshaw, H., and Labiosa, T.D. (1976). "The planning and execution of offshore site investigations for a North Sea gravity platform," OTC 2430. Proceedings, 8th Annual Offshore Technology Conference. 1, 61-72.

Kleiner, A., Anderson, B., and Gee, L. "A synergistic combination of technologies: Multibeam bathymetry, acoustic reflectivity, gravity, and magnetics in the deepwater Gulf of Mexico," OTC 10868. Proceedings, 31st Annual Offshore Technology Conference. II.

Kologinczak, John, Petty-Ray Geophysical, Inc. (1974). "STAGRAY System Improves Primary Pulse/Bubble Ratio in Marine Exploration," OTC 2020. Proceedings, 6th Annual Offshore Technology Conference. 1, 801-808.

Larner, Kenneth L., Mateker, Emil J., and Wu, Chang Shang Western Geophysical Co. (1974). "The new emphasis on reflection amplitude," OTC 2132. Proceedings, 6th Annual Offshore Technology Conference. 2, 10031014.

Leroy, C.C., Giacomo, C. Di, and Prost, J. (1974). "Acoustic measuring system and its performances," OTC 2026. Proceedings, 6th Annual Offshore Technology Conference. 1, 849-864.

Lowell, F.C., and Dalton, W.L. (1971). "Development and test of a state-of-theart sub-bottom profiler for offshore use," OTC 1340. Proceedings, Third Annual Offshore Technology Conference. I, 143-158.

Mahmood, A., and Hough, J. C. (1978). "Seabottom soil properties and acoustic characteristics" OTC 3208. Proceedings, 10th Annual Offshore Technology Conference. 3, 1353-1360.

McMillin, K. (1999). "Deepwater generates interest in seismic-while-drilling technology," Offshore 59(3).

Mosher, D. C., Currie, R. G., and Sullivan, D. (1997). "Monitoring of ocean disposal using side-scan mosaicing," EdgeNet Online, Society of Exploration Geophysicists electronic magazine. http://www.edge-online.org.

Nettleton, L.L. (1975). "Synergistic applications of multisensor marine geophysical data," OTC 2315. Proceedings, Seventh Annual Offshore Technology Conference. II, 707-712. 
Nauroy, J.F., and Meunier, J. (1993). "Geosis Project: Integration of geotechnical and geophysical data." Proceedings of International Conference on Offshore Site Investigation and Foundation Behaviour, Vol 28, Society of Underwater Technology, London, pp 107-113.

ORE Offshore Division. (1999). Internet site http://www.ore.com.

Pedotti, G., Dubois, J.C., and Meunier, J. (1990). "SHRIMP: A new equipment for precise subsurface soil investigation by high resolution seismic refraction," OTC 6230. Proceedings, 22nd Annual Offshore Technology Conference. 1, 271-276.

Peynaud F., Thomson and Pijanowski, J. (1979). "An acoustic doppler current meter," OTC 3457. Proceedings, 11th Annual Offshore Technology Conference. 2, 863-874.

Porter, W.J., and Bell, D.L. (1975). "Development of quantative remote acoustic indices for location and mapping of sea floor spoil deposits," OTC 2288. Proceedings, Seventh Annual Offshore Technology Conference. II, 411-418.

Porter, W.J., Bell, D.L., and Britton, L.C. (1974). "Multichannel towed arrays for remote measurement of marine sediment acoustical properties," OTC 2015. Proceedings, 6th Annual Offshore Technology Conference. 1, 763-770.

Radhakrishnan, R., and Subrahmanyam, R.V. (1982). "Seismic reflection profiling for near shore construction," OTC 4341. Proceedings, 14th Annual Offshore Technology Conference. 3, 485-490.

Reson, Inc. (1999). Internet site http://www.reson.com/resnfaq.htm.

Richards, Adrian F., and Parks, James M. (1977). "Geotechnical predictor equations for East Central North Pacific nodule mining area sediments," OTC 2773. Proceedings, 9th Annual Offshore Technology Conference. 1, 377-386.

Richter, Hemut, and Hansen, Rolf-Dieter. (1976). "Digital recording and processing of high resolution seismic for offshore soil investigation," OTC 2612. Proceedings, 8th Annual Offshore Technology Conference. 2, pp 953960.

Roberts, J.L. (1975). "An advanced acoustic position reference system," OTC 2173. Proceedings, Seventh Annual Offshore Technology Conference. I, pp 265-276.

Saad, A.H. (1993). "Interactive integrated interpretation of gravity, magnetic, and seismic data: Tools and examples," OTC 7079. Proceedings, 25th Annual Offshore Technology Conference. 1, 35-44. 
Schoenberger, M. (1996). "The growing importance of 3-D seismic technology," OTC 7955. Proceedings, 28th Annual Offshore Technology Conference. 1, 29-34.

Sonneland, L., Signer, C., Veire, H.H., Johansen, R.L., and Pedersen, L. (1997). "4D seismic on Gullfaks," OTC 8290. Proceedings, 29th Annual Offshore Technology Conference. 1, 147-152.

Sonsub. (1999). Internet site http://www.sonsub.com/rovs.htm.

Stankoff, Alain and Tait, R.A. (1977). "Underwater survey using an inertial navigation system," OTC 2815. Proceedings, 9th Annual Offshore Technology Conference. 2, 61-68.

Stockton, T.R., and McLennan, M.W. (1975). "Acoustic position measurement, an overview," OTC 2172. Proceedings, Seventh Annual Offshore Technology Conference. I, 255-264.

Stokes, A.W., Tilston, C.G., and Stirling, R.M. (1982). "A geophysical survey aids foundation design and cuts costs," OTC 4342. Proceedings, 14th Annual Offshore Technology Conference. 3, 491-500.

Stokoe, K.H., and Rosenblad, B.L. (1999). "Offshore geotechnical investigation with shear waves," OTC 10823. Proceedings, 31st Annual Offshore Technology Conference. 1.

Stokoe, K.H., Wright, S.G., Roesset, J.M., Gauer, R.C., and Sedighi-Manesh, M. (1990). "In-situ measurement of stiffness profiles in ocean bottom materials using the SASW method," OTC 6234. Proceedings, 22nd Annual Offshore Technology Conference. 1, 299-306.

Toth, J.R., and Amerigian, C.A. (1986). "Development of an advanced sampling device for the investigation of marine ferromanganese crust deposits," OTC 5235. Proceedings, Eighteenth Annual Offshore Technology Conference. 3, 127-134.

Toth, T., Vida, R., and Horvath, F. (1997). "Shallow-water single and multichannel seismic profiling in a riverine environment," EdgeNet Online, Society of Exploration Geophysicists electronic magazine http://www.edgeonline.org, November.

Trabant, P.K. (1997). "Single fold 3D seismic: Optimum tool for deepwater geohazards," OTC 8307. Proceedings, 29th Annual Offshore Technology Conference. 1, 293-298.

Ultra Electronics. (1999). http://www.ultra-electronics.co.uk. 
U.S. Army Corps of Engineers. (1999). "Use of single-head multi-beam surveying on Corps of Engineers navigation projects in the Los Angeles District," Engineering and Construction News 1(6), Internet publication http://www.usace.army.mil/inet/functions/cw/cecwe/notes/1999/jun99.pdf.

Vestgaard, K., and Hansen, K. "Super short baseline hydroacoustic navigation system," OTC 3100. Proceedings, 10th Annual Offshore Technology Conference. 1, 449-456.

Vigil, A.E., Frisbie, H.L., and Hatchett, G.L. (1975). "Deep sea survey system," OTC 2240. Proceedings, Seventh Annual Offshore Technology Conference. I, 915-922.

Watkins, J.S., Worzel, J.L., Ladd, J., and Hey, R. (1975). "Multichannel seismic reflection investigation of the Western Gulf of Mexico," OTC 2229. Proceedings, Seventh Annual Offshore Technology Conference. I, 797-806.

Wilde, P., Conti, U., and Dann, C. (1971). "Automatic multi-sensor electrochemical monitor for sea water measurements," OTC 1459.

Proceedings, Third Annual Offshore Technology Conference. II, 409-416.

Wilson, D. G., Guala, J. R., Palmer, H. D., and Blanton, J. (1976). "Sediment transport studies, nearshore Continental Shelf off Maryland," OTC 2443. Proceedings, 8th Annual Offshore Technology Conference. 1, 201-210.

Worzel, J. Lamar, and Watkins, Joel S. (1974). "Location of a lost drilling platform," OTC 2016. Proceedings, 6th Annual Offshore Technology Conference. 1, 771-772.

\section{In situ methods}

Ali, M.A. (1987). "Piston Explorer: an in-situ device for geotechnical investigation of subsurface conditions," OTC 5421. Proceedings, 19th Annual Offshore Technology Conference. 1, 541-548.

Anderson, V.C., Clinton, J.R., Gibson, D.K., and Kirsten, O.H. (1972). "Instrumenting RUM for in situ subsea soil surveys," Underwater Soil Sampling, Testing, and Construction Control, ASTM STP 501, American Society for Testing and Materials, pp 216-231.

Bayne, J.M., and Tjelta, T.I. (1987). "Advanced cone penetrometer development for in-situ testing at Gullfaks C," OTC 5420. Proceedings, 19th Annual Offshore Technology Conference. 1, 531-540.

Beard, R.M., and Lee, H.J. (1982). "A 40-ft static cone penetrometer," OTC 4300. Proceedings, 14th Annual Offshore Technology Conference. 2, 809818. 
Bowles, J.E. (1988. Foundation analysis and design. 4th ed., McGraw-Hill, pp 161-163.

Briaud, J-L, Riner, K.B., and Ohya, S. (1984). "Cyclic pressuremeter tests for cyclic lateral loads," OTC 4678. Proceedings, 16th Annual Offshore Technology Conference. 1, 275-282.

Briaud, J-L, Smith, T.D., and Meyer, B.J. (1983). "Using the pressuremeter curve to design laterally loaded piles," OTC 4501. Proceedings, 15th Annual Offshore Technology Conference. 1, 495-502.

Brucy, F., Fay, J.B., and Le Tirant, P. (1984). "Three years' experience with the offshore self-boring pressurementer 'PAM'," OTC 4677. Proceedings, 16th Annual Offshore Technology Conference. 1, 265-274.

De Ruiter, J., and Fox, D.A. (1975). "Site investigations for North Sea Forties Field," OTC 2246. Proceedings, Seventh Annual Offshore Technology Conference. II, 21-36.

Doyle, E.H., McClelland, B., and Ferguson, G.H. (1971). "Wire-line vane probe for deep penetration measurements of ocean sediment strength," OTC 1327. Proceedings, Third Annual Offshore Technology Conference. I, 21-32.

Dutt, R. N., Rainey, W. S., Hamilton, T. K., Pelletier, J. H., and Doyle, E. H. (1997). "Recent advances in deepwater Gulf of Mexico geotechnical investigations," OTC 8303. Proceedings, 29th Annual Offshore Technology Conference. 1, 249-257.

Ferguson, George H., McClelland, Bramlette, and Bell, Wiley D. (1977). "Seafloor cone penetrometer for deep penetration measurements of ocean sediment strength," OTC 2787. Proceedings, 9th Anuual Offshore Technology Conference. 1, 471-478.

FHWA. (1978). "Guidelines for cone penetration test performance and design," FHWA-TS-78-209, U.S. Department of Transportation Federal Highway Administration, Washington, DC.

Focht, J.A., Jr., and Kraft, L. M. (1977). "Progress in marine geotechnical engineering," ASCE Journal of the Geotechnical Engineering Division 103(10), 1097-1118.

Focht, J.A., Jr., Johnson, G.W., and Rivette, C.A. (1986). "Results of recent cone penetrometer testing in the Gulf of Mexico," OTC 5104. Proceedings, Eighteenth Annual Offshore Technology Conference. 1, 213-224.

Fountain, J.D. (1979). "Foundation information from exploration seismic data," OTC 3663. Proceedings, 11th Anuual Offshore Technology Conference. 4, 2677-2682. 
Hardies, C.E. (1975). "An advanced two axis acoustic current meter," OTC 2293. Proceedings, Seventh Annual Offshore Technology Conference. II, 465-476.

Heijnen, W.J., and Vermeiden, J. (1979). "Site investigation in the Eastern Scheldt, Netherlands," Offshore Site Investigation, Proceedings, conference sponsored by the Society for Underwater Technology, The Geological Society of London, and the Institution of Civil Engineers, Edited by D.A. Ardus and published by Graham and Trotman, LTD, London, pp 183-193.

Hirst, T.J., Richards, A.F., and Inderbitzen, A.L. (1972). "A static cone penetrometer for ocean sediments," Underwater Soil Sampling, Testing, and Construction Control, ASTM STP 501, American Society for Testing and Materials, pp 69-80.

Hitchings, Gordon A., Bradshaw, Heath, and Labiosa, Thomas D. (1976). "The planning and execution of offshore site investigations for a North Sea gravity platform," OTC 2430B. Proceedings, 8th Annual Offshore Technology Conference. 1, 61-74.

Humphrey, G. D., and Adams, J. B. (1995). "TSP- new solution for geotechnical studies in deep water environments," OTC 7673. Proceedings, 27th Annual Offshore Technology Conference. 1, 309-317.

Inderbitzen, A.L., and Simpson, F. (1972). "A study of the strength characteristics of marine sediments utilizing a submersible," Underwater Soil Sampling, Testing, and Construction Control, ASTM STP 501, American Society for Testing and Materials, pp 204-215.

James, E.L. (1987). "Geotechnical influences on subsea installations," Advances in Underwater Technology, Ocean Science and Offshore Engineering, Vol 2, Underwater Construction: Development and Potential, Society for Underwater Technology, London, pp 191-202.

Kutter, B. L., Arulanandan, K., and Dafalias, Y. F. (1979). "A comparison of electrical and penetration methods of site investigation," OTC 3488. Proceedings, 11th Annual Offshore Technology Conference. 2, 1105-1110.

Le Tirant, P., Fay, J.-B., Brucy, F., and Jezequel, J.-F. (1981). "A self-boring pressuremeter for deep sea soils investigations," OTC 4019. Proceedings, 13th Annual Offshore Technology Conference. 2, 115-126.

Lunne, T., and Christoffersen, H.P. (1983). "Interpretation of cone penetrometer data for offshore sands," OTC 4464. Proceedings, 15th Annual Offshore Technology Conference. 1, 181-192.

Lunne, T., and Powell, J.J.M. (1993). "Recent developments in in-situ testing in offshore soil investigations," Proceedings of International Conference on Offshore Site Investigation and Foundation Behaviour, Vol 28, Society of Underwater Technology, London, pp 148-180. 
Marr, L.S., and Endley, S.N. (1982). "Offshore geotechnical investigation using a cone penetrometer," OTC 4298. Proceedings, 14th Annual Offshore Technology Conference. 2, 783-798.

Meyer, B.J., Harman, D.E., and King, P.G. (1982). "Introduction of a new offshore cone penetrometer (CPT) device for the Gulf of Mexico," OTC 4299. Proceedings, 14th Annual Offshore Technology Conference. 2, 799808.

Noorany, I. (1972). "Underwater soil sampling and testing — a state-of-the-art review," Underwater Soil Sampling, Testing, and Construction Control, ASTM STP 501, American Society for Testing and Materials, pp 3-41.

Orenberg, P., True, D., Bowman, L, Herrmann, H., and March, R. (1996). "Use of a dropped dynamic penetrometer in cohesionless soil," OTC 8027. Proceedings, 28th Annual Offshore Technology Conference. 1, 639-648.

Perlow, M., and Richards, A.F. (1972). "In-place geotechnical measurements from submersible ALVIN in Gulf of Maine soils," OTC 1543 Preprint. Proceedings, 4h Annual Offshore Technology Conference. 1, I-333-340.

Preslan, W.L., and Babb, L. (1979). "Piezometer measurement for deep penetration marine applications," OTC 3461. Proceedings, 11 th Annual Offshore Technology Conference. 2, 901-908.

Reid, W.M., Fyffe, S., St.John, H.D., and Rigden, W.J. (1982). "The push-inpressuremeter," Symposium on the Pressuremeter and its Marine Applications, Paris.

Richards, A.F., McDonald, V.J., Olson, R.E., and Keller, G.H. (1972). "In-place measurement of deep sea soil shear strength," Underwater Soil Sampling, Testing, and Construction Control, ASTM STP 501, American Society for Testing and Materials, pp 55-68.

Rodriguez, J.I., Simone, A., Tichatscheck, C., and Boggess, R. (1995). "Evaluation of offshore penetration tests at El Palito Refinery, Venezuela," OTC 7665. Proceedings, 27th Annual Offshore Technology Conference. 1, 233-239.

Rose, V.C., and Ronsy, J.R. (1971). "A nuclear gage for in-place measurement of sediment density," OTC 1329. Proceedings, Third Annual Offshore Technology Conference. I, 43-52.

Schwarz, Sigmund D.and Conwell, Fred R. (1974). "A technique for the in-situ measurement of shear wave velocities (Vs) for deep marine foundations," OTC 2014. Proceedings, 6th Annual Offshore Technology Conference. 1, 755-762. 
Semple, R.M., and Rigden, W.J. (1983). "Site investigation for Magnus," OTC 4466. Proceedings, 15th Annual Offshore Technology Conference. 1, 205-216.

Stokoe, K.H., Arnold, E.J., Hoar, R.J., Shirley, D.J., and Anderson, D.G. (1978). "Development of a bottom-hole device for offshore shear wave velocity measurement," OTC 3210. Proceedings, 10th Annual Offshore Technology Conference. 3, 1367-1380.

Stremlau, T.H., and Spencer, S.G. (1980). "In situ bearing capacity evaluations," OTC 3751. Proceedings, 12th Annual Offshore Technology Conference. 2, 151-158.

Sullivan, R.A., Wright, S.J., and Senner, D.W.F. (1980). "Evaluation of design parameters from laboratory tests," Offshore Site Investigation. Proceedings, conference sponsored by the Society for Underwater Technology. The Geological Society of London, and the Institution of Civil Engineers, Edited by D.A. Ardus and published by Graham and Trotman, LTD, London, pp 201-215.

Suyama, K., Ohya, S., and Imai, T. (1982). "Development of the LLT Pressuremeter and its application. Prediction of pile behavior under horizontal loads," Symposium on the Pressuremeter and its Marine Applications, Paris.

Swan, Richard D., and Reimer, Charles M. (1974). "The use of sand probes in offshore operations," OTC 1972. Proceedings, 6th Annual Offshore Technology Conference. 1, 379-386.

Tjelta, T.I., Guttormsen, T.R., and Hermstad, T. (1986). "Large-scale penetration test at a deepwater site," OTC 5103. Proceedings, Eighteenth Annual Offshore Technology Conference. 1, 201-212.

Tjelta, T.I., Tieges, A.W.W., Smits, F.P., Geise, J.M., and Lunne, T.A. (1985). "In-situ density measurements by nuclear backscatter for an offshore soil investigation," OTC 4917. Proceedings, 17th Annual Offshore Technology Conference. 2, 201-206.

True, Daniel G. (1974). "Rapid penetration into seafloor soils," OTC 2095. Proceedings, 6th Annual Offshore Technology Conference. 2, 607-618.

Villet, W.C.B., and Darragh, R.D. (1985). "Interpretation of piezometric cone tests in highly overconsolidated offshore silts," OTC 4916. Proceedings, 17th Annual Offshore Technology Conference. 2, 187-200.

Vyas, Y.K., Angemeer, J., Murff, J.D., Neuberger, C.A., McNeilan, T., and Klejbuk, L.W. Jr. (1983). "Deepwater geotechnical site investigations: Santa Ynez Unit, offshore California," OTC 4467. Proceedings, 15th Annual Offshore Technology Conference. 1, 217-226. 


\section{Remote operations}

Banzoli, V., Tella, V. Di, Dossi, L., and Gava, P. (1976). "New concept of underwater remote controlled tracked vehicle for deep water trenching operations," OTC 2587. Proceedings, 8th Annual Offshore Technology Conference. 2, 647-664.

Bjerrum, A., and Krogh, B. (1998). "Martin 200," Hydro International, May/June.

Bybee, R.W. (1971). "Use of a submarine in offshore petroleum exploration,"OTC 1338. Proceedings, Third Annual Offshore Technology Conference. I, 129-130.

Conti, U., Wilde, P., and Richards, T.L. (1971). "Towed vehicle for constant depth and bottom contouring operations," OTC 1456. Proceedings, Third Annual Offshore Technology Conference. II, 385-392.

Dansette, N., and Robertson, N.C. "Subsea flexible pipeline burial using a lightweight pipeline trencher," OTC 7600. Proceedings, 26th Annual Offshore Technology Conference. IV, 847-850.

Fike, John W., and Dolan, Robert B. (1976). "A submersible diving system for science," OTC 2574. Proceedings, 8th Annual Offshore Technology Conference. 2, 529-538.

Fischer, F.J. (1975). "Driving analysis for initially curved marine conductors," OTC 2309. Proceedings, 7th Annual Offshore Technology Conference. 2, 633-640.

Frisbie, F.R., Wernli, R.L., and Given, D.W. (1986). "The role of the ROV in 1985: A capability in transition," OTC 5169. Proceedings, Eighteenth Annual Offshore Technology Conference. 2, 159-166.

Gradetshy, V., and Rachkov, M. (1996). "Climbing robot for underwater inspection of construction." Proceedings, 14th International Symposium on Automation and Robitics in Construction, Pittsburgh, PA, June 8-11.

Grobe, K., Amann, H., Conogan, R., and Simeoni, P. (1993). "Fiber optic telemetry for deep sea robotics," OTC 7276. Proceedings, 25th Annual Offshore Technology Conference. 4, 143-156.

Haferkamp, H., Bach, F., Ogawa, Y., and Rachkov, M. (1994). "Climbing robot for underwater cutting." Proceedings of International Conference on Oceans Engineering, Brest, France. 1, 602-607. 
Hironaka, M.C., and Green, W.C. (1971). "A remote controlled seafloor incremental corer," OTC 1325. Proceedings, Third Annual Offshore Technology Conference. I, 13-20.

Kistler, E.L. (1975). "WASP: A new concept for semisubmersibles," OTC 2286. Proceedings, Seventh Annual Offshore Technology Conference. II, 391-402.7

Mair, J., and White, J. (1995). "The changing role of the remotely operated vehicle in offshore operations," OTC 7852. Proceedings, 27th Annual Offshore Technology. 3, 429-439.

Mariano, J.J., and Ross, D.G. (1994). " Undersea fiber optic technology for the offshore community," OTC 7605. Proceedings, 26th Annual Offshore Technology Conference. 4.

Parkes, S.A. (1995). "A truly multi-role-vehicle," OTC 7855. Proceedings, 27th Annual Offshore Technology Conference. 3, 461-469.

Society for Underwater Technology. (1997). "Underwater robotics information system," published on Internet site http://www.sut.org.uk, 21 May.

\section{Soil sampling and testing}

Acker, W.L., Jr. (1974). Basic procedures for soil sampling and core drilling, Acker Drill Company, Scranton, PA.

Allen, R.L., Yen, B.C., and McNeill, R.L. (1978). "Stereoscopic x-ray assessment of offshore soil samples," OTC 3213. Proceedings, 10th Annual Offshore Technology Conference. 3, 1391-1400.

Angemeer, J. (1972). "Foundation investigations for drilling platforms in Cook Inlet," Underwater Soil Sampling, Testing, and Construction Control, ASTM STP 501, American Society for Testing and Materials, pp 232-241.

Arulanandan, K., Douglas, B. J., Green, R. K., and Arulmoli, K. (1979). "Anisotropic sand structure related to dynamic pore pressures," OTC 3487. Proceedings, 9th Annual Offshore Technology Conference. 2, 1095-1104.

Audibert, J.M.E., and Hamilton, T.K. (1998). "West Delta 58A site selection and characterization," OTC 8764. Proceedings, 30th Annual Offshore Technology Conference. 1.

Babcock, F.M., and Miller, H.J. (1972). "Correlation of Standard Penetration Test results with Vibracore sampler penetration rates," Underwater Soil Sampling, Testing, and Construction Control, ASTM STP 501, American Society for Testing and Materials, pp 81-89. 
Bailey, E.T., Davis, G.L., and Henderson, H.O. (1971). "Design of an automatic marine corer," OTC 1365. Proceedings, Third Annual Offshore Technology Conference. I, 397-416.

Blake, W.D., and Gilbert, R.B. (1997). "Investigation of possible relationship between undrained shear strength and shear wave velocity for normally consolidated clays," OTC 8325. Proceedings, 29th Annual Offshore Technology Conference. 1, 411-419.

Booth, James S., and Dunlap, Wayne A. (1977). "Consolidation state of upper continental slope sediments, northern Gulf Of Mexico," OTC 2788. Proceedings, 9th Annual Offshore Technology Conference. 1, 479-488.

Bouma, A.H., Hampton, M.A., Wennekens, M.P., and Dygas, J.A. (1977). "Large dunes and other bedforms in Lower Cook Inlet, Alaska," OTC 2737. Proceedings, 9th Annual Offshore Technology Conference. 1, 79-90.

Bouma, A.H., Rappeport, M.L., Orlando, R.C., Cacchione, D.A., Drake, D.E., Garrison, L. E., and Hampton, M. A. (1979). "Bedform characteristics and sand transport in a region of large sand waves, Lower Cook Inlet, Alaska," OTC 3485. Proceedings, 11th Annual Offshore Technology Conference. 2, 1083-1094.

Briaud, J-L., Riner, K.B., and Ohya, S. (1984). "Cyclic pressuremeter tests for cyclic lateral loads," OTC 4678. Proceedings, 16th Annual Offshore Technology Conference. 1, 275-282.

Bryant, W.R., and Deflache, A.P. (1971). "Geotechnical charts of deep water portion of the Gulf of Mexico," OTC 1468. Proceedings, Third Annual Offshore Technology Conference. II, 493-502.

Bryant, W.R., Shephard, L., and Dunlap, W. (1978). "Consolidation characteristics of Mississippi Delta sediments," OTC 3167. Proceedings, 10th Annual Offshore Technology Conference. 2, 1037-1048.

Butenko, J., and Barbot, J.P. (1979). "Geological hazards related to offshore drilling and construction in the Orinoco River delta of Venezuela," OTC 3395. Proceedings, 11th Annual Offshore Technology Conference. 1, 323330.

Campbell, K.J., and Hooper, J.R. (1986). "Engineering implications of deepwater geologic and soil conditions, Texas-Lousiana slope," OTC 5105.

Proceedings, Eighteenth Annual Offshore Technology Conference. 1, pp 225232.

Courville, P.W., and Maddox, S.D. (1993). "Rigless slimhole drilling," OTC 7331. Proceedings, 25th Annual Offshore Technology Conference. 4, 667-676. 
Dunlap, W.A., Bryant, W.R., Bennett, R., and Richards, A. (1978). "Pore pressure measurements in underconsolidated sediments," OTC 3168. Proceedings, 10th Annual Offshore Technology Conference. 2, 1049-1058.

Dutt, R.N., Doyle, E.H., Nandlal, S., and Ingram, W.B. (1986). "Frictional characteristics of calcareous sands from offshore Florida," OTC 5147. Proceedings, Eighteenth Annual Offshore Technology Conference. 1, 589-600.

Duval, B.C. (1975). "Exploratory drilling on the Canadian Continental Shelf, Labrador Sea," OTC 2155. Proceedings, Seventh Annual Offshore Technology Conference. I, 59-73.

Ewing, M. (1969). "Some results of deep ocean drilling," OTC 1003. Proceedings, 1st Annual Offshore Technology Conference. 1, 43-50.

Finn, W.D.L., and Byrne, P.M. (1971). "Analysis of ocean bottom sediments," OTC 1471. Proceedings, Third Annual Offshore Technology Conference. II, $525-532$.

Gemeinhardt, J.P., and Kwong-Yan, W. (1978). "Progress of consolidation of a marine clay in Borneo," OTC 3209. Proceedings, 10th Annual Offshore Technology Conference. 3, 1361-1366.

Harker, R.J., and Ball, J.H. (1975). "Design considerations in vibratory core sampling equipment," OTC 2292. Proceedings, Seventh Annual Offshore Technology Conference. II, 457-464.

Hartley, J.P., and Watson, T.N. (1993). "Investigation of a North Sea oil platform drill cuttings pile," OTC 7341. Proceedings, 25th Annual Offshore Technology Conference. 4, 749-756.

Hight, D.W. (1993). "A review of sampling effects in clays and sands." Proceedings of International Conference on Offshore Site Investigation and Foundation Behaviour, Vol 28, Society of Underwater Technology, London, pp 139-145.

Hironaka, M.C., and Green, W.C. (1971). "A remote controlled seafloor incremental corer," OTC 1325. Proceedings, Third Annual Offshore Technology Conference. I, 13-20.

Hooper, J.R. (1996). "Foundation soil motion in South Pass 47," OTC 7953. Proceedings, 28th Annual Offshore Technology Conference. 1, 17-26.

Hooper, J.R., and Preslan, W.L. (1979). "Pressurized shallow sands in the Mississippi Delta region," OTC 3483. Proceedings, 11th Annual Offshore Technology Conference. 2, 1063-1070. 
Hossain, M.K., and Briaud, T.-L. (1993). "Improved soil characterization for pipe piles in sand in API RP-2A," OTC 7193. Proceedings, 25th Annual Offshore Technology Conference. 2, 637-654.

James, E.L. (1987). "Geotechnical influences on subsea installations," Advances in Underwater Technology, Ocean Science and Offshore Engineering, Vol II, Underwater Construction: Development and Potential, Society for Underwater Technology, London, pp 191-201.

McCoy, F.W., Jr. (1972). "An analysis of piston coring through corehead camera photography," Underwater Soil Sampling, Testing, and Construction Control, ASTM STP 501, American Society for Testing and Materials, pp 42-54.

Noorany, I. (1972). "Underwater soil sampling and testing — a state-of-the-art review," Underwater Soil Sampling, Testing, and Construction Control, ASTM STP 501, American Society for Testing and Materials, pp 3-41.

Noorany, I., Kirsten, O.H., and Luke, G.L. (1975). "Geotechnical properties of sea-floor sediments off the coast of Southern California," OTC 2187. Proceedings, Seventh Annual Offshore Technology Conference. I, 389-398.

Overy, R.F., and Dean, A.R. (1986). "Hydraulic fracture testing of cohesive soil," OTC 5226. Proceedings, Eighteenth Annual Offshore Technology Conference. 3, 45-53.

Reece, A.R., and Grinsted, T.W. (1986). "Soil mechanics of submarine ploughs," OTC 5341. Proceedings, Eighteenth Annual Offshore Technology Conference. 4, 453-461.

Richardson, W.E., Neidell, N.S., and Kronberger, F.P. (1971). "Piggy-back-a versatile full capability marine exploration system," OTC 1460. Proceedings, Third Annual Offshore Technology Conference. II, 417-424.

Sangrey, D.A. (1972). "Obtaining strength profiles with depth for marine soil deposits using disturbed samples," Underwater Soil Sampling, Testing, and Construction Control, ASTM STP 501, American Society for Testing and Materials, pp 106-121.

Schwank, S.K. (1997). "Large size sampling tools for offshore exploration," OTC 8283. Proceedings, 29th Annual Offshore Technology Conference. 1, 91-99.

Storms, M.A., Nugent, W., and Cameron, D.H. (1983). "Hydraulic piston coring: a new era in ocean research," OTC 4622. Proceedings, 16th Annual Offshore Technology Conference. 3, 369-378. 
Sully, J.P., Sgambatti, J., Templeton, J.S., and Laya, E. (1995). "Geotechnical characterization of Rio Caribe soils," OTC 7663. Proceedings, 27th Annual Offshore Technology Conference. 1, 203-210.

Tirey, G.B. (1972). "Recent trends in underwater soil sampling methods," Underwater Soil Sampling, Testing, and Construction Control, ASTM STP 501, American Society for Testing and Materials, pp 42-54.

U.S. Army Corps of Engineers. (1996). Soil sampling engineer manual, Engineer Manual 1110-1-1906, Washington, DC.

Vallejo, L.E. (1982). "Evaluation of test methods designed to obtain the undrained shear strength of muds," OTC 4302. Proceedings, 14th Annual Offshore Technology Conference. 3, 11-20.

Wang, J.L., Vivatrat, V., and Ruser, J.R. (1982). "Geotechnical properties of Alaska OCS silts," OTC 4412. Proceedings, 14th Annual Offshore Technology Conference. 4, 415-434.

Westneat, Arthur S., and Porter, William. (1976). "Acoustic sediment classification involving gas-laden soils," OTC 2613. Proceedings, 8th Annual Offshore Technology Conference. 2, 961-966.

Young, A.G., Kraft, L.M., and Focht, J.A. (1975). "Geotechnical considerations in foundation design of offshore gravity structures," OTC 2371. Proceedings, 7th Annual Offshore Technology Conference. 2, 367-380.

Young, A.G., Quiros, G.W., and Ehlers, C.J. (1983). "Effects of offshore sampling and testing on undrained soil shear strength," OTC 4465. Proceedings, 15th Annual Offshore Technology Conference. 1, 193-204.

Zuidberg, H.M., Schrier, W.H., and Pieters, W.H. (1984). "Ambient pressure sampler system for deep ocean investigations," OTC 4679. Proceedings, 16th Annual Offshore Technology Conference. 1, 283-290. 


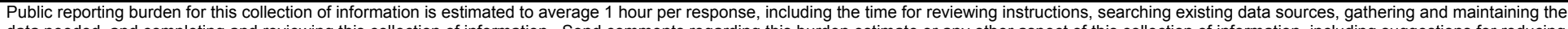

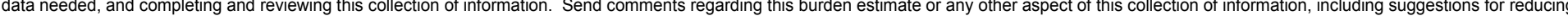

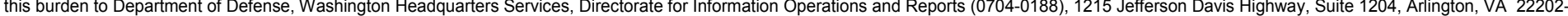

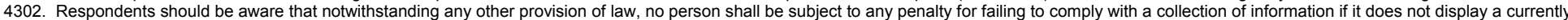
valid OMB control number. PLEASE DO NOT RETURN YOUR FORM TO THE ABOVE ADDRESS.

\begin{tabular}{l|l|l} 
1. REPORT DATE (DD-MM-YYYY) & 2. REPORT TYPE & 3. DATES COVERED (FrOm - TO)
\end{tabular}

4 TITI F AND SIIRTITI F

December $2001 \quad$ Final report

Underwater Geotechnical Foundations

5a. CONTRACT NUMBER

5b. GRANT NUMBER

5c. PROGRAM ELEMENT NUMBER

6. AUTHOR(S)

5d. PROJECT NUMBER

Landris T. Lee, Jr., Richard W. Peterson

5e. TASK NUMBER

5f. WORK UNIT NUMBER

INP WU 33144

\section{PERFORMING ORGANIZATION NAME(S) AND ADDRESS(ES)}

8. PERFORMING ORGANIZATION REPORT NUMBER

U.S. Army Engineer Research and Development Center

ERDC/GSL TR-01-24

Geotechnical and Structures Laboratory, 3909 Halls Ferry Road

Vicksburg, MS 39180-6199

\section{SPONSORING / MONITORING AGENCY NAME(S) AND ADDRESS(ES)}

10. SPONSOR/MONITOR'S ACRONYM(S)

U.S. Army Corps of Engineers

Washington, DC 20314-1000

11. SPONSOR/MONITOR'S REPORT

NUMBER(S)

Technical Report INP-01-1

\section{DISTRIBUTION / AVAILABILITY STATEMENT}

Approved for public release; distribution is unlimited.

\section{SUPPLEMENTARY NOTES}

\section{ABSTRACT}

This report provides an overview and description of the design and construction of underwater geotechnical foundations and offers preliminary guidance based on past and current technology applications. Most of the state-of-the-art technology has been developed during 60 years of experience by the marine offshore industry solving complex foundation engineering challenges in the deep-ocean frontier, selected design firms and contractors, and, to a limited extent, local practice. Direct applications may or may not be made to sitespecific underwater foundations in shallower rivers and inland waterways. However, most of the principles, techniques, and equipment are related.

Case histories of selected in-the-wet (underwater) foundation projects are discussed for several types of structures: navigation, flood control, and dam structures; bridges; immersed tube tunnels and pipelines; offshore oil platform structures; and other underwater-founded structures.

Three generalized underwater foundation types are described: improved-site, gravity-based, and pinned. Emphasis is placed on two of the most common pinned foundation types (piles and drilled shafts). Installation equipment and procedures are discussed, and differences between onshore and underwater foundation construction techniques are highlighted. Inspection and testing procedures are similar to those onshore, with the exception of pile load test frequency and methodologies.

Underwater foundations constructed in-the-wet may allow a significantly beneficial alternative to the more expensive in-the-dry cofferdam construction, as experience is gained in applying this technology to the unique project needs of the U.S. Army Corps of Engineers.

\section{SUBJECT TERMS}

Foundation engineering

Geotechnical engineering

Pile foundations

\section{SECURITY CLASSIFICATION OF:}

a. REPORT

UNCLASSIFIED b. ABSTRACT

UNCLASSIFIED
Underwater foundations

Underwater foundation construction

\section{LIMITATION} OF ABSTRACT

\section{NUMBER OF PAGES}

\section{9a. NAME OF RESPONSIBLE} PERSON

19b. TELEPHONE NUMBER (include area code) 